Departamento de Señales, Sistemas y Radiocomunicaciones Escuela Técnica Superior de Ingenieros de Telecomunicación Universidad Politécnica de Madrid

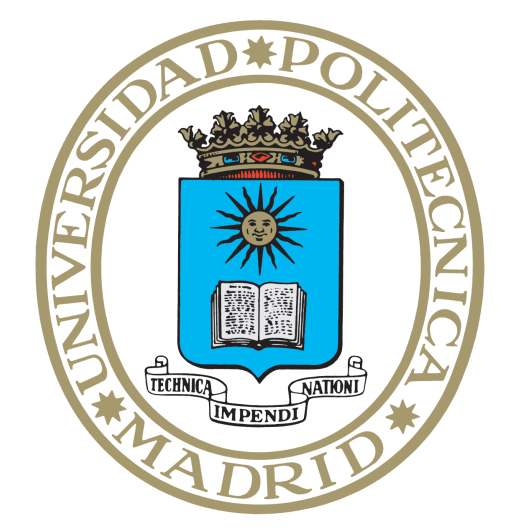

\title{
Contribución al análisis multiescala de señales. Aplicación a imágenes de suelos agrícolas y series financieras
}

\section{TESIS DOCTORAL}

Juan A. Piñuela Izquierdo

Febrero 2016 



\section{Contribución al análisis multiescala de señales. Aplicación a imágenes de suelos agrícolas y series financieras}

Dirigida por los Doctores

Diego Andina de la Fuente Ana María Tarquis Alfonso

Departamento de Señales, Sistemas y Radiocomunicaciones Escuela Técnica Superior de Ingenieros de Telecomunicación Universidad Politécnica de Madrid 

A todos los que consiguen que el día siguiente sea importante 



\section{Agradecimientos}

Han sido muchos años y muchos esfuerzos dispersos en distintas facetas de mi vida que me llevan a pensar en esta tesis como el cierre de un ciclo iniciado allá por el año 2000, cuando después del impacto que la crisis conocida después como crisis de las .com decidí un buen día apuntarme a los estudios de Doctorado sin más aspiración que recuperar la ilusión por el sector de las telecomunicaciones e iniciar un nuevo camino en el mundo de la investigación y la educación.

Supongo que si sigo en este mundo quince años después tendría que dar por tanto las gracias primero a haber descubierto en primera persona y en mi primera experiencia laboral que significan esas frases que relacionan crisis con oportunidad.

Tomando como referencia ese año y buscando que hasta en los problemas surge una oportunidad para mejorar son muchas las personas a las que tendría algo que agradecer durante estos años. Algunas ya no están, otras ya no están tan cerca, otras han aparecido y otras siempre han estado conmigo mostrando una lealtad imposible de no agradecer. Con todas ellas, las que me han acompañado en mi vida personal $\mathrm{y}$ a las que en este largo camino académico han tenido la paciencia de seguirme apoyando, quiero compartir la alegría de llegar a este punto. 



\section{Resumen}

En el campo del análisis multirresolución de señales, bien sean señales unidimensionales o imágenes, la transformada wavelet ( $\mathrm{u}$ ondícula) es una de las herramientas más atractivas y potentes debido a su capacidad de análisis de las estructuras y singularidades presentes en una señal cuando esta es analizada en distintas escalas.

Este trabajo parte de la investigación de cómo la modificación directa de los coeficientes wavelets permite añadir información en forma de marcas de agua a una imagen o también como con las mismas técnicas se pueden realizar esquemas relativamente sencillos de eliminación de ruido en imágenes. Estas aplicaciones son el primer paso para entender qué información capturan los coeficientes wavelet obtenidos mediante las distintas versiones existentes de transformada wavelet

Siguiendo la relación entre el módulo de los coeficientes wavelets resultantes en distintas escalas llegamos a poder caracterizar las singularidades presentes en señales o imágenes con aplicaciones prácticas en campos como el análisis de imágenes mamográficas. Esta relación no es más que el primer paso para enlazar la teoría wavelet con el formalismo multifractal, relación definida en primera instancia a partir de la transforma wavelet de módulo máximo. El análisis entre señal, transformada wavelet de módulo máximo e información local de cada coeficiente wavelet da origen a la contribución principal de este trabajo de tesis que consiste en la estimación directa de distintos parámetros multifractales a partir del cálculo de coeficientes derivados de manera local para cada muestra de una señal o pixel de una imagen.

La metodología propuesta se aplica en primer lugar a señales de una dimensión de gran complejidad o irregularidad como son las series financieras y específicamente los valores que componen el índice Dow Jones. El resultado permite la cuantificación de la volatilidad o riesgo asociado a cada uno de esas series.

En segundo lugar y como principal aplicación de la metodología de análisis multiescala propuesta, el trabajo de investigación se centra en cómo calcular parámetros multifractales en imágenes que reflejan la estructura de suelos agrícolas. Estas imágenes son obtenidas bien aplicando un tinte especial o mediante modernas técnicas de tomografía axial computarizada. En ambos casos, el objetivo es completar la caracterización estadística de la geometría de los flujos preferenciales de agua y otras sustancias, aspectos claves para el correcto tratamiento de suelos agrícolas.

Para validar e interpretar cada uno de los algoritmos desarrollados se utilizan señales multifractales sintetizadas y se comparan los resultados obtenidos en las distintas aplicaciones respecto de algoritmos ya consolidados en cada caso.

Palabras claves: Transformada Wavelet, Coeficientes de Lipschitz, Exponente de Hölder, Multifractales, Espectro multifractal, Análisis de Series Financieras, Análisis de Suelos Agrícolas, Tomografía computarizada. 



\section{Índice}

\begin{tabular}{|ll}
\hline Agradecimientos & VII
\end{tabular}

$\begin{array}{ll}\text { Resumen IX } & \text { IX }\end{array}$

\begin{tabular}{ll}
\hline 1. Introducción & 1
\end{tabular}

1.1. Análisis multiescala de señales . . . . . . . . . . . . . . . . 1

1.2. Wavelets, singularidades y análisis multifractal . . . . . . . . 2

1.3. Aplicación al análisis de imágenes de suelos agrícolas y series financieras 3

1.4. Contenido de la memoria . . . . . . . . . . . . . . 4

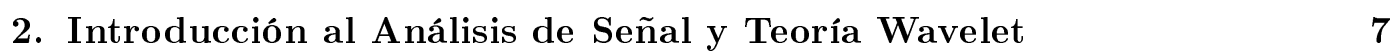

2.1. ¿Qué es una transformada wavelet?. . . . . . . . . . . . 7

2.2. Resolución Tiempo-Espacio / Frecuencia-Escala . . . . . . . . . . . 9 9

2.2.1. Expansión de señales en bases ortonormales . . . . . . . . . 9

2.2.2. Átomos Tiempo-Frecuencia . . . . . . . . . . . . . . . . 11

2.2.3. STFT: Transformada eventanada de Fourier y Transformada de Gabor . . . . . . . . . . . . . . . . 12

2.3. Transformada wavelet . . . . . . . . . . . . . . . . 14

2.3.1. Definición de función wavelet . . . . . . . . . . . . . . . 14

2.3.2. Análisis tiempo-escala o análisis con Q-constante . . . . . . . 16

\begin{tabular}{|l|l|l|}
\hline 3. Wavelets, Bancos de filtros y Análisis Multiresolución & 21
\end{tabular}

3.1. Wavelets y bancos de filtros . . . . . . . . . . . . . . 21

3.1.1. Expansión de Haar . . . . . . . . . . . . . . . . . . . . . 21

3.1.2. Expansión 'sinc'(Wavelets de Shannon) . . . . . . . . . . . 25

3.2. Análisis Multirresolución . . . . . . . . . . . . . . . . . 26

3.3. Algoritmo de obtención de los coeficientes wavelets . . . . . . . . . . 29

3.4. Momentos nulos o precisión . . . . . . . . . . . . . . . . 31

3.5. Aplicaciones de la manipulación directa de los coeficientes de la DWT 33

3.5.1. Una técnica wavelet para watermarking de imágenes . . . . . 33

3.5.2. Reducción de ruido en imágenes para segmentación de objetos en secuencias de vídeo . . . . . . . . . . . . . 37

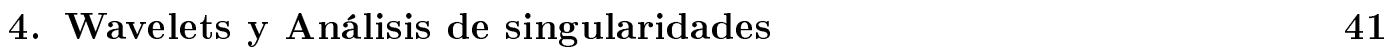

4.1. Wavelet" Zoom". . . . . . . . . . . . . . . . . . . . 41

4.1.1. Transformada Continua Wavelet (CWT) . . . . . . . . . . . 41 
4.1.1.1. Transformada Wavelet Diádica . . . . . . . . . . . . 41

4.1.1.2. Algoritmo ̀̀ Trous . . . . . . . . . . . . . . . . 42

4.1.2. Singularidades y wavelets . . . . . . . . . . . . . . . . . . . . . . . . . . . . . 44

4.1.2.1. Regularidad Lipschitz . . . . . . . . . . . . . . . . . . . . . . 44

$4.1 .2 .2 . \quad$ Momentos de desvanecimiento . . . . . . . . . . . . 44

4.1.2.3. Medidas de regularidad con wavelets . . . . . . . . 45

4.1.2.4. Puntos de máximo módulo . . . . . . . . . . . . . 46

4.2. Wavelet y análisis de singularidades en imágenes . . . . . . . . . . . . . 4 49

$4.2 .1 . \quad$ Detector de bordes de Canny . . . . . . . . . . . . . . . . . . . . . . . 49

$4.2 .2 . \quad$ Detección de bordes multiescala . . . . . . . . . . . . . . . 49

4.2.3. Regularidad Lipschitz en imágenes . . . . . . . . . . . . 50

4.2.4. Caracterización de singularidades en imágenes naturales . . . 51

4.3. Aplicación a la detección de calcificaciones en imágenes mamográficas 55

5. Formalismo multifractal y relación con Teoría Wavelet 59

5.1. Teoría matemática de los multifractales . . . . . . . . . . . . . . 59

5.1 .1$. Motivación . . . . . . . . . . . . . . . . 59

5.1.2. Introducción a las medidas fractales . . . . . . . . . 60

5.1.2.1. Dimensión de similitud . . . . . . . . . . . . . 61

5.1.2.2. Dimensión "Box-counting"'. . . . . . . . . . . . 62

5.1.3. Teoría multifractal . . . . . . . . . . . . . 63

5.1.3.1. Medida multifractal . . . . . . . . . . . . 63

$5.1 .3 .2 . \quad$ Exponentes de Hölder . . . . . . . . . . . . . . . . 64

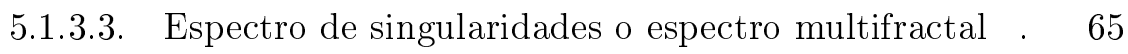

5.1 .3 .4 . Dimensión fractal generalizada . . . . . . . . . 65

5.1.3.5. $\quad$ Transformada de Legendre: Relación entre el espectro multifractal y la dimensión Fractal generalizada . . 67

5.1.4. Simulación $1 D$ con la "Escalera del Diablo" . . . . . . . . . 69

5.1.5. Simulacion $2 D$ con Multifractales "Sierpinski Carpets" . . . . 71

5.2. Formalismo multifractal basado en la transformada Wavelet . . . . . 75

5.2.1. Análisis multifractal y tratamiento de señales . . . . . . . . 75

5.2.2. Espectro multifractal y transformada wavelet de módulo máximo 76

5.2.3. Aspectos de implementación y limitaciones del enfoque wavelet 79

$\begin{array}{lll}5.3 . & \text { Estimación del espectro multifractal desde los coeficientes wavelet . . } & 80\end{array}$

6. Análisis Multiescala de Series Financieras 85

6.1. Introducción . . . . . . . . . . . . . . . 85

6.2. Estimación de la volatilidad sobre el mercado de valores Dow-Jones . 86

7. Cuantificación Multifractal de Suelos Agrícolas 95

$\begin{array}{lll}\text { 7.1. Análisis wavelet de imágenes de suelos agrícolas obtenidas por tintes } 95 & 95\end{array}$

7.1.1. Análisis de suelos arcillosos mediante imágenes . . . . . . . . 95

7.1.1.1. Análisis multifractal sobre la imagen de cada sección 98

7.1.1.2. Imágenes de masa de tinte . . . . . . . . . . . . 102

7.1.2. Análisis multifractal de suelos arcillosos y formalismo wavelet 104 
7.2. Cuantificación wavelet de imágenes de suelos obtenidas por CT . . . 109

7.2.1. Aplicación de la tomografía computarizada al estudio de suelos agrícolas . . . . . . . . . . . . . . . . . 109

7.2.2. Material para el estudio: Tomografía axial computarizada . . 109

7.2.3. Cuantificación de la estructura multifractal mediante método

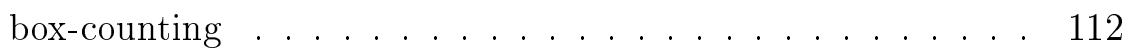

7.2.4. Cuantificación mediante estimación directa de coeficientes Lips-

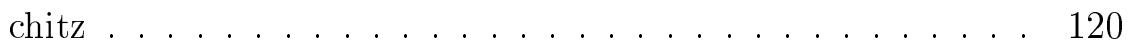

$\begin{array}{lr}\text { 8. Conclusiones } & 125\end{array}$

8.1. Contribución al análisis multiescala y multifractal. . . . . . . . . . 126

8.2. Aplicación a la estimación de volatilidad de series financieras . . . . 127

8.3. Aplicación a la cuantificacion multifractal de imágenes de suelos en estudios hidrológicos . . . . . . . . . . . . . . . 128

9. Futuras líneas de investigación

9.1. Cuantificación basada en la MODWT y correlación wavelet . . . . . 131

9.1.1. Definición e implementación de la Maximal Overlap Discrete

Wavelet Transform . . . . . . . . . . . . . 132

9.1.2. Análisis espacio-escala de suelos agrícolas mediante varianza

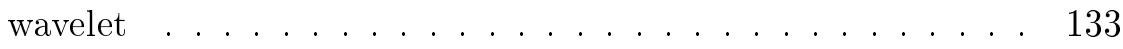

9.2. Análisis 3D en el dominio escala-espacio . . . . . . . . . . . . . 135

9.2.1. Análisis Multifractal Multidimensional . . . . . . . . . . . . 136

9.2.2. Análisis Wavelets Multidimensional . . . . . . . . . . . . . 136

\begin{tabular}{ll}
\hline Bibliografía & 139
\end{tabular} 



\section{Índice de figuras}

2.1. Caja de Heisenberg representando un átomo $\phi_{\gamma} \ldots \ldots$. . . . . . . 12

2.2. Cajas de Heisenberg de dos átomos enventanados de Fourier $g_{u, \xi}$ y $g_{u, \gamma} 13$

2.3. Señal original (arriba) y Espectrograma de la misma (abajo) . . . . . 14

2.4. Escalograma de la señal de la figura (2.3) . . . . . . . . . . . 15

2.5. Rectángulos de Heissemberg para (a) STFT y (b) Transformada Wavelet 16

3.1. Banco de filtros de dos canales implementando la base de Haar . . . 23

3.2. Filtrado a Q-cte. . . . . . . . . . . . . . . . 26

3.3. Implementación de la transformada wavelet discreta (DWT) mediante bancos de filtros . . . . . . . . . . . . . . . . . 30

3.4. Implementación de la transformada wavelet discreta (DWT) en imágenes - 2 Dimensiones . . . . . . . . . . . . . . 30

3.5. Descomposición wavelet y partición de frecuencias en procesamiento

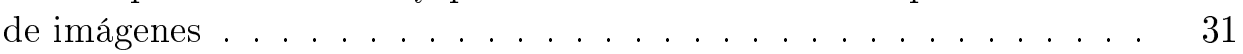

3.6. DWT de partida para la inserción de marcas de agua . . . . . . . . . 35

3.7. Matriz de pesos y diferencia entre imagen original y marcada . . . . 37

3.8. Medidas de correlación para distintas claves de marcado. . . . . . . . 37

3.9. Imagen original y con ruido . . . . . . . . . . . . . . . . . . 39

3.10. Segmentación en regiones mediante watersheds . . . . . . . . . 40

4.1. Implementación de la transformada wavelet continua mediante bancos 4

4.2. Detección de singularidades mediante transformada wavelet . . . . . 46

4.3. Transformada wavelet $W f(u . s)$ de una señal $f \ldots \ldots$. . . . . . . . . . . . . 47

4.4 . WTMM de $W f(u, s)$ de una señal $f \ldots \ldots \ldots$. . . . . . . 47

4.5. Ejemplo de caída de $\log _{2}|W f(u, s)|$ con respecto a $\log _{2}(s)$ para cálculo de regularidad Lipschitz . . . . . . . . . . . . . . . . 48

4.6. Módulo de la CWT de Lena a distintas escalas . . . . . . . . . . . . 51

4.7. Máximos locales de Lena a las distintas escalas . . . . . . . . . . . . . . 52

4.8. Superposición 3D de máximos locales de Lena . . . . . . . . . . . . 53

4.9. Propagación de máximos . . . . . . . . . . . . . . 53

4.10. Imagen de mapa de " $\alpha$ " entre escalas . . . . . . . . . . . . . . . . . 54

4.11. Ejemplo de mamografía . . . . . . . . . . . . . . . . 55

4.12. Módulo de la CWT para imagen de mamografía . . . . . . . . . . . 56

4.13. Detección de calcificaciones en base a valores de $\alpha$ prefijados . . . . . 57 
5.1. Curva de Koch de orden cuatro . . . . . . . . . . . . . . . . . 61

5.2. Conjunto de Cantor de orden cuatro . . . . . . . . . . . . . . 62

5.3. Escalera del diablo para $p_{1}=p_{2}=0,5 \ldots \ldots$. . . . . . . . . 69

5.4. Formalismo multifractal aplicado a la función "Escalera del Diablo" . 70

5.5. Formalismo multifractal aplicado a "Sierpinsky monofractal" . . . . . 72

5.6. Formalismo multifractal aplicado a "Sierpinsky multifractal" . . . . . 73

5.7. Indice de Nikkei . . . . . . . . . . . . . . . . . . . . . 75

5.8. Exponentes Hölder locales del Indice de Nikkei . . . . . . . . . . . . 76

5.9. Transformada wavelet del multifractal "Escalera del Diablo" . . . . . 77

5.10. Cálculo del espectro fractal . . . . . . . . . . . . . . . . 79

5.11. Extensión simétrica de la señal escalera del diablo . . . . . . . . . . . 80

5.12. Estimación directa del espectro fractal para la señal Escalera del diablo 81

5.13. Sierpinski monofractal y transformada wavelet continua . . . . . . . 82

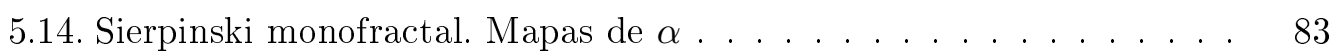

6.1. Valores normalizados de mínima y máximo volatilidad del índice Dow

Jones . . . . . . . . . . . . . . . . . . . . 88

6.2. Comparación de las estimaciones de volatilidad de método de referencia (rojo) y basado en wavelets (azul) $\ldots \ldots$. . . . . . . . . . 89

6.3. Estimación de volatilidad a partir de coeficientes locales para el índice Dow Jones $(1 \mathrm{de} 2) \ldots \ldots \ldots \ldots$. . . . . . . . . . . . 90

6.4. Estimación de volatilidad a partir de coeficientes locales para el índice Dow Jones $(2$ de 2$) \ldots \ldots \ldots \ldots \ldots$. . . . . . . . . . . . . . . 91

6.5. Comparación entre los índices reportados como de mínima y máxima

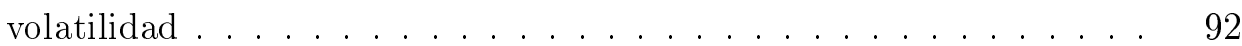

6.6. Histograma de coeficientes de Lipschitz locales para el índice GS (The Goldman Sachs Group, Inc) $\quad \ldots \ldots \ldots$. . . . . . . . . . 93

7.1. Imágenes de suelos tintados a diferentes profundidades (A) $20 \mathrm{~cm}$ y

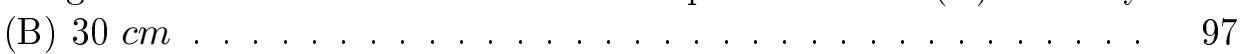

7.2. Función de partición en función de la escala para (A) $20 \mathrm{~cm}$ y (B) 30 $\mathrm{cm} \ldots \ldots \ldots \ldots \ldots \ldots$

7.3. Formalismo multifractal aplicado a imagen de profundidad $20 \mathrm{~cm}$. . 100 7.4. Formalismo multifractal aplicado a imagen de profundidad $30 \mathrm{~cm}$. . 101 7.5. Imagen de masa de tinte $($ dye-mass $) \ldots \ldots . \ldots . \ldots . . \ldots 102$ 7.6. Formalismo multifractal aplicado a imagen de masa de tinte (dye-mass) 103 7.7. Base wavelet utilizada: Mexican Hat . . . . . . . . . . . . . 105 7.8. Precisión en el análisis en relación al soporte de la wavelet de análisis 105 7.9. Región de 512x512 píxeles de la imagen de masa de tinte . . . . . . . 105 7.10. Transformada Wavelet Continua de la imagen de masa de tinte . . . 106 7.11. Máximos de la Transformada Wavelet Continua de la imagen de tinte 106 7.12. Mapa de $\alpha$ de la imagen masa de tinte . . . . . . . . . . . . . . 107 7.13. Histograma de coeficientes de Lipschitz para la imagen de masa de tinte 108 7.14. Planos ortogonales obtenidos para los 4 horizontes del estudio . . . . 110 7.15. Sub volúmenes asociados al horizonte A2 . . . . . . . . . . . . 111 
7.16. Sub volúmenes asociados al horizonte $\mathrm{AB}$. . . . . . . . . . . . . 111

7.17. Sub volúmenes asociados al horizonte Bt2 . . . . . . . . . . . . 111

7.18. Sub volúmenes asociados al horizonte $\mathrm{Bt} / \mathrm{Bw} \ldots \ldots \ldots$. . . . . 111

7.19. Formalismo multifractal aplicado al horizonte $A 2$, volumen $A$. . . . 112

7.20. Formalismo multifractal aplicado al horizonte $A 2$, volumen $B$. . . . 113

7.21. Formalismo multifractal aplicado al horizonte $A 2$, volumen $C$. . . . 113

7.22. Formalismo multifractal aplicado al horizonte $A B$, volumen $A$. . . . 114

7.23. Formalismo multifractal aplicado al horizonte $A B$, volumen $B$. . . . 114

7.24. Formalismo multifractal aplicado al horizonte $A B$, volumen $C$. . . . 115

7.25. Formalismo multifractal aplicado al horizonte $B t 2$, volumen $A$. . . . 115

7.26. Formalismo multifractal aplicado al horizonte $B t 2$, volumen $B$. . . . 116

7.27. Formalismo multifractal aplicado al horizonte $B t 2$, volumen $C$. . . . 116

7.28. Formalismo multifractal aplicado al horizonte $B t / B w$, volumen $A$. . 117

7.29. Formalismo multifractal aplicado al horizonte $B t / B w$, volumen $B$. . 117

7.30. Formalismo multifractal aplicado al horizonte $B t / B w$, volumen $C$. . 118

7.31. Comparación de los diferentes $\alpha_{0}$ obtenidos del análisis multifractal para los distintos horizontes-volúmenes . . . . . . . . . . . . . . 120

7.32. Comparación de los diferentes $\alpha_{m}$ estimados a partir de los coeficientes

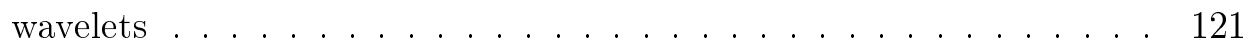

7.33. Histograma de mapa de $\alpha$ asociados a los diferentes horizontes / subvolúmenes . . . . . . . . . . . . . . . . . . 122

7.34. Mapa de $\alpha$ asociado al horizonte A2 . . . . . . . . . . . . . . . . 123

7.35. Mapa de $\alpha$ asociado al horizonte AB . . . . . . . . . . . . . . . . 123

7.36. Mapa de $\alpha$ asociado al horizonte Bt2 . . . . . . . . . . . . . . . . . . 123

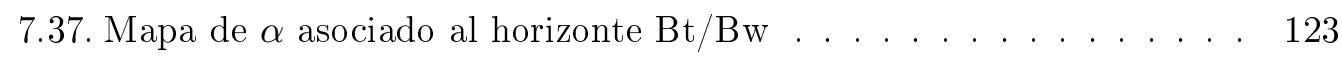

9.1. Ejemplo de análisis espacio-escala a partir de la varianza wavelet . . 134

9.2. Volumen resultante de la tomografía axial . . . . . . . . . . . . 135

9.3. Dimensión fractal generalizada computada en 24 direcciones . . . . . 136

9.4. Dimensión fractal generalizada 3D . . . . . . . . . . . . . 137 



\section{Índice de Tablas}

6.1. Estimación de la volatilidad del índice Dow Jones según (Han, 2011) y estimación directa mediante coeficiente wavelets . . . . . . . . . 87

7.1. Características multifractales de los distintos horizontes y subvolúmenes. Método de estimación directa . . . . . . . . . . . . . . . . . . . 119

7.2. Características multifractales de los distintos horizontes y subvolúmenes. Método "box-counting"] . . . . . . . . . . . . . . . . . . . . . . 119

7.3. Comparación de los distintos métodos en los diferentes horizontes /

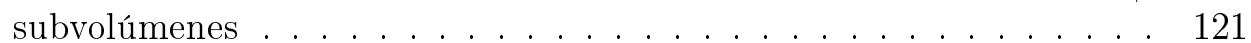





\section{Capítulo 1}

\section{Introducción}

\subsection{Análisis multiescala de señales}

Cuando escuchamos música, claramente "oímos" la variación temporal de las "frecuencias" sonoras. Estos eventos localizados de frecuencia no son tonos puros sino paquetes de frecuencias muy cercanas. Las propiedades de los sonidos se revelan con transformadas que descomponen las señales en funciones elementales que están bien concentradas tanto en tiempo como frecuencia. Esto da lugar a transformadas localizadas en el tiempo como la transformada de Fourier enventanada o la transformada wavelet ofreciendo cada una de ellas distintos compromisos en la resolución que en tiempo o en frecuencia se tiene del análisis de un problema concreto.

Utilizando términos propios de la teoría wavelet el concepto de resolución en frecuencia queda caracterizado por el parámetro de escala propio de las distintas versiones de la transformada wavelet (transformada continua, discreta, de módulo máximo, etc) que se describirán y utilizarán en distintas aplicaciones a lo largo de este trabajo de tesis.

Este parámetro de escala permite asimilar la transformada wavelet con un análisis multirresolución de señales o imágenes. Burt y Adelson en (Burt y Adelson, 1983) introdujeron este concepto en el campo de la visión artificial bajo el concepto de pirámide multirresolución donde proponen procesar una imagen de baja resolución en primera instancia para posteriormente incrementar dicha resolución afinando el análisis progresivamente.

Mallat (Mallat, 1989) llevó este concepto más allá imponiendo que las distintas imágenes correspondientes a cada espacio multirresolución puedan ser descompuestas en función de bases incorreladas entre sí para cada resolución como es el caso de las impuestas por la teoría wavelet. Esto llevo a una nueva forma de concebir, construir e implementar bases wavelets con multitud de aplicaciones prácticas.

Entre estas aplicaciones destaca la inclusión de estos algoritmos en distintos estándares de compresión como JPEG-2000 o MPEG-4. El estudio de estas técnicas en sistemas de compresión de imagen fija fue el objetivo del proyecto fin de carrera "Wavelet Packets: Procesamiento de imágenes en el dominio transformado" (Piñuela, 2000 que de alguna forma constituye el punto de partida de este trabajo de tesis.

Más allá de la capacidad de la transformada wavelet de aproximar funciones y por tanto comprimirlas adecuadamente en relación a las limitaciones de sistema 
visual humano, la transformada wavelet resulta especialmente atractiva y potente debido a que además del análisis multirresolución mencionado añade distintos marcos conceptuales para el análisis de las estructuras y singularidades presentes en una señal cuando esta es analizada en distintas escalas.

Utilizando este marco conceptual se llega a las primeras aplicaciones o ejemplos que desarrolla este trabajo de tesis como son los sistemas de marcas de agua (Piñuela et al., 2007a) y la eliminación de ruido en imágenes en los que la caracterización y modificación directa de los coeficientes wavelet a diferentes escalas se describen como ejemplos del trabajo desarrollado en el campo del análisis multiescala de señales e imágenes.

Destacar que la inclusión de distintos ejemplos de aplicación a lo largo de este documento busca dar un enfoque práctico y didáctico al mismo tiempo siguiendo los pasos del proceso de aprendizaje en teoría wavelet realizado a lo largo de estos años por el autor. De todos los ejemplos proporcionados, las aportaciones más significativas son el análisis de series financieras y en especial la cuantificación multifractal de suelos agrícolas y han de ser el punto de atención de la tesis relegando a las demás aplicaciones a ejemplos didácticos aunque su potencial como objeto principal de investigación bajo el marco del análisis multiescala de señales sea igualmente relevante.

\subsection{Wavelets, singularidades y análisis multifractal}

El segundo bloque de este trabajo de tesis parte de lo que podríamos denominar teoría Wavelet zoom. Con ello nos referiremos a la capacidad de una transformada wavelet de focalizar su análisis en estructuras concretas de una señal en un procedimiento análogo a un zoom óptico. En este sentido no son los coeficiente wavelets de manera aislada los que contienen la información relevante sino la relación entre los coeficientes a distintas escalas. Este análisis se puede aplicar a señales o imágenes naturales en aplicaciones más sofisticadas de eliminación de ruido, en la caracterización de los bordes de una imagen o en la ayuda al diagnóstico de imágenes médicas como por ejemplo en el estudio de imágenes mamográficas. En todos estos casos será la relación establecida en (Mallat y Hwang, 1992) y (Mallat y Zhong, 1992) entre los coeficientes wavelets y los exponentes de Lipschitz los que dan lugar a distintas aplicaciones basadas todas ellas, por tanto, en la caracterización de las singularidades presentes en una señal.

Como ejemplo de aplicación se documenta el trabajo realizado en (Gonzálvez y Piñuela, 2008) donde la caracterización de las singularidades presentes en una imagen digital de una mamografía supone la base del desarrollo del software necesario para el resto de simulaciones del proyecto.

En contraposición a las señales o imágenes naturales se encuentra el concepto de fractal o multifractal. En este caso en lugar de estudiar objetos, funciones y estructuras regulares pasamos a centrarnos en comportamientos esencialmente aleatorios. Fue en los años 70 cuando Benoit Mandelbrot creó una visión unificada para distintos ejemplos de objetos irregulares y procesos aleatorios bajo el nombre de geometría 
fractal.

La contribución mas importante de Mandelbrot fue reconocer que muchas de las estructuras complejas y dinámicas que se observan en diferentes áreas de la ciencia, podían ser estudiadas en un marco común, basado en conceptos de fractales e invarianza de escala. Los objetos fractales tienen la originalidad de presentar detalles en todas las escalas de observación, hecho muy común en la naturaleza, y que explica las dificultades que presentan para ser caracterizados mediante la geometría clásica.

Aún sin existir una definición concreta y precisa para el término fractal, decir que en este trabajo de tesis nos centraremos en dos de sus características más comúnmente aceptadas:

- Poseen estructura fina, lo que significa que contienen detalles a cualquier escala. No importa las veces que se aumente la visión de una parte de un fractal; siempre se observarán más y más detalles.

- Son demasiado irregulares para ser descritos mediante el lenguaje de la geometría clásica, tanto local como globalmente. Es decir, conceptos como longitud o superficie no pueden aplicarse para caracterizarlos.

El concepto de fractal se extiende a estructura multifractal como aquella señal o imagen en la que aparecen más de una estructura con propiedades fractales.

Cuando tratamos con estas señales ya no es posible calcular los exponentes de Lipschitz como ocurre con imágenes naturales, y por tanto, el objetivo del análisis multifractal ya no puede ser el análisis de cada singularidad sino proveer una estimación estadística de la distribución espacial o temporal que siguen esas singularidades, siendo los conceptos claves a modelar el espectro multifractal y la dimensión fractal generalizada.

En este contexto el uso de la transformada wavelet de módulo máximo (WTMM Wavelet Transform Modulus Maxima) se ha venido utilizando de manera progresiva como herramienta matemática para la caracterización de las propiedades multifractales de señales e imágenes (Muzy et al., 1991) a través de conceptos tales como la función de partición $Z(q, s)$ o el exponente de escalado $\tau_{q}$ que permiten calcular de manera sistemática el espectro multifractal. La descripción formal de cómo se relacionan la teoría wavelet con el formalismo multifractal clásico será, de este modo, aspecto central de est trabajo de tesis y marco teórico de los principales experimentos y contribuciones prácticas desarrolladas.

\subsection{Aplicación al análisis de imágenes de suelos agrícolas y series financieras}

El dominio de interés para la parte final de este trabajo de tesis es el de la hidrología o edafología y donde se centran las publicaciones más relevantes. El punto de partida es el trabajo de Ana M. Tarquis (Tarquis y McInnes, 2005) donde se estudian las propiedades fractales de imágenes de suelos arcillosos. Este tipo de estudios tiene como objetivo caracterizar el movimiento del agua y otras sustancias químicas en los 
suelos agrícolas, aspecto de vital importancia en la mejora de su productividad. En estos casos está comúnmente aceptado que en la mayoría de suelos, el agua circula a través de los denominado flujos preferenciales y estos pueden ser modelados a través del formalismo multifractal (Tarquis y McInnes, 2005).

Los primeros resultados fueron presentados con éxito en (Piñuela et al., 2007b) incluyendo la posibilidad de hacer una estimación directa del espectro multifractal a partir del análisis de los coeficientes de Lipschitz obtenidos. Esta opción guarda relación con propuestas anteriores en la literatura técnica de autores como (Struzik, 1999) en el ámbito del análisis de series financieras, pero no existe constancia de su aplicación en el campo del análisis de imágenes multifractales en general o de suelos agrícolas particular. Es por ello que este punto se considera que constituye la principal aportación realizada.

Por su parte, dada la relación con el trabajo presentado en (Struzik, 1999) respecto del análisis de series financieras y dado que estas señales presentan una enorme complejidad en términos de singularidades presentes en cada índice bursátil se consideró de gran interés aplicar las técnicas de estimación directa sobre estas señales en lo que constituye una aproximación a la estimación del riesgo asociado a cada inversión. Además, el hecho de aplicar los algoritmos desarrollados a señales unidimensionales facilita la implementación posterior de estos mismos métodos en señales de dos dimensiones como es el caso de las imágenes de suelos agrícolas. Los prometedores resultados obtenidos permiten afirmar que el análisis de la volatilidad en series financieras a partir de la estimación directa del espectro multifractal es la otra gran contribución de este trabajo de tesis y de ahí su inclusión en el título de la misma.

Un paso más allá están los resultados presentados en (Piñuela et al., 2010) donde en lugar de utilizar imágenes tintadas se partió de imágenes de distintas muestras de suelo obtenidas mediante tomografía axial computarizada (CAT). Las técnicas CAT se están imponiendo en los últimos años como forma de obtener imágenes representativas de la estructura del suelo dado su carácter no invasivo. En concreto se analizan tres secciones del volumen tridimensional obtenido al escanear las muestras de cuatro suelos $\mathrm{u}$ horizontes distintos.

En este marco se comparan los resultados proporcionados por el análisis multifractal clásico y el formalismo desarrollado mediante transformada wavelet, obteniendo resultados coherentes en el análisis global de los parámetros multifractales y con el valor adicional de que el enfoque de estimación directa del espectro multifractal permite detectar tanto la existencia de microestructuras locales en la imagen como diferenciar comportamientos específicos en escalas concretas.

\subsection{Contenido de la memoria}

La memoria de este trabajo de tesis comienza con la explicación básica de conceptos relativos a la resolución tiempo-frecuencia en las señales. Se analizan las diferencias entre el análisis de Fourier, en su versión enventanada (STFT) y la Transformada Wavelet y se introducen conceptos como los átomos tiempo-frecuencia que nos dan idea sobre la incertidumbre a la hora de definir con exactitud la resolución del análisis 
en tiempo / espacio o en frecuencia.

En el capítuo 2 y 3 se explican aspectos del análisis multirresolución que nos aporta la transformada wavelet, y conceptos claves en los distintos escenarios de aplicación que se describen en esta memoria como son el algoritmo de obtención de coeficientes wavelet, y los momentos de desvanecimiento como aspecto clave en el tipo de wavelet a utilizar en aplicaciones de análisis multiescala.

Al final del capítulo 3 dejamos ya de lado los principios básicos de la teoría wavelet y se describen las primeras aplicaciones prácticas con dos interesantes ejemplos de cómo la modificación directa de los coeficientes wavelet resultantes del análisis multirresolución en imágenes permite desarrollar dos interesantes aplicaciones en los campos de la protección de los derechos de autor en imágenes digitales y la eliminación de ruido previa a la segmentación de objetos en secuencias de vídeo.

Ya en el capítulo 4 nos centramos en el aspecto de "zoom" que nos ofrece la transformada wavelet. Así, mediante distintas variantes de transformada wavelet, podremos focalizarnos tanto en detalles pequeños de la señal como en aspectos más generales. Se explican conceptos relacionados con la llamada regularidad local de las señales y por tanto con el estudio de sus singularidades a través de la definición de distintos elementos característicos de la teoría wavelet como son los momentos de desvanecimiento o líneas de módulo máximo. En definitiva, se establece la base teórica del análisis de singularidades que se aplicará posteriormente.

Una vez establecida la teoría para señales unidimensionales se detalla la extensión a imágenes, y siguiendo la misma estructura que en el primer bloque los experimentos y simulaciones relativas a la caracterización de bordes y singularidades en imágenes naturales y en imágenes mamográficas completan esta segunda parte del proyecto.

La teoría multifractal desde un punto de vista clásico es presentada en el capítulo 5 donde se desarrollan algoritmos basados en el método de "box-counting" que serán claves en los experimentos principales como referencia para las implementaciones de los distintas técnicas propuestas.

Entre ellas y como propuesta principal de este trabajo de tesis destaca la estimación del espectro multifractal a partir de los coeficientes Lipschitz, estimados a su vez a partir de la evolución del módulo de la transformada wavelet entre dos escalas consecutivas. Esta propuesta encuentra similitudes con recientes publicaciones realizadas en el ámbito de la eliminación de ruido en imágenes naturales (Zhong y Ning, 2005) y el análisis de series financieras (Struzik, 1999), pero puede considerarse como una nueva forma de análisis multiescala de señales e imágenes.

Es precisamente en el ámbito del análisis de series financieras donde se aplica esta estimación en primer lugar tomando como señales a analizar los distintos valores componentes del índice Dow Jones. El análisis multiescala aplicado en este campo equivale a calcular la volatilidad de los indices bursátiles, aspecto clave en la gestión y evaluación de riesgos, campo donde las publicaciones realizadas hasta la fecha de la Barcena et al., 2010) y (Cedeno et al., 2011) están basadas en redes neuronales y por tanto el detalle de las mismas no quedan incluidas en este trabajo de tesis.

Las estimaciones de volatilidad resultantes son detalladas en el capítulo 6 antes de pasar a describir los experimentos principales del trabajo, llevados a cabo en el campo del análisis multifractal de imágenes de suelos agrícolas. Como ya se ha mencionado, primero se partirá de imágenes obtenidas a partir de tintes especiales para luego utilizar técnicas de tomografía axial computarizada. Esta es, sin duda, la 
contribución más significativa de este trabajo de tesis que se describe en el capítulo 7 y que dio origen a nuestras principales publicaciones (Piñuela et al., 2007b) y (Piñuela et al., 2010).

Finalmente las conclusiones principales de este trabajo y las futuras líneas de investigación son objeto de análisis en los capítulos 8 y 9 de la memoria. De entre todas las líneas de investigación futuras se han destacados dos como son el uso de otros parámetros wavelet como puede ser la correlación o la varianza o incluso la extensión del análisis a tres dimensiones según lo publicado por el autor de este trabajo en (Torres et al., 2008) y (Piñuela et al., 2009). 


\section{Capítulo 2}

\section{Introducción al Análisis de Señal y Teoría Wavelet}

\section{1. ¿Qué es una transformada wavelet?}

Durante las últimas décadas lo que globalmente podríamos llamar Teoría wavelet ha generado y sigue generando un creciente interés tanto en las áreas teóricas como aplicadas. Esto hace difícil definir con exactitud lo que entendemos por wavelet al encontrarse su marco de uso muy extendido tanto en el mundo de las matemáticas como en el de las ciencias aplicadas teniendo que adaptar su significado a los continuos avances que resultan de campos tan diversos.

Medicina, ingeniería eléctrica, teledetección, comprensión de señales e imágenes, reconocimiento de objetos, aplicaciones geofísicas y en general aplicaciones donde la detección de irregularidades locales es clave (electrocardiogramas, mamografías , vibraciones de motores, etc.), forman parte de una lista de áreas de aplicación cuyos límites se desconocen hoy en día.

Aún así y como posible definición, podemos hablar de la Teoría wavelet como un conjunto coherente de conceptos, métodos y algoritmos que se adaptan al procesamiento de una amplia variedad de señales y a la resolución de distintos problemas propios del análisis numérico.

Un punto a resaltar es que las wavelets no se basan en una nueva y brillante idea sino en conceptos que ya existían desde hace tiempo en muy distintos campos. A lo largo de los años, tanto teóricos como ingenieros han ido añadiendo mas y más herramientas a las bases de la teoría de análisis en frecuencia establecidas por Fourier en 1807, como primer ejemplo de lo que podríamos llamar teoría matemática de transformadas ortonormales de señales definidas en energía, teoría en la que como veremos encajará igualmente la transformada wavelet.

Durante muchos años la expansión de señales en bases de Fourier fue la única herramienta de la que se disponía y cuyas propiedades como base de representación de distintas familias de funciones se estudiaban desde un punto de vista matemático.

Cara a la aplicación de las técnicas de Fourier en aplicaciones prácticas y señales finitas y como veremos a continuación, se hace necesario recurrir a la denominada Transformada localizada de Fourier o Transformada de Fourier enventanada donde ya si manejamos una base de funciones definida tanto en tiempo como en frecuencia 
permitiendo aplicar el análisis de Fourier en multitud de aplicaciones tanto de señales unidimensionales como imágenes o vídeo (de hecho sigue siendo la opción preferente en la implementación de sistemas de compresión de imagen fija y secuencias de vídeo).

Pero es en esos casos de señales finitas donde la Transformada Wavelet resulta especialmente útil en comparación con el análisis de Fourier ofreciendo un compromiso flexible entre localización en el tiempo y en frecuencia mediante el uso de funciones de base de soporte o duración finita y con una resolución en frecuencia completamente definida a través del denominado parámetro de escala, aspecto clave y esencial en cualquier transformada wavelet.

Se suele considerar que es aproximadamente desde 1980 cuando la transformada wavelet se vino a aplicar a distintos problemas bien de manera complementaria a técnicas clásicas como el análisis espectral de Fourier o incluso como forma de resolver problemas que no pueden ser abordados por las técnicas clásicas de Fourier como es el caso del análisis de singularidades y estructuras multifractales en imágenes, problemas ambos que definen el campo de aplicación de este trabajo de tesis.

Es igualmente importante establecer desde el primer momento que no existe una transformada wavelet única, ni que resuelva todos los problemas, si no que es el análisis a priori del tipo de señal tratada y del objetivo que se pretenda (compresión, eliminación del ruido, segmentación de la imagen, análisis multifractal) lo que determina qué familia de wavelets (Haar, Daubechies, Coiflets, Sombrero Mexicano) se adapta mejor a las características de la señal a estudiar y cual de las distintas variantes de transformada wavelet será la más adecuada.

De cara al análisis de singularidades y caracterización estadística, en esta tesis aplicaremos prácticamente todas las variantes de la transformada wavelet. De este modo, partiremos de la denominada transformada wavelet discreta (DWT), habitual elección en problemas de compresión de imagen, en la que mediante el análisis estadístico de los denominados coeficientes de detalle y posterior modificación llegaremos a dos aplicaciones concretas como son la inserción de marcas de agua en imágenes digitales y la eliminación de ruido en secuencias de imágenes como paso previo para la segmentación y seguimiento de objetos en un vídeo.

Por otro lado, como elemento central de este trabajo se utilizará la transformada wavelet continua (CWT), que aunque genera una altísima redundancia de información, permitirá una gran flexibilidad en el análisis de singularidades al proveer, dada esa redundancia, la resolución temporal y espectral necesaria para aplicaciones de detección de singularidades en el espacio transformado.

Concretamente en el análisis de imágenes de suelos agrícolas, que será la principal aplicación presentada, se hará necesario detectar estructuras multifractales en la imagen, siendo la transformada wavelet continua y la transformada wavelet de módulo máximo (WTMM) los marcos o herramientas matemáticas de la teoría wavelet que nos permitirán cuantificar la estructura de cada imagen analizada, objetivo último y principal contribución de este trabajo de tesis. 


\subsection{Resolución Tiempo-Espacio / Frecuencia-Escala}

Cuando escuchamos música, claramente "oímos" la variación temporal de las "frecuencias" sonoras. Estos eventos localizados de frecuencia no son tonos puros sino paquetes de frecuencias muy cercanas. Las propiedades de los sonidos se revelan con transformadas que descomponen las señales en funciones elementales que están bien concentradas en tiempo y frecuencia. Las Transformadas de Fourier enventanadas y las transformadas Wavelet son dos clases importantes de descomposiciones tiempofrecuencia locales que solucionan el problema que el análisis de Fourier clásico supone en cuanto a resolución tiempo-frecuencia.

Y es que el análisis de Fourier tiene una seria desventaja. Cuando se realiza la transformación al dominio de frecuencias, se pierde la información temporal. Es decir, cuando se observa una transformación de Fourier de una señal, es imposible saber cuándo sucede un evento particular. Si una señal no cambia mucho en el tiempo (esto es, si la señal es estacionaria) esta desventaja no es muy importante, pero muchas señales interesantes contienen numerosas características no estacionarias o transitorias: tendencias, cambios bruscos, comienzos/finalizaciones de eventos, etc. Y estas características son a menudo la parte más importante de la señal en determinadas aplicaciones, con lo que el análisis de Fourier no es adecuado para estos casos.

Por eso, ya en 1910, Haar presentó como alternativa a las técnicas propuestas en la teoría de Fourier otro tipo de sistemas ortonormales en los que poder descomponer una señal dando lugar al caso más sencillo de wavelet.

Aún con importantes inconvenientes que veremos a lo largo de este proyecto y que le han relegado a un papel principalmente didáctico las wavelets de Haar son claves para entender el objetivo que se perseguía, que no era otro que buscar un sistema de representación en los que se revelaran las características locales de las señales, aspecto que como se ha comentado no cubrían las series de Fourier.

\subsubsection{Expansión de señales en bases ortonormales}

Para analizar las afirmaciones realizadas desde el punto de vista matemático, partimos de la definición de la transformada de Fourier:

$$
\hat{f}(\omega)=\int_{-\infty}^{+\infty} f(t) e^{-j \omega t} d t
$$

donde se observa que la transformada $\hat{f}$ se obtiene correlando $f$ con una onda sinusoidal $e^{j \omega t}$.

Como el soporte de esta última cubre todo el eje real, $\hat{f}(\omega)$ dependerá de los valores de $f(t)$ para todo el eje real $(\forall t \in \mathbb{R})$. Esta "mezcla" de información hace difícil analizar cualquier propiedad local de $f$ a partir de $\hat{f}$. Es decir, la información del instante temporal en el que aparece un contenido de una frecuencia concreta no está disponible.

Como definición alternativa podemos expresar la transformada de Fourier como el resto de transformadas de las que nos ocuparemos como una expansión lineal de una señal $f((t)$ que bajo ciertas circunstancias se puede expresar como combinación 
lineal de una familia de señales $\left\{\varphi_{i}\right\}_{i \in \mathbf{z}}$. Esto es:

$$
f(x)=\sum_{i \in \mathbb{Z}} \alpha_{i} \varphi_{i}
$$

Si el conjunto de funciones $\left\{\varphi_{i}\right\}$ es una base del espacio vectorial $\mathbb{S}$ tal que todas las funciones o señales $f(x) \in \mathbb{S}$ existirá un conjunto dual $\left\{\tilde{\varphi}_{i}\right\}_{i \in \digamma}$, tal que los coeficientes de la expansión (2.2) pueden calcularse como:

$$
\alpha_{i}=\sum_{n=-\infty}^{+\infty} \tilde{\varphi}_{i}[n] f[n], \quad \alpha_{i}=\int_{n=-\infty}^{+\infty} \tilde{\varphi}_{i}(t) f(t) d t
$$

dependiendo de si estamos trabajando con funciones discretas o continuas.

Un importante caso particular ocurre cuando el conjunto $\left\{\varphi_{i}\right\}$ es ortonorma $11 \mathrm{y}$ completo; hablamos entonces de base ortonormal de $\mathbb{S}$ que cumplirá $\varphi_{i}=\tilde{\varphi}_{i}$.

Asociar las ecuaciones (2.1) y 2.3 no es tarea fácil en tiempo continuo aunque a efectos prácticos basta destacar que la interpretación correcta es que estaríamos descomponiendo la función $f(t)$ como combinación lineal de infinitas exponenciales complejas separadas entre sí por incrementos infinitesimales de frecuencia.

Más sencillo es considerar en lugar de funciones en tiempo continuo, secuencias discretas donde la transformada de Fourier viene dada por:

$$
\hat{f}(\omega)=\sum_{-\infty}^{+\infty} f[n] e^{-j \omega n}
$$

que podemos igualmente discretizar dando lugar a la transformada discreta de Fourier o DFT (Discrete Fourier Transform) cuya expresión matemática es:

$$
\hat{f}_{i}=\sum_{k=0}^{N-1} f[n] e^{j \frac{2 \pi}{N} k i}
$$

que cumple con la relación $\hat{f}_{i}=\left.\hat{f}(\omega)\right|_{\omega=\frac{2 \pi}{N} k}$ tomando $k$ valores comprendidos entre $k=0$ y $k=N-1$.

Comparando 2.3 con 2.5 se concluye que la transformada de Fourier y en concreto su versión discretizada o DFT es un ejemplo concreto de descomposición lineal ortonormal en el que las funciones de base vienen dadas por:

$$
\left\{\varphi_{i}\right\}=\left\{e^{j \frac{2 \pi}{N} k i}\right\}
$$

y representa una descomposición completa de las secuencias discretas de longitud $L \leq N$

Por su parte, Haar propuso la siguiente base ortonormal:

$$
\varphi_{0}=[1,1]^{T} / \sqrt{2} \quad \varphi_{1}=[1,-1]^{T} / \sqrt{2}
$$

\footnotetext{
${ }^{1}$ A lo largo del proyecto usaremos los términos ortonormal y ortogonal indistintamente dependiendo de lo que deseemos resaltar. Basta normalizar por el módulo en el espacio vectorial concreto para obtener ortonormalidad a partir de ortogonalidad
} 
cuyos detalles de implementación dentro de la teoría wavelet y bancos de filtros será descrita más adelante, quedando la demostración de que efectivamente es una base completa fuera del alcance de este trabajo.

Aunque aparentemente no tengan relación, es interesante observar que la base propuesta por Haar es igual a la base de la transformada discreta de Fourier para $N=$ 2 (y secuencias de longitud 2). De ete modo quedan todas estas descomposiciones enmarcadas como expansiones lineales de señales o secuencias respecto de una familia de funciones base.

Motivado por este trabajo, el físico Gabor definió lo que podríamos llamar átomos tiempo-frecuencia elementales caracterizados por tener la mínima extensión posible en el plano espacio-frecuencia y que representan un concepto clave en la definición de bases wavelets (Gabor, 1946).

\subsection{2. Átomos Tiempo-Frecuencia}

Una transformada lineal de tiempo-frecuencia correlaciona la señal con una familia de ondas bien concentradas en tiempo y frecuencia. Estas ondas son las que el físico Gabor definió como átomos tiempo-frecuencia elementales caracterizados por tener la mínima extensión posible en el plano espacio-frecuencia. En mecánica cuántica ya era conocido el Principio de Incertidumbre de Heisenberg el cual mostraba como no podíamos reducir arbitrariamente la incertidumbre en la posición y el momento de una partícula libre. En concreto el estado de una partícula queda descrito en función de la resolución en el tiempo que nos dará su posición y de la resolución en frecuencia que nos dará su momento. Los átomos de Gabor buscar la mayor resolución posible en la medida de ambos parámetros simultáneamente.

Desde el punto de vista matemático partimos de una familia general de átomos tiempo-frecuencia $\left\{\phi_{\gamma}\right\}_{\gamma \in \Gamma}$, donde $\gamma$ es un parámetro multi-índice. Supongamos que ${ }^{2}$ $\phi_{\gamma} \in \mathbf{L}^{2}(\mathbb{R})$ y su módulo es igual a 1 . La correspondiente transformada tiempofrecuencia de $f$ se define como:

$$
T f(\gamma)=\frac{1}{2 \pi} \int_{-\infty}^{\infty} \hat{f}(\omega) \hat{\phi}_{\gamma}^{*}(\omega) d \omega
$$

Si el átomo $\left\{\phi_{\gamma}(t)\right\}$ es casi cero cuando $t$ está fuera de la vecindad de un punto $u$, entonces $\left\langle f, \phi_{\gamma}\right\rangle$ depende sólo de los valores de $f$ en esa vecindad. Igualmente, si $\hat{\phi}_{\gamma}^{*}(\omega)$ es despreciable para una $\omega$ lejana de una frecuencia $\xi$, resulta que $\hat{\phi}_{\gamma}^{*}(\omega)$ revela las propiedades de $\hat{f}$ en la proximidad de $\xi$.

Gabor propuso construir un átomo de Fourier enventanado a partir de una ventana $g$ trasladada por $u$ y modulada por la frecuencia $\omega$ según la expresión:

$$
\phi_{\gamma}\{(t)\}=g_{\omega, u}(t)=e^{j \omega t} g(t-u)
$$

de forma que la energía en el dominio transformado queda confinada tanto en el tiempo como en la frecuencia.

\footnotetext{
${ }^{2}$ Denotamos con $\mathbf{L}^{2}(\mathbb{R})$ denotamos al espacio vectorial de señales acotadas en energía. Este es el caso habitual tanto para análisis de Fourier como para transformadas wavelet. En el resto del proyecto siempre supondremos que las señales e imágenes cumplen este requisito
} 
En la misma línea y aunque nos estemos adelantando en el desarrollo del capítulo, un átomo wavelet resultará de una expansión por un parámetro de escala $s$ y una traslación por $u$ de una wavelet madre $\psi$ :

$$
\phi_{\gamma}\{(t)\}=\psi_{s, u}(t) \psi\left(\frac{t-u}{s}\right)
$$

En ambos casos, tanto wavelets como transformadas de Fourier enventanadas tienen su energía bien localizada en tiempo resolviendo el problema inicial de la transformada de Fourier que localiza la energía en frecuencia pero no en el tiempo, y como consecuencia, perdiendo la capacidad de detectar fenómenos locales.

Lo que resulta importante destacar a continuación es que al igual que existe una limitación insalvable para conocer la posición y momento de un partícula simultáneamente también estamos limitados en cuanto a capacidad de análisis simultáneo en tiempo y en frecuencia.

\subsubsection{STFT: Transformada eventanada de Fourier y Transformada de Gabor}

La porción de información proporcionada por $\left\langle f, \phi_{\gamma}\right\rangle$ se puede representar en un plano de tiempo-frecuencia $(t, \omega)$ mediante una región cuya localización y anchura depende de la distribución tiempo-frecuencia de $\phi_{\gamma}$. La extensión alrededor del punto de interés $\left(u_{\gamma}, \omega_{\gamma}\right)$ viene dada por las varianzas (precisiones en el tiempo):

$$
\begin{gathered}
\sigma_{t}^{2}(\gamma)=\int_{-\infty}^{\infty}\left(t-u_{\gamma}\right)^{2}\left|\phi_{\gamma}(t)\right|^{2} d t \\
\sigma_{\omega}^{2}(\gamma)=\frac{1}{2 \pi} \int_{-\infty}^{\infty}\left(\omega-\omega_{\gamma}\right)^{2}\left|\hat{\phi}_{\gamma}(\omega)\right|^{2} d \omega
\end{gathered}
$$

La resolución tiempo-frecuencia de $\phi_{\gamma}$ se representa en el plano tiempo-frecuencia $(t, \omega)$ mediante una caja de Heisenberg centrada en $\left(u_{\gamma}, \omega_{\gamma}\right)$, cuyo ancho a lo largo del tiempo es $\sigma_{t}^{2}(\gamma)$ y cuyo ancho en frecuencia es $\sigma_{\omega}^{2}(\gamma)$.

Esto queda ilustrado en la figura 2.1).

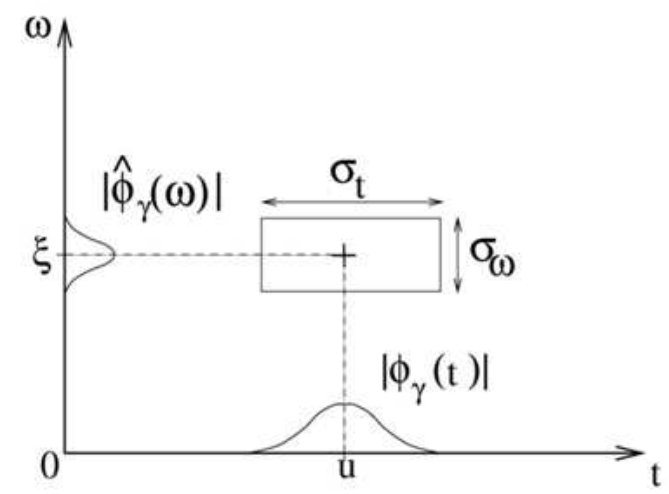

Figura 2.1: Caja de Heisenberg representando un átomo $\phi_{\gamma}$ 
La incertidumbre de Heisenberg prueba que el área del rectángulo es al menos $1 / 2$, o lo que es lo mismo,

$$
\sigma_{t}^{2} \sigma_{\omega}^{2} \geq \frac{1}{4}
$$

Y esta incertidumbre mínima se cumple cuando $g$ en es una función Gausiana (Chui, 2014), caso en el que $g_{u, \omega}$ es denominada función de Gabor. En general para una elección arbitraria de $g$, hablamos de Transformada de Fourier de "señales enventanadas" o Short Time Fourier Transform (STFT) dada por:

$$
\operatorname{STFT}(u, \omega)=\int_{-\infty}^{\infty} f(t) g(t-u) e^{j \omega} t d t
$$

La STFT, de la que la transformada de Gabor es por tanto un caso particular, transforma la función $f(t)$ en una función de dos dimensiones $(u, \omega)$, por lo que la representación de esta transformada se realiza sobre esas dos dimensiones en un plano frecuencia-tiempo, que recibe el nombre de espectrograma. El espectrograma mide la energía de $f$ en la vecindad tiempo-frecuencia de $(u, \omega)$ especificada por la caja de Heisenberg de $g_{u, \omega}$. El tamaño de esta caja de Heisenberg es independiente de $(u, \omega)$, lo que significa que una Transformada de Fourier enventanada tiene la misma resolución a lo largo del plano tiempo-frecuencia. Esto se puede observar en la figura 2.2 .

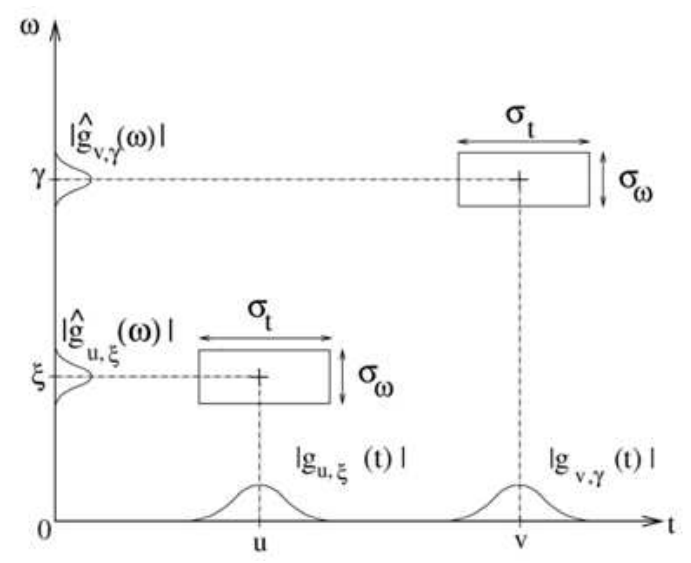

Figura 2.2: Cajas de Heisenberg de dos átomos enventanados de Fourier $g_{u, \xi}$ y $g_{u, \gamma}$

Como ejemplo práctico, la figura 2.3 muestra un espectrograma de una señal que incluye una chirp lineal cuya frecuencia aumenta, una chirp cuadrática de frecuencia decreciente y dos Gausianas moduladas localizadas en $t=0,5$ y $t=0,87$. Los puntos más oscuros indican mayor coeficiente de amplitud. La chirp lineal produce grandes coeficientes de amplitud a lo largo de la trayectoria de su frecuencia instantánea, que es una línea recta. La chirp cuadrática produce grandes coeficientes de amplitud a lo largo de una parábola, y las dos gausianas producen dos manchas a frecuencia alta y baja en $u=0,5$ y $u=0,87$.

Concluimos por tanto que la STFT representa un intento de obtener conjuntamente los marcos temporales y de frecuencias de una señal, aportando alguna información sobre cuándo y en qué frecuencias ocurre. No obstante, la información obtenida mediante esta técnica presenta una precisión limitada, ya que la precisión 

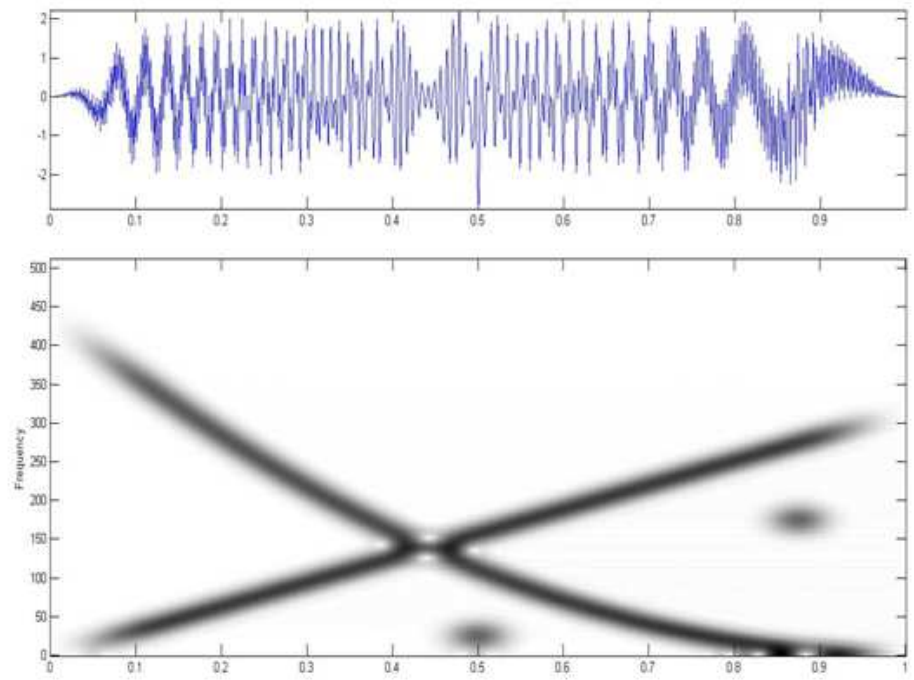

Figura 2.3: Señal original (arriba) y Espectrograma de la misma (abajo)

es función del tamaño de la ventana. Mientras que la información de tiempo y de frecuencia (obtenida por el STFT) puede ser útil, la desventaja es que, una vez se elige un tamaño particular para la ventana temporal, la ventana es la misma para todas las frecuencias. Muchas señales necesitan una aproximación mucho más flexible, donde se pueda variar el tamaño de la ventana para determinar más detalladamente tanto el tiempo como la frecuencia.

\subsection{Transformada wavelet}

\subsubsection{Definición de función wavelet}

El análisis wavelet representa el siguiente paso lógico: una técnica donde se utilice ventanas con tamaño variable. El análisis wavelet permite utilizar intervalos temporales largos donde queramos más información precisa de baja frecuencia, y regiones más cortas donde queramos una información de alta frecuencia. Por lo tanto, para analizar estructuras de señal de muy diferentes tamaños, necesitamos usar átomos de tiempo-frecuencia con diferentes soportes temporales.

Así, una transformada wavelet descompone las señales en wavelets expandidas y trasladadas. Se define una función wavelet $\psi$ (que en adelante se denominará wavelet madre) como una función de media nula:

$$
\int_{-\infty}^{\infty} \psi(t) d t=0
$$

Que es dilatada mediante un parámetro de escala $s$ y trasladada por un parámetro 
$u$ :

$$
\psi_{u, s}(t)=\frac{1}{\sqrt{s}} \psi\left(\frac{t-u}{s}\right)
$$

Desde el punto de vista de la expansión de señales, la transformada wavelet de $f \in \mathbf{L}^{2}(\mathbb{R})$ a la escala $s$ y en la posición $u$ se obtiene correlando $f$ con el átomo wavelet correspondiente a esa escala y posición según:

$$
W f(u, s)=\int_{-\infty}^{\infty} f(t) \psi_{u, s}^{*}(t)
$$

donde el símbolo $*$ indica conjugado (este proyecto se restringe a funciones wavelets reales por lo que la operación de conjugación puede obviarse para aliviar notación cuando así sea necesario).

Comparando este esquema con la STFT, vemos que la transformada wavelet también transforma una función de una variable en otra función de dos variables sobre un plano $(u, s)$ (plano escala-tiempo). Y a esta representación sobre ese plano de la transformada wavelet se la denomina escalograma, que como veremos ofrece una solución distinta a la propuesta por la transformada de Gabor.

Mientras esta ofrecía una resolución global tiempo-frecuencia óptima, la transformada wavelet ofrece mejor resolución en el tiempo a frecuencias altas (pero peor resolución en frecuencia), y mejor resolución en frecuencia a frecuencias bajas (pero peor en el tiempo). Esto está en concordancia con gran parte de las señales a las que nos enfrentamos en la práctica (las señales de baja frecuencia suelen ser de larga duración mientras que las de mayor frecuencia se corresponden con señales de más corta duración).

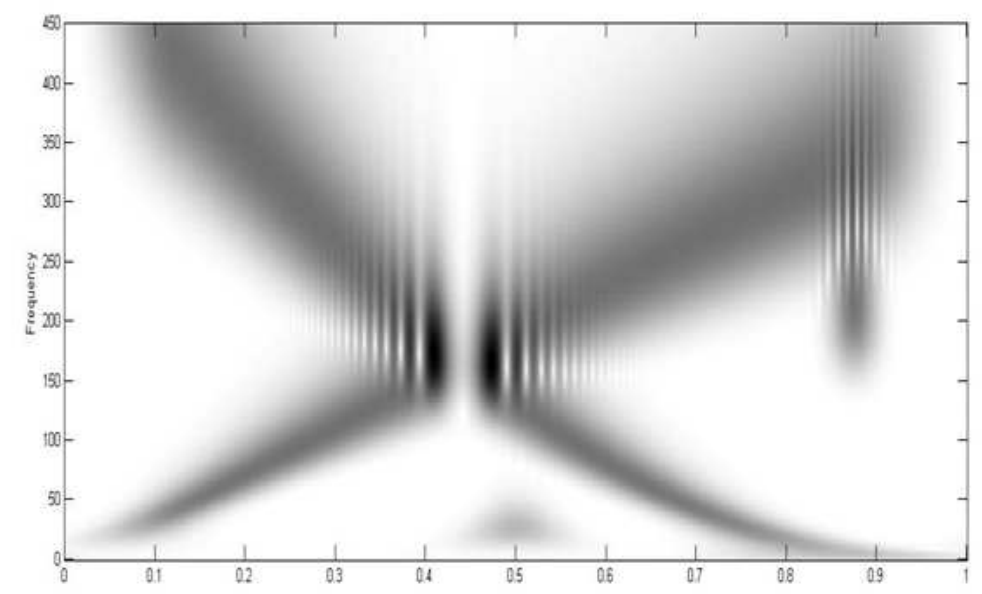

Figura 2.4: Escalograma de la señal de la figura 2.3

Utilizando la misma señal de ejemplo que con la STFT obtenemos la figura (2.4), donde observamos que la resolución en frecuencia del escalograma es mejor que la del espectrograma a bajas frecuencias pero peor en altas frecuencias. Esto explica por qué la transformada wavelet produce interferencias entre la función gausiana de alta frecuencia en $t=0,87 \mathrm{y}$ la chirp cuadrática en el mismo punto, mientras que el espectrograma de la figura 2.3 los separaba perfectamente. 
Por lo tanto podemos resumir las propiedades de la STFT y de la transformada wavelet respecto de la localización que ofrecen sus átomos fundamentales en los planos tiempo-frecuencia y tiempo-escala según la figura (2.5) que resalta la diferencias entre transformada de Gabor y Transformada Wavelet introduciendo el concepto de análisis con Q-constante que se desarrolla más adelante.
(a).- Transformada de Gabor
(b).- Transformada wavelet
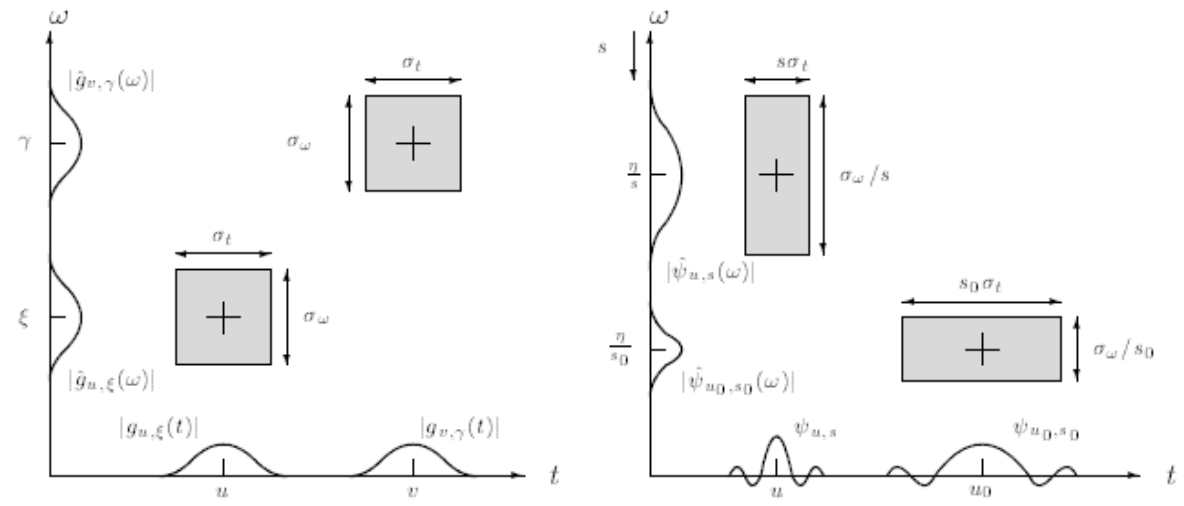

Figura 2.5: Rectángulos de Heissemberg para (a) STFT y (b) Transformada Wavelet

Así, la figura 2.5 muestra la división frecuencial realizada por la STFT y la transformada wavelet junto con las correspondientes funciones base. Los bloques representan la concentración en el plano tiempo-frecuencia cubierta por una función base dada.

Es importante resaltar en este punto que una transformada wavelet es completa; es decir cubre todo el plano escala tiempo y cumple la propiedad de conservación de energía siempre que la wavelet satisfaga una condición dada por (Mallat, 1998):

$$
\int_{-\infty}^{\infty} \frac{|\hat{\psi}(\omega)|^{2}}{\omega} d \omega<\infty \equiv \int_{-\infty}^{\infty}|\hat{\psi}(\omega)|^{2}|\omega|^{-1} d \omega<\infty
$$

Para garantizar que esta integral es finita debemos asegurar entonces la condición dada en 2.15 o lo que es lo mismo $\hat{\psi}(0)=0$.

\subsubsection{Análisis tiempo-escala o análisis con Q-constante}

Por tanto la transformada wavelet tiene la propiedad de ofrecer una resolución temporal que aumenta con la frecuencia central del filtro de análisis mientras que la proporción entre el ancho de banda en frecuencia del filtro y su frecuencia central permanece constante. Este requerimiento corresponde con el llamada análisis de Q-constante descrito en (Vetterli y LeGall, 1989) y (Vetterli y Herley, 1992). En términos de bancos de filtros, significa que en lugar de que las respuestas en frecuencia de los filtros estén regularmente espaciadas en el eje de frecuencias (como en el caso de la STFT), están regularmente espaciados en una escala logarítmica. 
Cuando la condición de ancho de banda relativo constante se cumple, la resolución es tiempo es arbitrariamente buena a altas frecuencias, mientras que la resolución en frecuencias es arbitrariamente buena a bajas frecuencias. Este tipo de análisis multirresolución funciona mejor si la señal considerada tiene componentes de alta frecuencia de pequeña duración y componentes de baja frecuencia de larga duración como ocurre con la mayoría de las imágenes, objeto de los primeros experimentos realizados en este proyecto.

Para justificar esta afirmación partimos de la definición de un "átomo" wavelet ya vista anteriormente y que repetimos aquí por conveniencia:

$$
\psi_{u, s}(t)=\frac{1}{\sqrt{s}} \psi\left(\frac{t-u}{s}\right)
$$

Podemos ver que en el tiempo, $\psi_{u, s}(t)$ esta centrado en $u$ con una extensión proporcional a $s$, mientras que en frecuencia, esa extensión es proporcional a $1 / s$ según:

$$
\hat{\psi}_{u, s}(\omega)=\sqrt{s} e^{-j u w} \hat{\psi}(s \omega),
$$

donde $\hat{\psi}$ es la transformada de Fourier de la wavelet madre. En consecuencia, el rectángulo que representa el átomo wavelet se caracterizará por una resolución en frecuencia proporcional a $s$ y en el tiempo proporcional a $1 / s$. Es lo que se ha venido a denominar análisis tiempo-escala o análisis con $Q$ constante, pues el área de los rectángulo (resolución global) permanece constante aún cambiando sus lados.

Matemáticamente:

$$
Q=\frac{\text { Frecuencia central }}{\text { Ancho de Banda }}=\frac{\eta / s}{\theta_{\omega} / s}=C^{t e}(\text { Independiente de la escala })
$$

Ya podemos dar una definición intuitiva del parámetro escala que juega un papel fundamental en la teoría wavelet. Dicho parámetro será el que nos permite hablar de la propiedad de "zoom-in/zoom-out" de la transformada wavelet y el que permite esa mayor flexibilidad a la hora de analizar las propiedades locales de las señales.

Cuando la escala decrece ( $s$ disminuye) el soporte de la wavelet $\psi_{u, s}(t)$ decrece como puede apreciarse en la expresión de $\psi_{u, s}(t)$, lo que implica que la porción de la señal que analizamos con esa wavelet es más pequeña (es como trabajar con una ventana de Gabor más estrecha) permitiendo una mejor resolución temporal. A cambio, perdemos resolución en frecuencia. Esto es lo ideal para analizar comportamientos locales en altas frecuencias (escalas pequeñas), lo que lleva a un proceso de inercia de identificar la escala como inversa de la frecuencia. Sin embargo una interpretación más intuitiva y especialmente válida para el procesamiento de imágenes, es pensar en el parámetro de escala como el "zoom" de una cámara. Cuando la escala decrece es como si nos acercamos a la imagen obteniendo una mejor visión de los detalles de esta, mientras que al aumentar la escala, nos alejamos obteniendo una visión global de la misma (de menor resolución espacial).

De esta visión intuitiva es de la que nace el análisis multirresolución, que analizaremos en detalle posteriormente. Según este enfoque vamos obteniendo visiones cada vez más globales a medida que aumentamos la escala, visiones que como parece lógico pensar podemos obtener en función de las visiones anteriores más detalladas. Esto da lugar a la implementación de la transformada wavelet como cascada de bancos de 
filtros iterados, en los que en cada etapa, vamos obteniendo visiones más globales de la señal a partir de la escala inmediatamente inferior.

Por último, resaltar dos aspectos más respecto de los átomos tiempo-frecuencia o tiempo-escala:

- Por un lado, el grado de solapamiento entre soporte temporal o frecuencial es el que da a las bases su carácter como bases ortogonales (hay solapamiento como en todos los casos, pero los coeficientes de la expansión obtenidos para los átomos que se solapan se anulan en las zonas de solapamiento) o frames (el grado de solapamiento indica cuanto son de linealmente dependientes). En un punto intermedio se encuentran las bases biortogonales, en las que con ayuda de una base dual conseguimos tener control sobre ese solapamiento pudiendo eliminar la redundancia.

- Si nos preguntamos sobre el carácter completo de una expansión lineal, podemos afirmar que esto será así cuando los distintos átomos de esa expansión cubran por completo el plano tiempo-frecuencia, pues de esta manera cualquier intervalo temporal o rango de frecuencias será analizada a través de uno u otro átomo.

La simplicidad y elegancia de este esquema y sobre todo su capacidad de adaptar su resolución en el tiempo y en frecuencia, en función de las características locales de las señales, provoco una densa actividad en busca de funciones $\psi(t)$ que cumplieran la condición (2.15) y que además permitieran representar de forma estable distintas funciones como combinación lineal de familias $\left\{\psi_{u, s}\right\}_{(u, s) \in \mathbb{R}^{2}}$. Esto condujo al descubrimiento de wavelets que forman bases ortonormales para distintos espacios funcionales como fueron las wavelets de Meyer, de Battle-Lemairé, y principalmente las wavelets de Daubechies quién construyo las primeras bases wavelets ortonormales de soporte compacto con las adecuadas características para la representación de señales (Daubechies, 1992).

Una formalización de estas construcciones fue proporcionada por Mallat y Meyer haciendo uso del llamado análisis multirresolución, lo cual proporciono un inesperado enlace de estas técnicas con otros campos, y en especial con bancos de filtros "multirate", que ya eran usados desde hacía tiempo en el procesamiento de señales. Por ejemplo, los filtros QMF (Quadrature Mirror Filter) se aplicaban habitualmente en la comprensión de voz en telefonía digital.

Paralelamente, en el campo del procesamiento de imágenes el concepto de análisis multirresolución estaba directamente relacionado con la llamada codificación piramidal propuesta por Burt y Adelson en la que sucesivas aproximaciones de las imágenes son codificadas partiendo de la versión menos detallada para conseguir, en cada paso imágenes de resoluciones cada vez mas finas.

Esta analogía entre los filtros de reconstrucción perfecta, de los que los filtros QMF son un caso particular y la implementación de la llamada Transformada Wavelet Discreta (DWT) puesta de manifiesto por el análisis multirresolución juega un papel fundamental para facilitar el análisis, diseño e implementación de transformadas wavelets aplicadas al procesamiento de la señal.

Por ello en los siguientes capítulos se describe en detalle esta relación entre teoría wavelet y análisis multirresolución. Primero se analiza esta relación desde el punto 
de vista de la teoría de bancos de filtros para luego analizar la definición axiomática de análisis multirresolución inicialmente expuesta por Mallat en (Mallat, 1989). 



\section{Capítulo 3}

\section{Wavelets, Bancos de filtros y Análisis Multiresolución}

\subsection{Wavelets y bancos de filtros}

En la búsqueda de expansiones lineales descrita en el capítulo anterior, el objetivo será llegar a funciones de base $\}^{1}\left\{\varphi_{k}[n]\right\}$ que sean completas en el espacio de secuencias $\ell_{2}(\mathbb{Z})$.

Estas expansiones están relacionadas con su posible implementación mediante bancos de filtros, lo cual demostraremos en base a dos ejemplos sencillos. En concreto veremos la Expansión de Haar y la Expansión "sinc" o wavelet de Shannon, que son casos extremos de expansiones de señales mediante banco de filtros. Para profundizar en la relación entre wavelets y bancos de filtros se recomiendan (Rioul y Vetterli, 1991), (Vetterli y Kovacevic, 1995) y (Strang y Nguyen, 1996).

Aún sin presentar propiedades que serán básicas en el procesamiento de la señal, éstos dos ejemplos permiten presentar los conceptos claves de la relación entre bancos de filtros y teoría wavelet en el caso de la expansión de Haar e introducir el análisis multirresolución para la expansión "sinc". Es por ello que se ha considerado relevante incluir el detalle de ambas expansiones en este capítulo.

\subsubsection{Expansión de Haar}

Ya vimos en (2.7) las funciones de base para esta expansión, ecuación que repetimos a continuación utilizando otra notación que nos facilitará el consiguiente desarrollo:

$$
\begin{gathered}
\varphi_{2 k}[n]= \begin{cases}\frac{1}{\sqrt{2}} & n=2 k, 2 k+1 \\
0 & \text { en el resto }\end{cases} \\
\varphi_{2 k+1}[n]= \begin{cases}\frac{1}{\sqrt{2}} & n=2 k \\
-\frac{1}{\sqrt{2}} & n=2 k+1 \\
0 & \text { en el resto }\end{cases}
\end{gathered}
$$

\footnotetext{
${ }^{1}$ Denotaremos con $\ell_{2}(\mathbb{R})$ al espacio vectorial de secuencias discretas acotadas en energía. Es decir que cumplen que $\sum_{n}|x[n]|<\infty$
} 
La transformada de $\mathrm{Haar}[2$ se define como:

$$
\begin{aligned}
X[2 k] & =\frac{1}{\sqrt{2}}(x[2 k]+x[2 k+1]) \\
X[2 k+1] & =\frac{1}{\sqrt{2}}(x[2 k]-x[2 k+1])
\end{aligned}
$$

Vemos, por tanto, que esta transformada proporciona dos salidas distintas para la entrada dada. Por un lado los coeficientes pares nos dan el promedio de la muestra actual de la señal de entrada con la siguiente muestra, mientras que la salida de los coeficientes transformados impares, nos da la diferencia entre esas mismas muestras.

Lo que interesa en este punto es la posible implementación de esta transformada mediante bancos de filtros. Para ello, consideramos los siguientes filtros discretos formados a partir de los coeficientes de las funciones de base:

$$
\begin{aligned}
& h_{0}[n]=\varphi_{0}[-n]= \begin{cases}\frac{1}{\sqrt{2}} & n=-1,0 \\
0 & \text { en el resto }\end{cases} \\
& h_{1}[n]=\varphi_{1}[-n]= \begin{cases}\frac{1}{\sqrt{2}} & n=0 \\
-\frac{1}{\sqrt{2}} & n=-1 \\
0 & \text { en el resto }\end{cases}
\end{aligned}
$$

Y en función de estos filtros la relación con la expansión de Haar vendrá dada por:

$$
\begin{gathered}
\left.h_{0}[n] \star x[n]\right|_{n=2 k}=\sum_{l \in \mathbb{Z}} h_{0}[2 k-l] x[l]=\frac{1}{\sqrt{2}}(x[2 k]+x[2 k+1])=X[2 k] \\
\left.h_{1}[n] \star x[n]\right|_{n=2 k}=X[2 k+1]
\end{gathered}
$$

Mediante la notación " ${ }_{n=2 k}$ " indicamos que estamos evaluando la convolución en los índices pares. Por lo tanto, los coeficientes transformados $X[2 k]$ y $X[2 k+1]$ pueden obtenerse de un banco de filtros de dos canales con filtros dados por 3.5 seguido de un diezmado por un factor 2 (lo cual es equivalente a evaluar la convolución en índices pares), según el esquema de la figura (3.1), que en lo que sigue denominaremos etapa o banco de análisis.

\footnotetext{
${ }^{2}$ Utilizamos mayúsculas para referirnos a los coeficientes transformados
} 


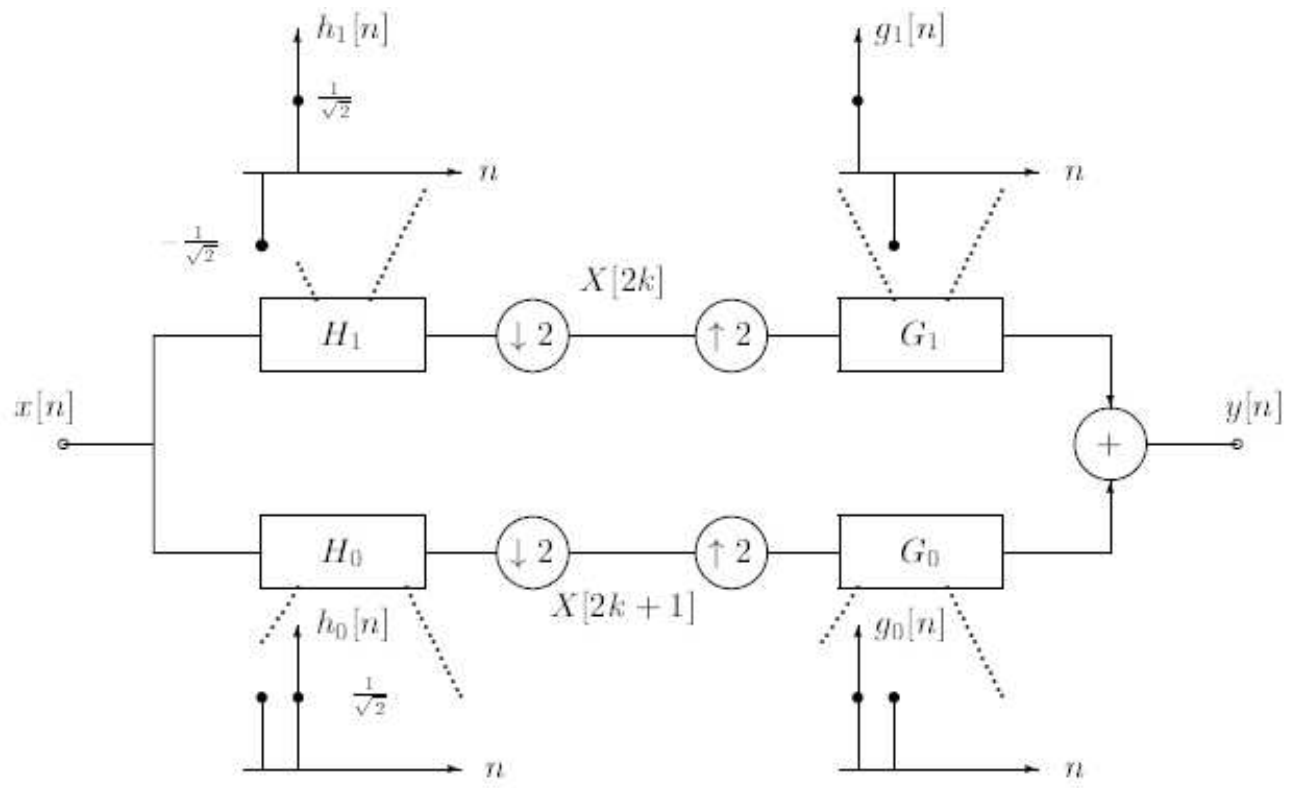

Figura 3.1: Banco de filtros de dos canales implementando la base de Haar 
En cuanto a la reconstrucción de la señal de entrada a partir de estos coeficientes partimos de la definición de expansión lineal dada por:

$$
x[n]=\sum_{k \in \mathbb{Z}} X[k] \varphi_{k}[n]
$$

Considerando coeficientes pares e impares por separado:

$$
x[k]=\sum_{k \in \mathbb{Z}} X[2 k] \underbrace{\varphi_{2 k}[n]}_{g_{0}[n-2 k]}+X[2 k+1] \underbrace{\varphi_{2 k+1}[n]}_{g_{1}[n-2 k]}
$$

Reconstruimos la señal, en la etapa de síntesis, mediante los filtros dados por:

$$
\begin{aligned}
& g_{0}[n]=\varphi_{0}[n] \quad \Rightarrow \quad g_{0}[n-2 k]=\varphi_{2 k}[n] \\
& g_{1}[n]=\varphi_{1}[n] \quad \Rightarrow \quad g_{1}[n-2 k]=\varphi_{2 k+1}[n]
\end{aligned}
$$

También en este caso podemos interpretar 3.10 como convoluciones. En este caso se trata de una convolución con los filtros $g_{0}[n]$ y $g_{1}[n]$ mientras que el factor 2 que comprime los "desplazamientos" $\left(g_{0}[n-\mathbf{2} k]\right)$ se corresponde con un expansor por un factor 2. Se llega de esta forma a la representación de la parte de síntesis del banco de dos canales, parte derecha de la figura (3.1).

Desde un punto de vista algebraico tendremos que:

$$
x_{0}[k]=\sum_{k \in \mathbb{Z}} y_{0}[k] \varphi_{2 k}[n] \quad \text { con: } \quad y_{0}[k]=X[2 k]=\left\langle\varphi_{2 k}, x\right\rangle
$$

donde con $\langle a, b\rangle$ denotamos al producto escalar entre los vectores $a$ y $b$ y que se corresponderá con la proyección ortogonal de $x[n]$ sobre el subespacio generado por $\varphi_{2 k}[n]$, y que en este caso corresponde como hemos dicho a una versión promediada de la entrada.

Por otro lado:

$$
x_{1}[k]=\sum_{k \in \mathbb{Z}} y_{1}[k] \varphi_{2 k+1}[n] \quad \text { con: } \quad y_{1}[k]=X[2 k+1]=\left\langle\varphi_{2 k+1}, x\right\rangle
$$

contendrá los detalles (componentes de alta frecuencia) necesarios para reconstruir $x[n]$ partiendo de la versión promediada.

Finalmente, conseguimos reconstrucción perfecta si hacemos:

$$
\begin{gathered}
x_{0}[2 k]+x_{1}[2 k]=\frac{1}{2}(x[2 k]+x[2 k+1])+\frac{1}{2}(x[2 k]-x[2 k+1])=x[2 k] \\
x_{0}[2 k+1]+x_{1}[2 k+1]=x[2 k+1]
\end{gathered}
$$

Es decir al final del banco de análisis-síntesis vamos obteniendo de manera entrelazada los coeficientes pares e impares de la señal de entrada.

Queda de este modo establecida la analogía entre bancos de filtros de reconstrucción perfecta y expansiones lineales que será una constante en cualquier expansión wavelet ortonormal. El problema de este ejemplo sencillo es fácilmente deducible si pensamos en la respuesta en frecuencia asociada con los filtros involucrados. Aún 
cuando la etapa de síntesis elimina el aliasing introducido por la etapa de análisis, los coeficientes transformados no logran separar efectivamente las bajas de las altas frecuencias debido a la escasa selectividad de los filtros usados. Esto conlleva a una mala resolución en frecuencia, al "colarse" componentes de relativa alta frecuencia en la versión paso bajo y viceversa.

En terminología de teoría wavelet tenemos un problema de regularidad de las bases utilizadas consecuencia de los pocos momentos nulos de las funciones de base utilizadas. No obstante la implementación de la expansión de cualquier base wavelet como banco de filtros seguirá las mismas pautas que las presentadas para la base de Haar y de ahí su indudable interés.

\subsubsection{Expansión 'sinc'(Wavelets de Shannon)}

En este caso se evita el problema anterior utilizando filtros paso bajo y paso alto ideales en lo que a su selectividad en frecuencia se refiere. El problema será que esos filtros representan una situación ideal, y la única forma de aproximarse a ello es con filtros de muy larga duración o soporte temporal, lo que imposibilita cualquier aplicación práctica. No obstante la descripción de este caso nos lleva de manera intuitiva al enlace entre expansiones wavelet y análisis multirresolución, aspecto principal del siguiente apartado de este trabajo.

En la expansión "sinc" los filtros de síntesis quedan definidos como:

$$
G_{0}\left(e^{j \omega}\right)=\left\{\begin{array}{ll}
\sqrt{2} & \omega \in[-\pi / 2, \pi / 2] \\
0 & \text { en el resto }
\end{array} \quad g_{0}[n]=\frac{1}{\sqrt{2}} \frac{\sin n \pi / 2}{n \pi / 2}\right.
$$

Y el correspondiente filtro paso alto se obtiene modulando $g_{0}[n]$ según:

$$
g_{1}[n]=(-1)^{n} g_{0}[1-n] \quad \longleftrightarrow \quad G_{1}\left(e^{j \omega}\right)=e^{j(\omega-\pi)} G_{0}\left(e^{j(\omega-\pi)}\right),
$$

que se corresponde con un filtro desplazado en frecuencia, lo que conduce a un filtro paso alto ideal.

Las funciones de base se obtienen según:

$$
\begin{aligned}
\varphi_{2 k}[n] & =g_{0}[n-2 k] \\
\varphi_{2 k+1}[n] & =g_{1}[n-2 k]
\end{aligned}
$$

Y los coeficientes de la expansión respecto de esta base, o lo que es lo mismo, los coeficientes transformados que resultan de la etapa de análisis se obtendrán mediante filtrado con $h_{0}[n]=g_{0}[-n]$ y $h_{1}[n]=g_{1}[-n]$ y posterior diezmado. Es proceso es por tanto completamente análogo al anterior ejemplo de la expansión de Haar.

Este ejemplo es el ideal para explicar la propiedad de descomposición en octavas de la transformada wavelet. Si sobre la salida del filtro paso bajo vamos aplicando sucesivas veces la descomposición en banda paso bajo y banda paso alto, vamos obteniendo en la salida paso bajo, bandas de anchura frecuencial mitad de la anchura anterior, como podemos ver en la figura (3.2). Notar que no cambiamos el filtro a usar en cada etapa sino que el resultado real del filtrado será ese como consecuencia del diezmado por un factor 2 que se realiza en cada etapa y que hace que el contenido frecuencial de cada subbanda con el que nos quedamos sea la zona del espectro que 
Efecto del diezmado
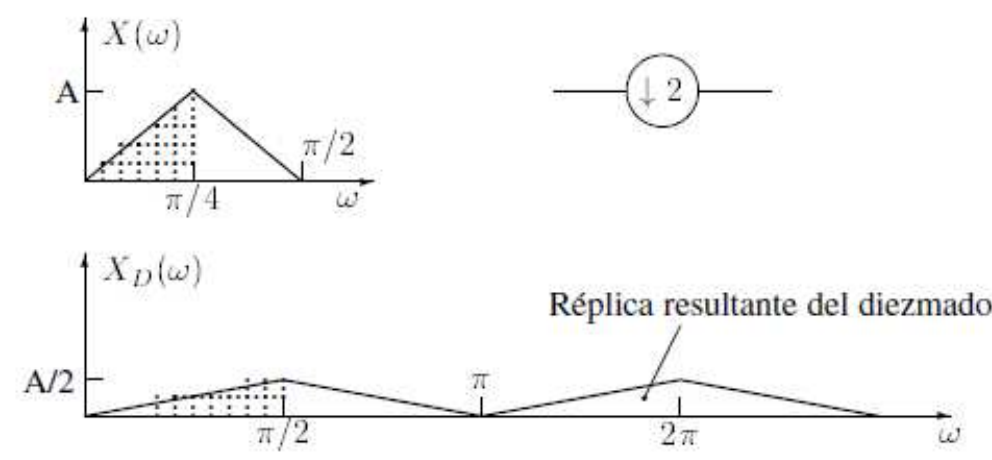

Iteración sobre la banda paso bajo

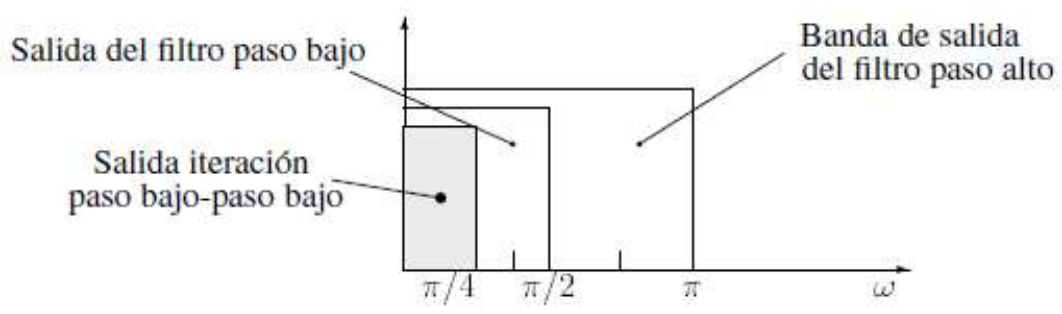

Figura 3.2: Filtrado a Q-cte

aparece sombreada en la figura y que como vemos, se corresponde con la banda $[0, \pi / 4]$ de la señal de entrada.

Si consideramos las diferentes bandas que vamos formando a la salida de las diferentes etapas, con objeto de medir el parámeto $Q=$ Frec. central/BW tendremos:

$$
Q_{1}=\frac{3 \pi / 4}{\pi-\pi / 2}=\frac{6}{4}=\frac{3}{2} \quad Q_{2}=\frac{3 \pi / 8}{\pi / 2-\pi / 4}=\frac{12}{8}=\frac{3}{2}
$$

Es decir, el análisis realizado cumple con la propiedad descrita de análisis a Qconstante salvo para la $Q$ asociada a la banda sombreada. Esto se debe a que la propiedad $Q=$ Cte se refiere a las bandas de detalle que vamos obteniendo en cada etapa de la iteración (en este caso las bandas $Q_{1}$ y $Q_{2}$ ), pero no a la última banda paso-bajo en la que dejamos de iterar el banco de dos canales.

Como veremos esta banda no esta asociada a ninguna wavelet sino a una función íntimamente relacionada con las wavelets a través del marco dado por el análisis multirresolución y que recibe el nombre de Función escalado.

\subsection{Análisis Multirresolución}

El objetivo del análisis multirresolución consiste en adaptar la resolución de una señal a las necesidades de una aplicación concreta. Como ya se mencionó, Burt y Adelson en (Burt y Adelson, 1983) introdujeron en el campo de la visión artificial el 
concepto de pirámide multirresolución una de cuyas aplicaciones consiste en procesar una imagen de baja resolución en primera instancia para posteriormente incrementar dicha resolución progresivamente.

Mallat (Mallat, 1989) llevó este concepto más allá imponiendo que las distintas imágenes correspondientes a cada espacio multirresolución puedan ser descompuestas en función de bases incorreladas entre sí para cada resolución. Esto llevo a una nueva forma de concebir, construir e implementar bases wavelets.

Desde el punto de vista matemático, la aproximación de una función a una resolución $j$ queda definida como la proyección ortonormal de esa función sobre un espacio $V_{j} \subset \mathbf{L}^{2}(\mathbb{R})$. Este espacio $V_{j}$ agrupa todas las posibles aproximaciones de una función que se realicen a esa resolución $j$.

En lo que sigue se denotarán a los niveles de resolución mediante $2^{-j}$, o lo que es lo mismo, el parámetro de escala de una expansión wavelet. Así el nivel de resolución de la señal original será $j=0$. Con $j \rightarrow+\infty$, es decir aumentando, perdemos resolución y en el extremo no aproximamos nada. De manera equivalente, con $j \rightarrow$ $-\infty$ podríamos aproximar cualquier función de $\mathbf{L}^{2}(\mathbb{R})$.

Siguiendo la definición axiomática de Análisis Multiresolución (Mallat, 1989) se llega a la existencia de una función $\phi$ tal que $\{\phi(t-n)\}_{n \in \mathbb{Z}}$ es una base para $V_{0}$, es decir, para la resolución original de la señal, por lo que podemos expresar cualquier función $f(t)$ del espacio vectorial $V_{0}$ como:

$$
f(t)=\sum_{n=-\infty}^{+\infty} a(n) \phi(t-n)
$$

En general para sucesivas resoluciones $j$, también por la propia definición de análisis multirresolución, podemos expresar la aproximación a escala $j$ en función de las siguientes funciones de base.

$$
\left\{2^{-j / 2} \phi\left(2^{-j} t-n\right), n \in \mathbb{Z}\right\} \text { es una base de } V_{j}
$$

A la función $\phi(t)$ que aparece en (3.17) se la denomina Función de Escala y ha de cumplir la siguiente expresión llamada relación a escala dos, ecuación de dilatación o ecuación de refinamiento:

$$
\phi(t)=\sqrt{2} \sum_{n=-\infty}^{+\infty} h_{0}[n] \phi(2 t-n)
$$

En el caso más habitual se impone una normalización del tipo $\left\|h_{0}[n]\right\|=1$ que será clave en el diseño de las bases wavelets y que equivale lógicamente a $\Phi(\omega=0)=1$ o

$$
H_{0}(\omega=0)=\sqrt{2}
$$

Del requisito de que la familia $\{\phi(t-n)\}_{n \in \mathbb{Z}}$ sea una base ortonormal de $V_{0}$ resulta que:

$$
\langle\phi(t), \phi(t+n)\rangle=\delta[n]
$$

Que se refleja en el dominio de la frecuencia en la siguiente condición (Mallat, 1998):

$$
\left|H_{0}(\omega)\right|^{2}+\left|H_{0}(\omega+\pi)\right|^{2}=2
$$


Ambas ecuaciones $(3.19)$ y 3.20$)$ constituyen las dos primeras condiciones necesarias para la obtención de bases wavelets como se detalla a lo largo de este capítulo.

El siguiente paso en este contexto de análisis multirresolución servirá para definir las bases wavelets ortonormales como funciones que generan las bases necesarias para incrementar la resolución de una aproximación multirresolución. Es decir, la expansión wavelet proporciona los "detalles" de f que aparecen en la escala genérica $2^{j-1}$ pero que se pierden al pasar a la aproximación inmediatamente inferior (de menor resolución), realizada a la escala $2^{j}$. Es decir:

$$
V_{j-1}=V_{j} \oplus W_{j}
$$

Se puede demostrar que la familia $\left\{\psi_{j, k}\right\}_{k \in \mathbb{Z}}$ es una base ortonormal de $W_{j}$ para la escala $2^{j}$ siendo:

$$
\hat{\psi}(\omega)=\frac{1}{\sqrt{2}} G\left(\frac{\omega}{2}\right) \hat{\phi}\left(\frac{\omega}{2}\right)
$$

Con $G_{0}(\omega)=e^{-j \omega} H_{0}^{*}(\omega+\pi)$ que en el dominio del tiempo se traduce en:

$$
g_{0}[n]=(-1)^{n} h_{0}^{*}[N-n]
$$

Esta ecuación (3.23) se añade por tanto a las ecuaciones 3.19 y 3.20 como condición de diseño de bases wavelets.

Dado que en cualquier análisis multirresolución se cumple que en el limite de detalle se puede aproximar cualquier secuencia de energía finita:

$$
\lim _{j \rightarrow-\infty} V_{j}=\text { Cierre }\left(\bigcap_{j=-\infty}^{+\infty} V_{j}\right)=\mathbf{L}^{2}(\mathbb{R})
$$

Se concluye que la siguientes expansión wavelet define una base para cualquier función $f \in \mathbf{L}^{2}(\mathbb{R})$ :

$$
f=\sum_{j=-\infty}^{+\infty} \sum_{k=-\infty}^{+\infty}\left\langle g, \psi_{j, k}\right\rangle \psi_{j, k}
$$

Del análisis detallado de la ecuación 3.25 se llega a la descripción del algoritmo de obtención de coeficientes wavelet en la conocida como transformada discreta wavelet (DWT) mediante bancos de filtros, filtros que a modo de resumen de lo expuesto en esta sección han de cumplir:

$$
\begin{gathered}
H_{0}(\omega=0)=\sqrt{2} \\
\left|H_{0}(\omega)\right|^{2}+\left|H_{0}(\omega+\pi)\right|^{2}=2 \\
G_{0}(\omega)=e^{-j \omega} H_{0}^{*}(\omega+\pi)
\end{gathered}
$$

Una vez cumplidas las condiciones dadas en (3.26) el algoritmo de obtención de coeficientes wavelets en base a operaciones básicas de teoría de bancos de filtros multirate se describe a continuación. 


\subsection{Algoritmo de obtención de los coeficientes wavelets}

En función de lo visto partimos de una función $f(t)$ que consideramos que se puede aproximar a escala $j=0$ según:

$$
f(t)=\sum_{n=-\infty}^{+\infty} a_{0}[n] \phi(t-n) \in V_{0}
$$

que al ser $\left.\{\phi(t-n)\}_{n \in \mathbb{Z}}\right\}$ una base ortonormal implica:

$$
a_{0}[n]=\langle f(t), \phi(t-n)\rangle=f * \phi(n)
$$

Mientras que los coeficientes wavelets vendrán dados por:

$$
d_{j}[n]=\langle f, \phi j, n\rangle
$$

para resoluciones $j>0$.

La transformada wavelet discreta (DWT) descompone sucesivamente cada aproximación $P_{V_{j}} f$ en una aproximación a menor resolución $P_{V_{j+1}} f$ más la información de detalle que se pierde al pasar de una resolución a otra y que se corresponde con los coeficientes wavelets $P_{W_{j+1}} f$. Mallat demostró en (Mallat, 1989) que esta descomposición puede implementarse mediante una serie de convoluciones discretas dadas por:

$$
\begin{aligned}
& a_{j+1}(p)=\sum_{n=-\infty}^{\infty} h[n-2 p] a_{j}(n) \\
& d_{j+1}\left(p 9=\sum_{n=-\infty}^{\infty} g[n-2 p] a_{j}(n)\right.
\end{aligned}
$$

La representación gráfica del proceso de descomposión wavelet se muestra en la figura (3.3) donde se implementan las ecuación (3.29) y (3.30) donde la multiplicación por 2 en el parámetro temporal se refleja en un bloque de diezmado típico del procesamiento multirate y que es en todo idéntico al esquema de bancos de filtros básicos de la expansión de Haar.

En cuanto al proceso de reconstrucción dado que $V_{j}=V_{j+1} \oplus W_{j+1}$ se puede descomponer $\phi_{j, p} \in V_{j}$ en función de la unión de bases de $V_{j+1}$ y $W_{j+1}$ según la ecuación:

$$
\phi_{j, p}=\sum_{n=-\infty}^{\infty}\left\langle\phi_{j, p}, \phi_{j+1, n}\right\rangle \phi_{j+1, n}+\sum_{n=-\infty}^{\infty}\left\langle\phi_{j, p}, \psi_{j+1, n}\right\rangle \psi_{j+1, n}
$$

Y sustituyendo $\phi_{j+1, p}$ y $\psi_{j+1, p}$ por las expresiones obtenidas previamente:

$$
a_{j}(n)=\sum_{n=-\infty}^{\infty} h[p-2 n] a_{j+1}(n)+\sum_{n=-\infty}^{\infty} g[p-2 n] d_{j+1}(n)
$$

que en el dominio del tiempo se traduce en un expansor de un factor 2 que se representa en la parte derecha de la figura 3.3 . 


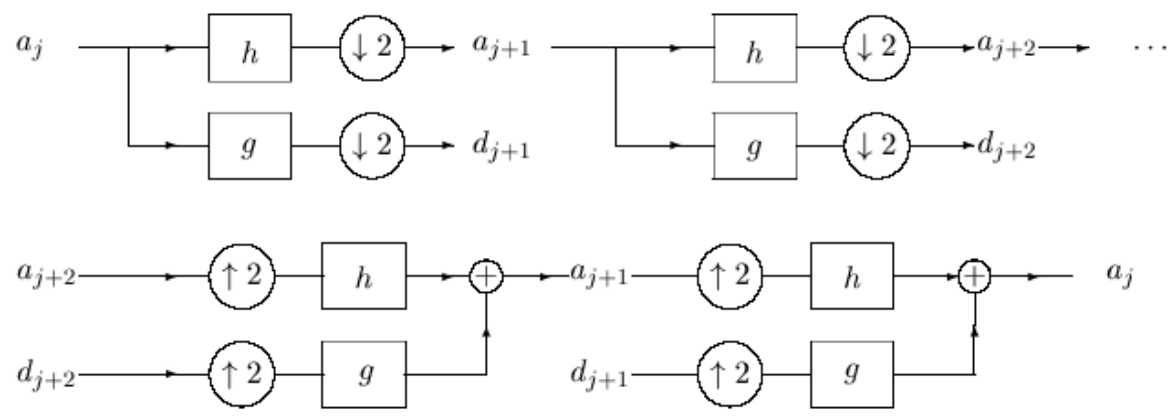

Figura 3.3: Implementación de la transformada wavelet discreta (DWT) mediante bancos de filtros

Para extender este procesamiento a múltiples dimensiones, el procedimiento más sencillo consiste en aplicar filtrado separable consistentes en aplicar el filtrado y diezmado / interpolación visto a cada una de las dimensiones de la señal. En el caso de las imágenes será por tanto aplicado el esquema de la figura (3.4) donde se analizan primero cada una de las filas de la imagen y luego cada unas de las columnas.

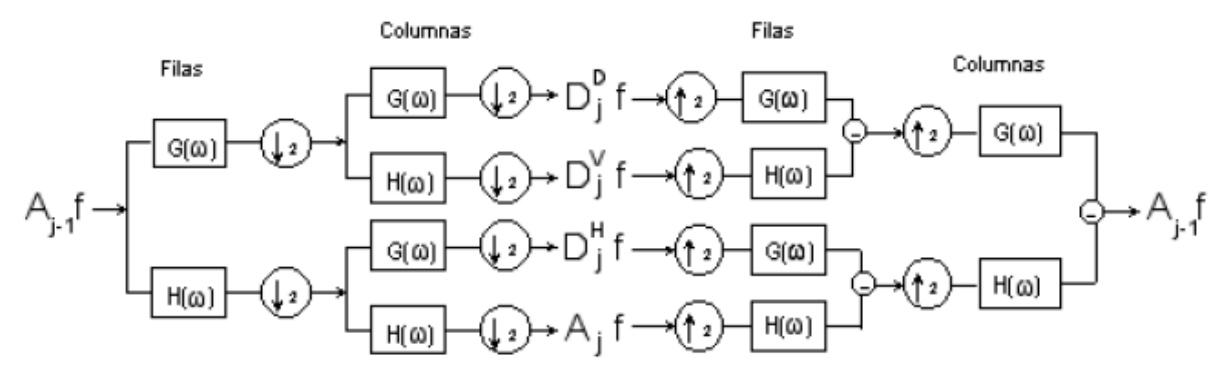

Figura 3.4: Implementación de la transformada wavelet discreta (DWT) en imágenes - 2 Dimensiones

Este proceso da lugar a una descomposición frecuencial del plano bidimensional que se muestra en la figura (3.5), donde queda justificada la denominación que se da a cada uno de los coeficientes wavelets para el caso de imágenes pues, por ejemplo $D_{j}^{H} f$ se corresponde con un filtrado paso alto en el sentido de las filas y paso bajo en el de las columnas. Por tanto contendrá información de las altas frecuencias que ocurren en el sentido de las filas (orientación horizontal) dando lugar a detalles o contornos de la imagen en sentido vertical.

Finalmente destacar que la aplicación reiterativa del algoritmo de descomposición wavelet suele representarse tal y como se muestra en la parte derecha de la figura, en forma de "pirámide" multirresolución donde en los niveles más altos están las subimágenes pertenecientes a menores resoluciones y a medida que aumenta la resolución y en consiguiente el tamaño de las sub-imágenes vamos descendiendo de la "pirámide". 

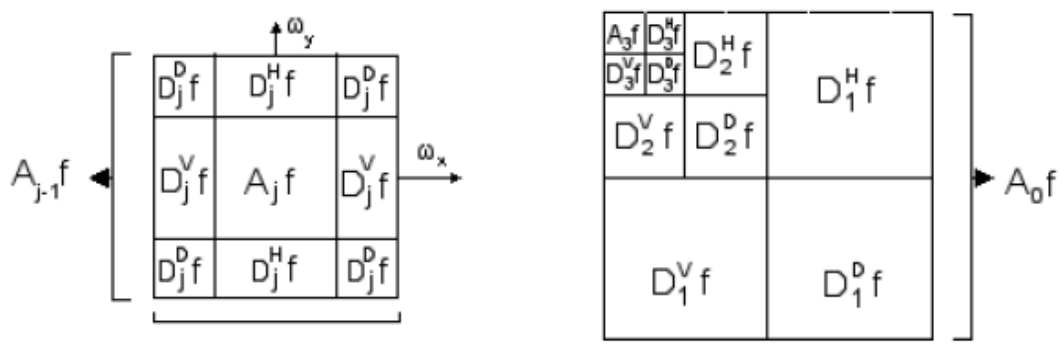

Figura 3.5: Descomposición wavelet y partición de frecuencias en procesamiento de imágenes

\subsection{Momentos nulos o precisión}

Para completar las ecuaciones básicas para el diseño de bases wavelets resumidas en (3.26) se añade en este apartado otra condición que sin ser necesaria es clave a la hora de elegir que base wavelet utilizar en cada aplicación. Este es el concepto de momentos nulos de la función de escala o momentos de desvanecimiento de la función wavelet.

Así, según el marco dado por el análisis multirresolución al iterar sobre la banda paso bajo se realiza una proyección ortogonal sobre el espacio $V_{j}$, de forma que para escala $j$ realizamos una aproximación $f_{j}(t)$ dada por:

$$
f_{j}(t)=\sum_{k=-\infty}^{+\infty} c_{j, k} 2^{j / 2} \phi\left(2^{t}-k\right)
$$

La precisión de esta aproximación $p$ depende principalmente de la función a aproximar y del filtro usado y en concreto de las dos siguientes reglas equivalentes.

- Existencia de $p$ ceros en $\pi$ para el filtro paso-bajo $H(\omega)$

$$
H(\omega)=\left(\frac{1+e^{-j \omega}}{2}\right) Q(\omega)
$$

- Que se traduce en $p$ reglas en el dominio del tiempo

$$
\sum_{n=0}^{N}(-1)^{n} n^{j} h[n]=0 \quad \text { para } \quad j=0,1, \ldots, p-1
$$

Para que existan esos $p$ ceros es necesario una longitud del filtro de al menos $L=2 p-1$. A efectos de análisis de singularidades interesa que $p$ sea lo mayor posible pero al implicar una mayor longitud implica una menor precisión en la localización en el tiempo. Queda de esta manera establecido el compromiso implicado en la elección de la wavelet concreta a utilizar en las distintas aplicaciones.

Este número de ceros recibe también el nombre de momentos de desvanecimiento de la descomposición wavelet y será la terminología más habitual usada en esta memoria. 
Destacar también que directamente relacionado con el número de momentos nulos se encuentra el concepto de regularidad. Por regularidad, nos referimos a la capacidad de la función de escala para representar adecuadamente la aproximación paso bajo de la señal. En principio está directamente relacionada con el número de momentos nulos $p$ pero a igualdad de $p$ distintas técnicas de diseño de la base wavelet generará bases más o menos regulares.

Así por ejemplo las wavelets de Daubechies resultan de realizar una descomposición espectral sobre la ganancia de los filtros dando lugar en su momento a lo que fue la primera técnica de construcción de bases wavelets de duración finita. Con el tiempo, han surgido otras técnicas que generan bases más regulares para un mismo valor de $p$ entre los que destaca el denominado esquema "Lifting" ((Sweldens, 1997) donde se construyen bases wavelets aplicando de manera sencilla distintas reglas directamente relacionadas principalmente con la teoría de bancos de filtros discretos. 


\subsection{Aplicaciones de la manipulación directa de los coe- ficientes de la DWT}

Aun sin ser contribuciones claves para este trabajo de tesis, se ha creído conveniente en este punto documentar dos aplicaciones concretas que facilitan entender que información capturan los coeficientes wavelets en su más básico esquema de aplicación como es la DWT. El primero de ellos describe una aplicación de inserción de marcas de agua en imágenes digitales que fue publicado en (( Piñuela et al., 2007a $)$ ) en el arranque de esta investigación mientras que el segundo se implementó en una aplicación comercial de definición y seguimiento de objetos en secuencias de vídeo.

Ambas aplicaciones fueron clave para definir el análisis y la eventual modificación de los coeficientes wavelet como aspecto esencial en la investigación a realizar y por tanto se ha creído conveniente documentarlo en cierto detalle antes de comenzar con el segundo bloque de la tesis se requiere tener claro como se relaciona el valor numérico de cada coeficiente wavelet con las características contenidas en cada señal o imagen analizada.

\subsubsection{Una técnica wavelet para watermarking de imágenes}

Una primera aproximación práctica a lo que significan los coeficientes wavelets y como se relacionan con la idea intuitiva que tenemos de una imagen se puede obtener a partir de su modificación directa en esquemas de inserción de marcas de agua digitales (watermarking). Es por tanto, el objetivo de esta primera aplicación, la simulación de un esquema de protección de derechos de la propiedad intelectual (IPR) basado en wavelets que permita además caracterizar qué información contienen los coeficientes wavelets y como su modificación directa afecta a la imagen original.

Las marcas de agua digitales son una de las soluciones posibles al problema de la protección de los derechos de la propiedad intelectual. El más típico escenario de protección de estos derechos ocurre cuando el autor de un trabajo desea probar que él es el único propietario de ese trabajo. Para ello, el autor puede insertar una marca de agua en la imagen que le identifique de manera unívoca, marca que por ejemplo puede solicitar a una autoridad certificadora dedicada a tal fin.

En este caso, el objetivo del sistema propuesto es verificar si la marca concreta o certificado está presente o no en una imagen. Se trata por lo tanto de lo que se ha convenido en llamar, un esquema de watermarking ciego, ya que como veremos, no se requiere de la imagen original para obtener la información insertada.

En estos esquemas se comprueba directamente la presencia o no de una marca conocida, siendo incapaz la solución propuesta de extraer una marca por sí misma. Esta limitación no viene provocada por la técnica wavelet elegida para la inserción de la marca, sino por la propia técnica de verificación de existencia. Para el desarrollo de un esquema que permitiese extraer la información concreta insertada en una imagen cualquiera bastaría con desarrollar un esquema que comparase la imagen original con la marcada y extrajese la información codificada de la diferencia entre ambas 
imágenes.

Respecto de los esquemas de marcas de agua es importante considerar los tres principales requisitos que han de cumplir, en principio contrapuestos y que ha de maximizar cualquier esquema de marcado (Barni y Bartolini, 2004):

- Imperceptibilidad: La marca insertada ha de ser lo menos visible posible. Es por ello que las técnicas de watermarking están fundamentalmente apoyadas en las características del sistema visual humano y es, desde este punto de vista donde la transformada wavelet aparece como una alternativa válida dada su similitud con los modelos teóricos de percepción humana $3^{3}$

- Capacidad: Cantidad de información en número de bits que un esquema de marcado es capaz de insertar en el medio digital considerado. En el caso que nos ocupa, insertaremos un bit en cada pixel de las subimágenes de detalle de más alta resolución de una descomposición wavelet, lo que da una capacidad de tres cuartas partes de la resolución de la imagen, siempre considerando que la imagen es de un único canal (imagen en escala de gris).

- Robustez: Se refiere a la capacidad que la marca tiene de seguir siendo detectable aún cuando la imagen sea modificada. Ejemplos de modificaciones en imágenes, son transformaciones geométricas, compresión a un nuevo formato, etc.

En el esquema simulado las secuencias a insertar en la imagen son secuencias binarias pseudoaleatorias consistentes en series de \pm 1 que se añadirán a los coeficientes wavelets resultantes de una descomposición en cuatro niveles de resolución. En concreto se añadirán en los tres niveles de detalle correspondientes a las más altas frecuencias aprovechando así la menor sensibilidad del sistema visual humano a estos niveles de detalle. Esto es, en los niveles $I_{0}^{H L}, I_{0}^{L H}$ y $I_{0}^{H H}$ del esquema mostrado en la parte izquierda de la figura adjunta junto con la descomposición obtenida para la imagen Lena

Cada valor binario es multiplicado antes de ser sumado a los coeficientes wavelets por un parámetro de peso determinado por el valor del salto de cuantificación permitido para ese coeficiente según lo expuesto en (Lewis y Knowles, 1992), lo cual, como veremos depende principalmente del grado de actividad (textura) de la vecindad de ese pixel.

Matemáticamente sea $x_{i} \in\{+1,-1\}$ cada elemento de la secuencia pseudoaleatoria con $i=0,1, \ldots, 3 M N-1$ siendo $2 M \times 2 N$ la resolución de la imagen original. Modificamos cada banda de frecuencias superior según el orden que muestran las siguientes ecuaciones:

$$
\begin{array}{r}
\tilde{I}_{0}^{L H}(i, j)=I_{0}^{L H}(i, j)+\alpha w^{L H}(i, j) x_{i N+j} \\
\tilde{I}_{0}^{H L}(i, j)=I_{0}^{H L}(i, j)+\alpha w^{H L}(i, j) x_{M N+i N+j} \\
\tilde{I}_{0}^{H H}(i, j)=I_{0}^{H H}(i, j)+\alpha w^{H H}(i, j) x_{2 M N+i N+j}
\end{array}
$$

donde $\alpha$ es una parámetro genérico que controla la intensidad de la marca y $w(i, j)$ es la función de peso que que depende del nivel de la pirámide multirresolución y de

\footnotetext{
${ }^{3}$ No todos los esquemas de marcado se basan en modelos de percepción humana. Por ejemplo, uno de los esquemas más sencillos usados en la práctica, es la modificación del valor de un pixel mediante la alteración del bit menos significativo
} 


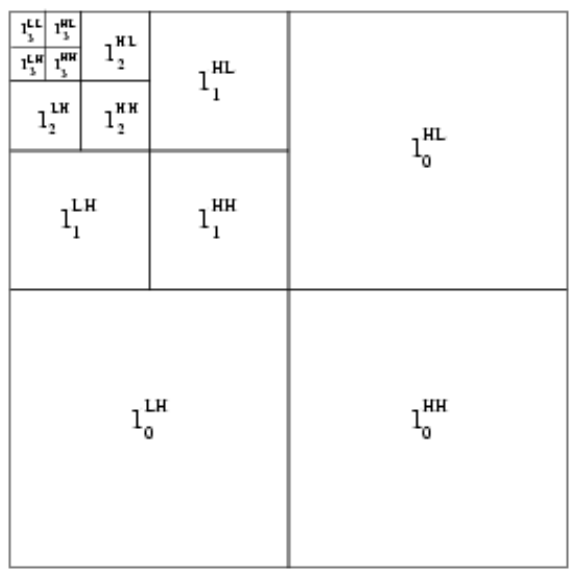

(a) DWT de 4 niveles.

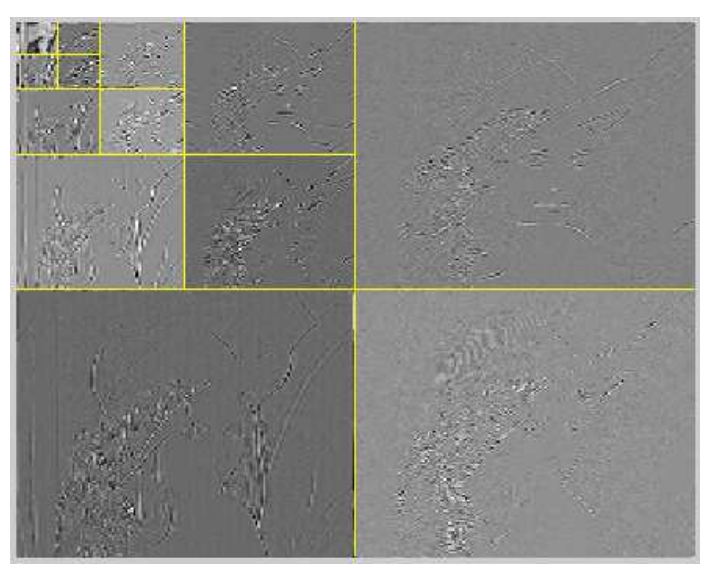

(b) Aplicado a la imagen Lena

Figura 3.6: DWT de partida para la inserción de marcas de agua

la orientación de la subimagen marcada. En concreto, para determinar la función de peso se utiliza como punto de partida el estudio de los factores que reflejados en los valores de los coeficientes wavelets afectan de manera directa a la visibilidad de la modificación realizada. Estos factores, de manera teórica son:

- Luminancia del fondo: Relacionado con la conocida Ley de Webber que establece que el ruido es menos apreciable cuando el fondo sobre el que se produce es de una luminancia elevada que cuando es más oscuro. Para determinar la luminancia del fondo podemos usar los coeficientes wavelets de los más bajos niveles de resolución: en concreto, los coeficientes de la subimagen $I_{0}^{L L}$.

- Proximidad a los bordes: Se refiere al enmascaramiento espacial que resulta de la sensibilidad decreciente a variaciones que tengan lugar en la imagen en las proximidades de los bordes abruptos. Dada la capacidad del análisis wavelet para realizar un análisis localizado de la señal, la proximidad que cada coeficiente a modificar tiene a un borde está directamente capturada por la posición del coeficiente, mientras que lo abrupto del borde (menos sensibilidad cuanto mayor sea la altura del borde que queda reflejada en el valor absoluto de los coeficientes de detalle en las proximidades del borde).

- Sensibilidad de cada banda: Es un valor fijo que depende del nivel de resolución y orientación que reflejen los coeficientes. En nuestro caso, donde sólo se modificarán los coeficientes wavelets de la banda de mayor resolución, únicamente se reflejará el hecho de que se tiene peor sensibilidad a los detalles diagonales que a los horizontales y verticales.

- Texturas: Se refiere al enmascaramiento que se produce en las zonas donde la actividad (como medida de la textura de una zona) que rodea a un coeficiente es elevada. Este es un factor fundamental en nuestra aplicación y para medirla se utiliza tanto el valor de los coeficientes de frecuencias intermedias como la varianza en los valores de los coeficientes de aproximación (la más baja resolución) que afectan a un coeficiente concreto. 
A partir de los factores vistos se llega a las siguientes fórmulas genéricas (Lewis y Knowles, 1992) que dan el máximo salto de cuantificación admisible en un esquema de compresión de imágenes realizado con una wavelet de Daubechies con orden 6 y que igualmente marcarán la máxima variación que podemos aplicar a un coeficiente para su marcado sin que visualmente se aprecie diferencia respecto de la imagen original:

$$
\begin{aligned}
& w^{\theta}(i, j)=q_{0}^{\theta}(i, j) \\
& q_{0}^{\theta}(i, j)=\Theta(l, \theta) \Lambda(l, i, j) \Xi(l, i, j) \\
& \Theta(l, \theta)=\left\{\begin{array}{ll}
\sqrt{2} & \text { si } \theta=H H \\
1 & \text { en el resto }
\end{array}\right\}\left\{\begin{array}{ll}
1,00 & \text { si } l=0 \\
0,32 & \text { si } l=1 \\
0,16 & \text { si } l=2 \\
0,10 & \text { si } l=3
\end{array}\right\} \\
& \Lambda(l, i, j)=\frac{1}{256} I_{3}^{L L}\left(1+\frac{i}{2^{3-l}}, 1+\frac{j}{2^{3-l}}\right) \\
& \Xi(l, i, j)=\sum_{k=1}^{3-l} \frac{1}{16^{k}} \sum_{\theta \in\{L H, H L, H H\}} \sum_{x=0}^{1} \sum_{x=0}^{1}\left[I_{k+l}^{\theta}\left(y+\frac{i}{2^{k}}, x+\frac{j}{2^{k}}\right)\right]^{2}+ \\
& \frac{1}{16^{3-l}} \operatorname{Var}\left\{I_{3}^{L L}\left(1+y+\frac{i}{2^{3-l}}, 1+x+\frac{j}{2^{3-l}}\right): \quad x=0,1 ; y=0,1\right\}
\end{aligned}
$$

Observar que en el esquema propuesto sólo usaremos el nivel $l=0$ aunque se proporcionen las fórmulas para todos los niveles. Cada uno de los factores utilizan las siguientes características del sistema visual humano:

- $\Theta(l, \theta)$ Aprovecha que el ojo es menos sensitivo a las bandas de alta resolución y a orientaciones diagonales que a las orientaciones verticales y horizontales.

- $\Lambda(l, i, j)$ Menos sensibilidad en aquellas áreas donde la imagen es más brillante.

- $\Xi(l, i, j)$ Menos sensibilidad a las áreas con mayor textura de la imagen (para medir la textura se utiliza la varianza (Var) de la vecindad como se aprecia en la fórmula de $\Xi(l, i, j)$.

Las siguientes imágenes muestran la imagen de pesos en la parte izquierda y la diferencia resultante entre la imagen original y la marcada para un factor general $\alpha=0,25$. No se muestra la imagen marcada porque visualmente es idéntica a la original. En concreto usando medidas de señal a ruido de pico típicas en compresión de imágenes resulta en un valor de $P S N R=47,42 d B$, cuando valores por encima de $36 d B$ suelen ser admitidos como imágenes indistinguibles para el ojo humano.

Para la posterior decisión sobre la presencia de esta clave pseudoaleatoria se realiza la siguiente medida de correlación (Barni et al., 1999).

$$
\rho=\sum_{i=0}^{M-1} \sum_{j=0}^{N-1} \tilde{I}_{0}^{L H}(i, j) x_{i N+j}+\tilde{I}_{0}^{H L}(i, j) x_{M N+i N+j}+\tilde{I}_{0}^{H H}(i, j) x_{2 M N+i N+j}
$$

La figura 3.8 muestra la medida de correlación para 100 claves aleatorias de la misma longitud que la generada siendo la situada en la posición número 10 la 


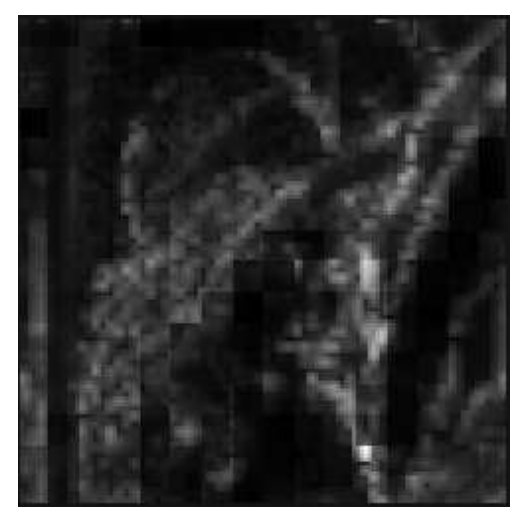

(a) Imagen de pesos.

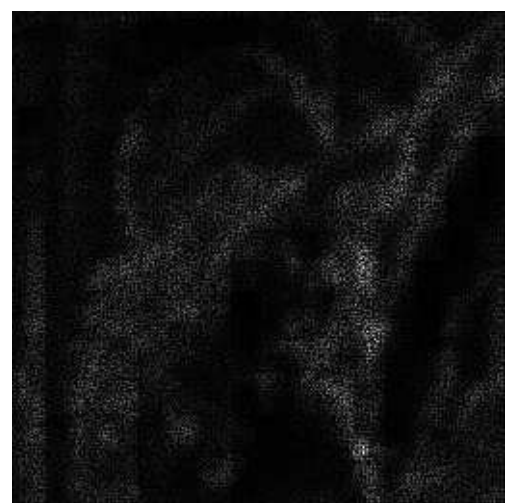

(b) Diferencia entre Lena y Lena marcada

Figura 3.7: Matriz de pesos y diferencia entre imagen original y marcada

respuesta a la clave aleatoria con la que se marco la imagen. Como puede apreciarse la diferencia es suficientemente significativa como para poder establecer un umbral que permita detectar o no la presencia de una marca concreta en una imagen.

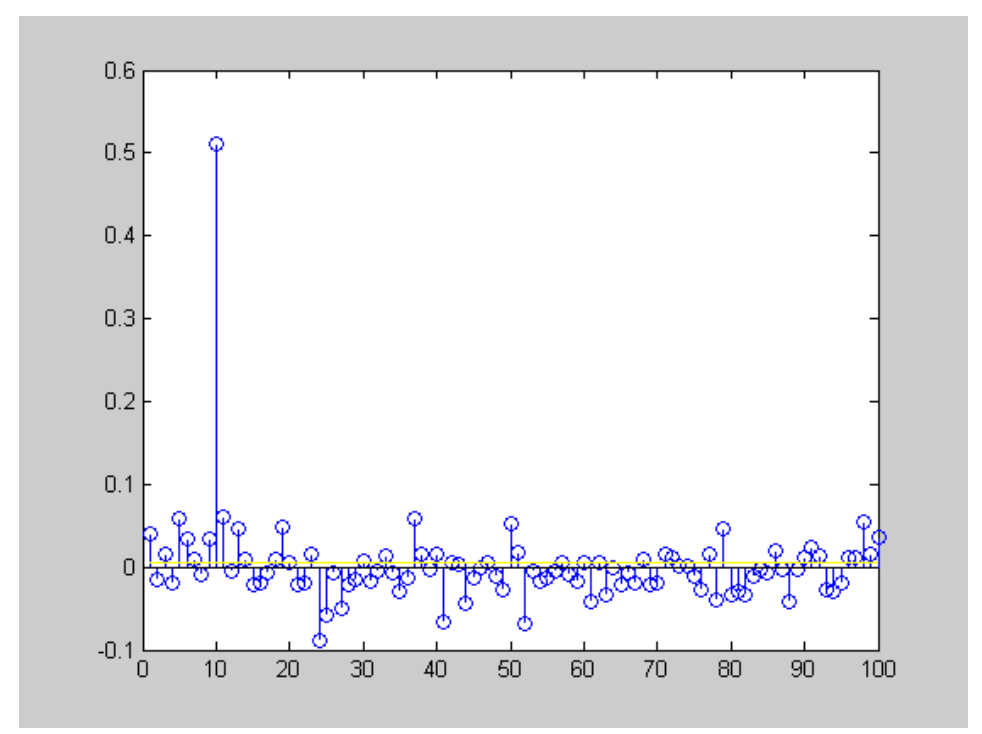

Figura 3.8: Medidas de correlación para distintas claves de marcado.

\subsubsection{Reducción de ruido en imágenes para segmentación de obje- tos en secuencias de vídeo}

La estimación de señales afectadas por ruidos aditivos se optimiza de una manera muy similar a la de encontrar una representación compacta de una señal. Por ejemplo si una señal esta afectada por ruido blanco gaussiano, la energía del ruido está distribuida uniformemente por todos los coeficientes. De esta manera si encontramos una representación de la señal que capture toda la energía en unos pocos coeficientes podemos eliminar gran parte del ruido simplemente poniendo a cero los coeficientes 
por debajo de un umbral.

En el caso de la umbralización wavelet el enfoque más sencillo posible consiste en imponer un umbral al valor absoluto de los coeficientes de la descomposición wavelet de manera que en caso de no superarlo se lleva el valor del coeficiente a cero. Esto puede interpretarse como una aproximación suave ya que llevar a cero los coeficientes wavelets de escalas menores que $j_{0}$ implica realizar una aproximación de esa señal a la resolución $2^{j_{0}}$.

Una elección de umbral típica (David L. Donoho, 1994) es $T=\sigma(2 \ln N)^{1 / 2}$ donde $\sigma^{2}$ es la varianza del ruido gaussiano aditivo estimado. Otra enfoque es el llamado de umbralización suave donde en este caso la función $\theta_{h}$ resulta ser:

$$
\theta_{h}(x)= \begin{cases}x-T & x \geq T \\ x+T & x \leq-T \\ 0 & |x| \leq T\end{cases}
$$

El enfoque desarrollado durante este trabajo ha consistido en realizar una umbralización en imágenes que tenga en cuenta la existencia de distintos bordes en la imagen. El algoritmo desarrollado se puede resumir en los siguientes pasos:

1. Descomposición wavelet discreta.

2. Cálculo de los bordes en un enfoque multiescala equivalente al que se presentará en el siguiente capítulo de detección de singularidades con wavelets y suavizado de los mismos con un filtro gaussiano con $\sigma^{2}=1$ aplicado sobre la salida del detector de bordes.

3. Umbralización fuerte de los coeficientes wavelets siguiendo las ecuaciones (3.44) siempre y cuando los coeficientes no estén afectados por la máscara de bordes.

Este sencillo esquema ha resultado en unos muy buenos resultados cuando se han aplicado a un esquema de segmentación de objetos basado en operadores morfológicos y en concreto en la transformación watersheds tal y como muestran las figuras 3.9 . y 3.10 . 


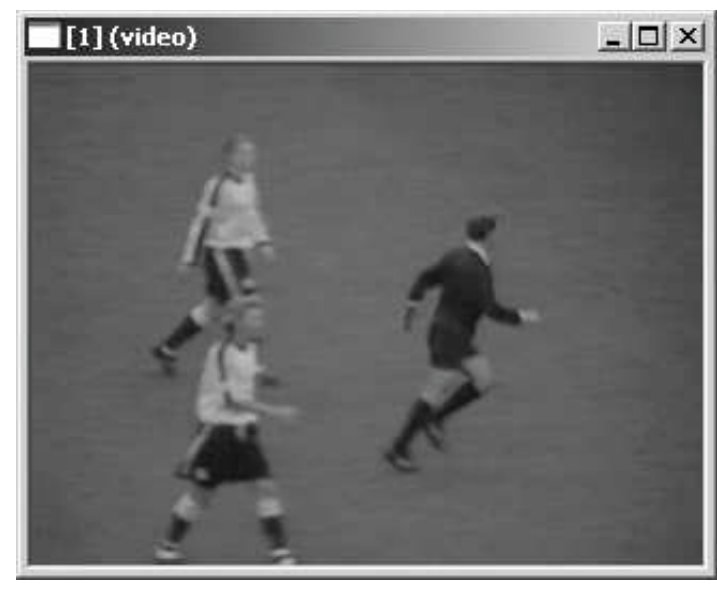

(a) Imagen original

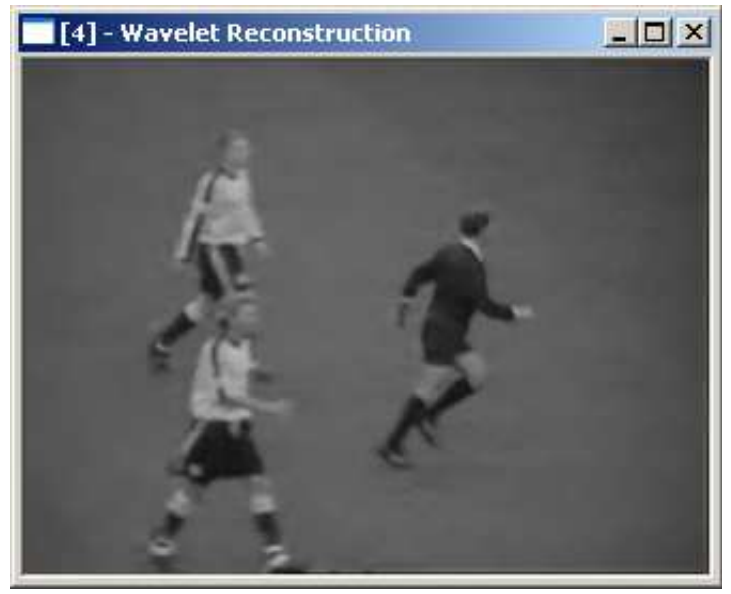

(b) Imagen procesada para eliminación de ruido

Figura 3.9: Imagen original y con ruido 


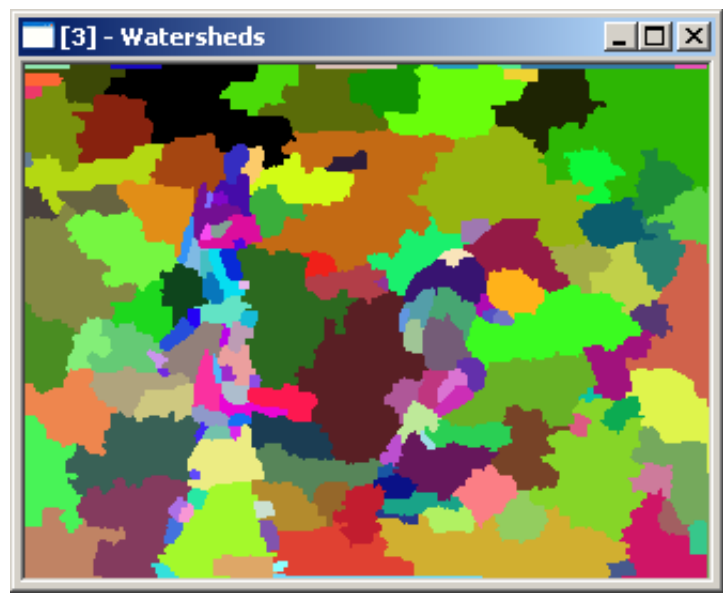

(a) Segmentación sobre la imagen original

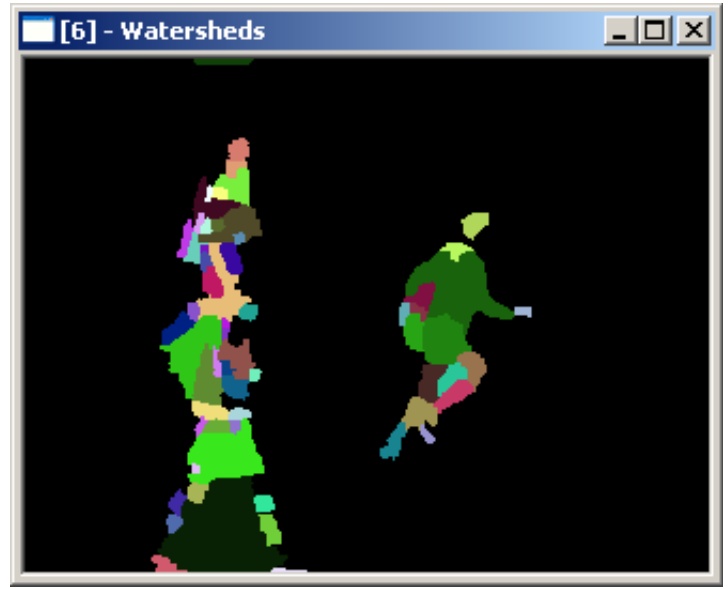

(b) Segmentación sobre la imagen con ruido eliminado

Figura 3.10: Segmentación en regiones mediante watersheds 


\section{Capítulo 4}

\section{Wavelets y Análisis de singularidades}

\subsection{Wavelet "Zoom"}

Una transformada wavelet puede focalizarse en estructuras de señal concretas con un procedimiento análogo a un zoom (en el sentido de que al reducir progresivamente el parámetro de escala las singularidades y estructuras irregulares de una señal quedan caracterizadas por la amplitud de los coeficientes wavelets.

A menudo estas singularidades llevan información esencial de la señal como ocurre en cualquier imagen pues indican la presencia de sus bordes o en señales de una dimensión como pueden ser electrocardiogramas o señales radar.

Veremos que la regularidad local de una señal está caracterizada por la caída en la amplitud de los coeficientes de la transformada wavelet a través de las escalas siendo los máximos locales de la transformada wavelet los valores clave para caracterizar las singularidades de las señales e imágenes.

Pero antes es necesario pasar de la idea de transformada discreta wavelet (DWT) a transformada continua (CWT) y las implicaciones que a efectos de implementación esto supone.

\subsubsection{Transformada Continua Wavelet (CWT)}

\subsubsection{Transformada Wavelet Diádica}

Ya en el capítulo 2 habíamos llegado a la definición de Tranformada wavelet según las expresiones 2.15, 2.16 y 2.17.

En el desarrollo allí presentado y que resumimos a continuación se establecían en primer lugar que una función wavelet $\psi$ o wavelet madre era necesariamente una función de media nula:

$$
\int_{-\infty}^{\infty} \psi(t) d t=0
$$

Que es dilatada mediante un parámetro de escala $s$ y trasladada por un parámetro $u$ :

$$
\psi_{u, s}(t)=\frac{1}{\sqrt{s}} \psi\left(\frac{t-u}{s}\right)
$$


de forma que la transformada wavelet continua o CWT queda definida por:

$$
W f(u, s)=\int_{-\infty}^{\infty} f(t) \psi_{u, s}^{*}(t)
$$

El objetivo que se presenta ahora es llegar a una implementación eficaz de la transformada continua que a efectos de detección precisa de singularidades ha de ser invariante en el tiempo. Para ello se discretiza la escala $s$ pero no el parámetro de desplazamiento $u$, lo que permitirá una implementación efectiva mediante el denominado Algoritmo à Trous.

Desde el punto de vista matemático la transformada wavelet diádica queda definida por:

$$
W f\left(u, 2^{j}\right)=\int_{-\infty}^{\infty} f(f) \frac{1}{\sqrt{2^{j}}} \psi\left(\frac{t-u}{2^{j}}\right) d t=f * \bar{\psi}_{2^{j}}(u)
$$

con:

$$
\bar{\psi}_{2^{j}}(u)=\psi_{2^{j}}(-t)=\frac{1}{2^{j}} \psi\left(\frac{-t}{2^{j}}\right)
$$

En lo que sigue siempre utilizaremos esta implementación diádica si resulta suficiente analizar esas escalas diádicas incluso cuando hablemos de transformada wavelet continua. Simplemente se trata, por tanto, de una manera eficiente de computar la transformada continua wavelet.

\subsubsection{Algoritmo à Trous}

En cuanto a la implementación de la transformada wavelet diádica partimos de funciones escalado y wavelets diseñadas mediante filtros discretos $h, g, \tilde{h}$ y $\tilde{g}$. En base a ellos, definiremos una serie discreta wavelet sobre $J$ octavas con muestreo diádico como:

$$
x[n]=\sum_{j=1}^{J} \sum_{k \in \mathbb{Z}} y^{(j)}[k] \tilde{g}^{(j)}\left[n-2^{j} k\right]+\sum_{k \in \mathbb{Z}} X^{(J)}[k] \tilde{h}^{(J)}\left[n-2^{J} k\right]
$$

donde:

$$
\begin{aligned}
X^{j}[2 k+1] & =\left\langle g^{(j)}\left[2^{j} k-l\right], x[l]\right\rangle, \quad j=1, \ldots, J \\
X^{J}[2 k] & =\left\langle h^{(J)}\left[2^{J} k-l\right], x[l]\right\rangle
\end{aligned}
$$

Como en la descomposición wavelet discreta, podemos ver esto como un banco de filtros en los que iteramos la rama paso bajo, y en la que la señal es expresada como suma de los detalles que resultan de cada etapa, más la versión paso bajo final.Las funciones de la base serán la familia de wavelets discretas:

$$
\left\{\tilde{g}^{(j)}\left[2^{j} k-l\right], \tilde{h}^{(J)}\left[2^{J} K-l\right]\right\}, j=1, \ldots, J y k, l \in \mathbb{Z}
$$

Y los coeficientes de la expansión se obtienen en función de la base dual caracterizada por los filtros $h^{(j)}[n]$ y $g^{(j)}[n]$.

La ecuación (4.6) muestra que en el cálculo de la transformada wavelet diádica se computan todos los desplazamientos enteros y no sólo los diádicos. El precio a pagar por este cambio respecto al algoritmo presentado para la transformada discreta wavelet, será tener un sobremuestreo y en consecuencia una representación redundante 
de la señal, no admisible en ciertas aplicaciones como puede ser la compresión de señales, pero que no implica ningún inconveniente en otras como puede ser el análisis de singularidades.

Trasladado a la implementación habitual de la DWT, implica la desaparición de los diezmadores, resultando en el esquema de la figura 4.1.

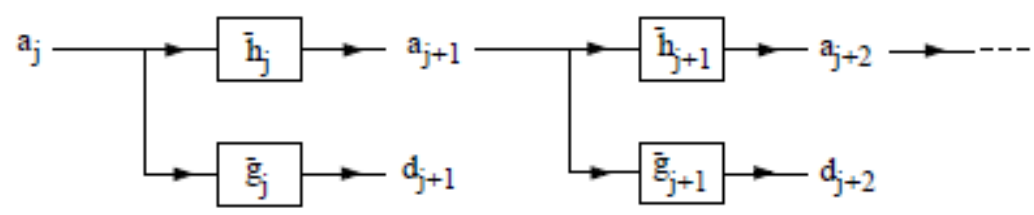

(a)

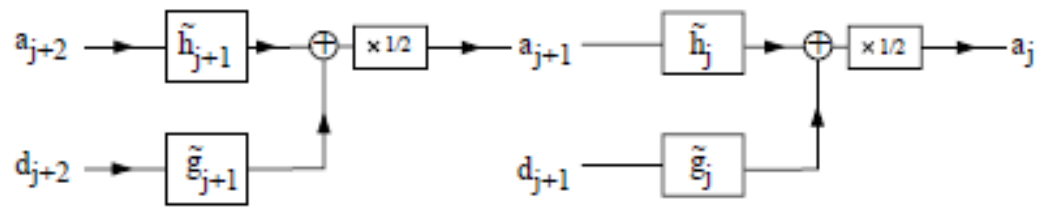

(b)

Figura 4.1: Implementación de la transformada wavelet continua mediante bancos de filtros

La convolución realizada en 4.6 con "filtros expandidos" como son $\tilde{g}^{(j)}\left[2^{j} k-l\right]$ o $\tilde{h}^{(J)}\left[2^{J} K-l\right]$ justifica la denominación de este algoritmo como algoritmo à trous (algoritmo con agujeros), pues en cada etapa, los filtros, al ser expandidos por un factor $2^{j}$ son modificados de forma que vamos introduciendo $2^{j}-1$ ceros (agujeros) entre sus muestras.

Para el caso de dos dimensiones extenderemos el algoritmo à trous de manera separable, convolucionando filas y después columnas. La imagen de entrada que supondremos normalizada a la escala $j=0$, la representaremos por $a_{0}[n, m]$, que podremos suponer que tiene la suficiente suavidad como para expresarla en función de una función continua $f$ como:

$$
a_{0}[n, m]=\langle f(x, y), \phi(x-n) \phi(y-m)\rangle .
$$

Donde como veremos a continuación, la función escalado $\phi(x, y)$ hace el papel de función suavizante (función de escala) de un detector multiescala.

De esta forma si denotamos un filtro separable por: $x y[n, m]=x[n] y[m]$, y al filtro obtenido insertando $2^{j}-1$ ceros entre cada muestra de $h[n]$ por $h^{(j)}[n]$ tendremos el siguiente algoritmo para implementar el algoritmo à trous (Mallat y Zhong, 1992):

$$
\begin{aligned}
& \begin{array}{l}
j=0 \\
\text { while }(j<J) \\
\qquad \begin{array}{l}
1 \\
j+1
\end{array}[n, m]=a_{j} \star g^{(j)} \delta[n, m] \\
d_{j+1}^{2}[n, m]=a_{j} \star \delta g^{(j)}[n, m] \\
a_{j+1}[n, m]=a_{j} \star h^{(j)} h^{(j)}[n, m] \\
j=j+1
\end{array} \\
& \text { end of while }
\end{aligned}
$$


Con $d_{j}^{1}$ nos referimos a los detalles verticales (altas frecuencias horizontales), que se corresponden con altas frecuencias en la dimensión vertical, por lo que serán captadas por el proceso: filtrado paso alto $\left(g^{(j)}\right)$ sobre las filas y filtrado con delta sobre las columnas. De igual manera con $d_{j}^{2}$ nos referiremos a los detalles horizontales.

Tras cada ejecución del bucle vamos obteniendo esos detalles, cuyos máximos y mínimos van a dar la posición de los bordes de la imagen, y una aproximación a una escala mayor, cuyo posterior procesamiento, nos dará bordes a una menor resolución (no aparecen bordes menos importantes).

\subsubsection{Singularidades y wavelets}

Se exponen en esta sección las definiciones y teoremas relacionados con los conceptos claves que la teoría wavelet ofrece para el análisis y caracaterización de singularidades en señales e imágenes.

\subsubsection{Regularidad Lipschitz}

Para caracterizar estructuras singulares, es necesario cuantificar la regularidad local de una señal $f(t)$. Los exponentes de Lipschitz proporcionan medidas de regularidad uniforme en intervalos de tiempo, pero también en cualquier punto $v$. Si $f$ tiene una singularidad en $v$, lo que significa que no es diferenciable en $\mathrm{v}$, entonces el exponente Lipschitz en $v$ caracteriza el comportamiento de esta singularidad.

\section{Definición.}

Una función $f$ es $\alpha$-Lipschitz $(\alpha>0)$ en un punto $v$ si existe una constante estrictamente positiva $K$ y un polinomio $p_{v}$ de grado $m=\lfloor\alpha\rfloor$ tal que:

$$
\forall t \in \mathbb{R}, \quad\left|f(t)-p_{v}(t)\right| \leq K|t-v|^{\alpha}
$$

Y una función $f$ es uniformemente $\alpha$-Lipschitz sobre el intervalo $[a, b]$ si cumple (4.9) en todo punto del intervalo con una constante $K$ independiente del punto considerado $v$.

En las señales prácticas que se utilizan en este trabajo se tiene que $0 \leq \alpha<1$ en el que siempre tendremos variaciones acotadas entre muestras consecutivas de la señal unidimensional o bidimensional considerada.

\subsubsection{Momentos de desvanecimiento}

A través de los momentos de desvanecimiento de una wavelet podemos saber su capacidad para analizar una función. En concreto si la wavelet tiene $n$ momentos de desvanecimiento entonces la transformada wavelet puede ser interpretada como un operador diferencial multiescala de orden $n$.

\section{Teorema.}

Una wavelet $\psi$ con un decaimiento rápido tiene $n$ momentos de desvanecimiento si y solo si existe $\theta$ con un decaimiento rápido tal que:

$$
\psi(t)=(-1)^{n} \frac{d^{n} \theta(t)}{d t^{n}}
$$


Donde con decaimiento rápido indicamos que por ejemplo una wavelet $p s i(t)$ tiene un decaimiento rápido si para cualquier exponente $m \in \mathbb{N}$ existe un $C_{m}$ que verifica:

$$
\forall t \in \mathbb{R}, \quad|\psi(t)| \leq \frac{C_{m}}{1+|t|^{m}}
$$

Si esto es así en virtud de (4.10) tendremos que una transformada wavelet se puede expresar como:

$$
W f(u, s)=s^{n} \frac{d^{n}}{d u^{n}}\left(f * \bar{\theta}_{s}\right)(u)
$$

Siendo:

$$
\bar{\theta}_{s}(t)=s^{-1 / 2} \theta(-t / s)
$$

La consecuencia práctica de esta teorema es que queda demostrada la conexión entre transformada wavelet y operadores diferenciales multiescala.

\subsubsection{Medidas de regularidad con wavelets}

La caída en el valor de la amplitud de la transformada wavelet a través de las sucesivas escalas está relacionada con la regularidad Lipschitz uniforme y local de la señal según el siguiente teorema.

\section{Teorema.}

Si $f \in \mathbf{L}^{2}(\mathbb{R})$ es $\alpha$-Lipschitz con $\alpha \leq n$ en el intervalo $[a, b]$, entonces existe $A>0$ tal que:

$$
\forall(u, s) \in[a, b] \times \mathbb{R}^{+}, \quad|W f(u, s)| \leq A s^{\alpha+1 / 2}
$$

En el sentido contrario, si $f$ está acotada y cumple (4.12) para un $\alpha<n$ no entero, entonces $f$ es $\alpha$-Lipschitz en $[a+\epsilon, b-\epsilon]$, para cualquier $\epsilon>0$.

De esta forma tenemos una condición casi necesaria y suficiente para medir la regularidad Lipschitz de una señal.

Es importante destacar que si $\psi$ tiene exactamente $n$ momentos de desvanecimientos, entonces la caída en amplitud de la transformada wavelet no da información de la regularidad Lipschitz para $\alpha>n$.

En cuanto a la medida de la regularidad local en un punto concreto el siguiente teorema nos proporciona un resultado análogo:

\section{Teorema.}

Si $f \in \mathbf{L}^{2}(\mathbb{R})$ es $\alpha$-Lipschitz con $\alpha \leq n$ en un punto $v$, entonces existe $A$ tal que:

$$
\forall(u, s) \in \mathbb{R} \times \mathbb{R}^{+}, \quad|W f(u, s)| \leq A s^{\alpha+1 / 2}\left(1+\left|\frac{u-v}{s}\right|^{\alpha}\right)
$$

En sentido contrario si $\alpha<n$ no es un entero y existe un $A$ y $\alpha^{\prime}<\alpha$ tal que:

$$
\forall(u, s) \in \mathbb{R} \times \mathbb{R}^{+}, \quad|W f(u, s)| \leq A s^{\alpha^{\prime}+1 / 2}\left(1+\left|\frac{u-v}{s}\right|^{\alpha^{\prime}}\right)
$$

entonces $f$ es $\alpha$-Lipschitz en el punto $v$. 
Para la interpretación de (4.13) supondremos que la wavelet $\psi$ tiene un soporte compacto igual a $[-C, C]$ y denominamos cono de influencia de $v$ en el plano escalatiempo al conjunto de puntos tales que $v$ está incluido en el soporte de:

$$
\psi_{u, s}(t)=\frac{1}{\sqrt{s}} \psi\left(\frac{t-u}{s}\right)
$$

soporte que vendrá dado, por lo tanto por $[u-C s, u+C s]$ o lo que es lo mismo por $|u-v| \leq C s$, cuya representación gráfica se muestra en 4.2 .

Si $v$ está en el cono de influencia de $u$, entonces $|W f(u, s)|$ esta influenciado por los valores de $f$ en $v$. Esto es lo que trata de mostrar la gráfica (4.2) donde se han aplicado estas ideas sobre un fragmento de señal, predominantemente suave y con varios cambios bruscos de amplitud.

Para varios de estos cambios bruscos se han marcado los conos de influencia, caracterizados por valores de coeficientes wavelets de amplitudes cuyo valor absoluto es superior a la media. Así las zonas más claras corresponden a los máximos de estas zonas, mientras que los más oscuros son valores negativos, pero también de alto valor absoluto.
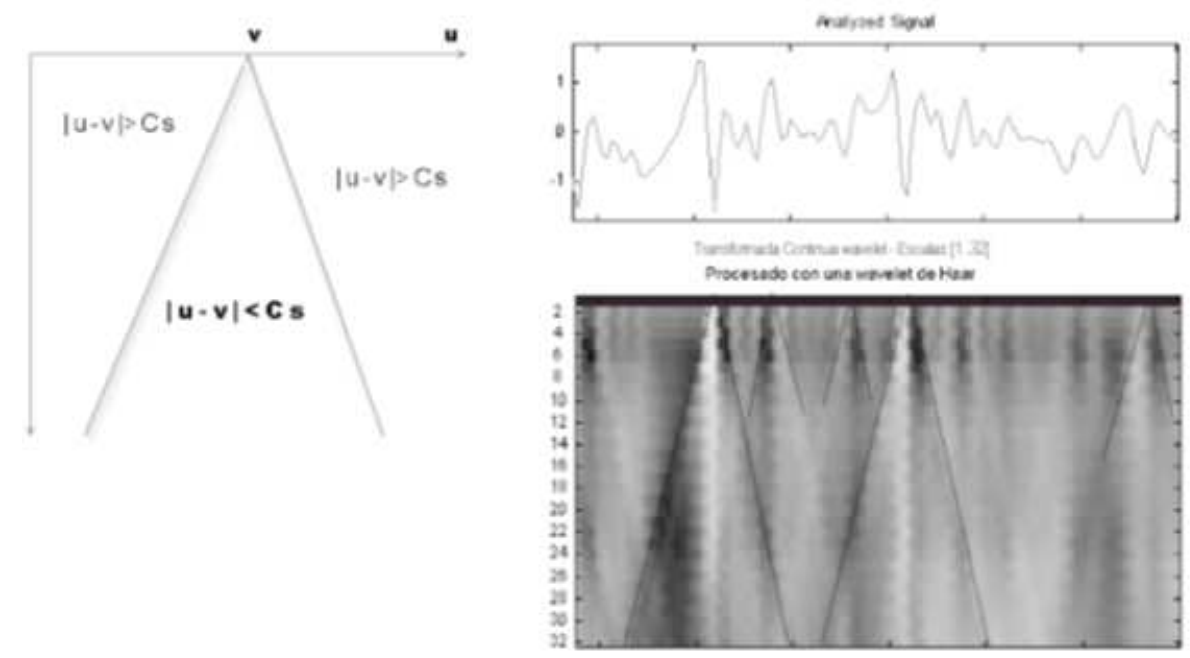

Figura 4.2: Detección de singularidades mediante transformada wavelet

\subsubsection{Puntos de máximo módulo}

Dado que la regularidad local de Lipschitz de una señal $f$ en un punto $u$ depende de la caída del módulo de los coeficientes wavelets a medida que utilizamos escalas de detalle el siguiente paso es utilizar en lugar de todo el plano $(u, s)$ sólo aquellos puntos del plano donde la transformada wavelet presente máximos locales. Es decir puntos $\left(u_{0}, s_{0}\right)$ que cumplan:

$$
\frac{\partial W f\left(u_{0}, s_{0}\right)}{\partial u}=0
$$

Este máximo local tiene que ser un máximo local estricto y como puede intuirse en la figura 4.2 vemos que las líneas $s(u)$ formadas uniendo máximos locales a 
través de las escalas convergen a la posición de las singularidades presentes en una señal. La siguiente figura 4.3 muestra el módulo de la transformada wavelet y las líneas que unen sus máximos (4.4) en lo que se ha convenido en llamar Transformada Wavelet de Módulo Máximo o WTMM (Wavelet Transform Modulus Maxima).
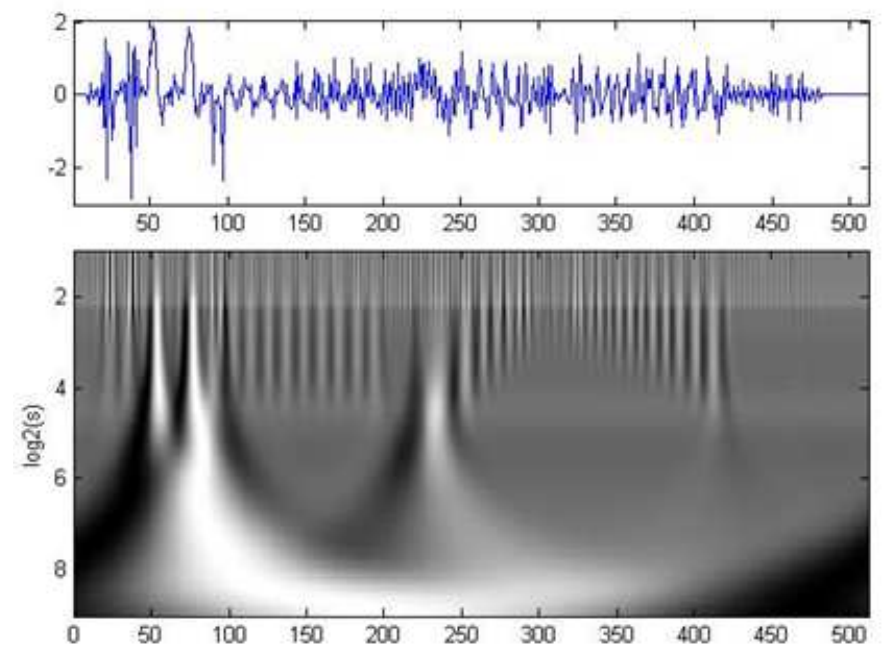

Figura 4.3: Transformada wavelet $W f(u . s)$ de una señal $f$

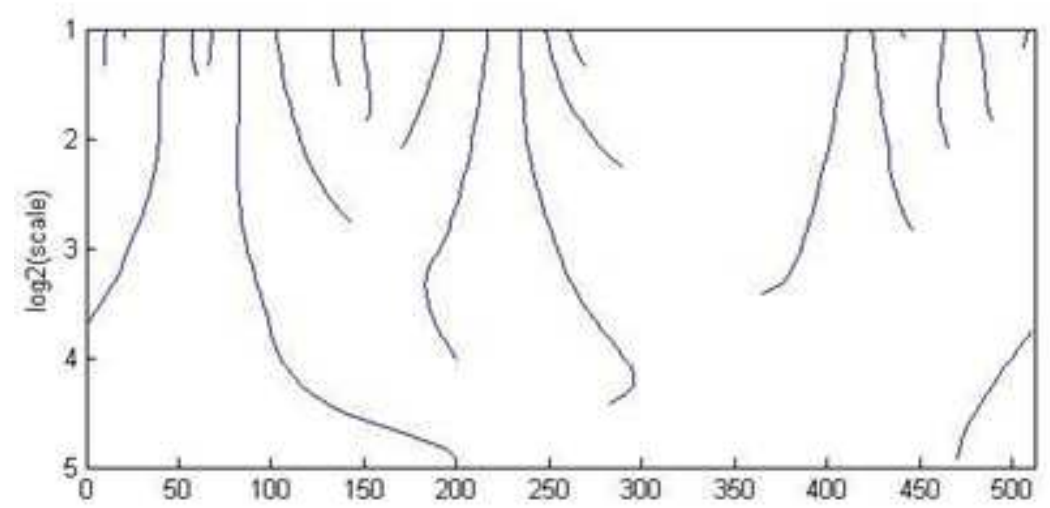

Figura 4.4: WTMM de $W f(u, s)$ de una señal $f$ 
Dada la analogía establecida entre las wavelets y los operadores diferenciales multiescala establecida en la ecuación 4.11 y que podemos reescribir cómo:

$$
W f(u, s)=s^{n} \frac{d^{n}}{d u^{n}}\left(f * \bar{\theta}_{s}\right)(u)
$$

los puntos cuyo módulo sea máximo local en la transformada wavelet serán los máximos de la primera derivada de $f$ suavizada por $\bar{\theta}_{s}$.

Para formar las líneas que conectan máximos la elección de la wavelet es clave siendo las derivadas de las gaussianas candidatos ideales para que la propagación sea completa a medida que avanzamos hacia escalas de detalle.

Cuando tenemos esas líneas de máximos conectados podremos calcular la regularidad Lipschitz a partir de la pendiente máxima de la gráfica de $\log _{2}|W f(u, s)|$ con respecto a $\log _{2}(s)$.

Como ejemplo, la figura (4.5) muestra en línea continua la caída de $\log _{2}|W f(u, s)|$ en función de $\log _{2}(s)$ a lo largo de la línea de máximo que converge en el punto $t=14$ mientras que la línea discontinúa lo hace para la línea de máximo que converge en $t=108$ que al ser una singularidad mucho más abrupta genera una caída mayor y por tanto un mayor exponente de Lipschitz.

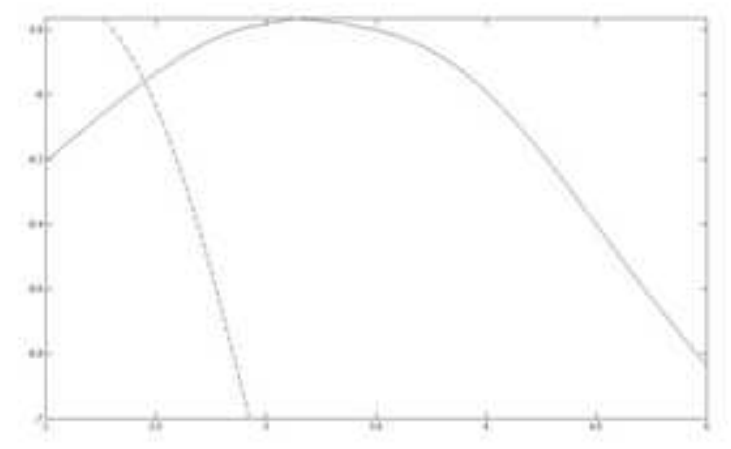

Figura 4.5: Ejemplo de caída de $\log _{2}|W f(u, s)|$ con respecto a $\log _{2}(s)$ para cálculo de regularidad Lipschitz

Como conclusión de este apartado se tienen por tanto que la relación entre el módulo de los coeficientes wavelets a través de las escalas está directamente relacionada con la caracterización de singularidades a través de los exponentes de Lipschitz. Y esta relación se calcula en señales esencialmente regulares a través de las líneas de módulo máximo construidas concatenando máximos locales de $|W f(u, s)|$ a través de las escalas. 


\subsection{Wavelet y análisis de singularidades en imágenes}

\subsubsection{Detector de bordes de Canny}

En procesamiento de imágenes es conocido y ampliamente usado desde hace décadas el algoritmo de Canny cómo uno de los mejores métodos para calcular bordes de una imagen (Canny, 1986).

Como muchos otros algoritmos de este tipo se detectan puntos de variación brusca en una imagen en un pixel calculando el módulo del gradiente:

$$
\vec{\nabla} f=\left(\frac{\partial f}{\partial x_{1}}, \frac{\partial f}{\partial x_{2}}\right)
$$

Un punto $y \in \mathbb{R}^{2}$ se define como borde si el módulo del operador gradiente $\vec{\nabla} f$ alcanza un máximo en $x=y$ cuando $x$ varía unidimensionalmente en la proximidad de $y$ en la dirección de máxima variación indicada por el operador gradiente.

\subsubsection{Detección de bordes multiescala}

Una versión multiescala de este detector de bordes se implementa suavizando la superficie con una función bidimensional $\theta(x, y)$ de la que generamos dos wavelets como derivadas parciales en cada una de las dos direcciones:

$$
\psi^{1}=-\frac{\partial \theta}{\partial x} \quad y \quad \psi^{2}=-\frac{\partial \theta}{\partial y}
$$

Este enfoque es característico de los detectores multiescala habituales en visión artificial, que suavizan la señal en distintas escalas y detectan variaciones agudas a partir de las derivadas primeras o segundas. La ventaja u objetivo de este enfoque es poder diferenciar entre bordes y texturas, pues lo que a una escala puede ser un borde, por ejemplo un ladrillo, a una escala mayor (menor resolución) puede ser una textura de una figura con bordes más relevantes, como ocurriría al considerar los bordes de una casa en lugar de los ladrillos aislados.

Dada la analogía entre wavelet y operador diferencial multiescala indicada en la ecuación 4.15 y que volvemos a expresar por conveniencia:

$$
W f(u, s)=s^{n} \frac{d^{n}}{d u^{n}}\left(f * \bar{\theta}_{s}\right)(u)
$$

se observa que para disponer de un operador multiescala, basta con parametrizar la función de suavizado en función de la escala $s=2^{j}$ de forma que:

$$
\theta_{2^{j}}(x, y)=\frac{1}{4^{j}} \theta\left(\frac{x}{2^{j}}, \frac{y}{2^{j}}\right)
$$


Con lo que los componentes de la transformada wavelet 2-D son proporcionales a las coordenadas del vector gradiente de $f$ suavizado por $\theta_{2^{j}}$ :

$$
\left(\begin{array}{l}
W^{1} f\left(2^{j}, x, y\right) \\
W^{2} f\left(2^{j}, x, y\right)
\end{array}\right)=s\left(\begin{array}{c}
\frac{\partial}{\partial x}\left(f \star \theta_{2^{j}}\right)(x, y) \\
\frac{\partial}{\partial y}\left(f \star \theta_{2^{j}}\right)(x, y)
\end{array}\right)=s \vec{\nabla}\left(f \star \theta_{2^{j}}\right)(x, y)
$$

A partir de esta expresión se puede obtener el módulo de la transformada wavelet como:

$$
M f\left(2^{j}, x, y\right)=\sqrt{\left|W^{1} f\left(2^{j}, x, y\right)\right|^{2}+\left|W^{2} f\left(2^{j}, x, y\right)\right|^{2}}
$$

Además de la información de módulo se hace necesario detectar el ángulo de manera que los puntos de máximo módulo serán aquellos que sean máximos locales en la dirección de este ángulo calculado como:

$$
A f\left(2^{j}, x, y\right)=\tan ^{-1}\left(\frac{W^{2} f\left(2^{j}, x, y\right)}{W^{1} f\left(2^{j}, x, y\right)}\right)
$$

Al igual que en el análisis para señales de una dimensión en este caso también se buscarán máximos locales del módulo para formar líneas de máximo que convergerán en las escalas de detalle a los bordes y estructuras significativas de la imagen.

Dado que el gradiente da la información de máxima variación será la perpendicular a esta dirección la que orienta el proceso de concatenación de máximos, como se verá en detalle a continuación.

\subsubsection{Regularidad Lipschitz en imágenes}

La caída en el valor de la amplitud de la transformada wavelet bidimensional de manera análoga a lo visto para señales de una dimensión depende de la regularidad de la imagen o sus exponentes Lipschitz. En el caso de dos dimensiones una función $f$ se dice $\alpha$-Lipschitz en $v=\left(v_{1}, v_{2}\right)$ con $0 \leq \alpha<1$ si existe $K>0$ tal que:

$$
\forall\left(x_{1}, x_{2}\right) \in \mathbb{R}^{2} \quad\left|f\left(x_{1}, x_{2}\right)-f\left(v_{1}, v_{2}\right)\right| \leq K\left(\left|x_{1}-v_{1}\right|^{2}+\left|x_{2}-v_{2}\right|^{2}\right)^{\alpha / 2}
$$

Y ese valor de $\alpha$ vendrá dado por la caída asintótica de $\left|W^{1} f\left(u, 2^{j}\right)\right|$ y $\left|W^{2} f\left(u, 2^{j}\right)\right|$ en la proximidad del punto considerado. Es decir, dada, una línea de máximos la caída de $\log _{2}\left|M f\left(u, 2^{j}\right)\right|$ respecto de $j$ marca el valor de $\alpha$.

Un enfoque más sencillo que será de gran utilidad al aplicar esta metodología a imágenes multifractales es asimilar este cálculo simplemente cuando un punto $\left(x_{0}, y_{0}\right)$ es clasificado como máximo en dos escalas consecutivas cualesquiera sin necesidad de formar cadenas de máximo en la dirección indicada por el gradiente. Podemos en ese caso hacer una estimación de su regularidad Lipschitz sin más que aplicar la siguiente fórmula.

$$
\alpha_{2^{j}}\left(x_{0}, y_{0}\right) \sim \log _{2}\left(\frac{M_{2^{j+1}}\left(x_{0}, y_{0}\right)}{M_{2^{j}}\left(x_{0}, y_{0}\right)}\right)+1
$$

siendo $M_{2^{j+1}}\left(x_{0}, y_{0}\right)$ y $M_{2^{j}}\left(x_{0}, y_{0}\right)$ los módulos de los coeficientes wavelets en dos escalas sucesivas. La justificación de este enfoque se detalla en la sección que trata la estimación directa del espectro multifractal, y como veremos nos ofrece interesantes resultados también cuando se aplica a imágenes naturales o mamografías digitales. 


\subsubsection{Caracterización de singularidades en imágenes naturales}

Para ejemplificar el proceso lo aplicaremos en primer lugar a la popular imagen de Lena. Partimos del módulo de la transformada continua wavelet o CWT en escalas diádicas, tal y como se muestra en la figura (4.6), donde se puede observar muy claramente en la anterior figura la capacidad de "zoom" de la transformada wavelet.
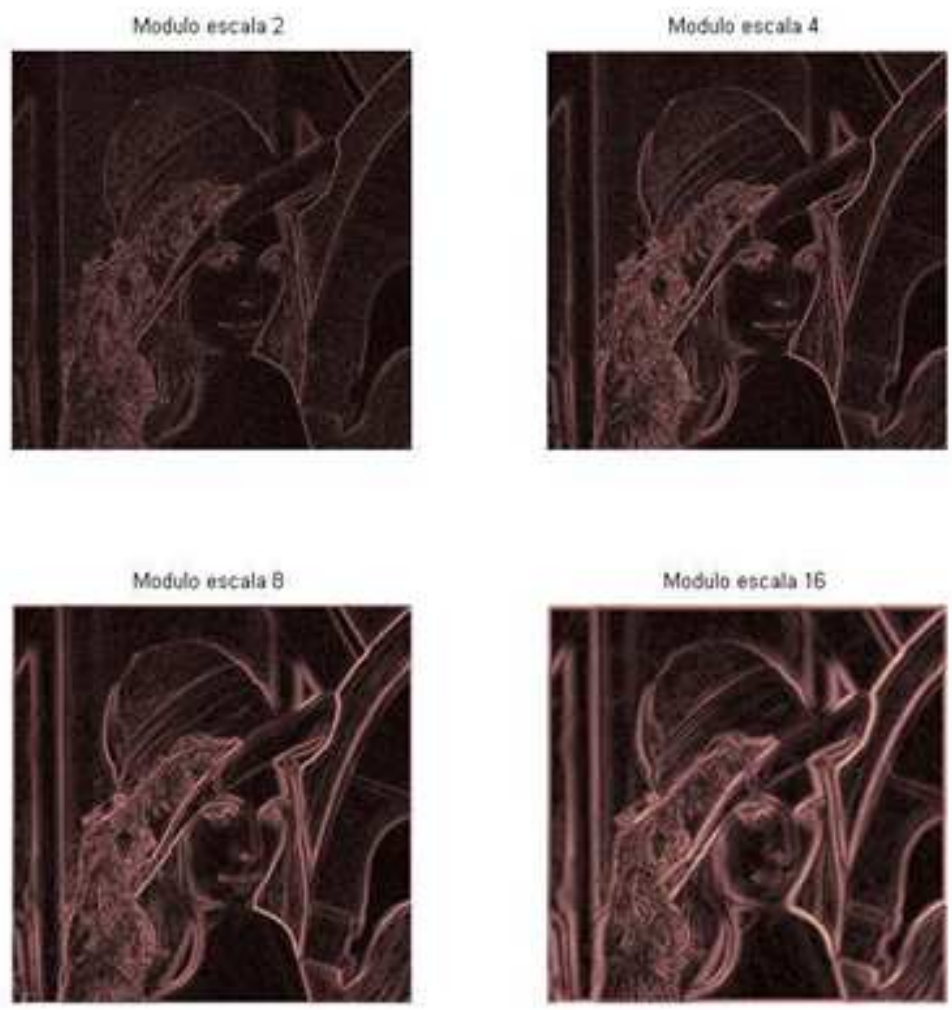

Figura 4.6: Módulo de la CWT de Lena a distintas escalas

A medida que aumentamos la escala se van perdiendo progresivamente los detalles y se van quedando solo los aspectos generales de la imagen (en este caso, los bordes principales de Lena).

Con la información del módulo y dirección de máxima variación ya podemos calcular los máximos locales en cada escala, obteniendo matrices de tipo binario que indicará que puntos son máximos y cuáles no.

A efectos de implementación el primer problema aparece al tener que cuantificar la dirección de máxima variación al estar trabajando con imágenes digitales con un número de pixeles limitado. Siguiendo la implementación del detector de bordes de Canny se cuantificarán estas direcciones de máxima variación entre 4 direcciones posibles. De este modo, se interpolarán los valores correspondientes a esa dirección a uno y otro lado del pixel considerado para determinar si el pixel es o no un máximo local en la dirección de máxima variación respecto de los valores interpolados y en consecuencia un borde.

El segundo problema viene de la necesidad de usar un determinado umbral en el 
módulo de la CWT a partir del cual ya sí considerar a un píxel como borde. Dada la dificultad de establecer este umbral, se aplicará también el algoritmo propuesto por Canny y conocido como ciclo de histéresis, en el que en función de dos umbrales en lugar de uno sólo clasificamos los bordes como fuertes o débiles (denotamos por tanto los umbrales como highThresh y lowThresh respectivamente). El uso de dos umbrales lleva a considerar como borde aquellos píxeles que pertenecen a bordes fuertes (intensidad de pixel por encima del umbral highThresh) y a aquellos que formando parte de bordes débiles tienen conectividad con bordes fuertes.

Aplicando ambas técnicas las imágenes binarias correspondientes a máximos locales se obtienen las imágenes (4.7) y (4.8) dónde en esta última figura se muestra una superposición 3D que permite apreciar perfectamente la diferencia entre las distintas escalas.
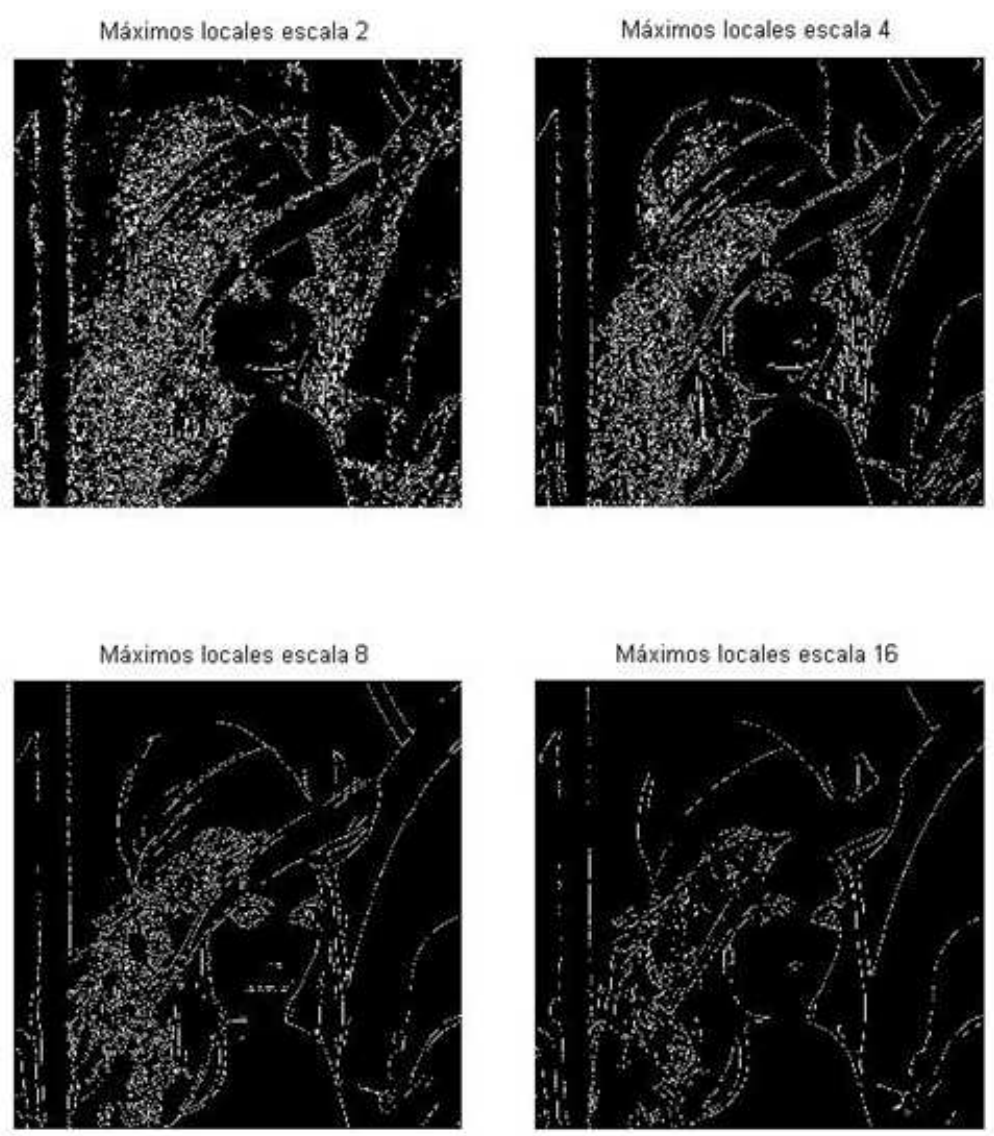

Figura 4.7: Máximos locales de Lena a las distintas escalas

Si mostramos sólo ciertas líneas de propagación de máximos para una mejor visualización del proceso obtenemos la imagen (4.9) donde se pueden observar claramente todos los casos posibles: el caso en que un máximo se propague a lo largo de todas las escalas, caso de que el máximo sólo se propague una o dos escalas o máximos que no se propagan.

Una vez construidas estas cadenas de propagación de máximos ya si es posible la caracterización de la singularidad de la imagen en cada punto de borde $\left(x_{0}, y_{0}\right)$ y 


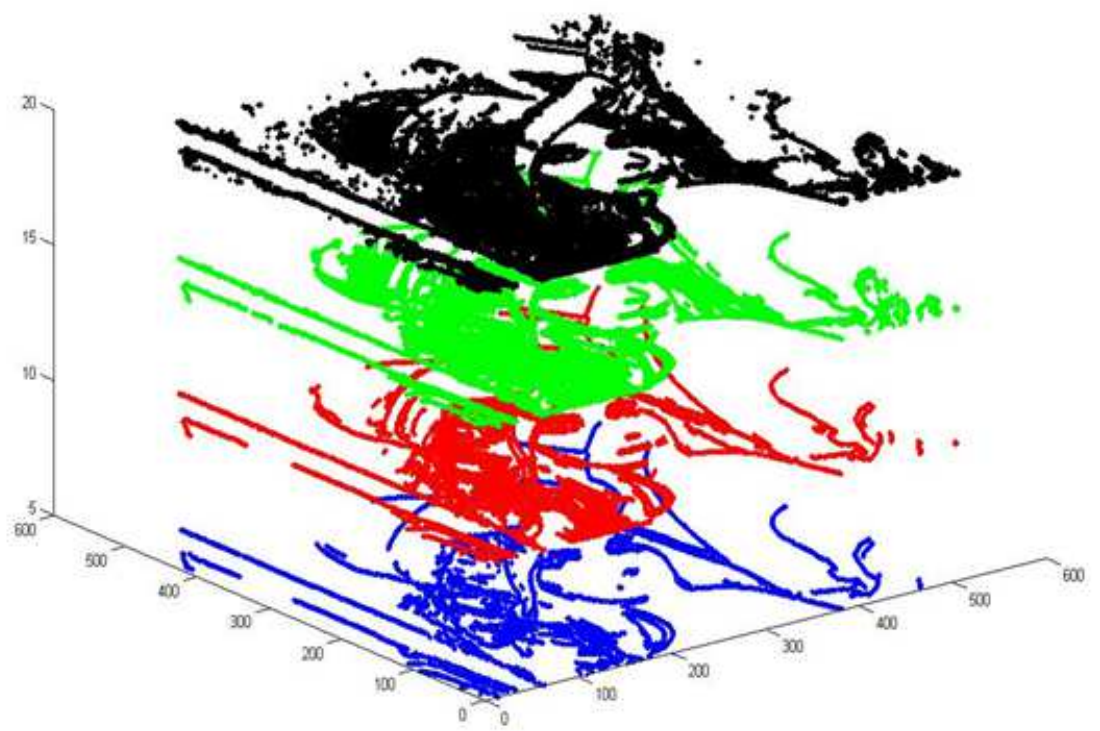

Figura 4.8: Superposición 3D de máximos locales de Lena

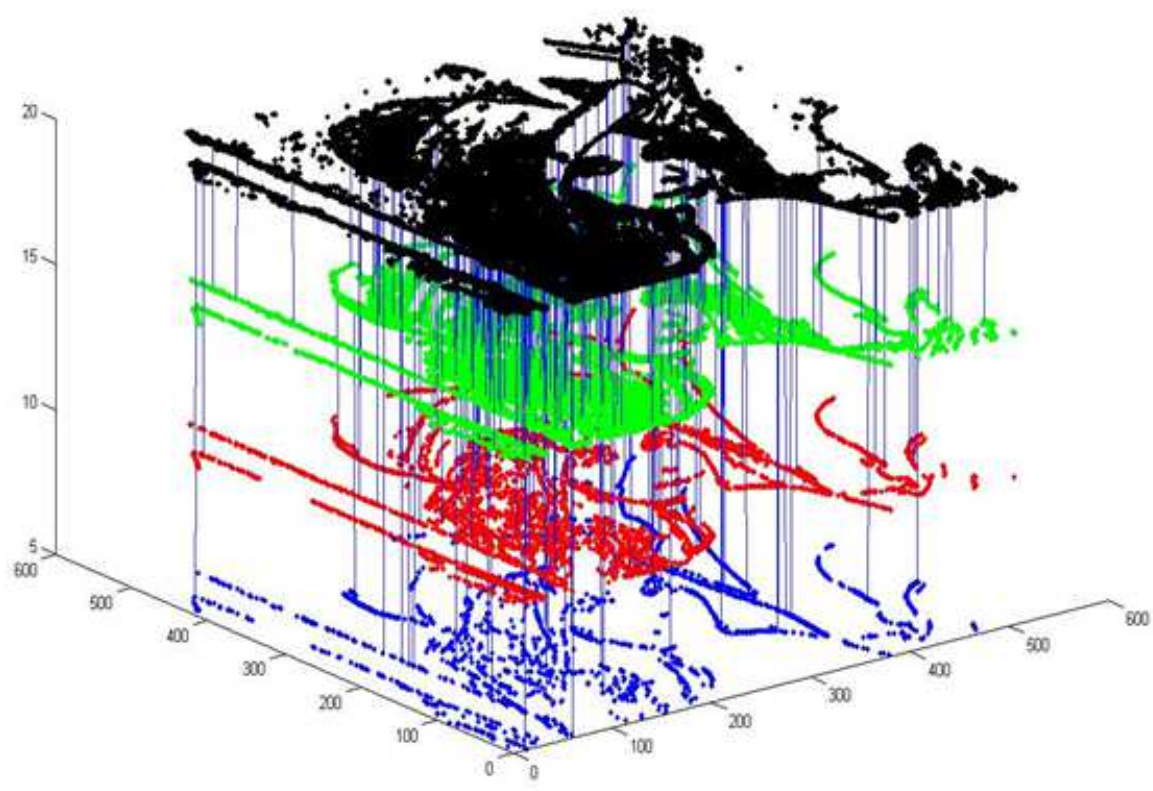

Figura 4.9: Propagación de máximos

entre dos escalas consecutivas mediante la ecuación 4.22 , es decir:

$$
\alpha_{2^{j}}\left(x_{0}, y_{0}\right) \sim \log _{2}\left(\frac{M_{2^{j+1}}\left(x_{0}, y_{0}\right)}{M_{2^{j}}\left(x_{0}, y_{0}\right)}\right)+1
$$

siendo $M_{2^{j+1}}\left(x_{0}, y_{0}\right)$ y $M_{2^{j}}\left(x_{0}, y_{0}\right)$ los módulos de los coeficientes wavelets en dos escalas sucesivas.

De este modo el experimento concluye con las imágenes denominadas como mapa de $\alpha$ donde en escala de pseudocolor se muestran los valores de $\alpha$ para cada pixel 
considerado como borde en dos escalas consecutivas.
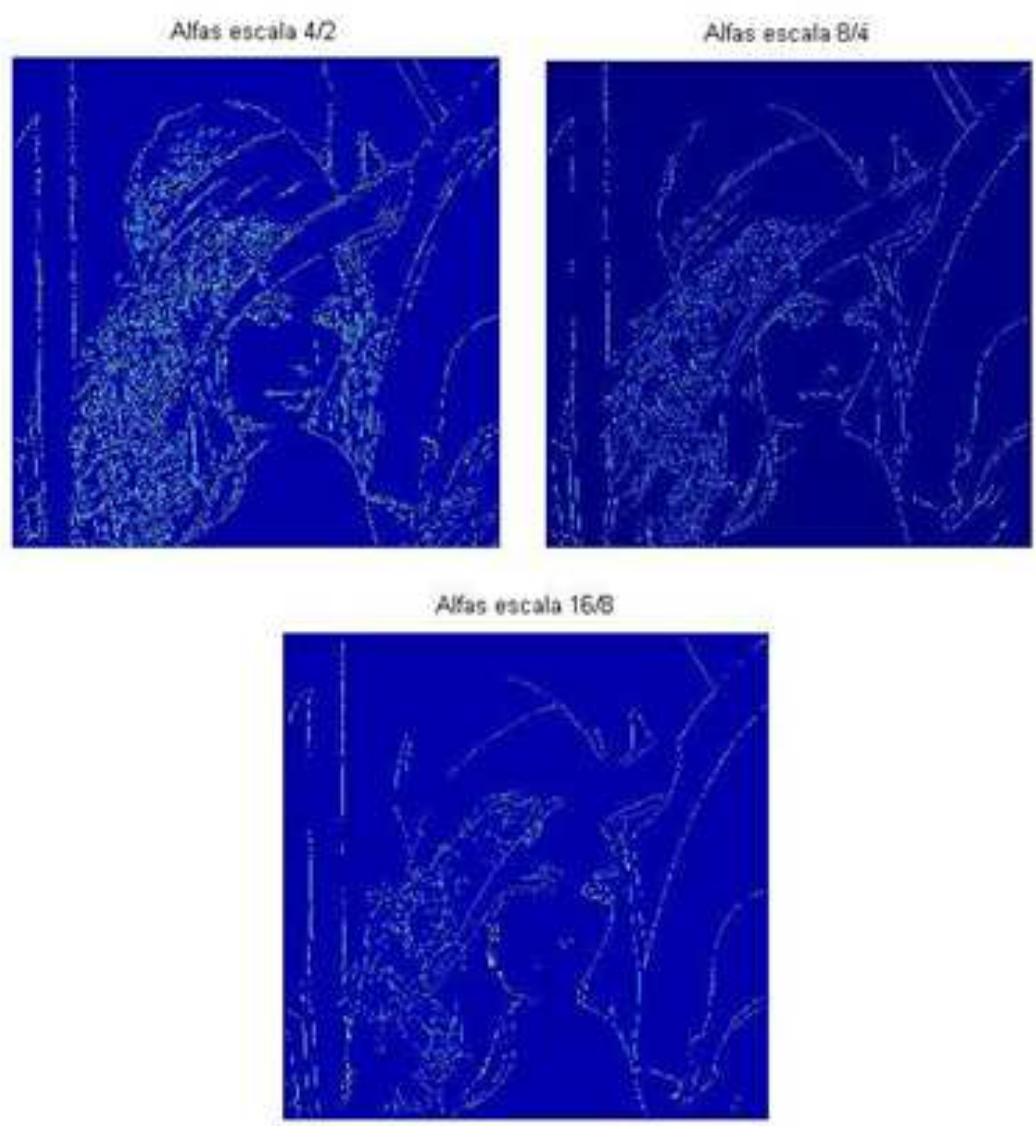

Figura 4.10: Imagen de mapa de " $\alpha$ " entre escalas 


\subsection{Aplicación a la detección de calcificaciones en imá- genes mamográficas}

Como aplicación concreta, se optó por hacer un estudio Gonzálvez y Piñuela, 2008) con imágenes de mamografías digitales al ser un campo en el que se pueden aplicar los conceptos desarrollados a lo largo de todo el capítulo sin tener que entrar en consideraciones teóricas especiales al más cerca de una imagen natural que de las estructuras multifractales que analizaremos más adelante. Como referencias principales de la aplicación de la teoría wavelet a este campo destacan (Laine et al., 1994), (Wang y Karayiannis, 1998) o (Balakumaran et al., 2009) o específicas del grupo de trabajo donde está integrada esta tesis como son (Ballesteros et al., 2002).

El objetivo de se estableció en la ayuda al diagnóstico mediante detección de calcificaciones. Como ejemplo tomaremos la mamografía (4.11) que presenta múltiples formas nodulares redondeadas distribuidas en el tejido y que como se comentaba anteriormente corresponde con el tipo de imagen que se puede estudiar mediante los conceptos descritos en este capítulo, ya que posee una estructura más o menos regular y una forma mejor definida y más intensa en el lugar en que se encuentre la malformación.

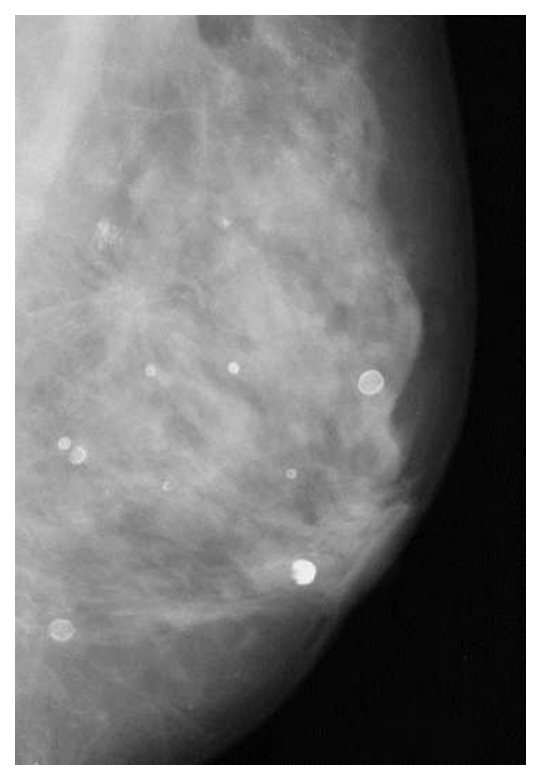

Figura 4.11: Ejemplo de mamografía

Dada la resolución de la imagen se realiza una descomposición en 4 niveles que mostramos en la gráfica 4.12.

A partir de la transformada wavelet continua y siguiendo la metodología desarrollada se llega a los mapas de $\alpha$ entre diferentes escalas mostrados en la figura 4.13. En base a distintos experimentos se determino empíricamente que los valores de $\alpha$ de los nódulos se corresponden con valores de $\alpha$ tales que $1 \leq \alpha \leq 1,75$. Por tanto estos 

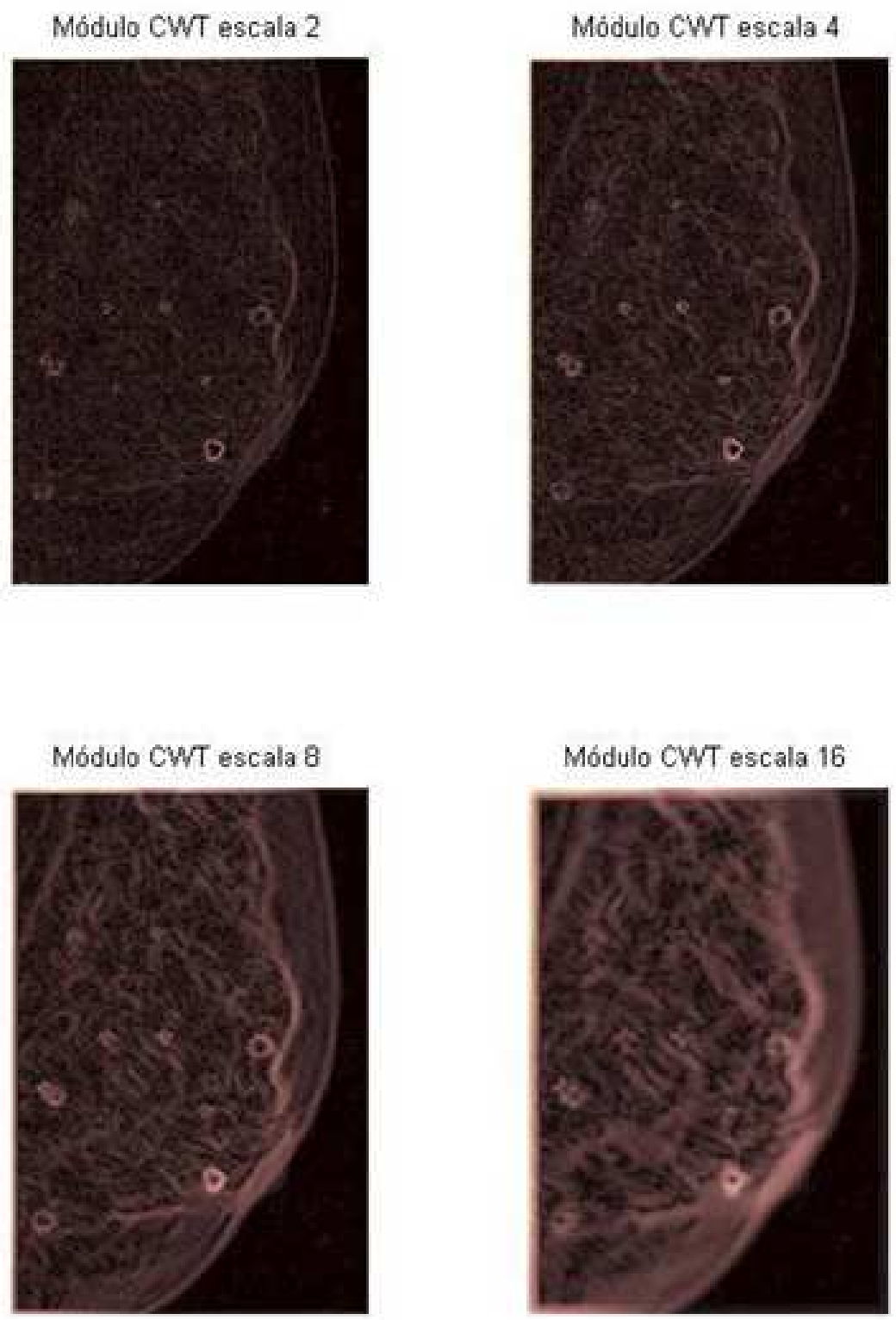

Figura 4.12: Módulo de la CWT para imagen de mamografía

valores se establecieron como umbrales para filtrar las singularidades detectadas y sólo aquellas con valores comprendidos entre estos valores se muestran en la imagen de forma que en el ejemplo mostrado en la figura se identifica aceptablemente los nódulos de la mamografía. 

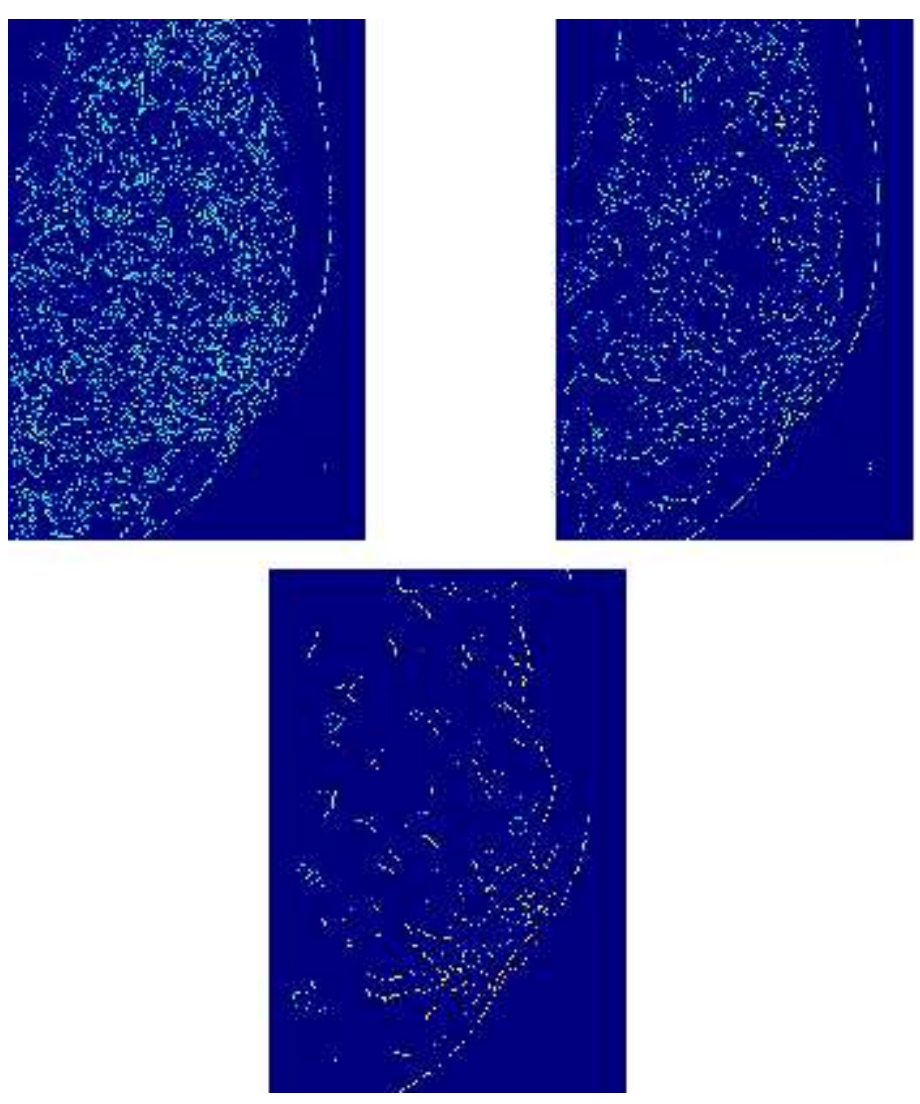

(a) Mapa de $\alpha$ entre escalas de una mamografía
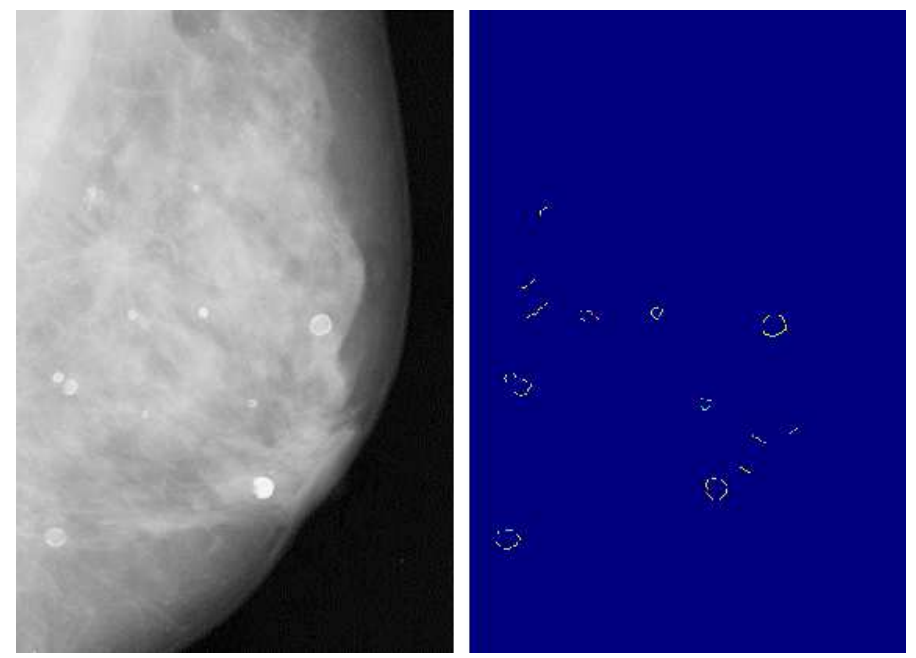

(b) Fitrado de singularidades para $0 \leq \alpha \leq 1,75$

Figura 4.13: Detección de calcificaciones en base a valores de $\alpha$ prefijados 



\section{Capítulo 5}

\section{Formalismo multifractal y relación con Teoría Wavelet}

\subsection{Teoría matemática de los multifractales}

\subsubsection{Motivación}

Durante gran parte de la historia, diferentes ramas de la matemática, como la geometría, el análisis numérico o el álgebra se han centrado en estudiar objetos, funciones y estructuras esencialmente regulares y sencillas. Con el desarrollo de la probabilidad, se comienza a estudiar los fenómenos en los que el azar parece tener un peso determinante. Así por ejemplo, en 1827, el botánico Robert Brown describe el movimiento, aparentemente aleatorio, de una partícula de polen al observarla al microscopio, dando lugar al movimiento browniano. Con el descubrimiento de fenómenos de este tipo, se empieza a entender la presencia de comportamientos estocásticos o aleatorios en muchos procesos de la naturaleza

Ya en los años 70 del siglo XX, Benoit Mandelbrot (Mandelbrot, 1977) fue capaz de reunir todos esos ejemplos de objetos irregulares y procesos aleatorios bajo una visión unificada: la geometría fractal.

La contribución mas importante de Mandelbrot fue reconocer que muchas de las estructuras complejas y dinámicas que se observan en diferentes áreas de la ciencia, podían ser estudiadas en un marco común, basado en conceptos de fractales e invarianza de escala. Los objetos fractales tienen la originalidad de presentar detalles en todas las escalas de observación, hecho muy común en la naturaleza, y que explica las dificultades que presentan para ser caracterizados mediante la geometría clásica.

Uno de los ejemplos más utilizados para entender como la geometría clásica falla en ciertos problemas es el trabajo del matemático inglés Lewis Fry Richardson quien en los años 50 del siglo XX, intentaba diseñar un modelo matemático para calcular el riesgo de que dos países entraran en guerra. Una de las variables que tenía en cuenta en su estudio era la longitud de la frontera compartida entre dos países colindantes. A pesar de que, a primera vista, puede parecer una información que debe ser precisa y fácil de conseguir, Richardson se encontró con grandes discrepancias. Así, por ejemplo, la frontera entre España y Portugal variaba entre 987 y 1214 kilómetros, según la fuente a la que consultara. Richardson se dio cuenta que estas discrepancias 
tenían su origen en el hecho de haberse usado diferentes escalas de medida, por lo que comenzó a investigar cómo variaba dicha longitud en función de la escala. Posteriormente, en 1967, Benoit Mandelbrot, tomando como base el trabajo empírico de Richardson, escribió su famoso artículo "¿Cuánto mide la costa de Gran Bretaña? Dimensión fraccional y autosemejanza estadística", en el cual reflejaba la misma paradoja acerca de cómo la longitud de una línea de costa depende de la escala de medida utilizada, aumentando ésta según disminuye la escala de medida y, por tanto, pudiendo llegar a ser, teóricamente, infinita.

De este modo, la geometría fractal es una extensión de la geometría clásica, con la ventaja de que puede ser usada para crear modelos precisos de estructuras físicas complejas.

No existe una definición concreta y precisa para el término fractal pero, tal y como indica Kenneth Falconer (Falconer, 2004), un fractal debe considerarse como un conjunto con ciertas propiedades características. La mayoría de los fractales cumplen con todas ellas, pero también se pueden encontrar fractales que incumplen alguna de estas caracaterísticas:

- Poseen estructura fina, lo que significa que contienen detalles a cualquier escala. No importa las veces que se aumente la visión de una parte de un fractal; siempre se observarán más y más detalles.

- Son demasiado irregulares para ser descritos mediante el lenguaje de la geometría clásica, tanto local como globalmente. Es decir, conceptos como longitud o superficie no pueden aplicarse para caracterizarlos.

- Habitualmente, presentan cierta auto-semejanza, ya sea exacta o aproximada. Un objeto es auto-semejante cuando está constituido por copias escaladas, trasladadas y/o rotadas de sí mismo.

- Normalmente, su dimensión fractal es mayor que su dimensión topológica.

- En la mayoría de los casos, su definición es muy simple y, muchas veces, es posible construirlo de forma recursiva.

\subsubsection{Introducción a las medidas fractales}

Para explicar el concepto de fractal y su relación con medidas invariantes a la escala sigamos con el ejemplo de calcular la longitud de una franja de terreno como puede ser la longitud de la costa marítima medida a través de un imagen ortográfica (Mandelbrot, 1967). En este tipo de imágenes para saber si las rocas que conforman la costa son de un tamaño u otro necesitamos una referencia de un tamaño conocido como pueden ser edificios o árboles. A medida que esta referencia es más pequeña la longitud de la costa aumenta conforme a una ley matemática de tipo base elevando a exponente (power-law), y es esta relación matemática establecida la que determinará la dimensión fractal.

Matemáticamente podemos modelar este efecto con uno de los fractales teóricos más sencillos como es la curva de Koch (Figura 5.1).

Este generador resulta de dividir una línea recta en 4 segmentos de longitud 1/3, con los dos segmentos centrales formando un triángulo. 


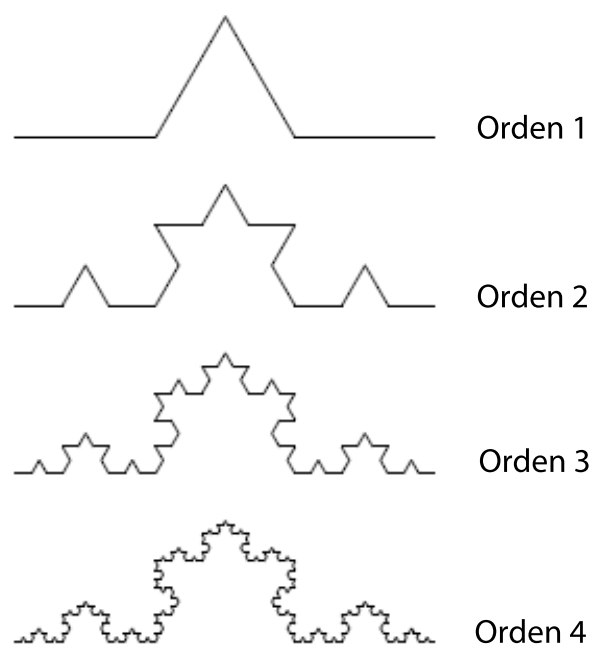

Figura 5.1: Curva de Koch de orden cuatro

Repitiendo el proceso obtenemos para la curva de orden dos, 16 segmentos de longitud $1 / 9$. Y en general, la longitud de la curva será $(4 / 3)^{k}$ después de $k$ iteraciones. En función de estas relaciones definimos la dimension de similitud como el factor $\frac{-\log m}{\log r}$ donde $m$ es el número de copias realizadas en cada iteración y $r$ el factor de escala. Para la curva de Koch se obtiene por tanto una dimension de $\frac{-\log 4}{\log 3} \approx 1,2619$ que representar una geometría mayor que dimension 1 (longitud infinita) pero menor que 2 (área cero).

El resultado así obtenido recibe el nombre de dimensión de similitud cuya definición formal y otros ejemplos de cálculo se detallan a continuación.

\subsubsection{Dimensión de similitud}

Definición.

Según este método un objeto fractal $F$ se divide en cajas que cubren el objeto de manera que denotamos por $N_{r}(F)$ al número de cajas y con $r$ su longitud o Área.

A medida que $r$ tienda a 0 el número de cajas $N_{r}(F)$ tenderá a infinito siendo la dimension fractal la medida de esa tendencia. Es decir, matemáticamente, expresamos la dimension fractal como:

$$
D_{B}(F)=\lim _{r \rightarrow 0} \frac{\log N_{r}(F)}{-\log r}
$$

Para ilustrar esta medida introducimos en este punto el fractal de Cantor, base de distintas simulaciones que se presentarán mas adelante: Para construir este fractal se parte de una línea que es dividida en tres segmentos en cada paso y donde además de la división en cada iteración se elimina el fragmento del medio permaneciendo los otros dos, tal y como se muestra en la figura (5.2).

En el primer paso la longitud será $2 / 3$ mientras que en la siguiente interacción será $4 / 9$ y en general $(2 / 3)^{k}$. Es decir, en el paso $k$ se tienen $N_{k}=2^{k}$ líneas de 


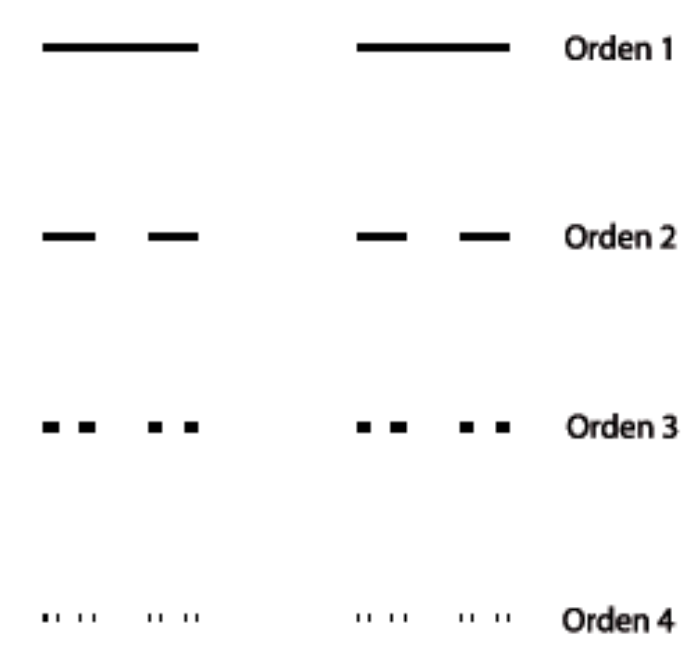

Figura 5.2: Conjunto de Cantor de orden cuatro

longitud $1 / 3^{k}$ por lo que:

$$
D_{B}(F)=\lim _{r \rightarrow 0} \frac{\log N_{r}(F)}{-\log r}=\lim _{k \rightarrow \infty} \frac{\log 2^{k}}{-\log 3^{-k}}=\frac{\log 2}{\log 3} \approx 0,6309
$$

Es decir, en este caso, su dimensión es mayor que 0 pero menor que 1 (dimensión de una línea), por tener longitud nula.

En el caso de la curva de von Koch, y aunque ya tenemos calculada su dimensión, aplicaríamos el mismo razonamiento notando que también existe un factor de escala $r=1 / 3$ y que el número de copias es $N=4$. Por tanto, la dimensión de similitud será:

$$
D_{B}(F)=-\frac{\log 4}{\log (1 / 3)} \approx 1,262
$$

Esta definición de dimensión fractal ofrece un resultado exacto para objetos con autosemejanza exacta. Sin embargo, para aquellos donde ésta no sea exacta o donde no se observe de manera tan clara, éste método no es apropiado. Otras definiciones que permiten una aplicación más genérica y ampliamente utilizadas son la dimensión de Hausdorff o covering dimension cuyo método de cálculo o definición puede consultarse por ejemplo en (Falconer, 2004) o la dimensión "box counting" que usaremos ampliamente como referencia en distintos experimentos.

\subsubsection{Dimensión "Box-counting"}

La dimensión box-counting (conteo de cajas) es una de las dimensiones fractales más extendidas y utilizadas, debido a su sencillo cálculo matemático y estimación empírica.

Apareció en 1930 y ha recibido multitud de denominaciones: dimensión Minkowski, dimensión Minkowski-Bouligand, entropía de Kolmogorov, entropía de dimensión, dimensión métrica, densidad logarítmica y dimensión de información. 
La idea consiste en cubrir un conjunto $\mathrm{u}$ objeto con conjuntos de diámetro $r$ y contar el número de dichos conjuntos necesarios.

De una manera más precisa: sea $F$ cualquier subconjunto de $\mathbb{R}^{n}$ no vacío y acotado (con dimensión finita) y sea $N_{\delta}(F)$ el menor número de conjuntos de dimensión máxima $\delta$ que puede cubrir $F$. Se definen las dimensiones Box-counting superior e inferior de $\mathrm{F}$ como:

$$
\begin{aligned}
& \underline{\operatorname{dim}_{B} F=\lim _{\delta \rightarrow 0}\left(\inf \left\{\frac{\log N_{\delta}(F)}{-\log \delta}\right\}\right)} \\
& \overline{\operatorname{dim}_{B}} F=\lim _{\delta \rightarrow 0}\left(\inf \left\{\frac{\log N_{\delta}(F)}{-\log \delta}\right\}\right)
\end{aligned}
$$

Si ambos valores coinciden, se define la dimensión box-counting $\left(\operatorname{dim}_{B}\right)$ como:

$$
\operatorname{dim}_{B} F=\lim _{\delta \rightarrow 0} \frac{\log N_{\delta}(F)}{-\log \delta}
$$

Habitualmente, se suele utilizar como conjunto para cubrir el objeto cubos de diámetro $\delta$. En el caso de un objeto embebido en un plano, los cubos serán cuadrados, y de ahí proviene el nombre de conteo de cajas.

Por tanto, la dimensión box-counting es el exponente de la ley de potencias que sigue la medida del objeto a diferentes escalas. Para obtener una estimación de la dimensión box-counting es suficiente realizar una gráfica bi logarítmica del número de cajas $N_{\delta}(F)$ contra el diámetro $\delta$ e interpolar linealmente la pendiente.

\subsubsection{Teoría multifractal}

La curva de Koch y el conjunto de Cantor son ejemplos de monofractales pues ambos quedam caracterizados por sólo una dimensión y su importancia es fundamentalmente teórica dado que las señales prácticas serán en general multifractales y en lugar de por una dimensión quedarán caracterizadas por un espectro de dimensiones.

Las distintas teorías y métodos para la caracterización del espectro multifractal hacen uso del concepto de medida como cantidad numérica que define el tamaño de un conjunto. Este concepto se define formalmente a continuación junto con las otros parámetros multifractales de los que nos ocuparemos: exponente de Hölder, espectro de singularidades o espectro multifractal y dimensión fractal generalizada.

\subsubsection{Medida multifractal}

\section{Definición.}

Definimos $\mu$ como una medida sobre $\mathbb{R}^{n}$ si $\mu$ asigna un número no negativo a cada subconjunto de $\mathbb{R}^{n}$ y es tal que $\mu(\emptyset)=0$ y $\mu(A) \leq \mu(B)$ si $A \subset B$.

Si $A_{1}, A_{2}, \ldots$ es una secuencia de conjuntos se tiene que:

$$
\mu\left(\bigcup_{i=1}^{\infty} A_{i}\right) \leq \sum_{i=1}^{\infty} \mu\left(A_{i}\right)
$$

donde la igualdad se cumple cuando los conjuntos $A_{i}$ son disjuntos. 


\subsubsection{Exponentes de Hölder}

\section{Definición.}

Dada una medida $\mu$ sobre $\mathbb{R}^{n}$, se define el exponente de Hölder de $\mu$ sobre un objeto $F$ como:

$$
\alpha_{\mu}(F)=\frac{\log \mu(F)}{\log \operatorname{diam}(F)}
$$

siendo $\operatorname{diam}(F)$ el diámetro del objeto $F$ que también denotaremos por $|F|$.

Dicho de otra forma $\mu(F)$ será la cantidad de masa que cae dentro del conjunto $F$ y dependerá del tamaño de este según una ley de potencias equivalente a la ecuación 5.7) y que podemos expresar como:

$$
\mu(F) \sim|F|^{\alpha}
$$

Esta exponente describe un comportamiento de ley de escala de la medida a nivel global. Sin embargo, es posible que dicho exponente $\alpha$ no sea constante en todos los puntos del conjunto, por lo que extendemos la definición para usarla a nivel local.

Para usar este concepto de manera local usamos bolas de radio $r$ centradas en el punto $x$ que denotamos por $B_{r}(x)$ y el exponente de Hölder local queda definido como:

$$
\alpha_{\mu}(x)=\lim _{r \rightarrow 0} \alpha_{\mu}\left(B_{r}(x)\right)
$$

Observar la similitud de este concepto con la dimensión box-counting vista anteriormente. Intuitivamente, si la masa está distribuida de una forma regular, el exponente Hölder tendrá el valor de la dimensión del espacio $\mathbb{R}^{n}$. Por el contrario, si la distribución es muy irregular, el valor del exponente indica cómo de irregular es en cada punto.

Extendemos igualmente el concepto de exponente de Hölder a funciones. Para ello partimos del concepto de oscilación de la función $f$ en el objeto $F$ dada por:

$$
\beta(f, F)=\sup \left\{f(t)-f\left(t^{\prime}\right) \quad t, t^{\prime} \in F\right\}
$$

Y el exponente de Hölder será:

$$
\alpha(F)=\frac{\log \beta(f, F)}{\log \operatorname{diam}(F)}
$$

Que presenta distintos problemas a la hora de definirlo de manera local, por lo que en los últimos años se ha tendido a la siguiente definición para el exponente de Hölder local aplicado a funciones.

\section{Definición.}

Se dice que la función $f: \Omega \rightarrow \mathbb{R}$ pertenece al espacio de Hölder $C_{l}^{s}(\Omega)$ con $0<s<1$ si existe una constante $C$ tal que para cualesquiera $x, y \in \Omega$ :

$$
|f(x)-f(y)| \leq C|x-y|^{s}
$$

Y el exponente de Hölder quedará definido como:

$$
\alpha_{l}(\Omega)=\sup \left\{s \text { tal que } f \in C_{l}^{s}(\Omega)\right\}
$$




\section{Definición.}

Y mediante el uso de $I_{n\{n \in \mathbb{N}\}}$, secuencia de intervalos decrecientes que contienen a $x_{0}$ definiremos el exponente local de la función $f$ en $x_{0}$ como:

$$
\alpha_{l}\left(x_{0}\right)=\sup _{n \in \mathbb{N}} \alpha_{l}\left(I_{n}\right)=\lim _{n \rightarrow+\infty} \alpha_{l}\left(I_{n}\right)
$$

El exponente Hölder da una medida de la fortaleza de la singularidad, o de la regularidad, de la función $\mathrm{f}$ en los alrededores del punto $x_{0}$.

Así, el exponente de Hölder en el punto $x_{0}$ mide cuánto de irregular es la función $f$ en dicho punto. Cuanto mayor sea el valor del exponente, más regular es la función. Por ejemplo, si $\alpha_{l}\left(x_{0}\right)=2,5$ significa que en $x_{0}$ la función $f$ posee primera y segunda derivada, pero no tercera.

Dada su definición y comparada con la de la regularidad Lipschitz o coeficientes de Lipschitz propios de la teoría wavelet vista en el capítulo anterior utilizaremos ambos conceptos indistintamente pues a efectos prácticos proporcionan la misma información.

\subsubsection{Espectro de singularidades o espectro multifractal}

\section{Definición.}

Como aproximación básica se parte de la distribución de irregularidades de una medida $\mu$ de bolas o cubos de radio $r$ en $\mathbb{R}^{n}$ de manera similar a la dimensión fractal calculada con el método box counting. En este caso si denotamos como $N_{r}(\alpha)$ el número de bolas o cubos cuya medida cumple $\mu \geq r^{\alpha}$ se define el espectro de singularidades como:

$$
f_{C}(\alpha)=\lim _{\epsilon \rightarrow 0} \lim _{r \rightarrow 0} \frac{\log ^{+}\left(N_{r}(\alpha+\epsilon)-N_{r}(\alpha-\epsilon)\right)}{-\log r}
$$

donde $\log ^{+}(x) \equiv \operatorname{máx}\{0, \log x\}$, asegurando que el espectro sea siempre una cantidad no negativa. Podemos deducir que dado (5.15), existirán un $\eta>0$ y $\epsilon>0$ suficientemente pequeños que cumplan:

$$
r^{-f_{c}(\alpha)+\eta} \leq N_{r}(\alpha+\epsilon)-N_{r}(\alpha-\epsilon) \leq r^{-f_{c}(\alpha)-\eta}
$$

De esta forma $f_{C}(\alpha)$ cumple la siguiente relación respecto del número $d N_{r}$ de cubos o bolas $C$ cuya medida cumplirá $\mu(C) \sim r^{\alpha}$.

$$
d N_{r}(\alpha) \sim r^{-f_{C}(\alpha)}
$$

que indica que $f_{C}(\alpha)$ es un exponente que mide como los cubos de medida $r^{\alpha}$ se escalan según $r \rightarrow 0$.

\subsubsection{Dimensión fractal generalizada}

\section{Definición.}

Para su definición partimos del momento $q$-esimo de la probabilidad $p_{i}$. Esta probabilidad queda definida como la probabilidad de que un punto se encuentre en la bola $i$ y viene dada por:

$$
p_{i}=\frac{\mu\left(C_{i}\right)}{\mu(\operatorname{soporte}(\mu))}=\frac{\int_{C_{i}} d \mu}{\int_{\text {soporte }(\mu)} d \mu} \sim r^{\alpha_{i}}
$$


Y su momento $q$ - esimo será:

$$
M_{q}(r)=\sum p_{i}^{q}
$$

La dimensión multifractal se encuentra a partir de la siguiente relación:

$$
M_{q}(r) \sim r^{\tau(q)}
$$

siendo:

$$
\tau(q)=(q-1) D_{q}
$$

Que permite expresar la dimensión $D_{q}$ como:

$$
D_{q}=\lim _{r \rightarrow 0} \frac{1}{q-1} \frac{\log M_{q}(r)}{\log r}
$$

Para $q=0$, obtenemos $D_{0}$, dimensión fractal ya expresada en (5.1):

$$
\lim _{q \rightarrow 0} D_{q}=\lim _{r \rightarrow 0} \frac{\log \sum p_{i}^{0}}{\log r}=\lim _{r \rightarrow 0}-\frac{\log N_{r}}{\log r}
$$

Y para $q=1$ utilizando Taylor resulta en:

$$
D_{1}=\lim _{r \rightarrow 0} \frac{\sum p_{i} \log p_{i}}{\log r}
$$

que recibe el nombre de dimensión de información en virtud del término $\sum p_{i} \log p_{i}$, bien conocido en teoría de la Información como medida de la información asociada a una probabilidad $p_{i}$.

Un término especialmente relevante es la dimensión de correlación obtenida para $q=2$, que permite además expresar la dimensión multifractal generalizada $D_{q}$ en función de ella. Para ello partimos de la siguiente suma de correlación:

$$
C(r)=\frac{1}{N(N-1)} \sum_{j=1}^{N} \sum_{i=j+1}^{N} \Theta\left(r-r_{i j}\right),
$$

donde se define $\Theta(r)$ como:

$$
\Theta(r)= \begin{cases}0 & \text { si } r<0 \\ 1 & \text { si } r \geq 0\end{cases}
$$

y $r_{i j}$ como la distancia entre dos puntos $i$ y $j$.

En virtud de esta definición podemos escribir la suma de correlación como:

$$
C_{q}(r)=\frac{1}{N} \sum_{j=1}^{N}\left[\frac{1}{N-1} \sum_{k=1, k \neq j}^{N} \Theta\left(r-r_{i j}\right)\right]^{q-1}
$$

Para llegar finalmente a:

$$
D_{q}=\lim _{r \rightarrow 0} \frac{1}{q-1} \frac{\log C_{q}(r)}{\log (r)}
$$


En las simulaciones software a veces se usa la ecuación (5.27) para el cálculo de la dimensión fractal generalizada $D_{q}$, pero nosotros nos basaremos en (5.21), salvo para $q=1$ donde se usara la ecuación (5.23).

Finalmente la relación entre el espectro de singularidades y la dimensión fractal generalizada viene dada por:

$$
\begin{gathered}
\alpha_{k}=\frac{d}{d q}\left[(q-1) D_{q}\right] \\
f\left(\alpha_{k}\right)=q \frac{d}{d q}\left[(q-1) D_{q}\right]-(q-1) D_{q}
\end{gathered}
$$

donde se ha utilizado la siguiente relación:

$$
\tau(q)=(q-1) D_{q}
$$

o lo que es lo mismo, que $\tau(q)$ es la transformada de Legendre de $f(\alpha)$, aspecto sobre el que profundizaremos más adelante.

\subsubsection{Transformada de Legendre: Relación entre el espectro multifrac- tal y la dimensión Fractal generalizada}

Como complemento a las definiciones anterior, profundizaremos en la relación comentada en la que $\tau(q)$ aparece como transformada de Legendre de $f(\alpha)$ pues es la base de las implementaciones realizadas en el marco de formalismo multifractal clásico y además es clave para entender como se relacionará la transformada wavelet con el formalismo multifractal.

Para ello partimos del propio objetivo del formalismo multifractal establecido en el cálculo del espectro multifractal $f(\alpha)$. Conceptualmente, este objetivo consiste en obtener el exponente Hölder de cada punto y, posteriormente, calcular la dimensión Hausdorff de cada subconjunto formado por puntos con mismo exponente Hölder.

Para poder implementar este algoritmo sobre toda la medida el procedimiento a seguir es similar a lo comentado en el apartado anterior pero ahora introducimos el concepto de función de partición $Z(\epsilon)$ como la función que formamos a partir de la división del soporte de la medida mediante cajas de tamaño $\epsilon$ centrada en el punto $x$ calculada como:

$$
Z(\epsilon)=\sum_{i} \mu\left(B_{\epsilon}\left(x_{i}\right)\right)
$$

De la definición de exponente Hölder punto a punto para medidas dado en (5.8), que repetimos aquí por conveniencia:

$$
\alpha_{\mu}(x)=\lim _{r \rightarrow 0} \alpha_{\mu}\left(B_{r}(x)\right)
$$

se puede generalizar que:

$$
\mu\left(B_{\epsilon}(x)\right)^{q} \sim \epsilon^{\alpha q} \quad \text { cuando } \quad \epsilon \rightarrow 0^{+}
$$


Por tanto, si se calculan los momentos de orden $q$ de la función partición cuando el tamaño de la caja tiende a cero, se obtiene que:

$$
Z_{q}(\epsilon)=\sum_{i} \mu\left(B_{\epsilon}\left(x_{i}\right)\right)^{q} \sim \epsilon^{\tau(q)}
$$

De la expresión anterior, el exponente $\tau(q)$ dependerá directamente de la distribución global de la regularidad de todos los puntos y, en función, del valor de $q$ se dará mayor peso a los valores más frecuentes $(q>0)$ o a los más "raros" $(q<0)$. Despejando:

$$
\tau(q)=\lim _{\epsilon \rightarrow 0} \frac{\log Z_{q}(\epsilon)}{\log \epsilon}
$$

Y de $\tau(q)$ llegamos a $f(\alpha)$ a través de la transformada de Legendre, esto es:

$$
\begin{array}{r}
\alpha(q)=\frac{d \tau(q)}{d q} \\
f(\alpha)=\operatorname{mí}_{q}\{q \alpha-\tau(q)\}
\end{array}
$$

Este método de cálculo de $D_{q}$ y las curvas $f(\alpha)$ será el implementado en los distintos experimentos 


\subsubsection{Simulación $1 D$ con la "Escalera del Diablo"}

De cara a la validación de las simulaciones realizadas sobre señales unidimensionales se mostrará como a partir del fractal denominado escalera del diablo se obtienen distintas medidas fractales. El origen de este fractal es el conjunto de Cantor visto anteriormente. Aunque presenta distintos problemas en cuanto a su cálculo con los métodos clásicos su elección obedece, como veremos, a que nos permite deducir interesantes conclusiones cuando llegue el momento de aplicar metodología basada en técnicas wavelets.

La escalera del diablo se genera a partir del conjunto de Cantor a través de una integral cuyo soporte coincide con los distintos intervalos formados. Esta integral posee en el límite un número infinito de escalones con cada escalón correspondiendo a un intervalo eliminado en el proceso iterativo de construcción del conjunto de Cantor.

Matemáticamente, si denotamos por $d \mu_{\infty}$ a la medida del conjunto de Cantor, la escalera del diablo es la integral:

$$
f(t)=\int_{0}^{t} d \mu_{\infty}(x)
$$

que sera una función creciente en el dominion $[0,1]$. La siguiente figura $(5.3)$ muestra la escalera del diablo obtenida con $p_{1}=0,5$ and $p_{2}=0,5$. Para la comparación de los distintos algoritmos, mencionar que su dimensión fractal teórica es $D=\log (2) / \log (3)=0,6309$.

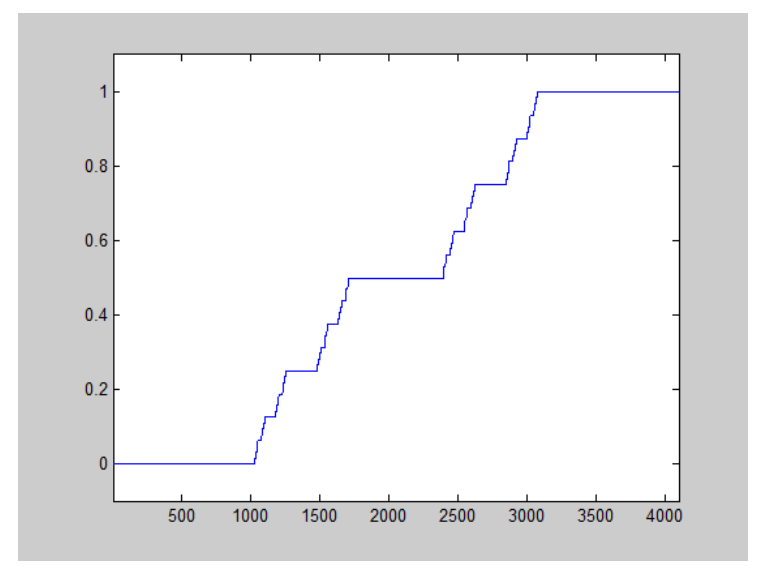

Figura 5.3: Escalera del diablo para $p_{1}=p_{2}=0,5$

Utilizando una primera implementación del método "box-count" disponible en (Moisy, 2008) se obtiene la gráfica (a) de (5.4) que indica que sólo en un rango concreto de escalas la señal tiene un comportamiento multifractal caracterizada por un valor de $\alpha=0,7925$ ligeramente desviado del valor teórico mencionado. En la implementación desarrollada para este trabajo de tesis del método "box-counting" se obtiene la función de partición representada en la gráfica (b) de (5.4) en la que también se observan problemas respecto del comportamiento multifractal ideal al obtener pendientes que distan de tener una pendiente constante en todas las escalas (gráfica (a) de (5.4). 
Calculando el espectro fractal en las escalas y valores de $q$ adecuados se obtiene un espectro multifractal como el mostrado en la gráfica (c) de 5.4 donde el valor máximo del espectro, parámetro clave a lo largo de este trabajo de tesis se obtiene para un valor de $\alpha_{\max }=0,6647$ para $q \leq 0$ y $\alpha_{\max }=0,6814$ para $q>00^{1}$

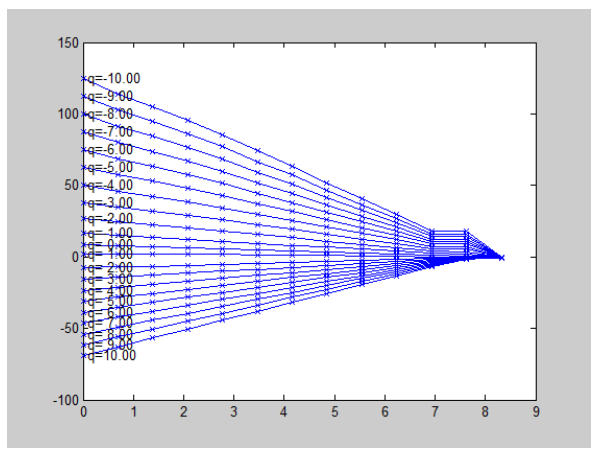

(a) Función de Partición

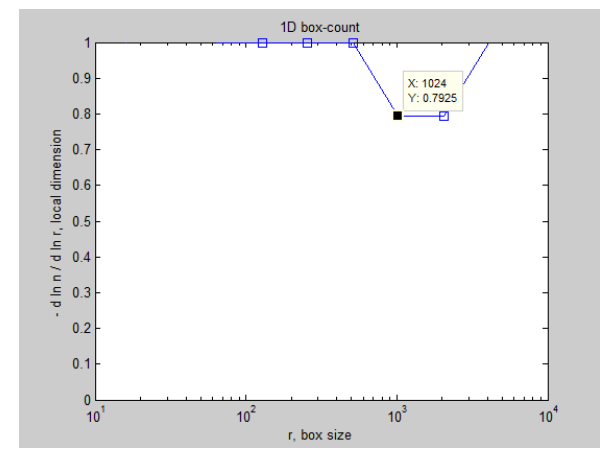

(b) Ley de escalado "box-counting" (Moisy 2008)

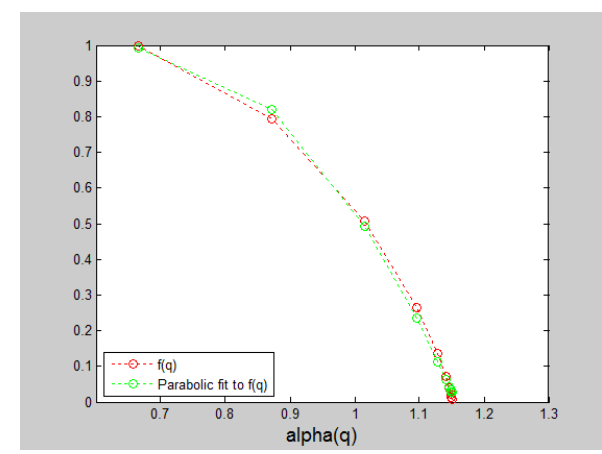

(d) Espectro multifractal $q \leq 0$ según algoritmo "box-counting" propio

(c) Espectro multifractal $q>0$ según algoritmo "box-counting" propio

Figura 5.4: Formalismo multifractal aplicado a la función "Escalera del Diablo"

\footnotetext{
${ }^{1}$ Es necesario separar el análisis pues como muestra la función de partición el comportamiento en este caso es muy distinto en $q \leq 0$ y $q>0$
} 


\subsubsection{Simulacion $2 D$ con Multifractales "Sierpinski Carpets"}

En cuanto a la validación de las simulaciones realizadas sobre imágenes binarias de los experimentos principales utilizaremos otro fractal / multifractal sintético. Por ello, introducimos en este punto los denominados Sierpinski Carpets (Perfect et al., 2006). Este multifractal se construye partiendo un cuadrado sólido de longitud unidad que es dividido en $b^{2}$ cuadrados más pequeños de longitud $1 / b$ para distintos factores de escala $b=2,3,4$, etc. Además de este proceso su construcción requiere de un parámetro de probabilidad $p$ relacionado con el paso siguiente en el cual, $b^{2}-n$ de esos cuadrados más pequeños permanecen siendo el resto eliminados.

Así, a nivel de implementación en cada iteración y cuadrado generado se elige un número entre una distribución de probabilidad uniforme en el rango $[0,1]$. Si el número resultante es mayor que el parámetro $p$ elegido la parte generada es eliminado. Si es menor, permanece. De este modo, en la figura (5.5) se han usado como parámetros $b=2$ y $p=0,3$ hasta llegar a un tamaño de imagen de 128x128 píxeles (las partes blancas son las que se mantienen y las negras las eliminadas).

En la misma figura (5.5) se muestran los resultados obtenidos al aplicar el formalismo multifractal clásico. La forma de representar el resultado en este caso y a lo largo del trabajo de tesis consiste en presentar en cada figura los siguientes gráficos:

- Función de partición dada por la ecuación (5.31):

$$
Z(\epsilon)=\sum_{i} \mu\left(B_{\epsilon}\left(x_{i}\right)\right)
$$

- Dimensión fractal generalizada dada por las ecuaciones 5.21) y por 5.23 para $q=1$. Esto es:

$$
\begin{gathered}
D_{q}=\lim _{r \rightarrow 0} \frac{1}{q-1} \frac{\log M_{q}(r)}{\log r} \\
D_{1}=\lim _{r \rightarrow 0} \frac{\sum p_{i} \log p_{i}}{\log r}
\end{gathered}
$$

- Espectro multifractal o espectro de singularidades dado por (5.36):

$$
\begin{gathered}
\alpha(q)=\frac{d \tau(q)}{d q} \\
f(\alpha)=\min _{q}\{q \alpha-\tau(q)\}
\end{gathered}
$$

- Mismo espectro multifractal en base al algoritmo desarrollado por T. Vadakkan (Vadakkan, 2009).

El resultado cómo puede verse resulta en un valor $f(\alpha)=1,5850$ independientemente de $\alpha$ como es de esperar para una medida monofractal. Si calculamos también los valores que denominaremos $\alpha_{\min }, \alpha_{\max }$ y el centroide del espectro multifractal que denotamos por $\alpha_{c}$ obtenemos como era de esperar que $\alpha_{\min }=\alpha_{\max }=\alpha_{c}=1,5850$.

En cuanto a las dimensión fractal generalizada se obtiene un valor constante de $D_{q}=15850$ excepto para el término $D_{0}$ que como siempre coincide con la dimensión topológica (es decir $D_{0}=2$ ). 


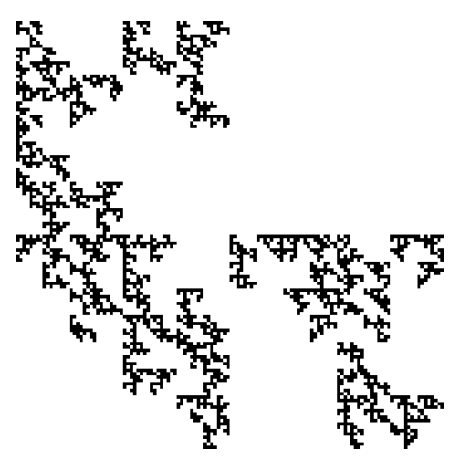

(a) Sierinski monofractal para $p=0,3$ y $b=2$

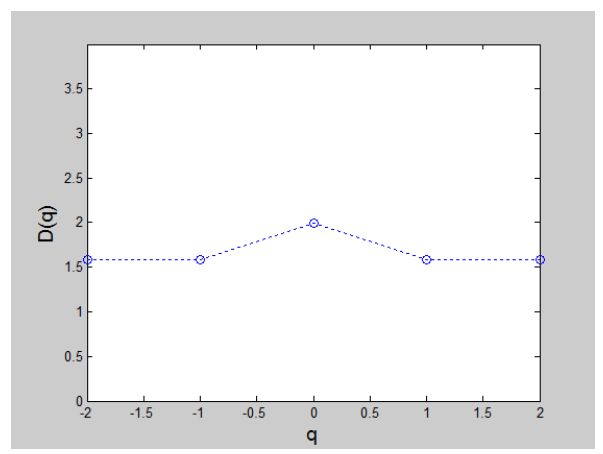

(c) Dimensión fractal generalizada $D_{q}$

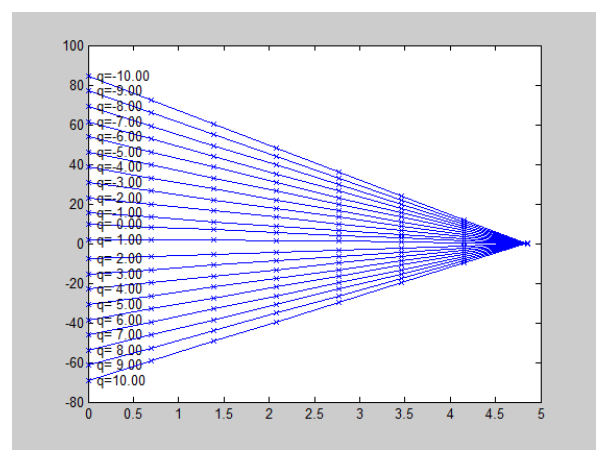

(b) Función de Partición

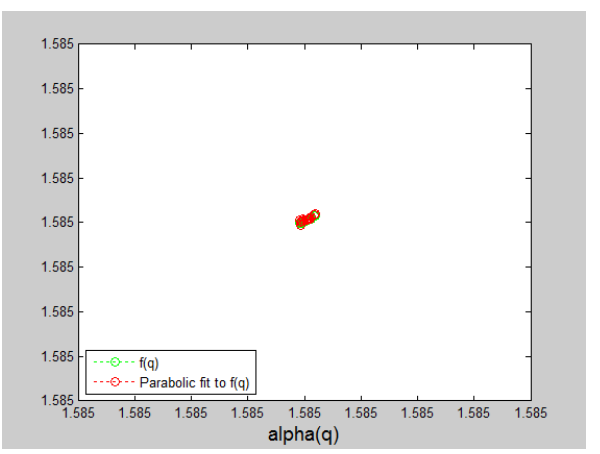

(d) Espectro multifractal

Figura 5.5: Formalismo multifractal aplicado a "Sierpinsky monofractal"

Sin querer entrar en detalles matemáticos que pueden consultarse en (Perfect et al. 2006), para pasar al caso de multifractal, no hay más que modificar el algoritmo de forma que la "masa" que antes se repartía en modo todo o nada entre los $b^{2}$ cuadrados generados en cada iteración (según fueran luego eliminados o permanecieses) es una "masa" que ahora se reparte proporcionalmente según un proceso en cascada entre los nuevos cuadrados.

Tanto la imagen multifractal como las imágenes que muestran los parámetros relevantes se muestran en la figura 5.6 . 


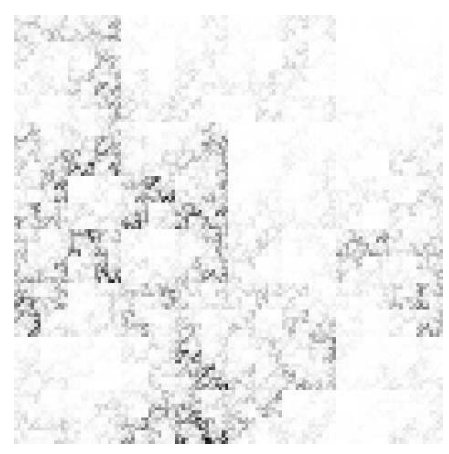

(a) Sierinski multifractal para $p=0,3$ y $b=2$

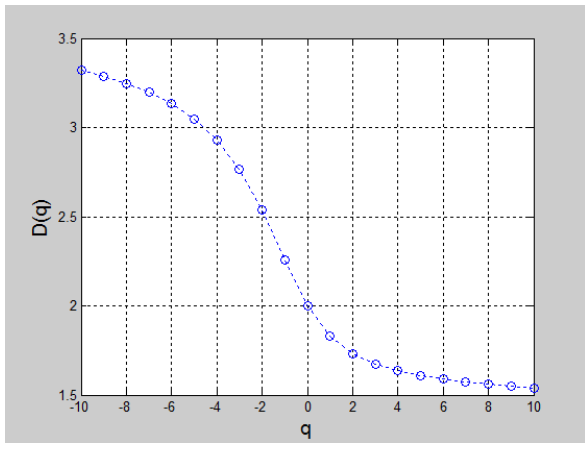

(c) Dimensión fractal generalizada $D_{q}$

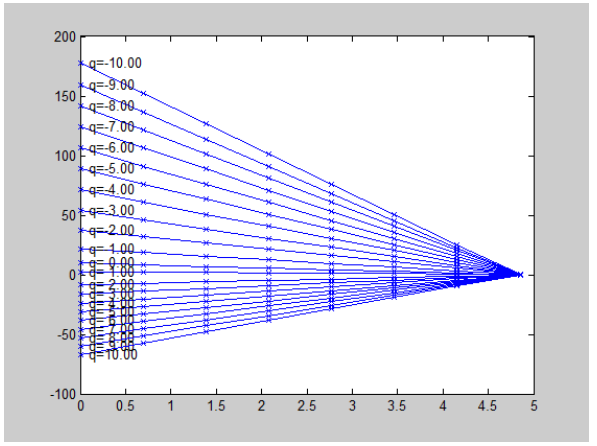

(b) Función de Partición

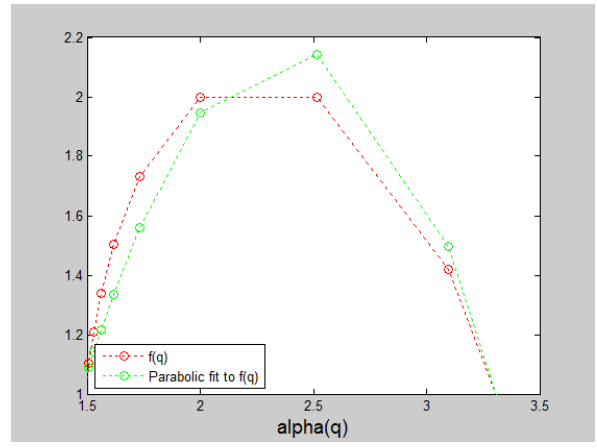

(d) Espectro multifractal "Box-counting"

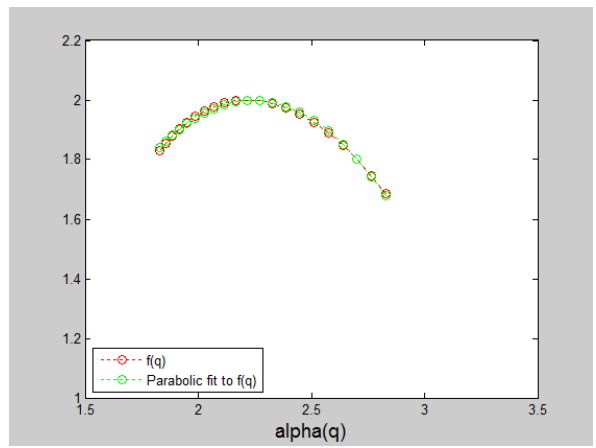

(e) Espectro multifractal (Vadakkan, 2009)

Figura 5.6: Formalismo multifractal aplicado a "Sierpinsky multifractal" 
En este caso los valores relevantes del análisis son:

- Método de estimación directa (Vadakkan, 2009):

$\alpha_{\min }=1,8291, \alpha_{\max }=2,8275, \alpha_{c}=2,2548$ y $\alpha_{0}=2,2177$

- Método "box-counting"

$\alpha_{\min }=1,4668, \alpha_{\max }=3,6544, \alpha_{c}=1,9880$ y $\alpha_{0}=2,257 \mathrm{c}^{2}$

Podemos concluir de la comparativa de dos métodos de análisis fractal realizados que desde el punto de vista cuantitativo será el valor donde el espectro alcanza su máximo, denotado con $\alpha_{0}$ y que será por tanto el valor tomado para comparar os métodos wavelet con los métodos clásicos del análisis multifractal.

\footnotetext{
${ }^{2}$ En este caso se calcula el máximo como valor medio entre los dos máximos que presenta el espectro multifractal calculado
} 


\subsection{Formalismo multifractal basado en la transformada Wavelet}

\subsubsection{Análisis multifractal y tratamiento de señales}

El avance y desarrollo en la teoría y en las técnicas de la geometría fractal ha propiciado su uso en otros campos como, por ejemplo, el del procesado de señal, donde ha dado lugar al, llamado, análisis multifractal. Debe reseñarse que el éxito del análisis fractal no proviene del hecho de que se aplique sobre señales o imágenes fractales. De hecho, la mayoría de las señales del mundo real no muestran las propiedades asociadas a los fractales, salvo una irregularidad a muchas escalas. La relevancia del análisis fractal proviene del uso de métodos fractales sobre señales complejas con estructuras singulares. Es decir, el uso de herramientas y métodos basados en la geometría fractal sobre señales irregulares se demuestra de gran utilidad, ya que dicha irregularidad contiene valiosa información sobre la señal. Destacar a Abry et al., 2013) como revisión de los modelos matemáticos aplicados al tratamiento de señales y derivados del formalismo multifractal.

Una señal que se suele utilizar para demostrar la validez de un análisis de señal basado en multifractales son los índices bursátiles que se caracterizan por una altísima irregularidad y que nos sirven como ejemplo para asociar los exponentes de Hölder a la singularidad de una señal del mismo modo que los coeficientes Lipschitz mencionados en en análisis de singularidades mediante transformada wavelet.

Utilizando la definición dada por la ecuación (5.14 que repetimos aquí de nuevo:

$$
\alpha_{l}\left(x_{0}\right)=\sup _{n \in \mathbb{N}} \alpha_{l}\left(I_{n}\right)=\lim _{n \rightarrow+\infty} \alpha_{l}\left(I_{n}\right)
$$

se puede calcular los exponentes Hölder del índice de Nikei de la figura (5.7) compuesto por 5,313 valores que presentan una irregularidad extrema.

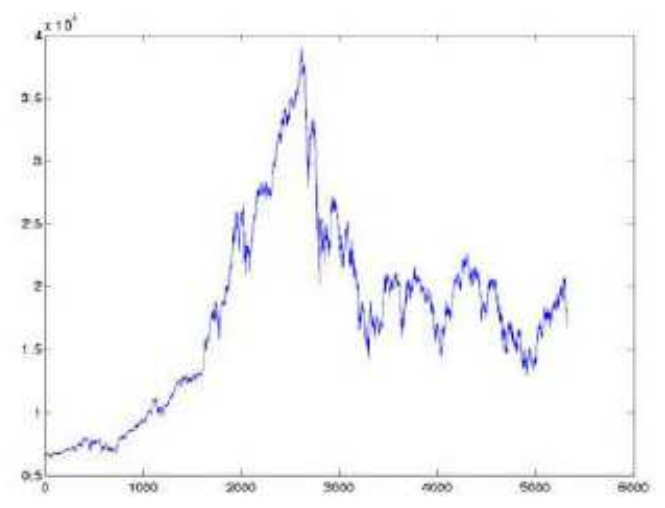

Figura 5.7: Indice de Nikkei

Los analistas financieros operan sobre el logaritmo del índice. Para calcular el exponente de Hölder local del logaritmo del índice en cada punto $x$ se determina para valores creciente de $\epsilon$ una par $(y, z)$ para el cual la oscilación de la señal dentro de una bola centrada en $x$ y de radio $\epsilon$ está contenida. Una regresión bilogarítmoca entre los valores $(y, z)$ encontrados y las distancias $|y-z|$ proporcionará los exponentes 
locales.

La mayoría de los exponentes se encuentran en $[0,1]$ lo que demuestra que la señal es continua pero no diferenciables, es decir, altamente irregular con varios picos allá donde hechos notorios sucedieron.

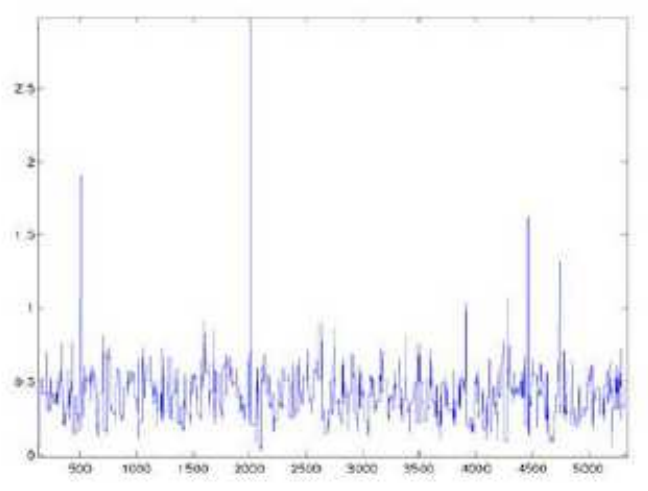

Figura 5.8: Exponentes Hölder locales del Indice de Nikkei

En este punto podemos concluir que con la información proporcionada por los coeficientes de Hölder sería suficiente. En cambio habrá situaciones en las que no será suficiente con tener la información local de manera aislada y deberemos llegar a la caracterización de $D_{q}$ y $f(\alpha)$ según lo visto el capítulo anterior.

En este sentido la transformada wavelet de módulo máximo nos ofrece un compromiso entre cálculo de coeficientes de manera directa y el formalismo que se deriva en este capítulo en el que al igual que con el método "box-counting", la transformada wavelet permite calcular $D_{q}$ y $f(\alpha)$ con una exactitud que dependerá de la estructura multifractal concreta.

\subsubsection{Espectro multifractal y transformada wavelet de módulo má- ximo}

Cuando tratamos con señales multifractales en sentido estricto no es posible calcular los exponentes de Lipschitz tal y como se vio en el capítulo dedicado a análisis de singularidades mediante transformada wavelet, dado que las señales de este tipo presentan distintas singularidades en todo su dominio de definición. Es decir, hasta en el mejor de los casos y como consecuencia de la discretización cada muestra de la señal o imagen se corresponde con un intervalo de tiempo o espacio donde la señal contiene un infinito número de singularidades. Las transformada wavelet fue relacionada con el formalismo wavelet por primera vez en (Arneodo et al. 1988) y su aplicación a distintos fenómenos naturales ha contribuido significativamente al avance del formalismo multifractal como se destaca en (Arneodo et al. 1994) y (Struzik, 1999).

Como ejemplo de las simulaciones realizadas se mostrará como a partir del fractal denominado escalera del diablo se obtienen las distintas medidas fractales. Como vimos en el capítulo anterior, el origen de este fractal es el denominado conjunto de Cantor y su dimensión fractal es $D=\log (2) / \log (3)=0,6309297$.

Recordar que la escalera del diablo se genera a partir del conjunto de Cantor a 
través de una integral cuyo soporte coincide con los distintos intervalos formados. Esta integral posee en el límite un número infinito de escalones con cada escalón correspondiendo a un intervalo eliminado en el proceso iterativo de construcción del conjunto de Cantor. La figura (5.9) muestra la escalera del diablo obtenida con $p_{1}=0,475$ and $p_{2}=0,525$, su transformada wavelet y los máximos locales del módulo de la misma.

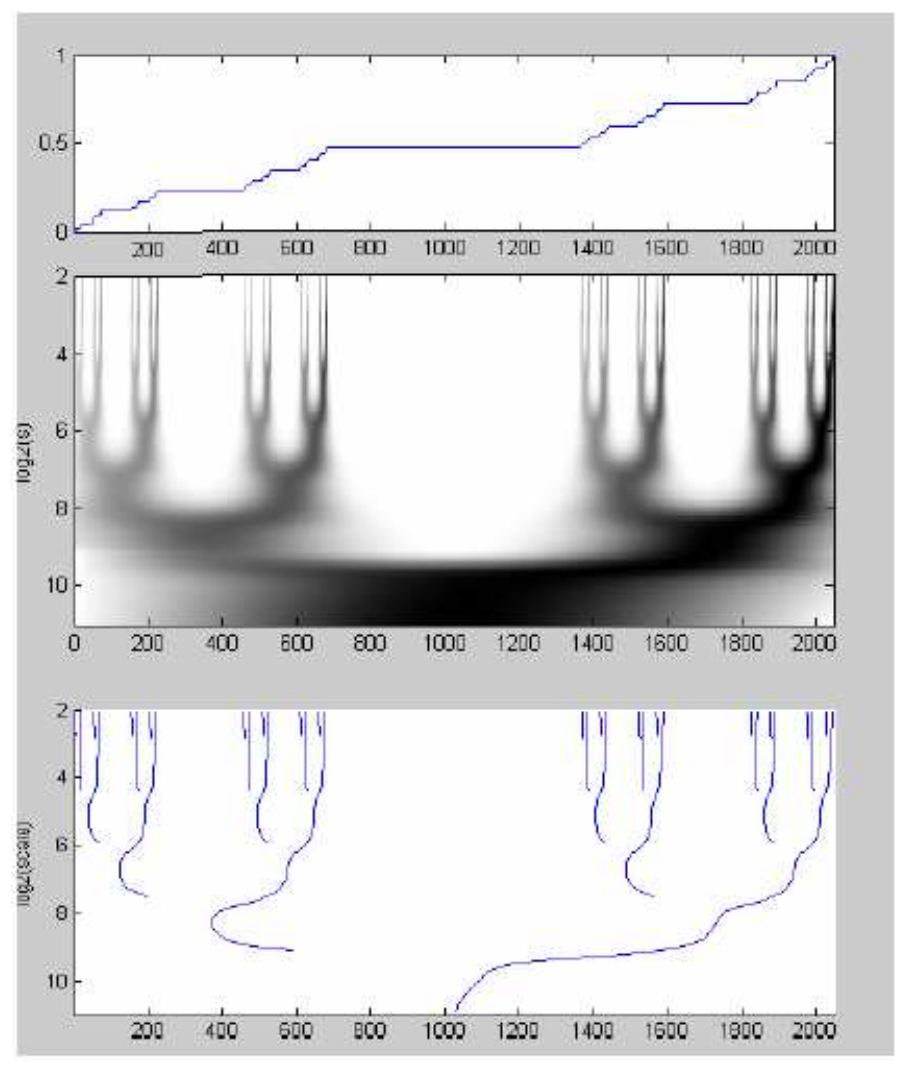

Figura 5.9: Transformada wavelet del multifractal "Escalera del Diablo"

Cuando se trata de encontrar la distribución estadística de las singularidades presentes en una señal como la del ejemplo, se usan dos medidas principalmente. Por un lado está la denominada dimensión fractal generalizada expuesta en (Turiel, 2001) mientras que en nuestro caso nos centramos en el cálculo del espectro multifractal, concepto ya definido en el capítulo anterior y cuyo cálculo en base a la transformada wavelet de módulo máximo es desarrollado en detalle en (Mallat, 1998). Los puntos principales de lo allí expuesto se resumen a continuación.

\section{Definición.}

Sea $S_{\alpha}$ el conjunto de todos los puntos de la señal donde la regularidad de la señal medida como exponentes de Lipschitz es igual a $\alpha$. El denominado espectro de singularidades 0 $D(\alpha)$ de una señal es la dimensión fractal de $S_{\alpha}$. Y llamaremos soporte del espectro a los valores de $\alpha$ tales que $S_{\alpha}$ es no vacío.

Cuando el soporte de $S_{\alpha}$ se restringe a un único valor tenemos los denominados multifractales homogéneos mientras que en los casos más habituales entre los que se 
encuentra nuestro campo de aplicación este soporte será mayor.

El procedimiento de cálculo de $D(\alpha)$ se resume en los siguientes puntos:

1. Sea $u[n]$ la posición de todos los puntos donde el módulo de la transformada wavelet continua alcanza máximos locales.

2. Calculamos la función de partición $Z$ que mide la suma elevada a la potencia $q$ de todos esos puntos de máximo según la ecuación:

$$
Z(q, s)=\sum_{s}\left|W f\left(u_{n}, s\right)\right|^{q}
$$

3. Para cada $q \in \mathbb{R}$ el denominado exponente de escalado mide la caída asintótica de la función de partición $Z(q, s)$ como:

$$
\tau_{q}=\lim _{s \rightarrow 0} \frac{\log Z(q, s)}{\log s}
$$

En este paso, de manera intuitiva podemos afirmar que, dado que $q$ selecciona un rango concreto de los máximos locales de la transformada wavelet $3^{3}$ la función de escalado captura la distribución de los puntos con diferentes valores de regularidad Lipschitz: los coeficientes bajos son capturados para $q$ muy negativos descartando los exponentes de alto valor dándose la situación opuesta para los coeficientes Lipschitz de alto valor.

4. Usando la transformada de Legendre obtenemos el espectro multifractal como (Mallat y Zhong, 1992):

$$
D(\alpha)=\min _{q}\left(q\left(\alpha+\frac{1}{2}\right)-\tau_{q}\right)
$$

El $D(\alpha)$ obtenido será siempre convexo por lo que en ocasiones (Tarquis y McInnes, 2005) se dice que una señal es multifractal cuando su espectro fractal existe y tiene la forma de una parabola invertida.

Destacar antes de mostrar los resultados obtenidos que el espectro $D(\alpha)$ está relacionado con otras caracterizaciones multifractales usadas a menudo como puede ser la dimensión fractal generalizada, calculada como:

$$
D_{q}=\frac{\tau_{q}}{q-1}
$$

Hay dos valores de $D_{q}$ especialmente relevantes. La dimensión fractal generalizada que se obtiene para $q=0$ proporciona el soporte de la señal y coincide con la dimensión topológica. Por su parte $D_{1}$ (obtenida aplicando la regla de L'Hopital en 5.43 proporciona la entropía de la señal. En concreto un valor cercano a 1.0 indica un sistema con discontinuidades uniformemente distribuidas en todas las escalas, mientras que a medida que se acerca a 0.0 indica la presencia de una escala donde se revelan gran parte de las singularidades.

Las siguientes figuras muestran este procedimiento aplicado a la escalera del diablo:

\footnotetext{
${ }^{3}$ Para $q<0$ la suma esta dominada por los puntos de módulo de pequeño valor absoluto, mientras que para $q<0$ la suma esta dominada por los puntos donde el módulo es grande
} 


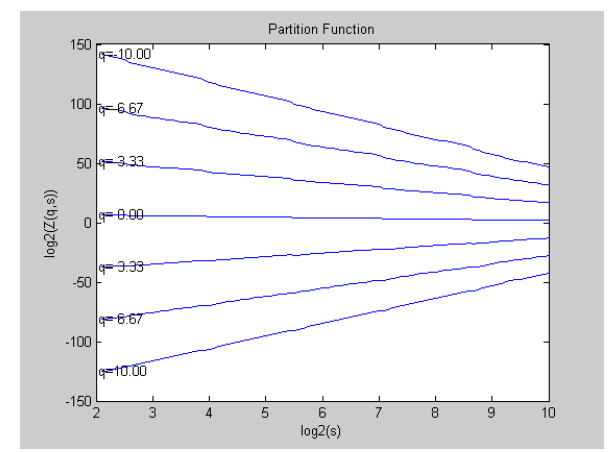

(a) Función de partición para distintos valores de $q$

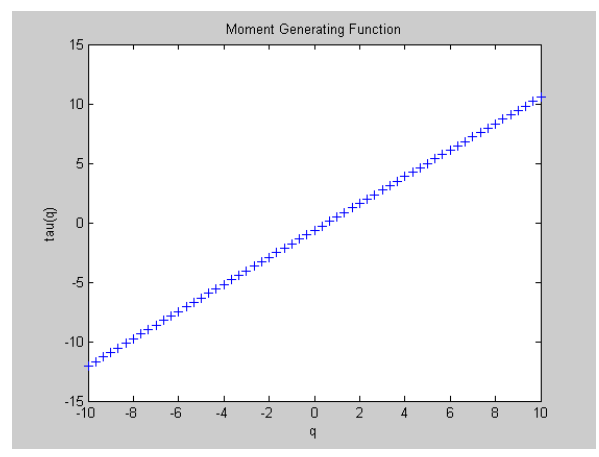

(b) Exponentes de escalado

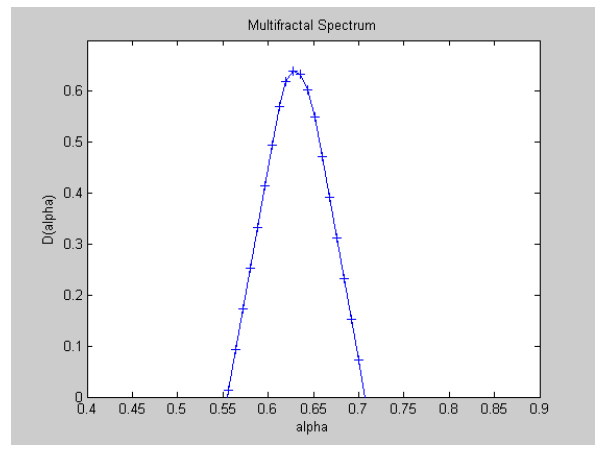

(c) $D(\alpha)$ calculado según 5.42

Figura 5.10: Cálculo del espectro fractal

\subsubsection{Aspectos de implementación y limitaciones del enfoque wa- velet}

En la implementación proporcionada en el paquete de software WaveLab de la simulación anterior, tomada del ejemplo proporcionado en (Mallat, 1998) destacan los siguientes aspectos prácticos:

1. La señal $x$ de partida o escalera del diablo es reflejada de forma simétrica partir de la muestra $n=4096$ resultando en la señal $x$ mostrada en la figura (5.11) que es analizada en 132 escalas con la transformada continua wavelet usando como wavelet de análisis el sombrero mexicano o mexican-hat como suele ser habitual al aplicar wavelets al formalismo multifractal (Muzy et al., 1993).

2. El principal problema de cálculo de espectros multifractales a partir de la transformada wavelet resulta ser la gran dependencia de las escalas consideradas para el análisis. En este caso se eligen de las 96 escalas las que van desde la 25 a la 84. Será de estas escalas de las que se busquen sus máximos locales y calculen las funciones de partición asociadas.

La necesidad de realizar una extensión simétrica es un requisito habitual en el procesamiento de señales pero el segundo punto revela el problema de este enfoque como es la gran dependencia de los resultados respecto de la escala de análisis elegida. 


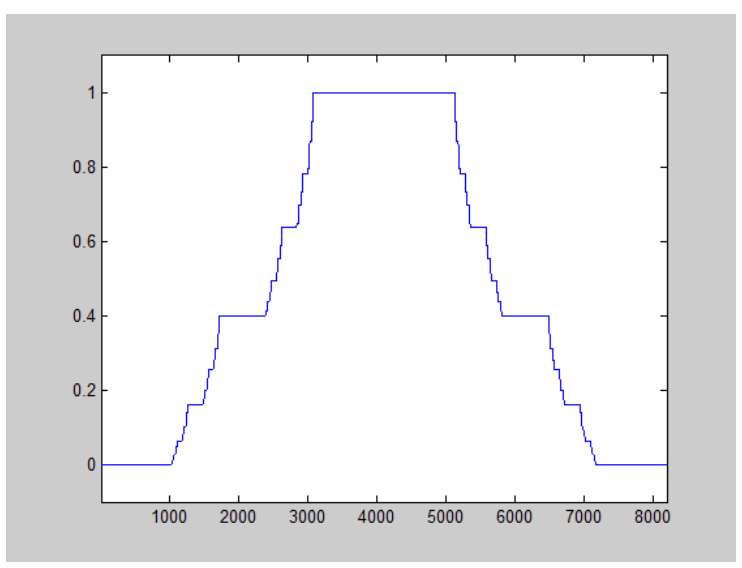

Figura 5.11: Extensión simétrica de la señal escalera del diablo

\subsection{Estimación del espectro multifractal desde los coefi- cientes wavelet}

Es importante observar que en la ecuación (5.40) como uno de los primeros pasos del procedimiento de cálculo de $D(\alpha)$ la información de las cadenas de máximo no se utiliza entrando sólo en juego el módulo de los coeficientes de la transformada wavelet en aquellos puntos donde esos coeficientes son máximos locales. Igualmente relevante es observar que la información local de las singularidades se pierde obteniendo únicamente una estimación global de los parámetros multifractales.

Se cumple además en el análisis de una señal correspondiente a una serie financiera o en una imagen de suelo agrícola como las que se utilizarán en este trabajo de tesis que si trazamos los valores del módulo de la transformada wavelet su variación a lo largo de las escalas depende tanto de la escala de análisis que es imposible computar un coeficiente de Lipschitz para esa singularidad como pendiente de ese módulo respecto de las escalas pues el resultado presenta una pendiente constante en modo alguno.

Estos hechos motivaron una línea de investigación que analizase la evolución del módulo de la transformada wavelet escala a escala derivando un coeficiente de Lipschiz para cada singularidad en cada una de las escalas de análisis tal como

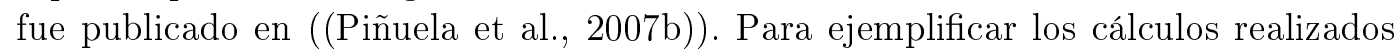
tomamos de nuevo como ejemplo la señal Escalera del diablo.

Sobre esta señal y tal como se comentaba en los aspectos de implementación, sobre su extensión simétrica calculamos una trasformada wavelet continua o CWT en las escalas diádicas $s=2^{j} \quad j=0,1, \ldots 5$. A continuación calculamos los máximos locales a cada una de las escalas. Y en esos puntos o máximos locales calcularemos la evolución del módulo de la transformada wavelet a largo de las escalas siempre y cuando en las escalas sucesivas exista al menos un máximo local con el que conectarse.

De esta evolución obtenemos el de coeficiente Lipschitz local de $x_{0}$ en la escala 
$2^{j}$ como: 4 relativo a la escala $j$ como:

$$
\alpha_{2^{j}}\left(x_{0}\right) \sim \log _{2}\left(\frac{M_{2^{j+1}}\left(x_{0}\right)}{M_{2^{j}}\left(x_{0}\right)}\right)
$$

Superponiendo los valores de $\alpha_{2^{j}}\left(x_{0}, y_{0}\right)$ para los puntos donde la transformada wavelet es máxima en al menos dos escalas consecutivas sobre la señal obtenemos la gráfica mostrada en 5.12 .

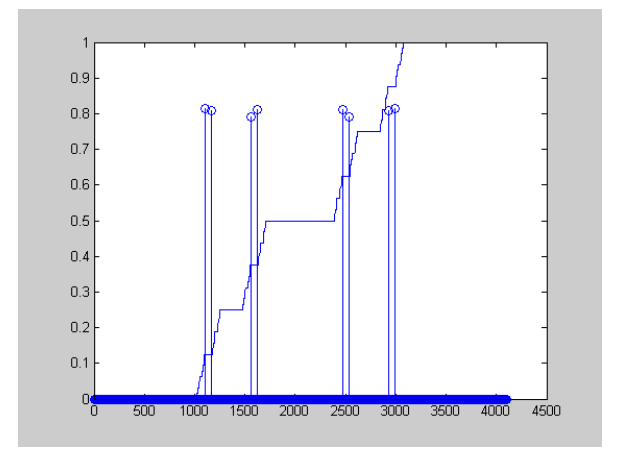

(a) Señal y singularidades locales para la escala $2^{3}$

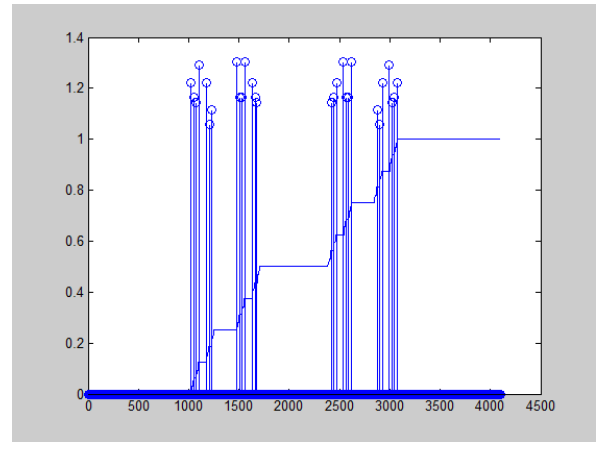

(b) Señal y singularidades locales para la escala $2^{1}$

Figura 5.12: Estimación directa del espectro fractal para la señal Escalera del diablo

Los valores obtenidos son muy significativos tanto en su valor medio como si calculamos el centroide de la distribución resultante de los coeficientes $\alpha$ con valor mayor que cero. Así en la escala más final se obtiene un valor medio de $\alpha_{m}=0,8065$ y un centroide de $\alpha_{c}=0,8068$ que resulta muy próximo al valor obtenido mediante análisis "box-count" en el capítulo anterior que fue $\alpha=0,7925$.

Si construimos una distribución de estas estimaciones de singularidad a lo largo de todas las escalas y posiciones para obtener una visión global de la estructura de la señal el valor de $\alpha$ para el cual la distribución alcanza un máximo es de $\alpha=0,735$ más cercano al valor teórico de $\alpha=0,6309$.

Este enfoque se relaciona directamente con la propuesta de (Struzik, 1999) donde sugiere un modelo genérico de multiplicación en cascada de los coeficientes de singularidad para obtener, siguiendo su notación, estimaciones locales del exponente de Hölder entre dos escalas según:

$$
\hat{h}_{s_{l o}}^{s_{h i}}=\frac{\log \left(W f \omega_{p b}\left(s_{l o}\right)\right)-\log \left(W f \omega_{p b}\left(s_{h i}\right)\right)}{\log \left(s_{l o}\right)-\log \left(s_{h i}\right)}
$$

Donde denotamos con $s_{h i}$ a la escala más fina de análisis y con $W f \omega_{p b}(s)$ al valor de la transformada wavelet en la escala $s$ sobre la línea de máximo $\omega_{p b}$.

Para seguir investigando al validez del enfoque el siguiente paso será analizar la extensión de este análisis a imágenes y en concreto a los "Sierpinski carpets" ya

\footnotetext{
${ }^{4}$ Recordar de nuevo que utilizamos indistintamente coeficiente de Lipschitz o exponente de Hölder para referirnos a la estimación de la regularidad o singularidad local de una señal; el la primera denominación es más propia de la literatura wavelet mientras que la segunda es más habitual en el campo del análisis multifractal
} 
analizados en el capítulo anterior en simulaciones realizadas con análisis multifractal clásico.

Pero antes, y desde el punto de vista teórico es importante relacionar este enfoque también con el trabajo de (Zhong y Ning, 2005) en el que al igual que en el trabajo previamente mencionado de (Struzik, 1999) se mencionan los problemas en trazar la líneas de máximo cuando las singularidades de la señal no están aisladas. Estos problemas son más relevantes aún en el caso de imágenes como las que serán objeto de estudio en este trabajo de tesis. Por ello, (Zhong y Ning, 2005) propone realizar una estimación de los coeficientes Lipschitz en cada escala siguiendo la ecuación (5.46) que supone la extensión de (5.44) al caso de dos dimensiones:

$$
\alpha_{2^{j}}\left(x_{0}, y_{0}\right) \sim \log _{2}\left(\frac{M_{2^{j+1}}\left(x_{0}, y_{0}\right)}{M_{2^{j}}\left(x_{0}, y_{0}\right)}\right)+1
$$

La diferencia de nuestro enfoque es que restringimos el cálculo 5.46, tal y como comentamos sólo a puntos de módulo máximo que puedan ser conectados con otros puntos de las mismas características en al menos una escala. De este modo el método propuesto se sitúa en una posición intermedia entre el enfoque de (Zhong y Ning, 2005) y (Struzik, 1999).

Analizando primero el caso monofractal se muestra en la figura (5.13) la imagen original y el módulo de la transformada continua wavelet en tres escalas sucesivas correspondiente a la parte superior derecha, inferior izquierda e inferior derecha respectivamente.
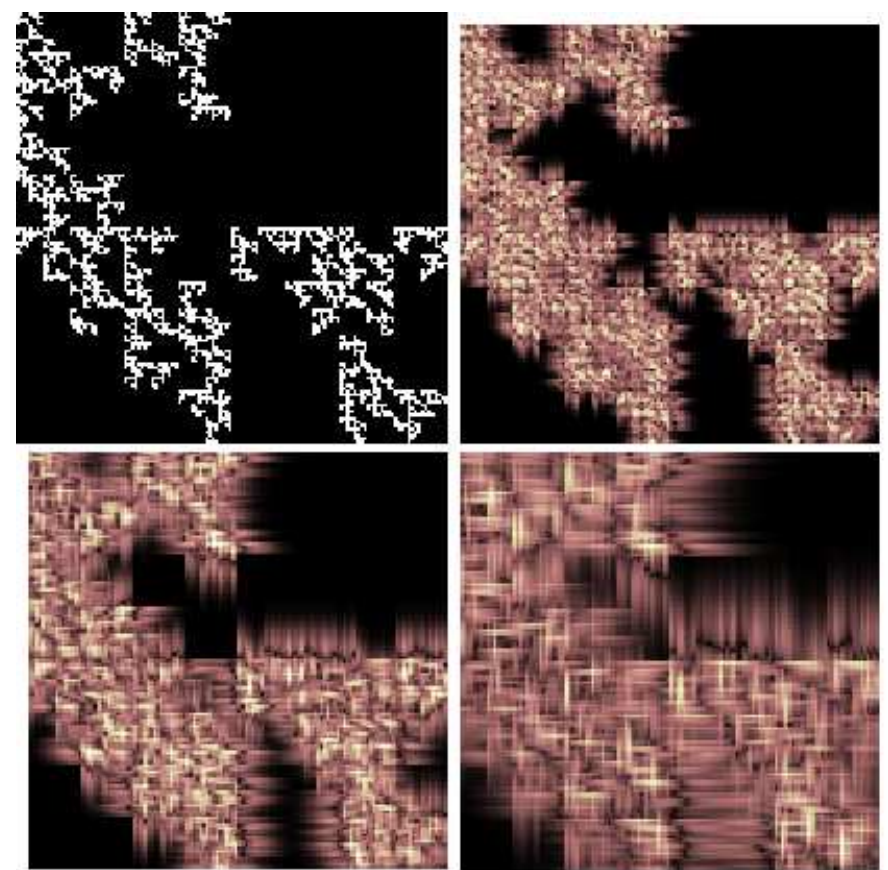

Figura 5.13: Sierpinski monofractal y transformada wavelet continua

Aplicando la ecuación (5.46) se obtienen las imágenes (5.14) o mapas de $\alpha$ locales: 

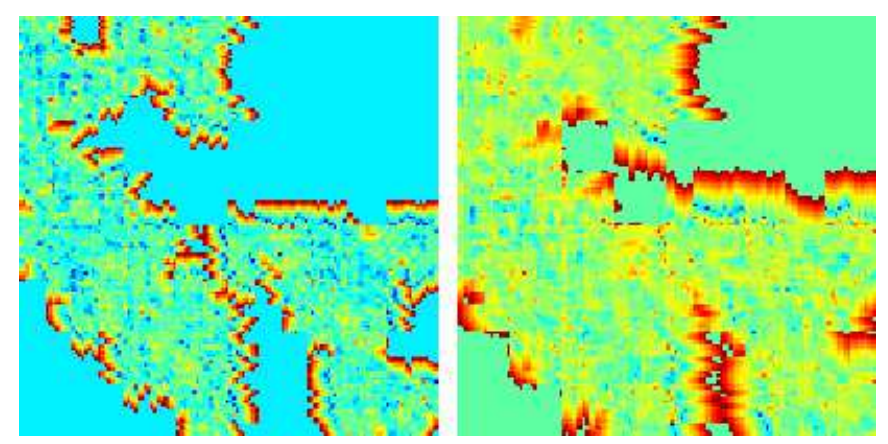

Figura 5.14: Sierpinski monofractal. Mapas de $\alpha$

Numéricamente se obtienen los siguientes resultados para el caso monofractal (valor teórico $\alpha_{c}=1,5850$ ):

- Para la escala más de detalle:

- $\alpha_{m}=1,67821$

- $\alpha_{c}=1,67821$

- Para la segunda escala ${ }^{5}$

- $\alpha_{m}=1,6731$

- $\alpha_{c}=1,6739$

Y en el caso multifractal se tiene:

- Para la escala más de detalle:

- $\alpha_{m}=1,9030$

- $\alpha_{c}=1,9033$

- Para la segunda escala ${ }^{6}$

- $\alpha_{m}=1,8503$

- $\alpha_{c}=1,8506$

La coherencia de estos resultados y la potencia que ofrece su interpretación para realizar tanto un análisis global como escala a escala son la base de los experimentos principales de este trabajo de tesis, resultados que se describen en los siguientes dos capítulos de este trabajo de tesis.

\footnotetext{
${ }^{5} \mathrm{Al}$ trabajar con una imagen de baja resolución como es $128 \mathrm{x} 128$ pixeles sólo analizamos en tres escalas

${ }^{6} \mathrm{Al}$ trabajar con una imagen de baja resolución como es $128 \times 128$ pixeles sólo analizamos en tres escalas
} 



\section{Capítulo 6}

\section{Análisis Multiescala de Series Financieras}

\subsection{Introducción}

Lo que podríamos llamar teoría financiera tiene como uno de sus principales objetivos entender cómo funcionan los mercados de valores capturando la esencia del proceso que conforma cada valor. Las distintas evidencias empíricas respecto de las propiedades estadísticas de estas series son la base de modelos y predicciones sobre los valores y por tanto un aspecto clave en la economía actual.

En el ámbito de este trabajo de tesis el interés esta en describir las propiedades multiescala de las series financieras, aspecto de reciente interés en la literatura sobre el tema con (Matteo et al., 2005) y (Morales et al., 2012) como referencias destacadas. La extrema complejidad de las series financieras como señales hacen que sea un ámbito adecuado para un enfoque multiescala o multifractal pues las singularidades ocurren continuamente e incluso los eventos más extremos, que hacen variar el valor de la serie de forma abrupta ocurren con una probabilidad bastante mayor que lo que permite modelar distribuciones gaussianas u otras técnicas habituales cuando se analizan señales en gran medida regulares.

Conocer esta probabilidad de los eventos más extremos es esencial para la gestión de riesgos como puede ser en la predicción de bancarrota, aspecto que está siendo investigado siguiendo un enfoque basado principalmente en redes neuronales por el autor de este trabajo de tesis en (de la Barcena et al., 2010) y (Cedeno et al., 2011).

En el contexto de las series financieras el comportamiento multiescala que pretendemos caracterizar estará relacionado con la volatilidad de la serie o valor (Bouchaud y Potters, 2003). En una definición en términos financieros, la volatilidad es una medida de la frecuencia e intensidad de los cambios del precio de un activo o de un tipo y es definida en primera instancia como la desviación estándar de dicho cambio en un horizonte temporal específico. Se usa por tanto, con frecuencia para cuantificar el riesgo asociado al valor.

$\mathrm{Al}$ representar incertidumbre y riesgo puede analizarse como un aspecto negativo, pero sin embargo, es un aspecto calve para obtener beneficio si se vende en los picos y se compra en las bajas y mayor será el beneficio cuanto más alta sea la volatilidad.

En los últimos años el método más utilizado para este tipo de análisis es el 
denominado DFA (Detrended Fluctuation Analysis) iniciado en (Kantelhardt et al. 2001) como forma de detectar las propiedades monofractales de series financieras y detectar correlaciones a largo plazo en series ruidosas y no estacionarias y que derivo en su variante multifractal descrita en (Kantelhardt et al., 2002). Otras referencias habituales en el análisis de series ruidosas son (Hu et al., 2001) y en campos específicos es muy interesante citar como referencias a (Buldyrev et al., 1995) en el campo del análisis de ADN, (Ivanov et al., 1996) y (Bunde et al., 2000) en el análisis de electrocardiogramas o (Koscielny-Bunde et al., 1998) en registros metereológicos,

\subsection{Estimación de la volatilidad sobre el mercado de va- lores Dow-Jones}

Como punto de referencia para el estudio a realizar se tomo la implementación de cálculo de volatilidad de (Han, 2011) partiendo de distintos valores del índice Dow Jones con 1 año de antigüedad y con estimaciones de volatilidad en un horizonte temporal de una semana ( 7 valores) obtenidos con fecha 8 de Diciembre de 2015 .

De los 31 valores del Dow Jones analizados los casos extremos de volatilidad con fecha fueron en el caso de mínima volatilidad el valor de UTX (United Technologies Corporation) con una volatilidad a 7 días de $v=0,1425$ y para máxima volatilidad el valor de UNH (United Health Care) con $v=0,3303$.

Ambos índices normalizados de forma que sus valores de cierre diarios tomen valores entre 0 y 1 se muestran en la figura (6.1).

Si aplicamos las técnicas de análisis de singularidades wavelets basadas en la transformada continua y las líneas de máximo no se consigue el resultado esperado pues cada valor representa una discontinuidad respecto del siguiente. Igualmente si aplicamos técnicas multifractales el comportamiento de la serie no responde en modo alguno. Por ejemplo, aplicando el método "boxcount" resulta en un valor aproximadamente constante de dimensión fractal igual a 1 para todas las escalas para cualquiera de estas señales, no pudiendo por tanto cuantificar la volatilidad mediante estos métodos.

Así que directamente se aplican las técnicas de estimación del espectro multifractal a partir de los coeficientes wavelets de las distintas escalas. Numéricamente los resultados obtenidos son coherentes con el algoritmo de referencia utilizado en cada una de las cotizaciones analizadas:

- Para UTX se obtiene $\alpha_{m}=0,2300$ y $\alpha_{c}=0,2275$

- Para UNH se obtiene $\alpha_{m}=0,2309$ y $\alpha_{c}=0,2304$

Donde con $\alpha_{m}$ denotamos el valor medio de los coeficientes de Lipschitz mayores que 0 y con $\alpha_{c}$ al centroide de la distribución en modo de histograma de esos mismos coeficientes. Dado que ambos valores son muy aproximados en los análisis realizados en la tabla (6.1) se muestra la comparación entre la estimación dada por la referencia (Han, 2011) con $\alpha_{m}$. 


\begin{tabular}{|l|l|l|}
\hline Símbolo & Volatilidad & $\alpha_{m}$ \\
\hline MMM & 0.1871 & 0,2044 \\
\hline AXP & 0.1445 & 0,1573 \\
\hline AAPL & 0.2395 & 0,1839 \\
\hline BA & 0.1915 & 0,1991 \\
\hline CAT & 0.2399 & 0,2399 \\
\hline CVX & 0.2714 & 0,2239 \\
\hline CSCO & 0.1907 & 0,2069 \\
\hline KO & 0.1657 & 0,2337 \\
\hline DD & 0.1912 & 0,2559 \\
\hline XOM & 0.2394 & 0,2385 \\
\hline GE & 0.1516 & 0,2613 \\
\hline GS & 0.3189 & 0,1918 \\
\hline HD & 0.2341 & 0,2180 \\
\hline IBM & 0.1493 & 0,2078 \\
\hline INTC & 0.2420 & 0,2089 \\
\hline JNJ & 0.1902 & 0,1908 \\
\hline JPM & 0.2740 & 0,2278 \\
\hline MCD & 0.1610 & 0,2254 \\
\hline MRK & 0.3104 & 0,2386 \\
\hline MSFT & 0.2448 & 0,2509 \\
\hline NKE & 0.2619 & 0,2393 \\
\hline PFE & 0.2548 & 0,2173 \\
\hline PG & 0.2046 & 0,2318 \\
\hline TRV & 0.2665 & 0,2490 \\
\hline TWTR & 0.2822 & 0,2706 \\
\hline UNH & 0.3303 & 0,2309 \\
\hline UTX & 0.1425 & 0,2300 \\
\hline VZ & 0.2023 & 0,2232 \\
\hline V & 0.2319 & 0,2421 \\
\hline WMT & 0.1958 & 0,2482 \\
\hline DIS & 0.2972 & 0,2083 \\
\hline & & \\
& & \\
\hline
\end{tabular}

Tabla 6.1: Estimación de la volatilidad del índice Dow Jones según (Han, 2011) y estimación directa mediante coeficiente wavelets 


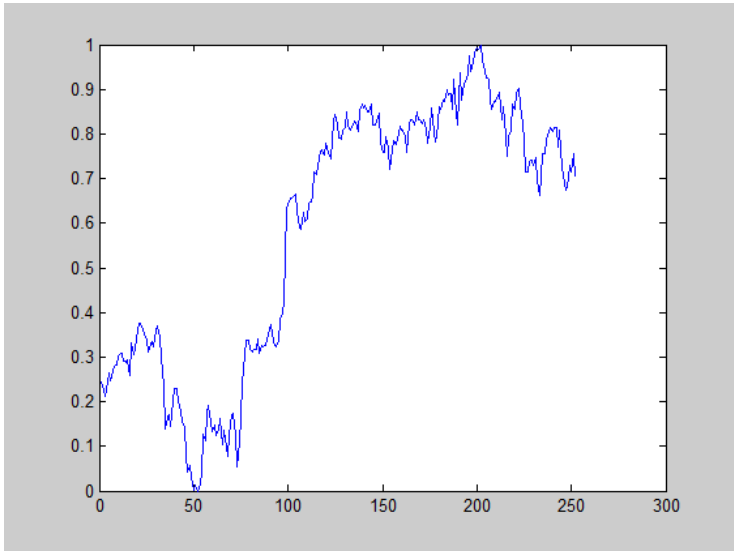

(a) Cotización de UTX

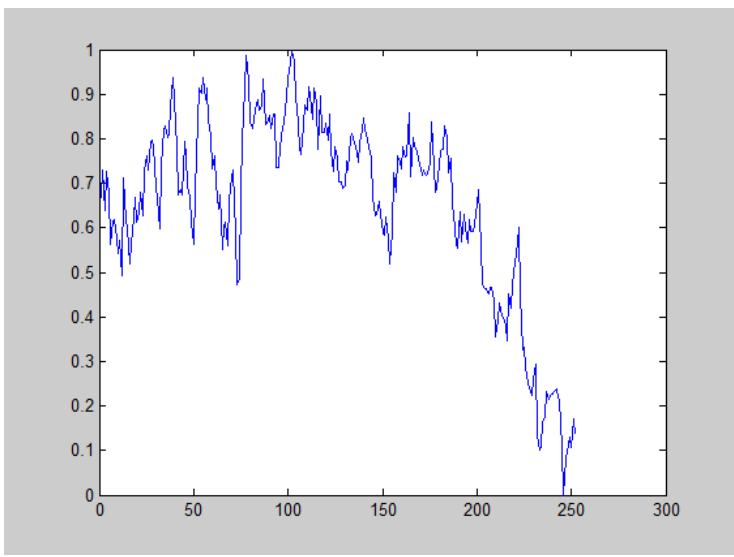

(b) Cotización de UNH

Figura 6.1: Valores normalizados de mínima y máximo volatilidad del índice Dow Jones 
La representación gráfica de la figura $\sqrt{6.2}$ muestra la comparación de los valores reflejados en 6.1):

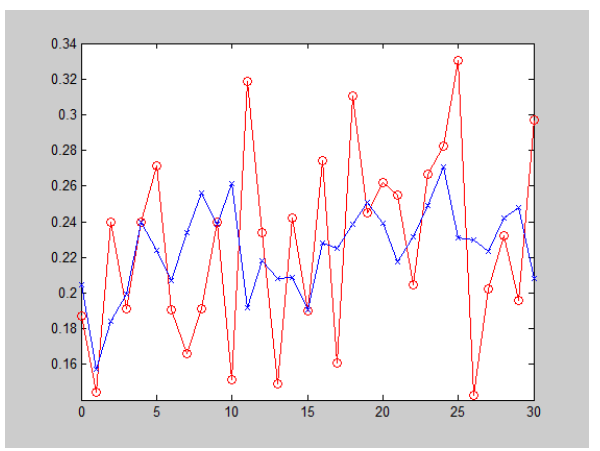

Figura 6.2: Comparación de las estimaciones de volatilidad de método de referencia (rojo) y basado en wavelets (azul)

Las siguientes figuras (6.3) y 6.4 muestran superpuestas las series analizadas y los mapas de $\alpha$ locales correspondientes a la escala de análisis utilizada. 


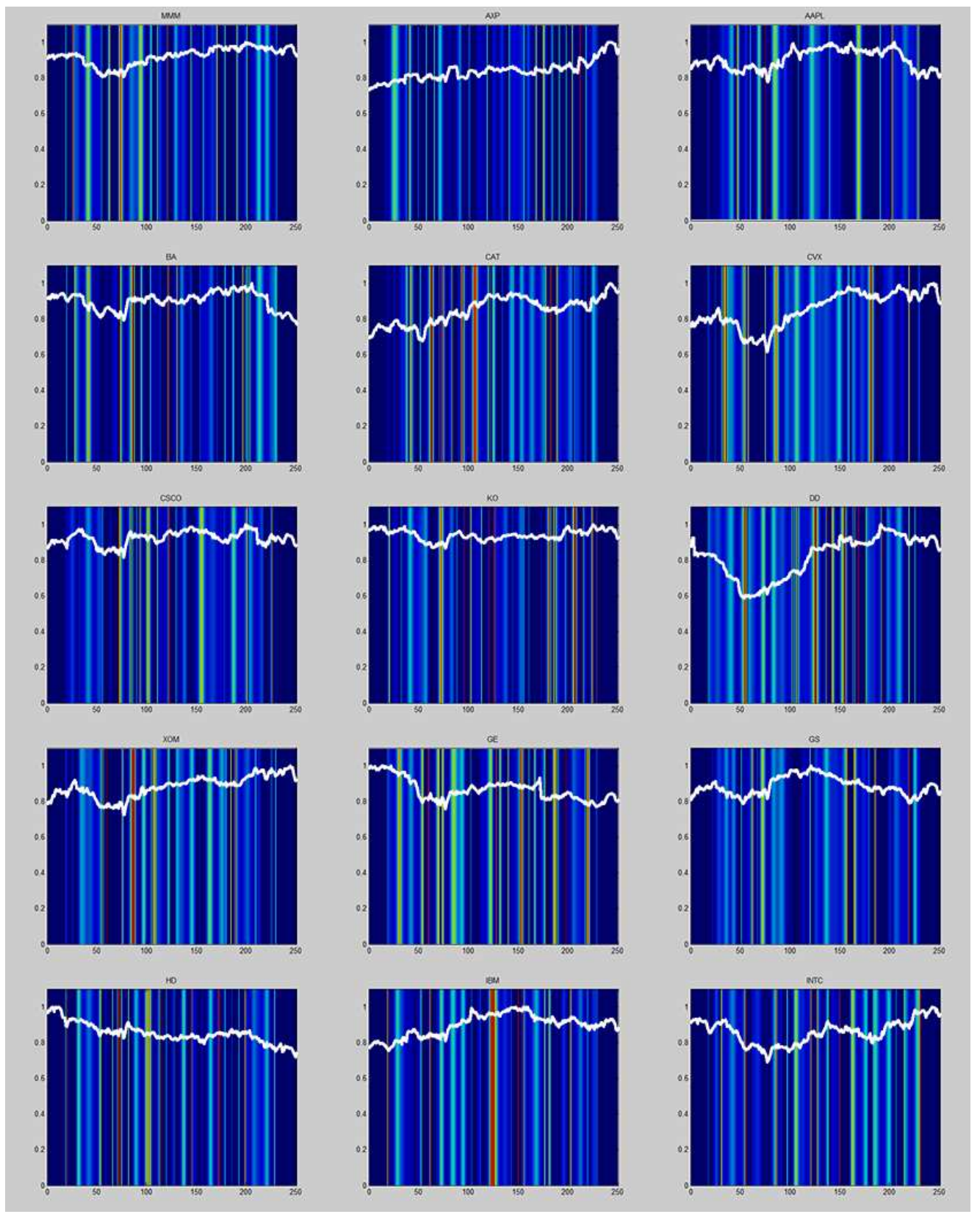

Figura 6.3: Estimación de volatilidad a partir de coeficientes locales para el índice Dow Jones (1 de 2) 

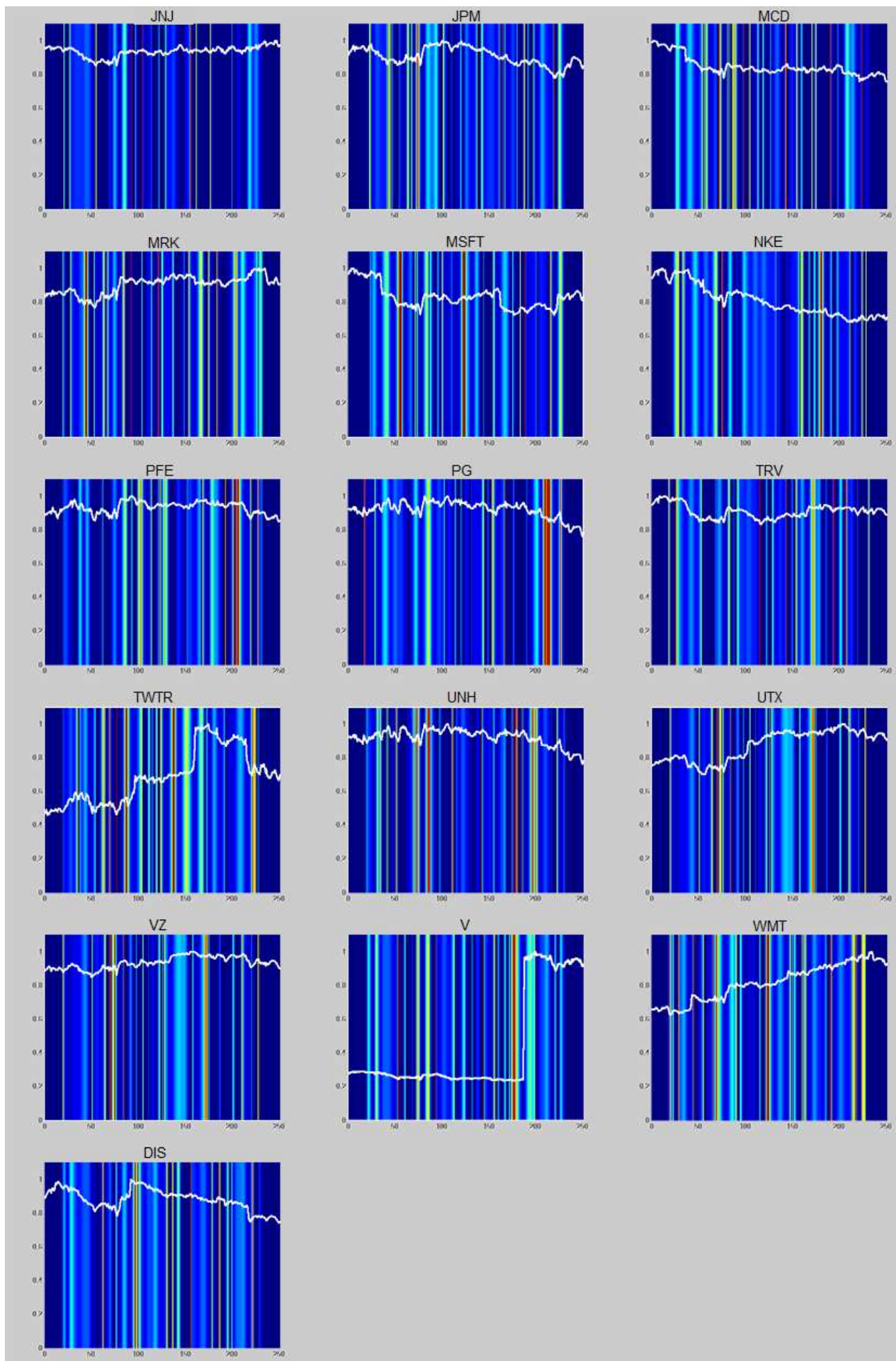

Figura 6.4: Estimación de volatilidad a partir de coeficientes locales para el índice Dow Jones (2 de 2$)$ 
Resulta interesante analizar con más detalle los índices correspondientes a los casos donde se genera una mayor diferencia entre ambos métodos y los casos extremos para el método desarrollado.

Así resulta extraño que en el método de referencia el valor de máxima volatilidad sea el de UNH cuando existen otros valores con variaciones visualmente mucho más significativa como puede ser el valor de Twitter Inc. (TWTR) que aún siendo caracterizado con alta volatilidad en el método de referencia no es en modo alguno uno de los valores caracterizados como de mayor riesgo.

Parecido es el resultado respecto del valor mínimo que como decíamos se corresponde con UTX y que en el método desarrollado e incluso visualmente parece de cierto riesgo. En cambio, en el método desarrollado el mínimo valor resulta para el índice de American Express Company (AXP). En este caso, ambos métodos reflejan un bajo valor de volatilidad como resulta esperable en base al análisis visual del índice, al tratarse sin duda de uno de los más estables de los analizados.

La comparación de los histogramas obtenidos para estos valores mencionados que en uno o en otro método resultan en mínimos y máximos de volatilidad se muestran en la figura 6.5).

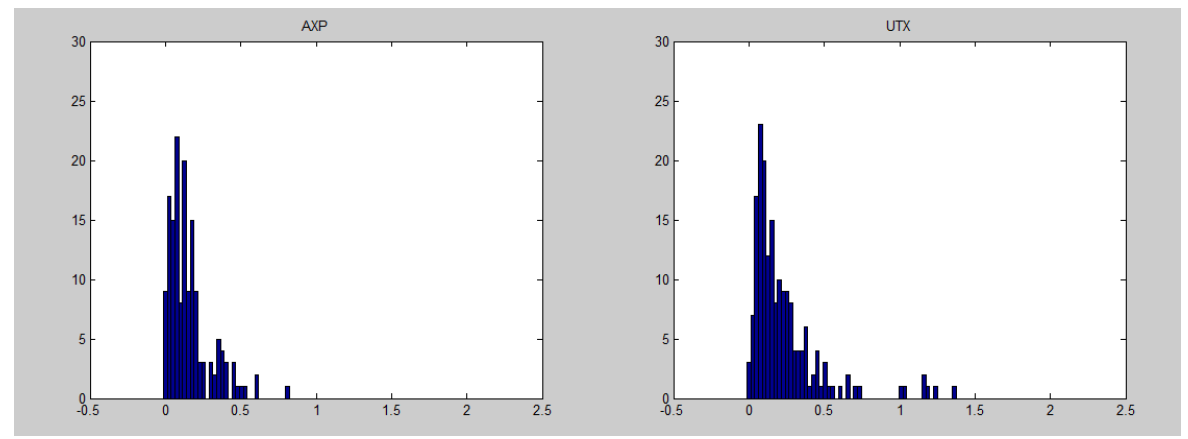

(a) Mínima volatilidad: AXP y UTX

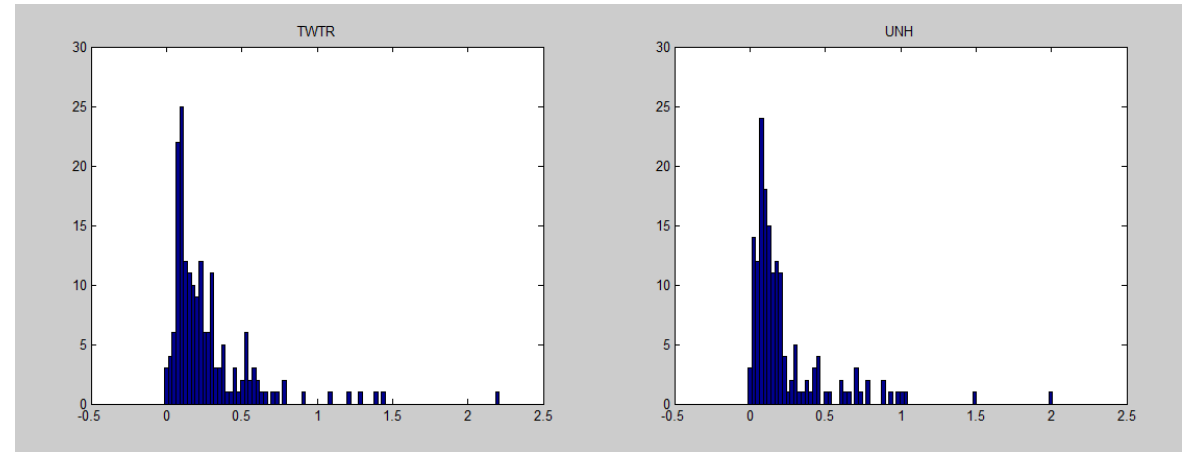

(b) Máxima volatilidad: TWTR y UNH

Figura 6.5: Comparación entre los índices reportados como de mínima y máxima volatilidad

Por último mostramos el histograma del índice correspondiente a GS, The Goldman Sachs Group, Inc en la figura (6.6) donde se aprecia la mayor diferencia entre ambos métodos. En la gráfica de mapa de $\alpha$ este índice tanto en la evolución temporal como en el mapa de $\alpha$ es especialmente regular por lo que se considera más 
adecuado el resultado reportado en nuestra propuesta. El histograma mostrado, de hecho, tiene una estructura más parecida a los casos de mínima volatilidad como AXP y UTX que a los índices más volátiles.

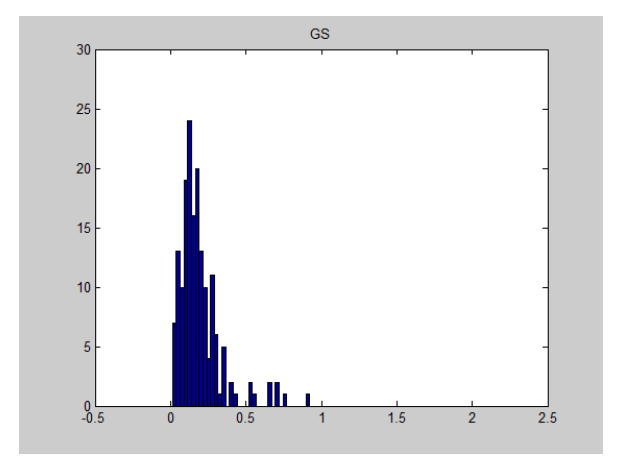

Figura 6.6: Histograma de coeficientes de Lipschitz locales para el índice GS (The Goldman Sachs Group, Inc)

Visto todo lo anterior y como cierre de este apartado decir por tanto, que la estimación de la volatilidad realizada a partir de los coeficientes Lipschitz de la señal permite extraer las siguientes conclusiones:

1. Al igual que otros métodos puede ofrecer un único valor representativo de la volatilidad de un índice bursátil medido como valor medio de los coeficientes de Lipschitz. El valor reportado ofrece interesantes resultados cuantitativamente.

2. Permite una representación que refleja gráficamente y permite detectar a lo largo del tiempo la existencia de eventos especialmente significativos o la ausencia de los mismos.

3. La representación en forma de histograma de los coeficientes obtenidos, al proporcionar información análoga al del espectro multifractal informa de la distribución probabilística de que cambios más o menos abruptos sucedan en cada una de las series y dentro de que rango de cambio, como se comentó al comparar los histogramas respectivos de United Technologies Corporation (UTX) y United Health Care (UNH). 



\section{Capítulo 7}

\section{Cuantificación Multifractal de Suelos Agrícolas}

\subsection{Análisis wavelet de imágenes de suelos agrícolas ob- tenidas por tintes}

El experimento principal desarrollado durante este proyecto de tesis y aplicación principal del cálculo del espectro multifractal mediante wavelets ha sido el análisis de imágenes agrícolas resultando en diferentes publicaciones realizadas en congresos y revistas internacionales desde el año 2006.

La investigación realizada fue soportada por la "Comisión Interministerial de Ciencia y Tecnología-CICYT" como parte del proyecto AGL2006-12689/AGR, por la Comunidad Autónoma de Madrid y la Universidad Politécnica de Madrid (UPM) como parte del proyecto Rp5/11261.

El punto de arranque para la investigación es el artículo (Tarquis y McInnes, 2005) liderado por la codirectora de esta tesis Ana María Tarquis que se describe en primer lugar. En él se analiza la estructura multiescala de imágenes de suelos arcillosos.

\subsubsection{Análisis de suelos arcillosos mediante imágenes}

Partimos de distintos experimentos realizados con infiltraciones de tintes sobre suelos arcillosos con el objetivo de determinar su variabilidad, su porosidad espacial y la existencia de las denominadas vías preferenciales.

La estimación de estas características es clave para evaluar el transporte de agua y sustancias químicas como elementos principales para el cultivo siendo por tanto un aspecto de importancia fundamental en la Hidrología.

Sin querer profundizar en esta ciencia, decir que está ampliamente aceptado que en la gran mayoría de tipos de suelos el agua y las distintas sustancias fluyen fundamentalmente a través de vías preferenciales. Por ello, su variabilidad espacial determinadas a través de experimentos basados en tintar el suelo a distintas profundidades es clave para determinar si y con qué velocidad las sustancias alcanzan capas cada vez más profundas del suelo analizado (Heuvelman y McInnes, 1997). En concreto a más espaciados que estén las vías preferenciales, más rápido el flujo y en consecuen- 
cia menos posibilidades hay de absorción y / o degradación de un contaminante que llegará de esta forma a las capas más profundas del suelo (Lin et al., 1996).

Los experimentos con trazas de colorantes eran usados habitualmente para estudiar estas distribuciones de vías preferenciales en estudios como (Flury y Fluhler, 1994) y (Flury y Fluhler, 1995). El enfoque más habitual para describir los patrones formados por el tinte es analizar la variación vertical a distintas profundidades de la cobertura que el tinte supone en cada superficie.

En la publicación (Tarquis y McInnes, 2005) y en la primera publicación relacionada con el objetivo principal de este trabajo de tesis (Piñuela et al., 2007b), las imágenes fueron obtenidas a partir de un experimento realizado en Texas, en una superficie de cinco hectáreas dedicada a la investigación agrícola. El tipo de suelo elegido es usado fundamentalmente para plantar algodón, maíz, distintos tipos de grano y pastos enriquecidos. El experimento se realizó después de la cosecha del maíz sobre una parcela labrada de $2 \times 2$ metros.

La parcela fue regada durante varios días para establecer un nivel uniforme y estable de humedad, momento en el cual fue regada con una disolución de 30 gramos por litro de agua del colorante denominado "Azul brillante FCP" de uso habitual en la industria alimentaria. Seis días después de realizado el riego con esta sustancia se excavaron secciones paralelas horizontales separadas entre ellas por 5 centímetros hasta que ya no se encontrase resto de tinte. De este modo y para el experimento realizado resultaron 15 secciones (16 contando la primera capa de superficie) que fueron fotografiadas en el momento de la excavación con una resolución de 2048x2048 pixeles de manera que cada pixel representa una superficie algo menos que $1 \mathrm{~mm}^{2}$. El valor de cada pixel puede ser negro (superficie tintada) o blanco (superficie no alcanzada por el tinte).

Como ejemplo de las imágenes así obtenidas se muestran a continuación dos de las secciones. En concreto las correspondientes a las profundidades de $20 \mathrm{~cm}$ y 30 $\mathrm{cm}$.

Tal y cómo muestras estas imágenes y es lo más frecuente, este tipo de imágenes formadas a partir de cómo el tinte fluye por las distintas capas de un suelo, siguen un patrón impredecible en el detalle, pero predecible en el sentido de que las escalas más pequeñas del patrón, convenientemente ampliadas, son estadísticamente similares a escalas mayores de un mismo patrón. Se trata por tanto de una similitud estadística propicia para aplicar un formalismo multifractal. El trabajo de (Pachepsky et al. 2000), (Kravchenko et al., 1999) o (Posadas et al., 2003) documenta ampliamente los resultados obtenidos al aplicar esta metodología a distintos tipos de suelos utilizando formalismos multifractales.

Una vez establecido el enlace entre este tipo de imágenes y el formalismo multifractal el principal experimento de este trabajo de tesis quedo establecido, en primer lugar, en investigar este enlace desde el punto de vista de las similitudes, ventajas e inconvenientes que el formalismo multifractal clásico o el basado en transformadas wavelets ofrecen en el análisis de este tipo de imágenes. 

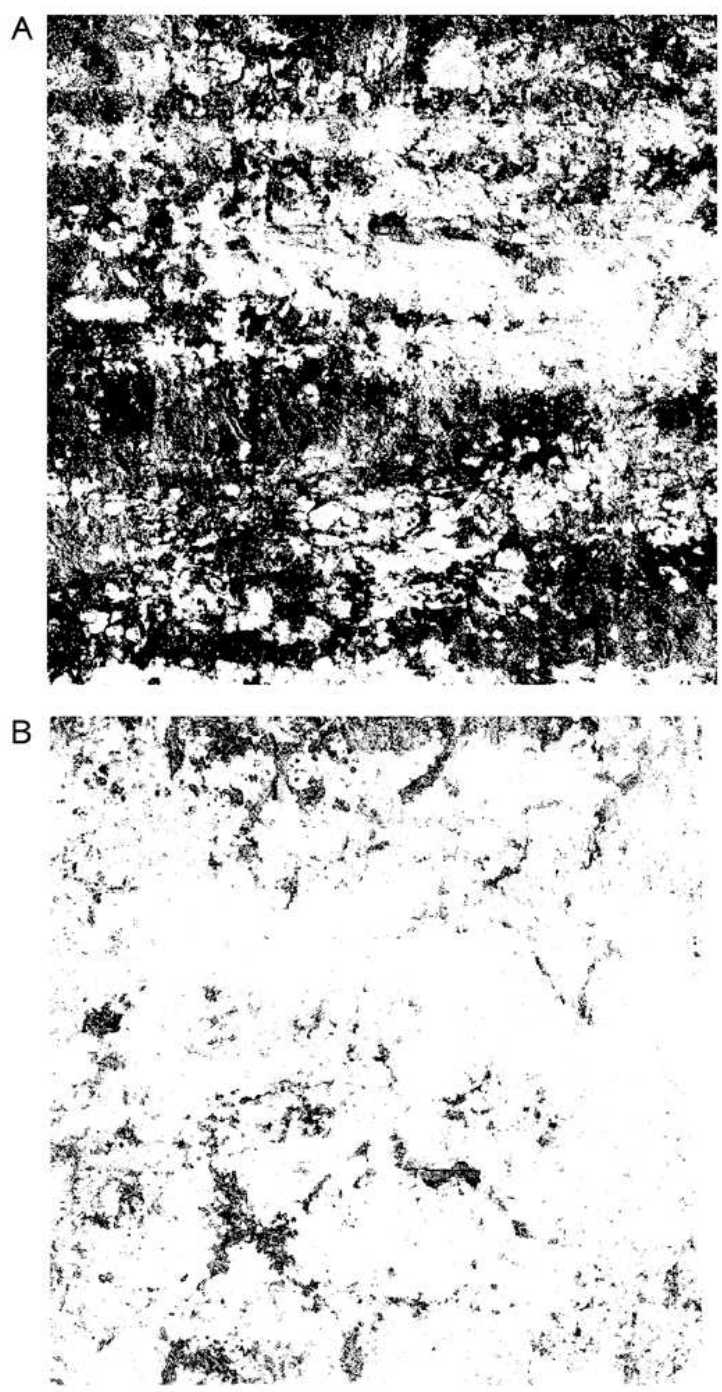

Figura 7.1: Imágenes de suelos tintados a diferentes profundidades (A) $20 \mathrm{~cm}$ y (B) $30 \mathrm{~cm}$ 


\subsubsection{Análisis multifractal sobre la imagen de cada sección}

En los primeros estudios que sobre la estructura del suelo se realizaron se seguía fundamentalmente un enfoque monofractal, siendo desde el punto de vista matemático una aproximación demasiado sencilla dada la complejidad y heterogeneidad en el comportamiento observado en las variaciones del suelo (Kravchenko et al. 1 1999).

Por ello a lo largo de los años se han ido sucediendo aproximaciones multifractales entre las que destacan por ejemplo (Folorunso et al., 1994) y (Muller, 1996).

La primera aproximación para aplicar la metodología multifractal a los suelos del experimento consiste en analizar cada una de las imágenes por separado en busca de patrones dependientes de la escala. En este sentido al ser imágenes de únicamente dos niveles las metodologías wavelets no resultan especialmente adecuadas y se muestran sólo los resultados obtenidos al aplicar el formalismo multifractal visto.

Así la figura 7.2 muestra las funciones de partición en escalas bi-logarítmicas para las secciones mostradas anteriormente (de profundidades 20 y $30 \mathrm{~cm}$ ). En ambos casos se observa un patrón claro en dos zonas diferentes. Una primera con una relación lineal entre escala y función de partición y una segunda con pendiente prácticamente constante. Es por tanto la zona de escalas grandes donde esa relación lineal demuestra la existencia de un comportamiento fractal en las imágenes obtenidas.

Por su parte, los resultados obtenidos al aplicar el formalismos multifractal clásico se muestran a su vez en las figuras 7.3 y $(7.3)$, donde lo mas noticeable es la diferencia entre computar la dimensión fractal generalizada sobre todas las escalas (ya mencionábamos que las funciones de partición no correspondían a un comportamiento multifractal propiamente dicho) o sólo al rango de escalas donde la función de partición muestra pendientes constantes. 

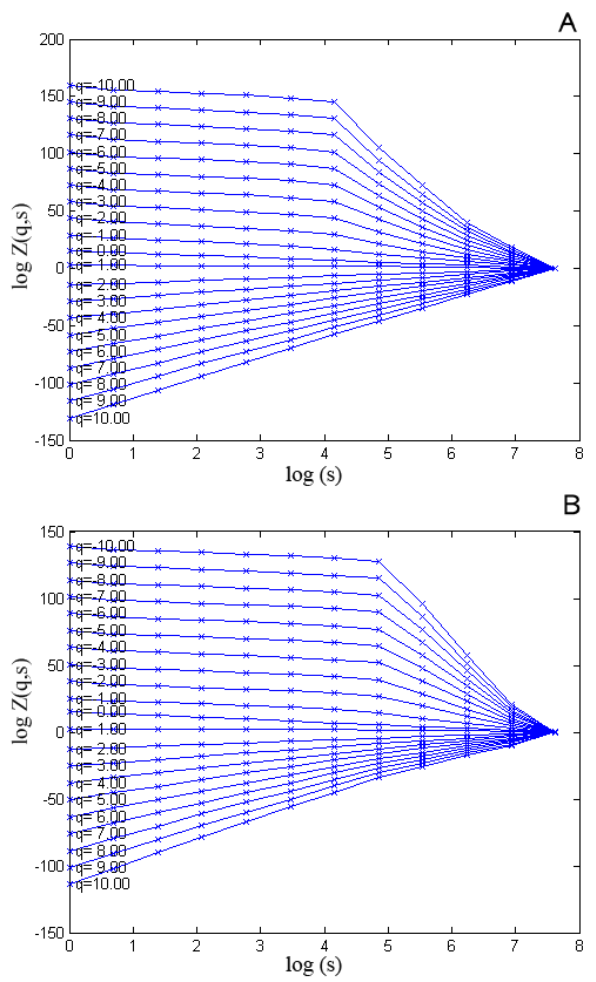

Figura 7.2: Función de partición en función de la escala para (A) $20 \mathrm{~cm}$ y (B) $30 \mathrm{~cm}$ 


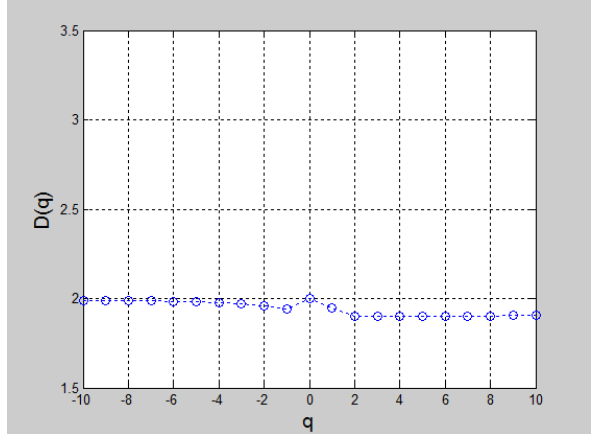

(a) Dimensión fractal generalizada $D_{q}$

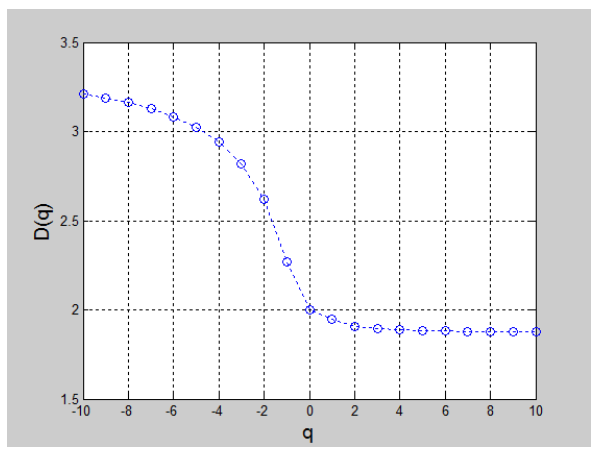

(c) Dimensión fractal generalizada $D_{q}$ restringida a 7 puntos

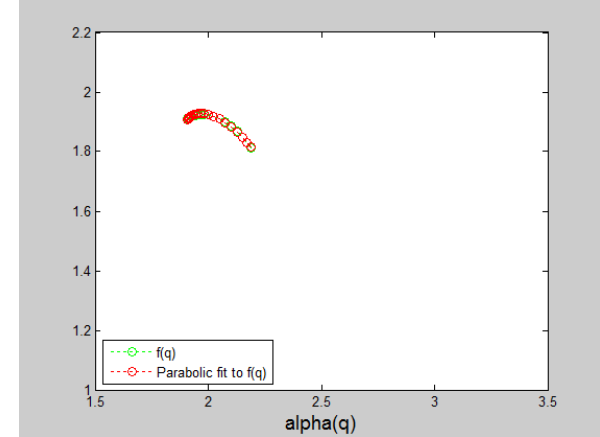

(b) Espectro multifractal método directo

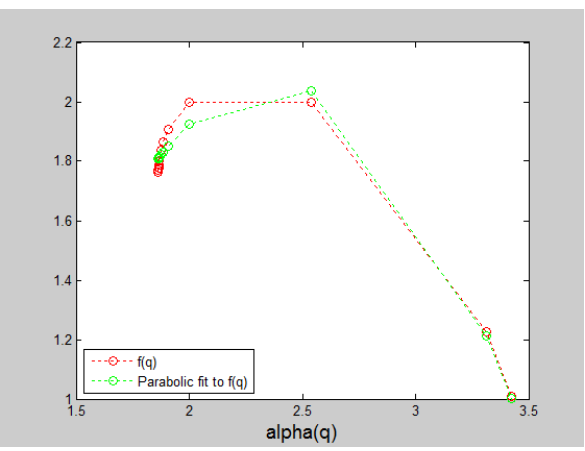

(d) Espectro multifractal "box-counting" restringida a 7 puntos

Figura 7.3: Formalismo multifractal aplicado a imagen de profundidad $20 \mathrm{~cm}$ 


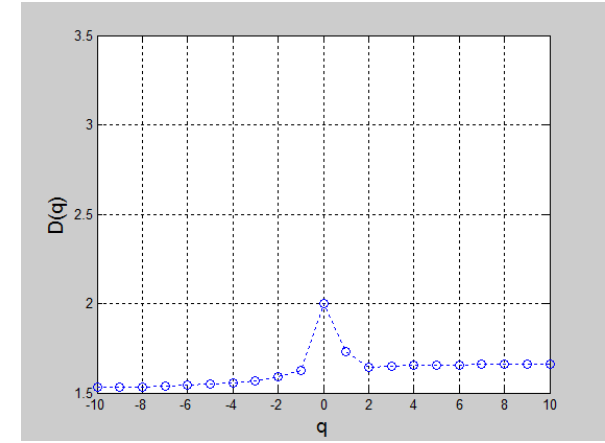

(a) Dimensión fractal generalizada $D_{q}$

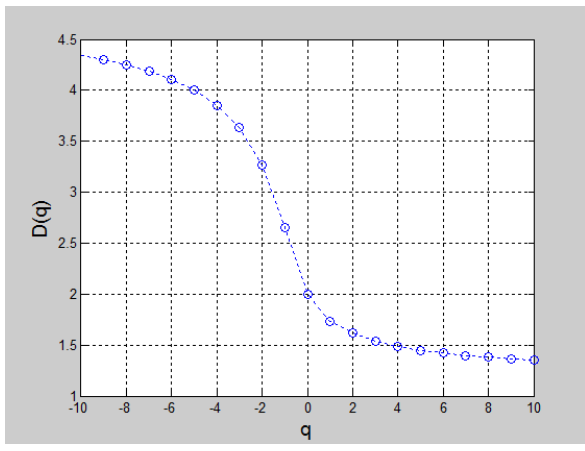

(c) Dimensión fractal generalizada $D_{q}$ restringida a 5 puntos

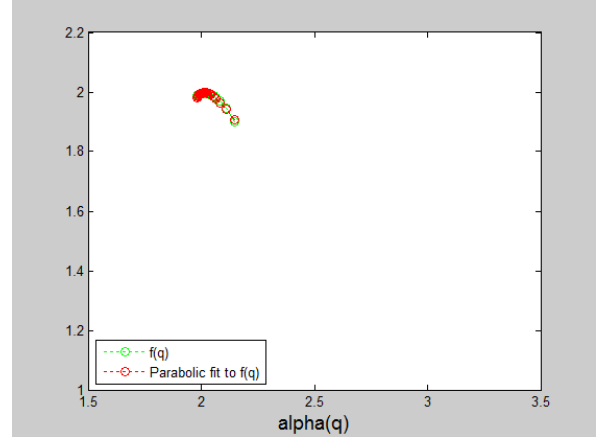

(b) Espectro multifractal método directo

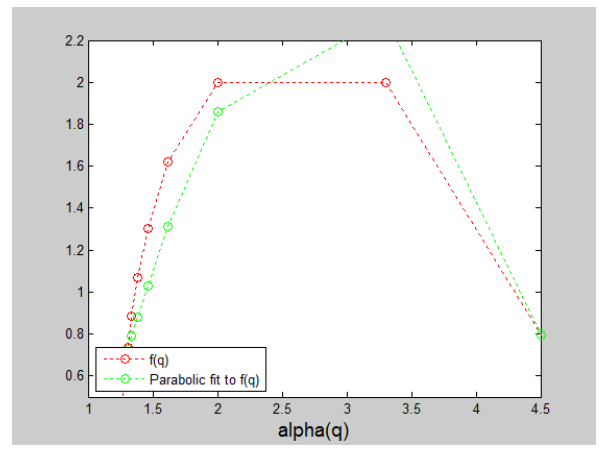

(d) Espectro multifractal "box-counting" restringida a 5 puntos

Figura 7.4: Formalismo multifractal aplicado a imagen de profundidad $30 \mathrm{~cm}$ 


\subsubsection{Imágenes de masa de tinte}

Otra aproximación al estudio consiste en formar dos imágenes que denominamos imagen de masa de tinte (dye mass) donde en cada pixel sumamos la cantidad de pixeles tintados en esa posición concreta y la imagen de profundidad de tinte (dye depth) donde con un valor entre 0 y 15 indicamos la máxima profundidad alcanzada por el tinte en una posición dada.

Mostramos a continuación la imagen de masa de tinte obtenida en el experimento utilizando el negativo o imagen complementaria para una mejor visualización (las zonas claras de la imagen se corresponde con zonas de menor masa y las oscuras con las zonas donde el tinte más ha penetrado).

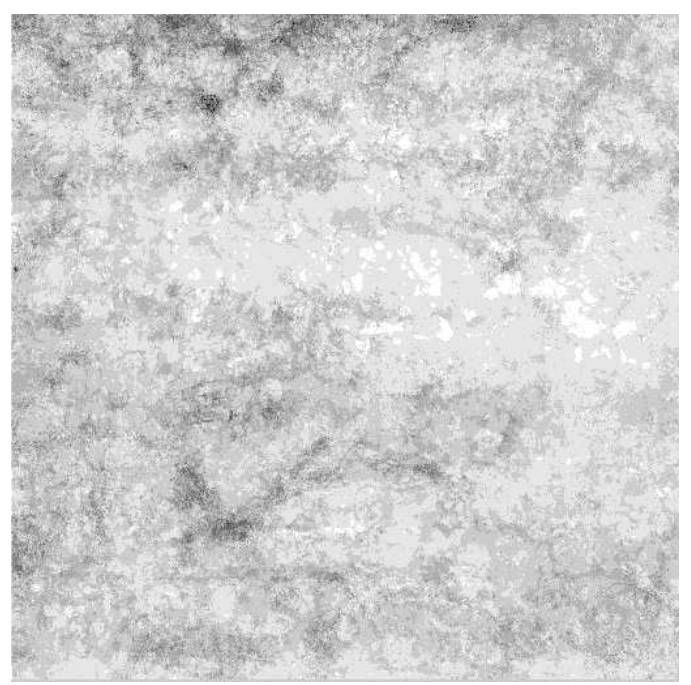

Figura 7.5: Imagen de masa de tinte (dye-mass)

La función de partición resultante es mostrada en la gráfica (7.6) exhibiendo aproximadamente el mismo comportamiento visto para las imágenes de cada una de las secciones. Esto es, el comportamiento fractal se observa para escalas mayores que un cierto umbral.

Numéricamente se obtienen los siguientes resultados:

- Método de estimación directa (Vadakkan, 2009):

- $\alpha_{\min }=1,9820, \alpha_{\max }=2,1459, \alpha_{c}=2,0279$ y $\alpha_{0}=2,0157$

- Método "box-counting"

- $\alpha_{\min }=1,8216, \alpha_{\max }=2,4475, \alpha_{c}=2,1151$ y $\alpha_{0}=2,0384$. 


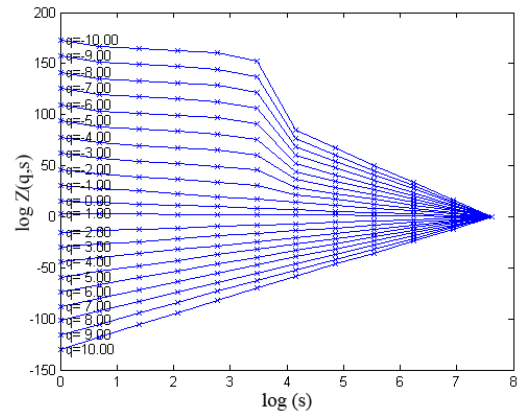

(a) Función de partición en función de la escala

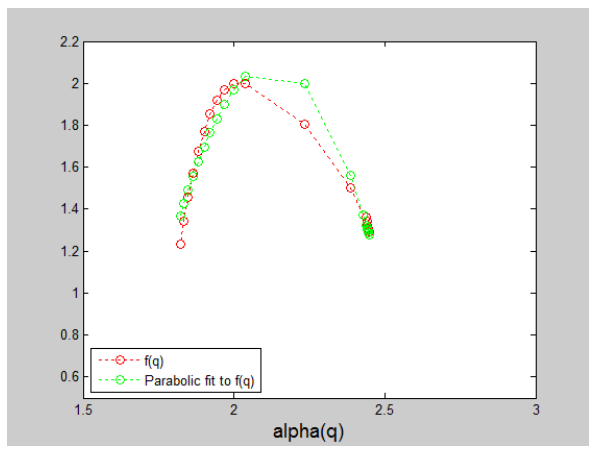

(c) Espectro multifractal "box-counting"

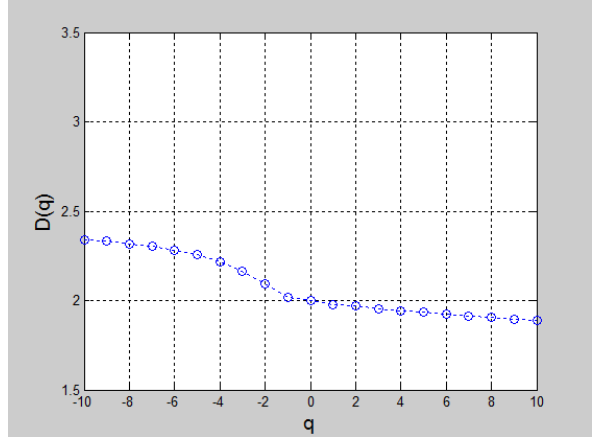

(b) Dimensión fractal generalizada $D_{q}$

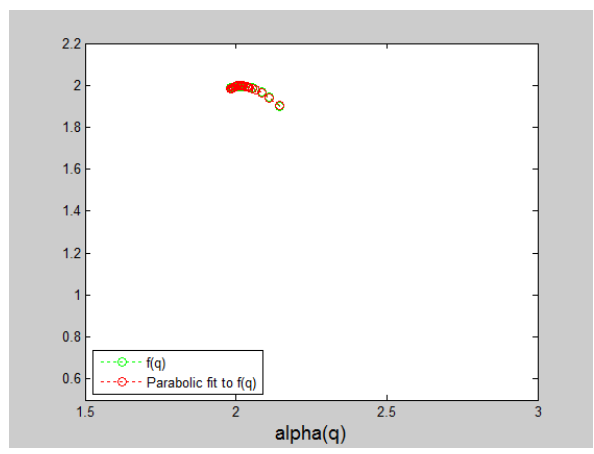

(d) Espectro multifractal método directo

Figura 7.6: Formalismo multifractal aplicado a imagen de masa de tinte (dye-mass) 


\subsubsection{Análisis multifractal de suelos arcillosos y formalismo wavelet}

Dados los resultados anteriores el primer paso en la investigación a realizar fue desarrollar el formalismo multifractal basado en la transformada wavelet a las imágenes mencionadas anteriormente. Los experimentos y resultados que se presentan a continuación fueron publicados en distintos congresos dando lugar a la primera publicación relacionada con este trabajo de tesis (Piñuela et al., 2007b). Muchos de los puntos que mencionamos a continuación se han detallado en secciones anteriores de esta memoria pero se repetirán en lo que sigue buscando detallar una explicación completa del procedimiento aplicado en este experimento.

Así, tomamos como punto de partida la imagen de masa de tinte de la figura (7.5) a la que aplicaremos el formalismo multifractal basado en transformada wavelet comentado en capítulos anteriores. El primer punto a considerar es la elección de una función wavelet concreta. La elección ideal sería aquella que cubriese el rango de coeficientes de Lipschitz que tratamos de detectar.

De este modo el punto de partida del análisis viene dado por el siguiente teorema ya mencionado en el capítulo dedicado al formalismo multifractal basado en la transformada wavelet.

\section{Teorema.}

Si $f \in \mathbf{L}^{2}(\mathbb{R})$ es $\alpha$-Lipschitz con $\alpha \leq n$ en el intervalo $[a, b]$, entonces existe $A>0$ tal que:

$$
\forall(u, s) \in[a, b] \times \mathbb{R}^{+}, \quad|W f(u, s)| \leq A s^{\alpha+1 / 2}
$$

En el sentido contrario, si $f$ está acotada y cumple (7.1) para un $\alpha<n$ no entero, entonces $f$ es $\alpha$-Lipschitz en $[a+\epsilon, b-\epsilon]$, para cualquier $\epsilon>0$.

De esta forma tenemos una condición casi necesaria y suficiente para medir la regularidad Lipschitz de una señal en un intervalo siempre y cuando la función wavelet posea un valor $n$ de momentos de desvanecimiento mayor que el coeficiente Lipschitz $\alpha$ que deseamos medir. Dado este punto parece que la mejor elección será una wavelet con el mayor valor posible de momentos de desvanecimiento, pero hay que tener en cuenta que este requisito implica en general un soporte mayor y por tanto una estimación menos fina de los coeficientes de regularidad.

Dado que en general en una imagen multifractal no podemos asumir ningún valor de regularidad predefinido se optó por utilizar en el experimento la wavelet conocida como sombrero mexicano que no es más que la derivada de una función gaussiana. Esta wavelet se muestra en la gráfica (7.7).

Insistir que la menor precisión de esta transformada wavelet en relación con otras de mucho menor soporte, recordar que viene dado por la siguiente gráfica en la que se define el llamado cono de influencia de una singularidad en la transformada wavelet continua (CWT) mostrado en la figura (7.8). En ella suponemos una wavelet con soporte compacto igual a $[-C, C]$ de forma que en cada escala este soporte es dilatado y trasladado siguiendo el escalado del análisis wavelet dado por $\psi\left(\frac{t-u}{s}\right)$ de forma que en la escala $s$ los valores de la CWT afectados por esa singularidad tendrá un soporte de valor $[u-C s, u+C s]$, es decir, más grande o menos preciso en relación directamente proporcional a $[-C, C]$ o soporte original de la función wavelet madre $\psi$. 


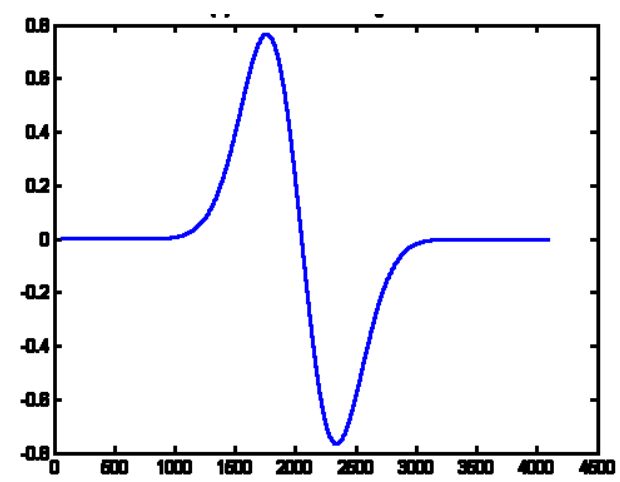

Figura 7.7: Base wavelet utilizada: Mexican Hat
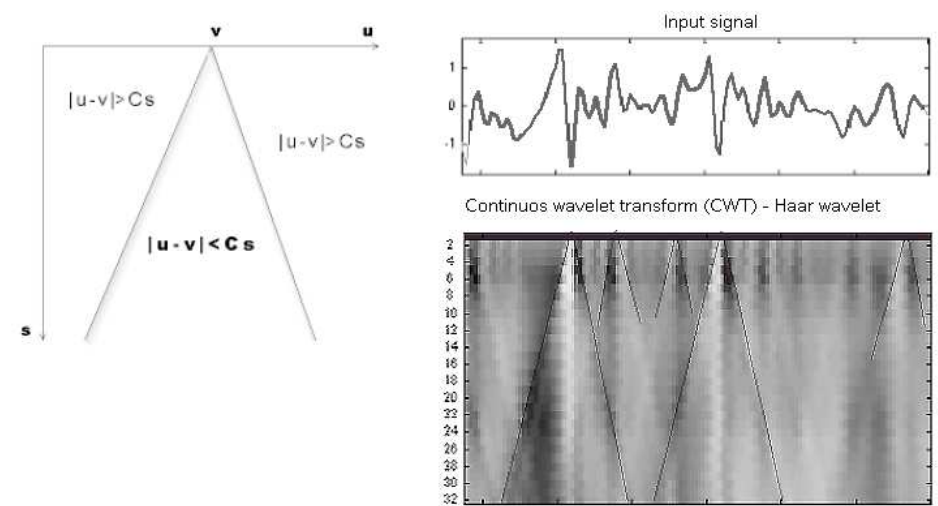

Figura 7.8: Precisión en el análisis en relación al soporte de la wavelet de análisis

A efectos de ilustrar el proceso en la imagen de tinte objeto de estudio se muestra en la siguiente secuencia de imágenes una región de 512x512 pixeles y el resultado de aplicar la transformada wavelet continua a las escalas $s=2$ y $s=8$, pudiendo apreciar claramente como la singularidad que aparece en la región seleccionada de la imagen afecta el módulo de la CWT en cada vez un soporte mayor.

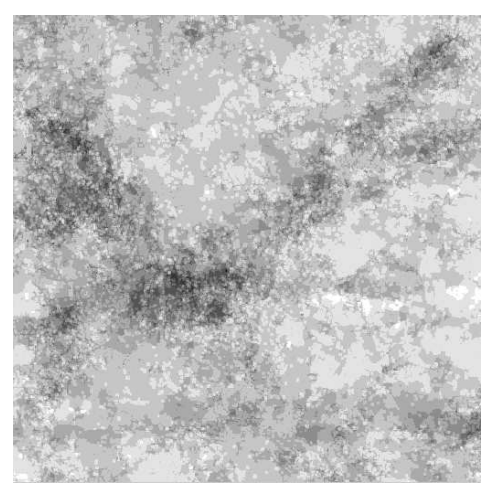

Figura 7.9: Región de 512x512 píxeles de la imagen de masa de tinte

Como ya se indico estamos interesados en los puntos de módulo máximo, es decir 


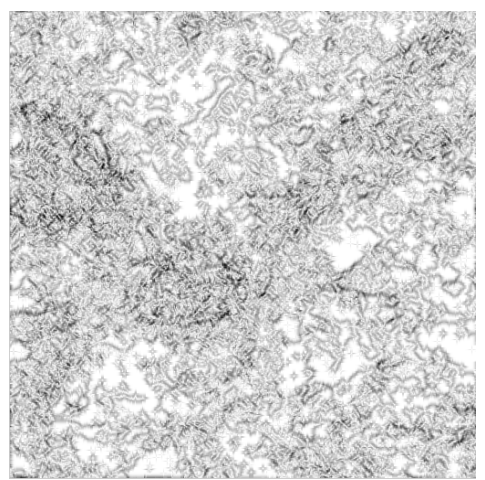

(a) Módulo CWT a escala $s=2$.

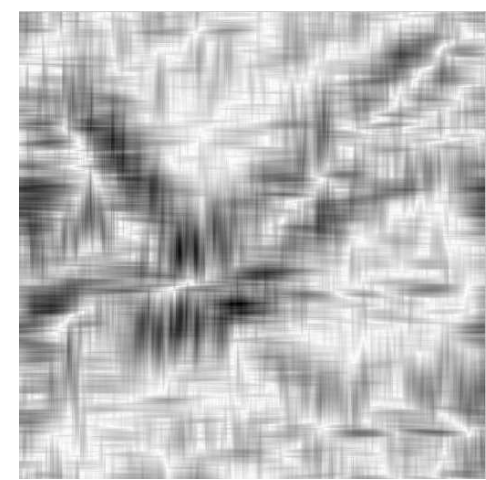

(b) Módulo CWT a escala $s=8$

Figura 7.10: Transformada Wavelet Continua de la imagen de masa de tinte

máximos locales del módulo de la CWT que en el caso de trabajar con imágenes se corresponden con puntos donde el valor del módulo:

$$
M f(s, x, y)=\sqrt{\left|W^{1} f(s, x, y)\right|^{2}+\left|W^{2} f(s, x, y)\right|^{2}}
$$

es un máximo local en la dirección dada por:

$$
A f(s, x, y)=\tan ^{-1}\left(\frac{W^{2} f(s, x, y)}{W^{1} f(s, x, y)}\right)
$$

dando lugar a las imágenes siguientes en las que se observa que el número de máximos que se propagan a través de las escalas será cada vez menor.

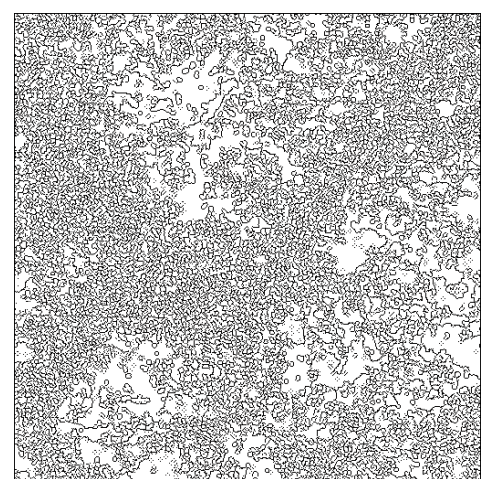

(a) Máximos del Módulo a escala $s=2$

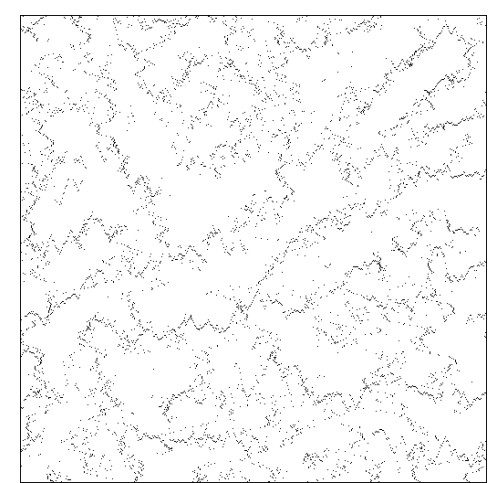

(b) Máximos del Módulo a escala $s=8$

Figura 7.11: Máximos de la Transformada Wavelet Continua de la imagen de tinte

El siguiente paso para completar el análisis multifractal basado en la transformada wavelet pasa por trazar la posición de los máximos afrontando los problemas de ambiguedad que resultan de este proceso en el caso de señales multidimensionales ya mencionados en otras aplicaciones por (Hsung y Siu, 1999) y (Zhong y Ning, 2005). Estos problemas de ambigüedad y que el estudio realizado con el método clásico de box-counting revele previamente la existencia de un comportamiento fractal sólo 
a partir de una determinada escala nos lleva a considerar un método alternativo sugerido en (Struzik, 1999) en el que tratamos de estimar el espectro multifractal directamente a partir de los valores del coeficiente de Lipschitz calculados a partir de la ecuación (7.1). A partir de esta ecuación y en el caso de dos dimensiones podemos escribir la siguiente relación entre los valores de la transformadas wavelet en dos escalas consecutivas $s_{1}$ y $s_{0}$ y para un punto de módulo máximo $\left(x_{0}, y_{0}\right)$.

$$
W f\left(s_{0}, x_{0}, y_{0}\right) \sim\left(s_{1} / s_{0}\right)^{\alpha_{0}\left(x_{0}, y_{0}\right)-1} W f\left(s_{1}, x_{0}, y_{0}\right)
$$

Con lo que la estimación directa de los coeficientes $\alpha$ se puede calcular según la expresión:

$$
\alpha\left(s_{0}, x_{0}, y_{0}\right) \sim \log _{2}\left(\frac{W f\left(s_{1}, x_{0}, y_{0}\right)}{W f\left(s_{0}, x_{0}, y_{0}\right)}\right)+1
$$

Representando estos valores en la denominada imagen de mapa de $\alpha$ resulta la figura (7.12) donde se ha utilizado una escala de psudocolor inversa sobre los valores de $\alpha$, al ser la manera en la que mejor se refleja la variación.

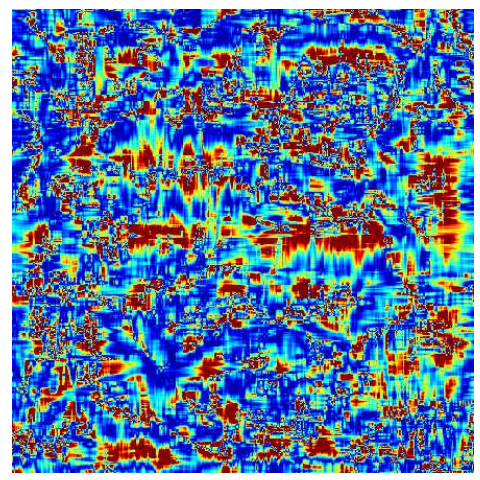

Figura 7.12: Mapa de $\alpha$ de la imagen masa de tinte

Y, por último, si representamos los valores de estos coeficientes en modo de histograma, de forma que en cada valor de $\alpha$ se muestra el numero de pixeles que en la imagen contienen un valor de $\alpha$ entre los límites de cada barra del histograma, se obtiene la figura (7.13).

El cálculo del centroide de este histograma resulta en un valor de $\alpha_{c}=1,9636$, muy similar al valor obtenido a partir del método de box-counting, mientras que el valor donde ese histograma alcanza un máximo es de $\alpha_{0}=1,8950$. Ambos valores ofrecen un resultado similar al obtenido con el formalismo multifractal clásico siguiendo la coherencia de los resultados observada con multifractales sintéticos como son los "Sierpinski Carpets".

De este modo el siguiente paso en la investigación era claro. Determinar si la estimación directa del espectro multifractal podría considerarse un método cuantitativo válido para el análisis de estructuras multifractales a través de la comparación de los valores obtenidos al analizar diferentes suelos u horizontes. La aplicación de estos métodos a imágenes obtenidas mediante tomografía axial computarizada permitió realizar esta comparación y es objeto del análisis que se describe en el siguiente capítulo. 


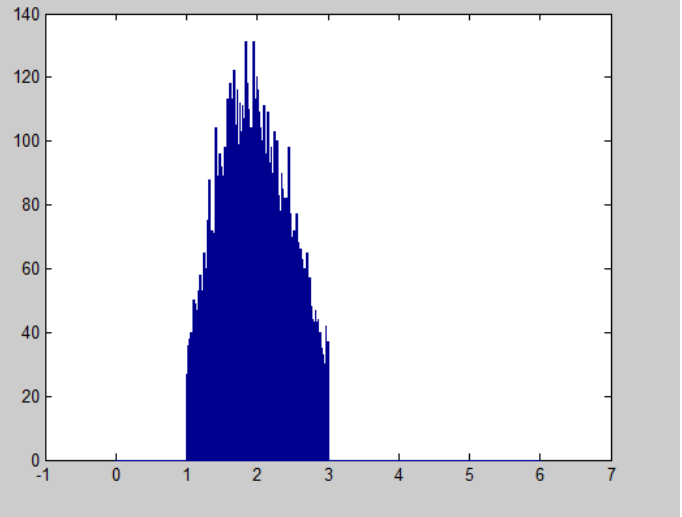

Figura 7.13: Histograma de coeficientes de Lipschitz para la imagen de masa de tinte 


\subsection{Cuantificación wavelet de imágenes de suelos obte- nidas por $\mathrm{CT}$}

\subsubsection{Aplicación de la tomografía computarizada al estudio de sue- los agrícolas}

Pasamos ya a describir el experimento principal realizado en este trabajo de tesis resultado de aplicar los principios ya vistos al análisis de imágenes de suelos agrícolas obtenidas mediante tomografía computarizada (Computed Tomography) que abreviaremos por sus siglas CT, y que dio lugar a la publicación relacionada de mayor impacto (Piñuela et al., 2010). En ella se prueba que sobre el material de estudio proporcionado, la técnica de estimación directa del espectro multifractal permite cuantificar adecuadamente las características de distintos suelos u horizontes o incluso sub volúmenes de un mismo horizonte.

\subsubsection{Material para el estudio: Tomografía axial computarizada}

La tomografía computarizada (CT) ha proporcionado una alternativa para observar la estructura interna del suelo sin impacto físico y proporcionando información tridimensional por lo que han sido base de diferentes estudios hidrológicos desde (Anderson et al., 1988), (Grevers y Jong, 1994), (Peyton et al., 1994), (Perret et al., 1997), (Pierret et al., 2002) o (Gibson et al., 2006).

Los principios de la tomografía computarizada parten de los trabajos de (Hounsfield, 1973) y una revisión de los métodos aplicados en análisis de suelos puede consultarse en (Taina et al., 2008).

Sin entrar en detalles del proceso de tomografía axial, decir que el material proporcionado por R.J. Heck como uno de los autores de (Piñuela et al., 2010$)$ fueron obtenidos de cuatro suelos ( $u$ horizontes siguiendo la terminología habitual en el campo de la Geología) ubicados en el estado de Pernambuco, al noreste de Brasil donde la vegetación propia de una selva costera marca las características del terreno. Para conocer en detalle las técnicas y procesos aplicados hasta llegar a las imágenes foco del estudio pueden consultarse (Elliot y Heck, 2007).

Así, los horizontes están caracterizados por ser de tipo argisol o hidromorfo, términos que en hidrología o edafología caracterizan a este tipo de suelo como profundo y fértil pero con problemas de drenaje interno, y en consecuencia presencia constante de agua, lo cual constituye una limitación para ciertos cultivos.

Las muestras fueron obtenidas mediante un micro escáner de la empresa GE Healthcare con parámetros de obtención fijados en $155 \mathrm{keV}$ y $25 \mu \mathrm{A}$ para mediante un posterior procesado con el software propietario de la mencionada empresa para obtener tres sub volúmenes de resolución 256×256×256 correspondientes a un tamaño de arista de 11,54mm y cuya interpretación física se muestra en la figura 7.14 . En las imágenes las regiones más oscuras se corresponden con regiones de menor atenuación (mayor porosidad) y las más claras representan componentes más sólidos.

El resultado por tanto del experimento y punto de inicio de nuestro trabajo serán 12 imágenes que se muestran en las figuras 7.15), 7.16), (7.17) y (7.18). La propia visualización de las mismas o incluso de (7.14) muestran mayor presencia de zonas oscuras (mayor porosidad) en los horizontes A2 y Bt/Bw en comparación con AB y 
Bt2. También es interesante observar es interesante observar en los sub volúmenes correspondientes al horizonte $\mathrm{AB}$ la presencia de distintas zonas en la imagen especialmente blancas y que dificultan enormemente la comparación basada en cálculos de parámetros globales pues cualquiera de los métodos propuestas es sensible a ese comportamiento local alejado de lo esperado en una imagen multifractal. No obstante, el impacto de este problema en los distintos enfoques resulta especialmente interesante de analizar.

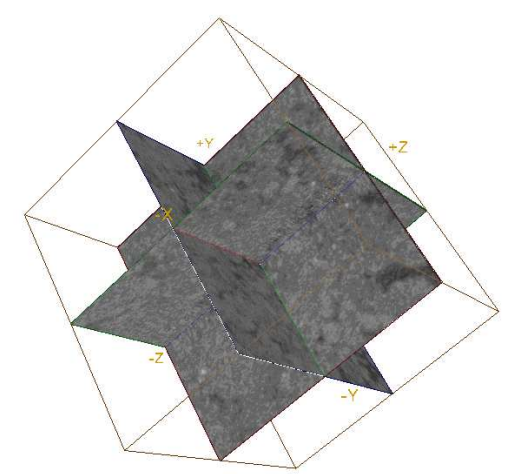

(a) A2

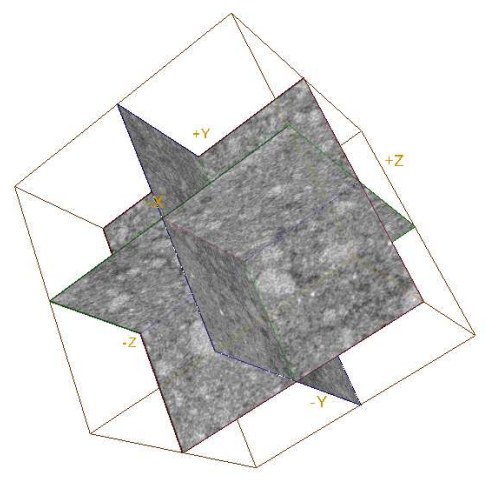

(c) Bt2

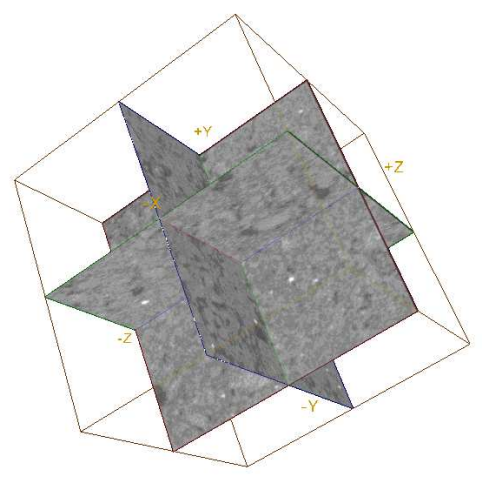

(b) $\mathrm{AB}$

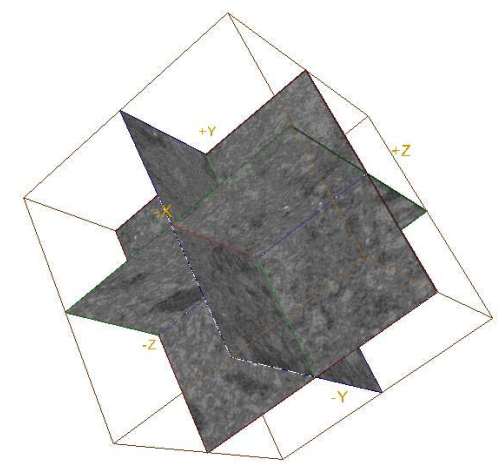

(d) $\mathrm{Bt} / \mathrm{Bw}$

Figura 7.14: Planos ortogonales obtenidos para los 4 horizontes del estudio 

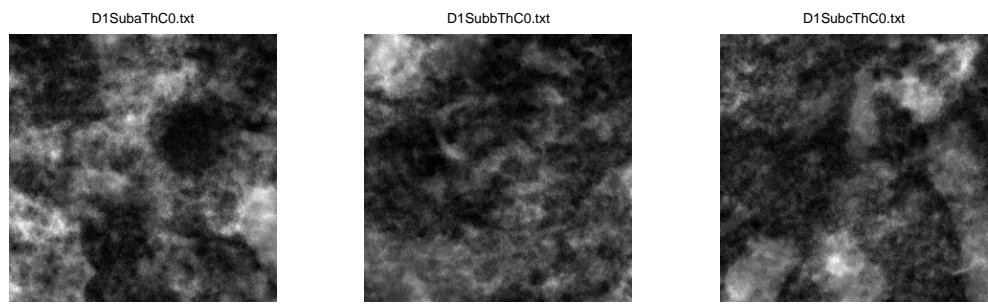

Figura 7.15: Sub volúmenes asociados al horizonte A2
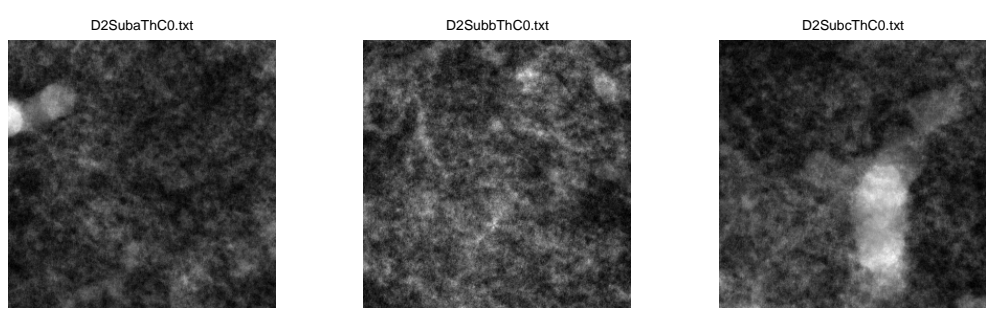

Figura 7.16: Sub volúmenes asociados al horizonte AB
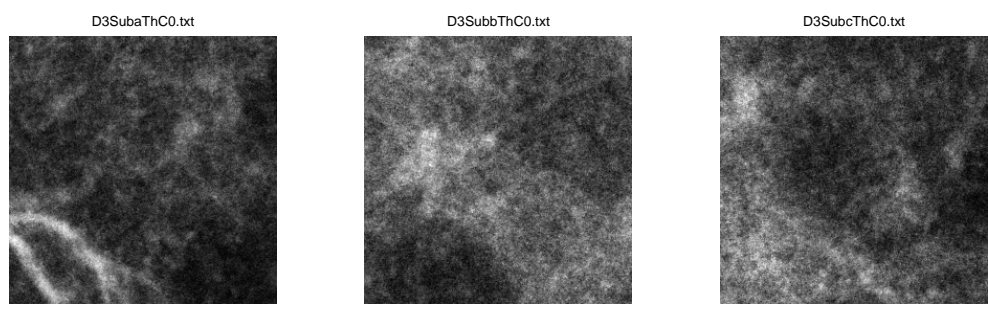

Figura 7.17: Sub volúmenes asociados al horizonte Bt2
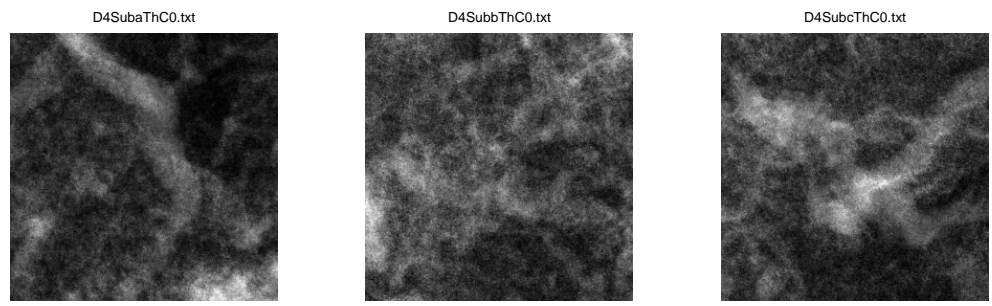

Figura 7.18: Sub volúmenes asociados al horizonte Bt/Bw 


\subsubsection{Cuantificación de la estructura multifractal mediante método box-counting}

En el primero de los estudios realizados sobre imágenes tintadas en (Tarquis y McInnes, 2005) y (Piñuela et al., 2007b) se había obtenido una dependencia importante de la escala de análisis, de forma que las imágenes tanto de cada sección o profundidad como las imágenes de masa y profundidad de tinte exhibían un comportamiento multifractal únicamente a partir de una escala dada.

Aplicando los mismos métodos a las imágenes (7.15), (7.16), (7.17) y (7.18) se obtiene por el contrario unas funciones de partición con pendiente prácticamente constante llevando a identificar fácilmente un análisis multifractal. Los resultados gráficos del análisis multifractal se muestran a continuación para cada uno de los casos.

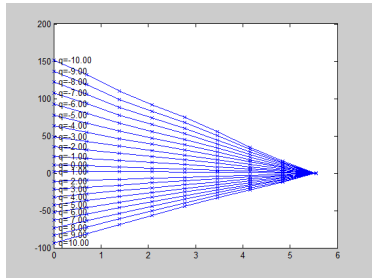

(a) Función de partición en función de la escala
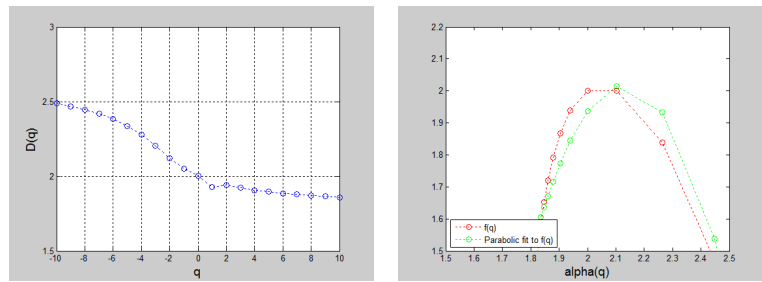

(b) Dimensión fractal ge- (c) Espectro multifractal neralizada $D_{q}$

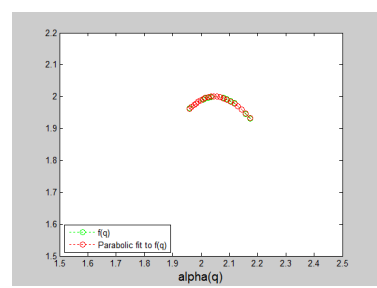

(d) Espectro multifractal método directo 

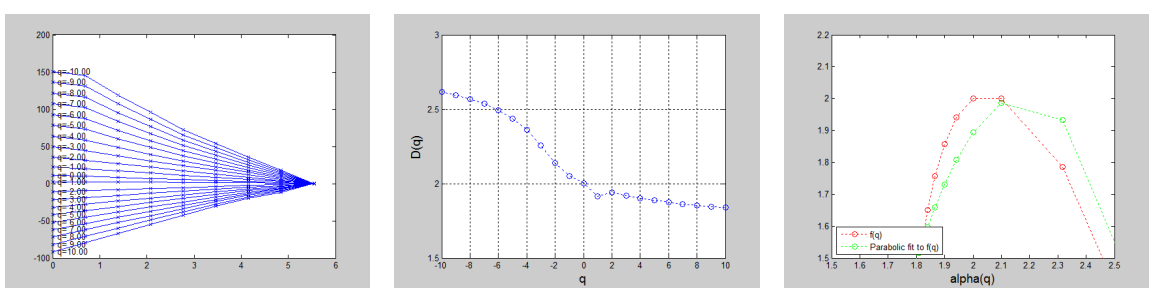

(a) Función de partición en (b) Dimensión fractal ge- (c) Espectro multifractal función de la escala neralizada $D_{q}$ "box-counting"

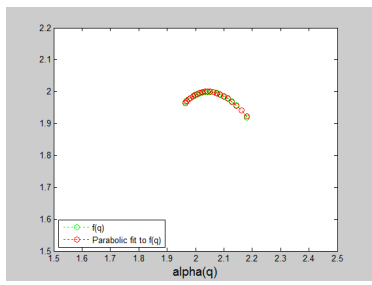

(d) Espectro multifractal método directo

Figura 7.20: Formalismo multifractal aplicado al horizonte $A 2$, volumen $B$

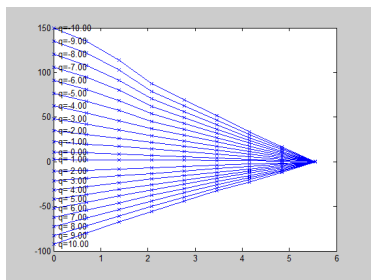

(a) Función de partición en función de la escala
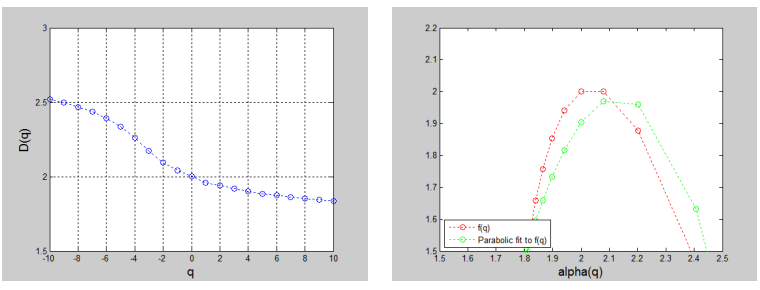

(b) Dimensión fractal ge- (c) Espectro multifractal neralizada $D_{q}$

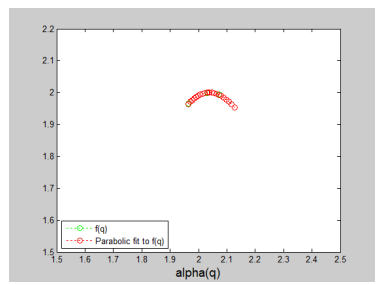

(d) Espectro multifractal método directo

Figura 7.21: Formalismo multifractal aplicado al horizonte $A 2$, volumen $C$ 

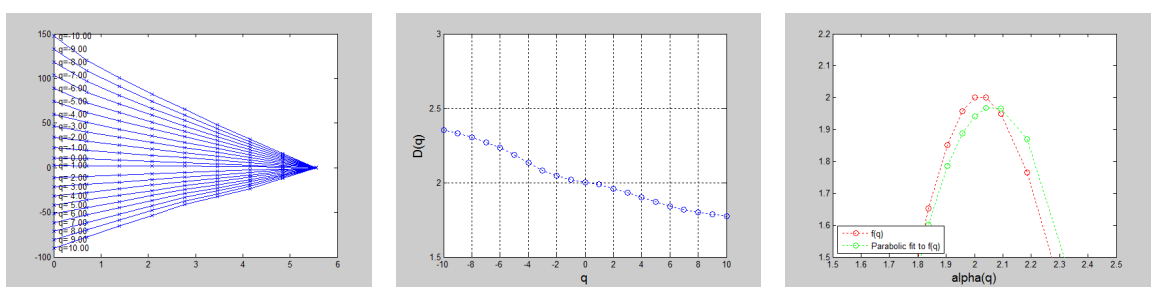

(a) Función de partición en (b) Dimensión fractal ge- (c) Espectro multifractal función de la escala neralizada $D_{q}$ "box-counting"

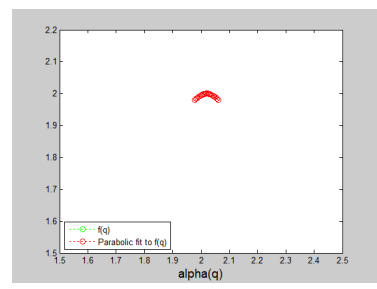

(d) Espectro multifractal método directo

Figura 7.22: Formalismo multifractal aplicado al horizonte $A B$, volumen $A$
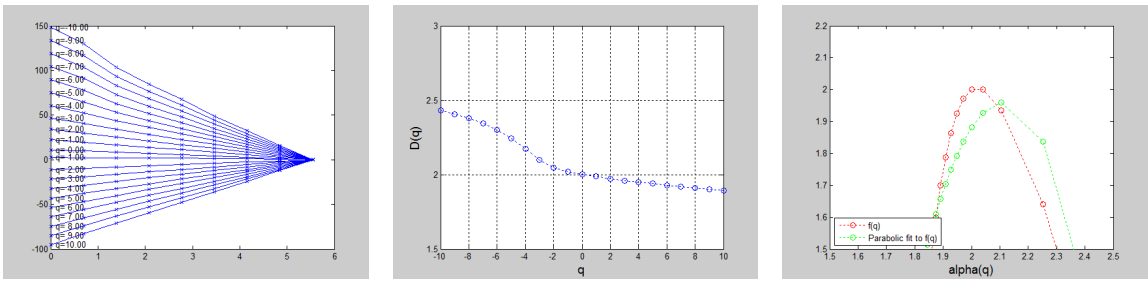

(a) Función de partición en (b) Dimensión fractal ge- (c) Espectro multifractal función de la escala neralizada $D_{q}$

"box-counting"

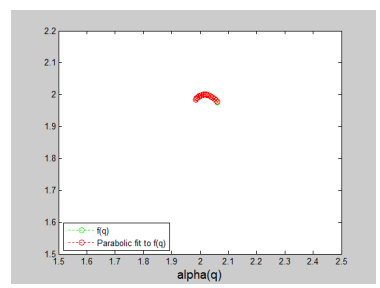

(d) Espectro multifractal método directo

Figura 7.23: Formalismo multifractal aplicado al horizonte $A B$, volumen $B$ 

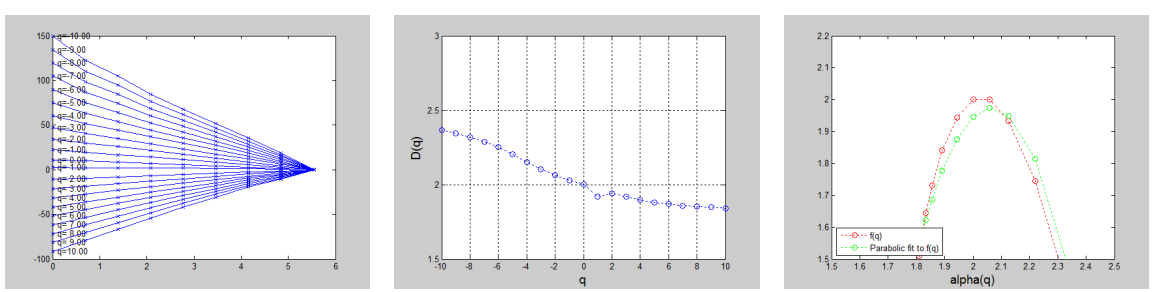

(a) Función de partición en (b) Dimensión fractal ge- (c) Espectro multifractal función de la escala neralizada $D_{q}$ "box-counting"

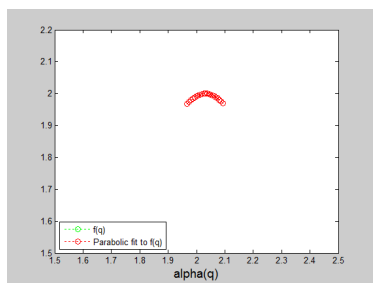

(d) Espectro multifractal método directo

Figura 7.24: Formalismo multifractal aplicado al horizonte $A B$, volumen $C$

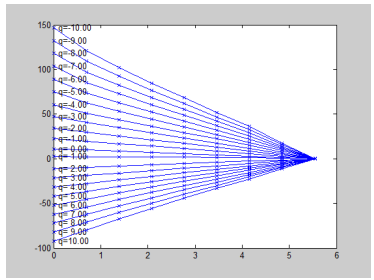

(a) Función de partición en función de la escala
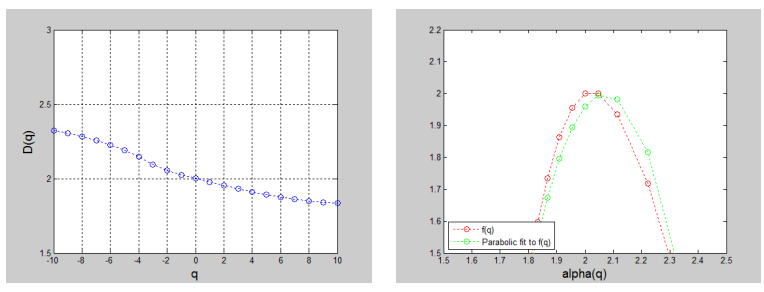

(b) Dimensión fractal ge- (c) Espectro multifractal neralizada $D_{q}$

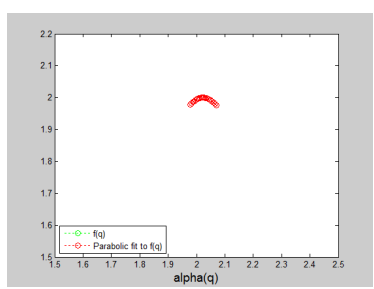

(d) Espectro multifractal método directo

Figura 7.25: Formalismo multifractal aplicado al horizonte $B t 2$, volumen $A$ 

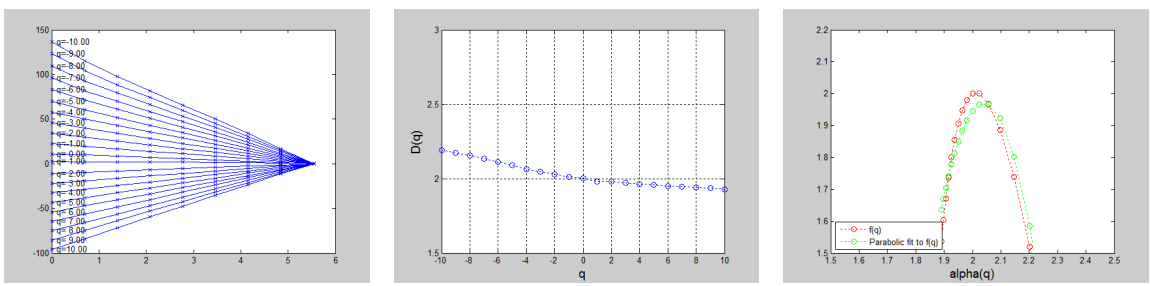

(a) Función de partición en (b) Dimensión fractal ge- (c) Espectro multifractal función de la escala neralizada $D_{q}$ "box-counting"

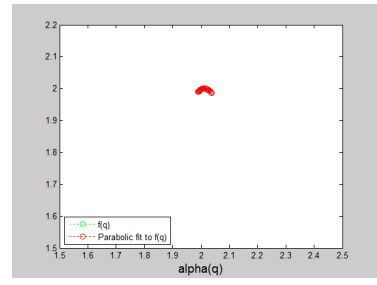

(d) Espectro multifractal método directo

Figura 7.26: Formalismo multifractal aplicado al horizonte $B t 2$, volumen $B$
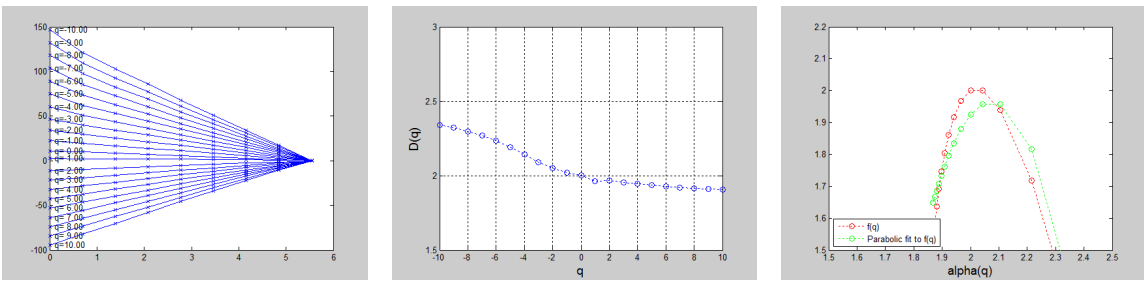

(a) Función de partición en (b) Dimensión fractal ge- (c) Espectro multifractal función de la escala neralizada $D_{q}$

"box-counting"

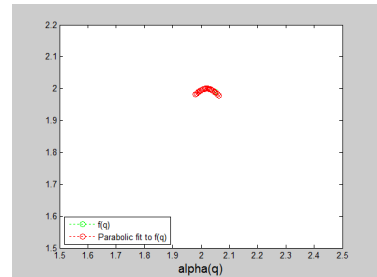

(d) Espectro multifractal método directo

Figura 7.27: Formalismo multifractal aplicado al horizonte $B t 2$, volumen $C$ 

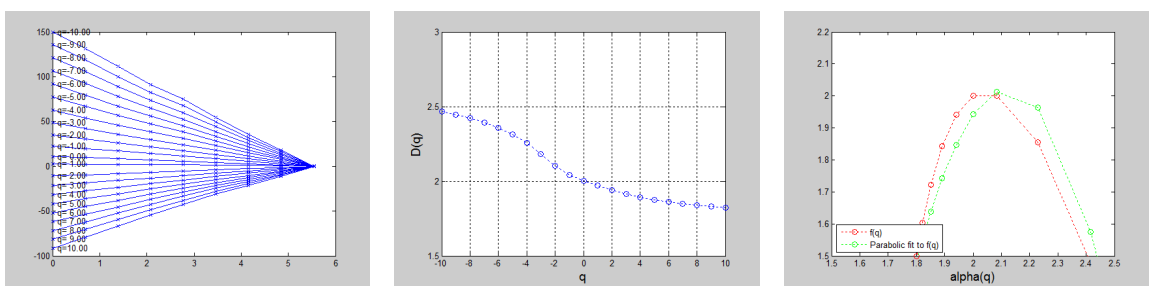

(a) Función de partición en (b) Dimensión fractal ge- (c) Espectro multifractal función de la escala neralizada $D_{q}$ "box-counting"

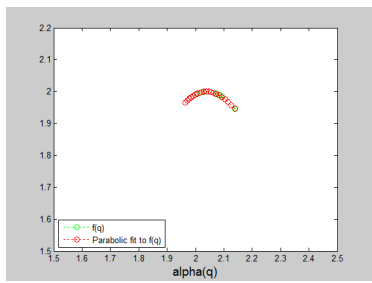

(d) Espectro multifractal método directo

Figura 7.28: Formalismo multifractal aplicado al horizonte $B t / B w$, volumen $A$

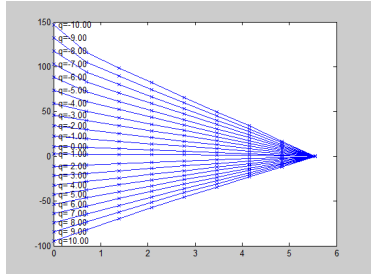

(a) Función de partición en (b) función de la escala
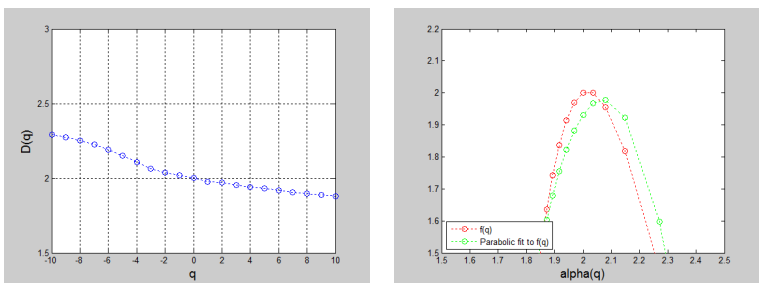

(b) Dimensión fractal ge- (c) Espectro multifractal neralizada $D_{q}$

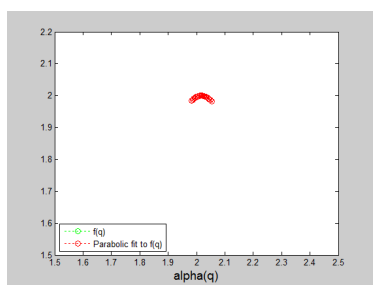

(d) Espectro multifractal método directo

Figura 7.29: Formalismo multifractal aplicado al horizonte $B t / B w$, volumen $B$ 

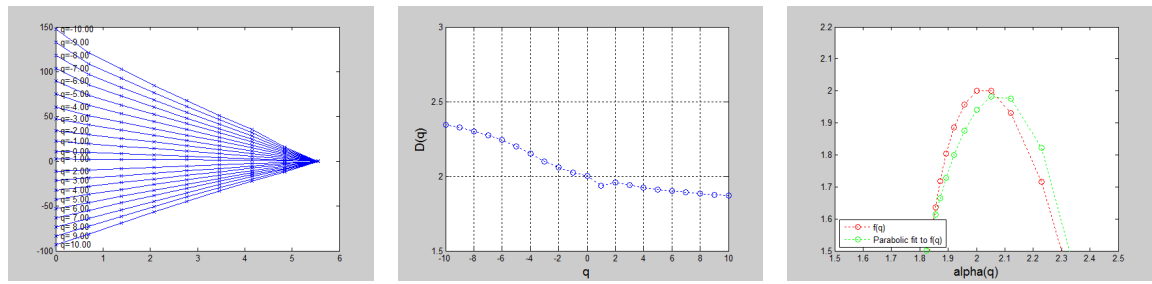

(a) Función de partición en (b) Dimensión fractal ge- (c) Espectro multifractal función de la escala neralizada $D_{q}$ "box-counting"

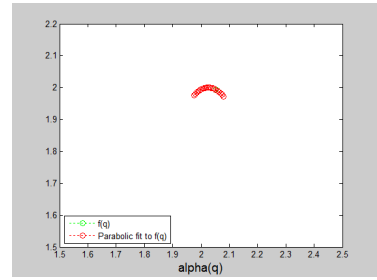

(d) Espectro multifractal método directo

Figura 7.30: Formalismo multifractal aplicado al horizonte $B t / B w$, volumen $C$ 
Calculando a partir de las funciones de partición los parámetros $\alpha_{\min } \mathrm{y} \alpha_{\max }$ como límites del soporte del espectro multifractal, $\alpha_{c}$ valor centroide de los $\alpha$ computados y $\alpha_{0}$ como valor de $\alpha$ para el cual el espectro multifractal alcanza su valor máximo obtenemos las tablas (7.1) y 7.2 para los distintos horizontes y sub volúmenes.

\begin{tabular}{|l|l|l|l|l|l|}
\hline Horizonte & Subvol. & $\alpha_{\min }$ & $\alpha_{\max }$ & $\alpha_{c}$ & $\alpha_{0}$ \\
\hline A2 & A & 1,9608 & 2,1733 & 2,0536 & 2,0460 \\
\hline & B & 1,9635 & 2,1807 & 2,0525 & 2,0423 \\
\hline & C & 1,9644 & 2,1269 & 2,0407 & 2,0380 \\
\hline AB & A & 1,9791 & 2,0603 & 2,0200 & 2,0201 \\
\hline & B & 1,9844 & 2,0607 & 2,0190 & 2,0170 \\
\hline & C & 1,9671 & 2,0925 & 2,0312 & 2,0321 \\
\hline Bt2 & A & 1,9771 & 2,0702 & 2,0230 & 2,0226 \\
\hline & B & 1,9893 & 2,0382 & 2,0123 & 2,0114 \\
\hline & $\mathrm{C}$ & 1,9814 & 2,0641 & 2,0208 & 2,0197 \\
\hline Bt/Bw & A & 1,9648 & 2,1384 & 2,0482 & 2,0379 \\
\hline & $\mathrm{B}$ & 1,9837 & 2,0530 & 2,0174 & 2,0168 \\
\hline & $\mathrm{C}$ & 1,9752 & 2,0804 & 2,0264 & 2,0256 \\
\hline
\end{tabular}

Tabla 7.1: Características multifractales de los distintos horizontes y subvolúmenes. Método de estimación directa

\begin{tabular}{|l|l|l|l|l|l|}
\hline Horizonte & Subvol. & $\alpha_{\min }$ & $\alpha_{\max }$ & $\alpha_{c}$ & $\alpha_{0}$ \\
\hline $\mathrm{A} 2$ & $\mathrm{~A}$ & 1,8156 & 2,6792 & 2,0950 & 2,1023 \\
\hline & $\mathrm{B}$ & 1,7869 & 2,8364 & 2,0857 & 2,1014 \\
\hline & $\mathrm{C}$ & 1,7791 & 2,7424 & 2,0364 & 2,0794 \\
\hline $\mathrm{AB}$ & $\mathrm{A}$ & 1,6850 & 2,5812 & 1,9929 & 2,0409 \\
\hline & $\mathrm{B}$ & 1,8300 & 2,6605 & 2,0222 & 2,0394 \\
\hline & $\mathrm{C}$ & 1,8040 & 2,5744 & 2,0183 & 2,0593 \\
\hline $\mathrm{Bt} 2$ & $\mathrm{~A}$ & 1,7736 & 2,5092 & 2,0373 & 2,0475 \\
\hline & $\mathrm{B}$ & 1,8903 & 2,3544 & 2,0357 & 2,0249 \\
\hline & $\mathrm{C}$ & 1,8677 & 2,5380 & 2,0493 & 2,0431 \\
\hline $\mathrm{Bt} / \mathrm{Bw}$ & $\mathrm{A}$ & 1,7656 & 2,6612 & 2,0726 & 2,0837 \\
\hline & $\mathrm{B}$ & 1,8196 & 2,4750 & 2,0351 & 2,0352 \\
\hline & $\mathrm{C}$ & 1,8178 & 2,5391 & 2,0444 & 2,0523 \\
\hline
\end{tabular}

Tabla 7.2: Características multifractales de los distintos horizontes y subvolúmenes. Método "box-counting"

A modo de conclusión se compara en la gráfica (7.31) la evolución a lo largo de los distintos horizontes para los tres sub volúmenes A, B y $\mathrm{C}$ de tres variables:

- $\alpha_{0}$ del método de estimación directa

- $\alpha_{0}$ del método "box-counting"

- $\alpha_{c}$ o centroide del espectro del método "box-counting" 


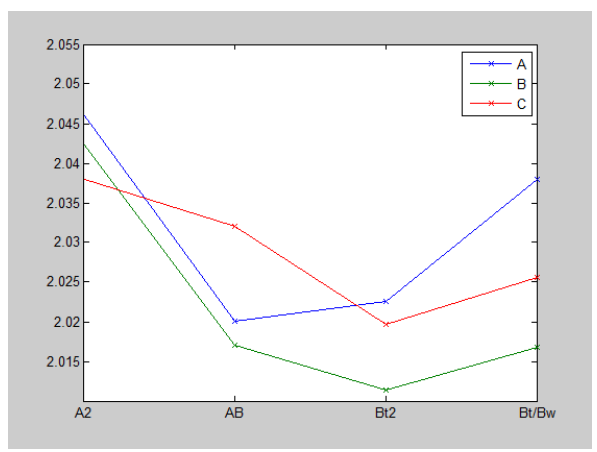

(a) $\alpha_{0}$ método estimación directa

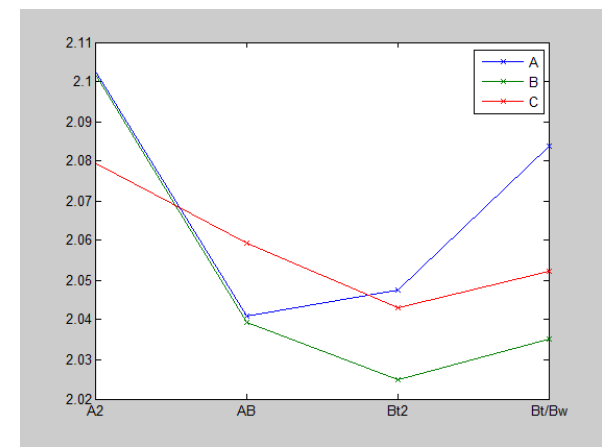

(b) $\alpha_{0}$ método "box-counting"

Figura 7.31: Comparación de los diferentes $\alpha_{0}$ obtenidos del análisis multifractal para los distintos horizontes-volúmenes

\subsubsection{Cuantificación mediante estimación directa de coeficientes Lipschitz}

Cómo se mencionó en el capítulo anterior, al tratar con en el análisis multifractal de las imágenes tintadas, se propuso en (Piñuela et al., 2007b) el uso de estimación directa del espectro multifractal a partir del cálculo de los coeficientes de singularidad en distintas escalas según las ecuaciones (7.4) y (7.5), ecuación esta última que repetimos aquí por conveniencia:

$$
\alpha\left(s_{0}, x_{0}, y_{0}\right) \sim \log _{2}\left(\frac{W f\left(s_{1}, x_{0}, y_{0}\right)}{W f\left(s_{0}, x_{0}, y_{0}\right)}\right)+1
$$

Al aplicar estas ecuación sobre los distintos sub volúmenes de cada uno de los horizontes se obtiene las siguientes imágenes de mapas de alpha que representamos utilizando mapas de color como técnica de pseudocolor para facilitar su interpretación en las imágenes 7.34, 7.35, 7.36 y 77.37).

La tabla 7.3 muestra los valores medios $\alpha_{m}$ y $\alpha_{c}$ obtenidos mediante estimación directa del espectro multifractal de los coeficientes $\alpha$ y se muestran igualmente los valores $\alpha_{0}^{d}$ y $\alpha_{0}^{b}$ ya reportados anteriormente al aplicar los métodos multifractales de estimación directa y "box-counting" respectivamente.

Que gráficamente lleva al resultado mostrado en la figura $(7.32)$ siguiendo la misma lógica que en las gráfica 7.31:

Comparando los resultados obtenidos con uno y otro enfoque se observa que la tendencia global es aproximadamente la misma pero el análisis wavelet es considerablemente más sensible a la presencia de estructuras especialmente irregulares en parte de la imagen como ocurre con el horizonte $\mathrm{AB}$ en los subvolúmenes $\mathrm{A}$ y $\mathrm{C}$.

Es importante destacar además de la comparación global la potencia del análisis localizado de los diferentes $\alpha$ que se muestran a continuación en las imágenes de mapas de $\alpha$. Pero antes es especialmente interesante observar la distribución de los histogramas calculados a partir de esos $\alpha$ locales mostrados en la figura (7.33). En ellos se puede observar claramente como el volumen de puntos considerados en el histograma aumenta al pasar del horizonte $A 2$, al $A B$ y del horizonte $A B$ al $B t / B w$. Es decir, existen más puntos singulares. Es la distribución de esas singularidades, 


\begin{tabular}{|l|l|l|l|l|l|}
\hline Horizonte & Subvol. & $\alpha_{m}$ & $\alpha_{c}$ & $\alpha_{0}^{d}$ & $\alpha_{0}^{b}$ \\
\hline A2 & A & 2,0846 & 2,0847 & 2,0460 & 2,1023 \\
\hline & B & 2,1000 & 2,0999 & 2,0423 & 2,1014 \\
\hline & C & 2,1798 & 2,1797 & 2,0380 & 2,0794 \\
\hline AB & A & 2,0530 & 2,0530 & 2,0201 & 2,0409 \\
\hline & B & 1,9754 & 1,9767 & 2,0170 & 2,0394 \\
\hline & C & 2,0775 & 2,0776 & 2,0321 & 2,0593 \\
\hline Bt2 & A & 2,0920 & 2,0920 & 2,0226 & 2,0475 \\
\hline & $\mathrm{B}$ & 2,0063 & 2,0065 & 2,0114 & 2,0249 \\
\hline & $\mathrm{C}$ & 1,9907 & 1,9906 & 2,0197 & 2,0431 \\
\hline Bt/Bw & A & 2,1943 & 2,1943 & 2,0379 & 2,0837 \\
\hline & $\mathrm{B}$ & 2,0635 & 2,0634 & 2,0168 & 2,0352 \\
\hline & $\mathrm{C}$ & 2,1089 & 2,1090 & 2,0256 & 2,0523 \\
\hline
\end{tabular}

Tabla 7.3: Comparación de los distintos métodos en los diferentes horizontes / subvolúmenes

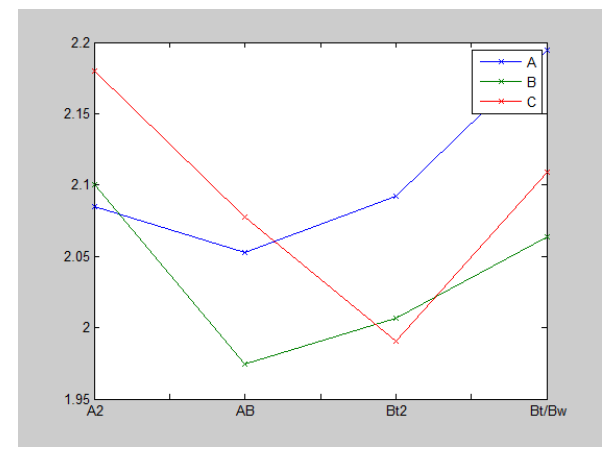

Figura 7.32: Comparación de los diferentes $\alpha_{m}$ estimados a partir de los coeficientes wavelets

correspondiendo a valores mayores de $\alpha$ en los horizontes $A 2$ y $B t / B w$, la que hace que los valores medios o centroides de $\alpha$ sean mayores en $A 2$ y $B t / B w$ (especialmente en este último caso). 


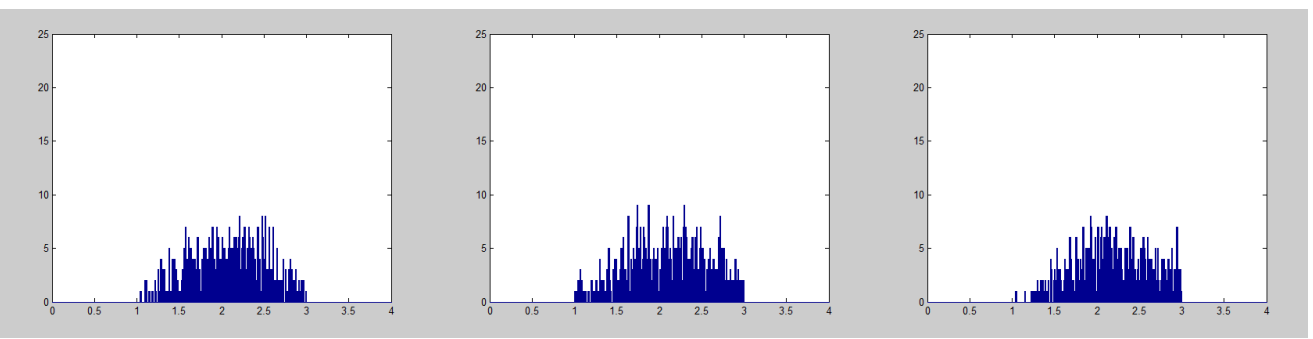

(a) Horizonte A2

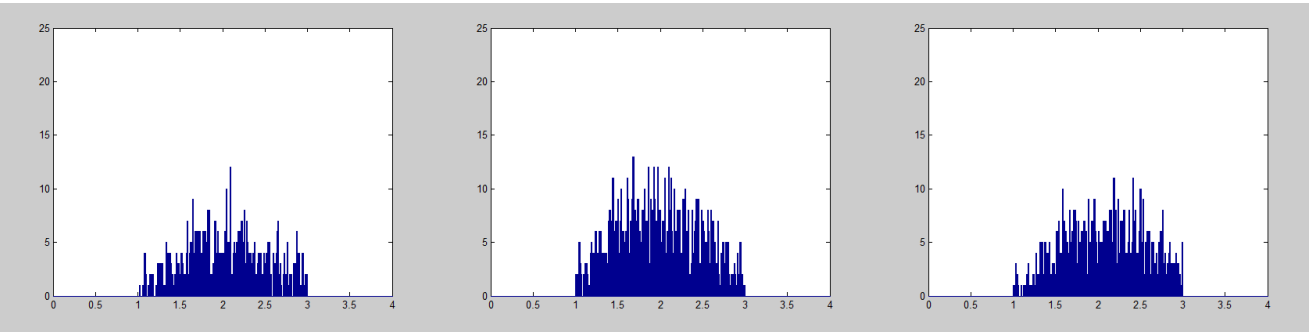

(b) Horizonte AB

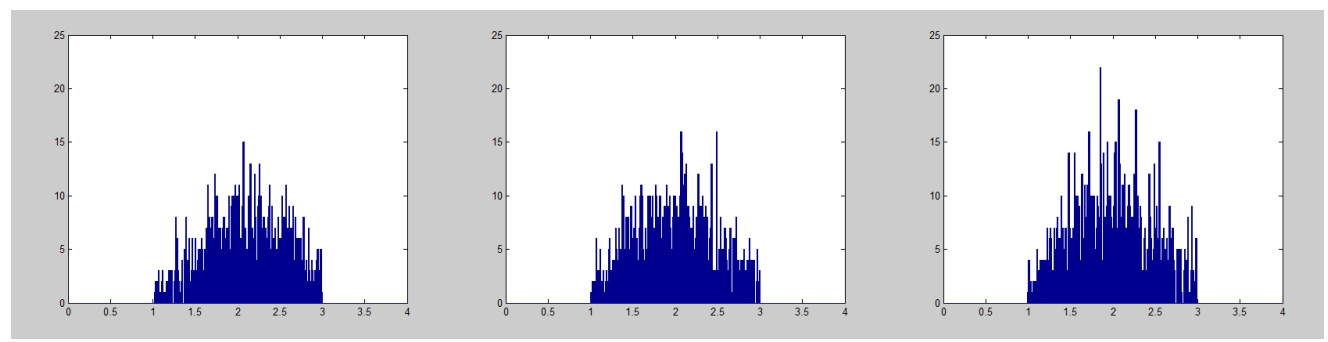

(c) Horizonte Bt2

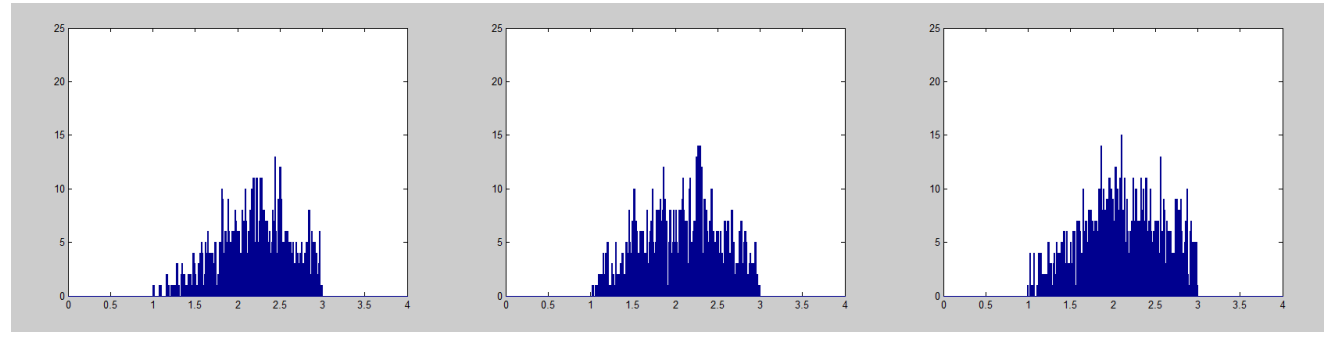

(d) Horizonte $\mathrm{Bt} / \mathrm{Bw}$

Figura 7.33: Histograma de mapa de $\alpha$ asociados a los diferentes horizontes / subvolúmenes 


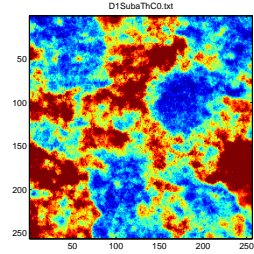

(a) Subvolumen A

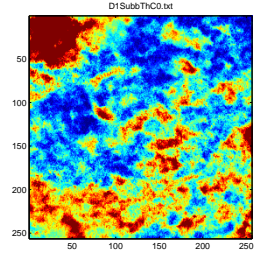

(b) Subvolumen B

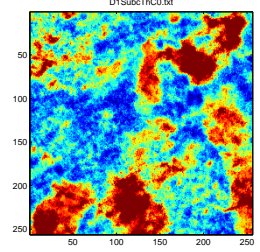

(c) Subvolumen C

Figura 7.34: Mapa de $\alpha$ asociado al horizonte A2

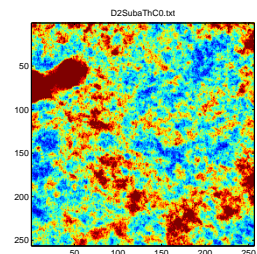

(a) Subvolumen A

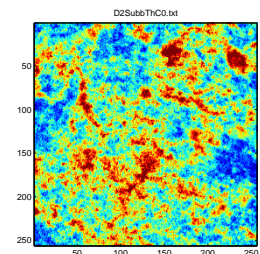

(b) Subvolumen B

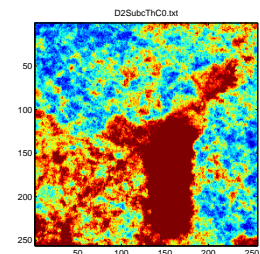

(c) Subvolumen C

Figura 7.35: Mapa de $\alpha$ asociado al horizonte AB

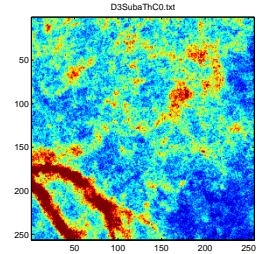

(a) Subvolumen A

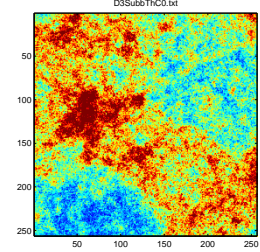

(b) Subvolumen B

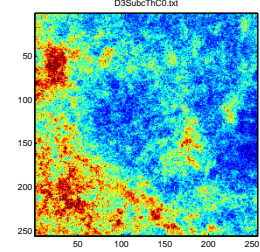

(c) Subvolumen C

Figura 7.36: Mapa de $\alpha$ asociado al horizonte Bt2

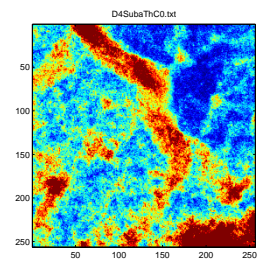

(a) Subvolumen A

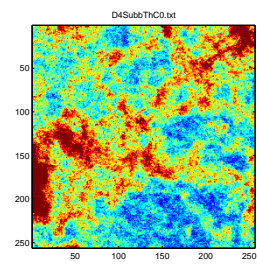

(b) Subvolumen A

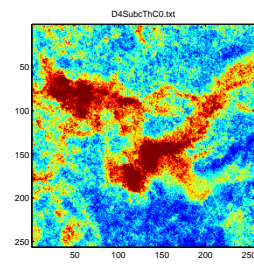

(c) Subvolumen C

Figura 7.37: Mapa de $\alpha$ asociado al horizonte $\mathrm{Bt} / \mathrm{Bw}$ 



\section{Capítulo 8}

\section{Conclusiones}

Este trabajo de tesis se enmarca en la relación existente entre análisis multifractal y transformadas wavelets. La teoría wavelet es por tanto la herramienta matemática usada para caracterizar aspectos multiescala de señales o imágenes desde un punto de vista multifractal y son este tipo de señales o imágenes las que componen el campo de aplicabilidad principal de esta investigación.

El marco matemático para esta relación fue establecida en (Mallat y Hwang, 1992 dónde siguiendo la variación del módulo de los coeficientes wavelets a través de las escalas se demuestra la posible caracterización de singularidades en señales e imágenes a través de los coeficientes de Lipschitz.

En señales esencialmente regulares esta relación se calcula a través de las líneas de módulo máximo construidas concatenando máximos locales de $|W f(u, s)|$ a través de las escalas.

En cambio, cuando tratamos con señales esencialmente no regulares existen problemas en la definición de estas líneas de máximo que conducen a una caracterización global de las singularidades a través del formalismo multifractal y en concreto el denominado espectro multifractal o espectro de singularidades $f(\alpha)$. Este enfoque es detallado a lo largo de la memoria, primero desde un enfoque clásico y después desde la conexión con la transformada wavelet de módulo máximo establecida en (Mallat, 1998 concluyendo que existe una dependencia tan fuerte en la selección de las escalas wavelet adecuadas para tal análisis que, especialmente en el caso de imágenes multifractales su aplicabilidad resultaba especialmente compleja.

Distintos experimentos realizados por el autor investigando esta conexión en el ámbito del análisis de imágenes de suelos arcillosos primero (Piñuela et al., 2007b) y en la estimación de la volatilidad de series financieras después (Cedeno et al., 2011), llevaron a considerar la hipótesis que tanto a nivel global, como local o incluso a escala a escala es posible cuantificar las características multiescala o multifractales de señales o imágenes a través del cálculo de coeficientes de Lipschitz siguiendo las pautas establecida en (Mallat y Hwang, 1992) incluso para esas señales esencialmente irregulares o multifractales aún con importantes diferencias que llevan a justificar el título del trabajo como contribución al análisis multiescala o multifractal.

Los métodos desarrollados encuentran paralelismos con el trabajo de autores como (Hsung y Siu, 1999) que propone estimar el espectro de singularidades a partir de estimaciones locales de exponentes de Hölder (mismo significado que los coeficientes de Lipschitz mencionados) y cuya distribución en forma de histograma muestra 
resultados análogos a los que resultan del cálculo del espectro multifractal tanto cualitativa como cuantitativamente. La principal diferencia de nuestra propuesta es que mientras (Hsung y Siu, 1999) sigue utilizando los valores del módulo de los coeficientes wavelets a través de líneas de máximos entre dos escalas límites, mientras que en nuestro caso sólo se requiere que esos puntos sean máximos locales no aislados. Es decir, nuestro enfoque impone que ha de existir al menos otro máximo en la escala siguiente y en la vecindad del coeficiente wavelet considerado.

Esta propuesta encuentra también relación en el campo del procesamiento de imágenes con el trabajo de (Zhong y Ning, 2005) donde se incluye una justificación matemática que valida la forma de calcular coeficientes Lipschitz a través únicamente de dos escalas. La diferencia con nuestro enfoque es que en (Zhong y Ning, 2005) se calculan los coeficientes en todos los puntos mientras que en nuestra propuesta como se mencionaba anteriormente sólo consideramos máximos locales conectados de alguna forma a través de al menos dos escalas. Esta diferencia de enfoque se justifica perfectamente dado el diferente objetivo de cada trabajo.

La implementación del método comentado utilizando señales e imágenes bien conocidas en el campo del análisis multifractal muestran la coherencia y validez del enfoque propuesto y su implementación al obtener resultados muy aproximados a los valores teóricos en cada caso. Igualmente válidos son los resultados obtenidos en el campo del análisis de series financieras donde la estimación de la volatilidad de un índice bursátil se considera suficientemente relevante para profundizar en la inclusión de los resultados obtenidos en esquemas de decisión de riesgos bursátiles basados en redes neuronales como el coautorizado en (Cedeno et al., 2011).

Establecida la principal aportación matemática y una vez validada su implementación, sin duda las conclusiones principales y las publicaciones más significativas (Piñuela et al., 2010), giran alrededor de la aplicabilidad de este enfoque en el campo de la caracterización multifractal de imágenes de suelos agrícolas. Estas imágenes son obtenidas por distintas técnicas como son la aplicación de tintes especiales o la tomografía computarizada. Los resultados obtenidos son no sólo coherentes con los publicados utilizando otros métodos si no que los complementan ofreciendo un detalle local y escala a escala que permiten nuevas interpretaciones acerca de la estructura de suelos agrícolas.

De modo más detallado las siguientes secciones describen conclusiones parciales de cada uno de los grandes apartados en los que se divide la memoria.

\subsection{Contribución al análisis multiescala y multifractal}

El uso de la transformada wavelet aplicada en distintos campos es desde hace años más que habitual como demuestra el hecho de haber sido incluida en distintos estándares de compresión como JPEG-2000 o MPEG-4. El estudio de estas técnicas en sistemas de compresión de imagen fija fue el objetivo del proyecto fin de carrera (Piñuela, 2000), punto de arranque de este trabajo de tesis, donde las conclusiones obtenidas mostraban la potencia de las técnicas wavelets en distintas aplicaciones y sobre todo en esquemas de compresión de imagen fija siguiendo los trabajos de (Shapiro, 1993) y (Said et al., 1996).

Dentro de ese trabajo y como una de sus principales aportaciones, se presento en 
el año 1999 el denominado Enfoque Wavenet dentro del proyecto On-Air en el que la Universidad Politécnica de Madrid por medio de la E.T.S.I. de Telecomunicación colaboraba en el desarrollo de nuevas tecnologías de transmisión de vídeo.

Dicho enfoque hacía uso de la capacidad de la transformada wavelet para detectar singularidades aisladas de la señal con el objetivo de reducir drásticamente la exigencia en numero de bits de aplicaciones de videoconferencia limitadas a entornos de comunicaciones móviles de bajo ancho de bando como en ese momento eran las redes GSM o GPRS. El punto clave de la propuesta era la separación entre los bordes significativos de una imagen respecto de lo que podríamos llamar sus texturas, que siempre aportan menos en aplicaciones de videoconferencia tan limitadas en tasa binaria. Esta etapa de preprocesamiento y postprocesamiento se incluyo como elemento clave en el estándar de vídeo H-264 o MPEG-4 versión 10, si bien basándose en otros fundamentos matemáticos.

Ya en ese momento las conclusiones no podían ser más que positivas en cuanto a la flexibilidad y potencia de aplicar técnicas wavelet a distintos problemas del procesamiento de señales y en concreto el procesamiento de imagen.

Dentro de estos problemas, la memoria de este trabajo parte de aplicaciones sencillas de extracción y manipulación directa de los coeficientes de la transformada discreta wavelet en imágenes naturales. Estas aplicaciones en el campo de la protección de derechos de autor a través de marcas de agua o la eliminación de ruido en secuencias de imágenes para la posterior segmentación de objetos de vídeo fueron las primeras implementaciones realizadas con éxito durante la investigación y que se describen en esta memoria como elemento esencial para entender el significado del procesamiento wavelet en imágenes naturales. Los resultados obtenidos se consideraron igualmente excelentes dado el objetivo de cada una de estas aplicaciones demostrando la potencia y flexibilidad de la teoría wavelet aplicada a imágenes naturales.

Una línea de investigación menos documentada en la literatura era la aplicación de la transformada wavelet de módulo máximo en distintas aplicaciones aún cuando sus fundamentos teóricos fueran igualmente establecidos en los primeros años de la década de los 90 .

El análisis de singularidades en imágenes naturales en aplicaciones como la ayuda al diagnóstico en mamografías y los buenos resultados obtenidos constituyeron un paso clave para entender la relación entre coeficientes wavelet provenientes de una descomposición de módulo máximo y exponentes de Lipschitz inspirando las siguientes etapas en la investigación y su elección como marco teórico del trabajo de tesis.

\subsection{Aplicación a la estimación de volatilidad de series financieras}

En el contexto de las series financieras el comportamiento multiescala esta relacionado con la volatilidad de la serie o índice bursátil (Kantelhardt et al., 2002). En una definición en términos financieros, la volatilidad es una medida de la frecuencia 
e intensidad de los cambios del precio de un activo o de un tipo y es definida en primera instancia como la desviación estándar de dicho cambio en un horizonte temporal específico. Se usa por tanto, con frecuencia para cuantificar el riesgo asociado al valor. En este sentido la metodología propuesta complementa las publicaciones realizadas en (de la Barcena et al., 2010) y (Cedeno et al., 2011), estando en este momento pendiente investigar como integrar las estimaciones multiescala en las redes neuronales en las que se basan las publicaciones citadas.

Comparado con otros métodos, la estimación de la volatilidad realizada a partir de los coeficientes Lipschitz de la señal lleva a las siguientes conclusiones:

1. Al igual que otros métodos puede ofrecer un único valor representativo de la volatilidad de un índice bursátil medido como valor medio de los coeficientes de Lipschitz mayores que cero detectado en la descomposición wavelet.

2. Permite una representación que refleja gráficamente y permite detectar a lo largo del tiempo la existencia de eventos especialmente significativos o la ausencia de los mismos.

3. La representación en forma de histograma de los coeficientes obtenidos, al proporcionar información análoga al del espectro multifractal informa de la distribución probabilística de que cambios más o menos abruptos sucedan en cada una de las series.

Finalmente indicar que no sólo se está tratando de integrar estas estimaciones basadas en técnicas wavelet como complemento a las redes neuronales basadas en aprendizaje mediante metaplasticidad en el campo de las series financieras sino también en otros campos donde el análisis multiescala ha resultado siempre de gran valor, como es en el diagnóstico de anomalías en electrocardiogramas. En lo que a la parte de aprendizaje y redes neuronales esta investigación ya ha dado sus primeros resultados en forma de publicaciones como co autor en (Fombellida et al., 2015).

\subsection{Aplicación a la cuantificacion multifractal de imáge- nes de suelos en estudios hidrológicos}

El principal campo de aplicación de los métodos propuestos se ha desarrollado en el ámbito de la Hidrología o ciencia que entre otras cosas estudia la distribución y circulación del agua en la superficie de la Tierra. Fue el trabajo de A.M. Tarquis en (Tarquis y McInnes, 2005) el establecido como punto de partida para investigar la aplicabilidad de técnicas wavelet en imágenes multifractales. En el mencionado trabajo se estudian las propiedades multifractales de imágenes de suelos arcillosos, pues está comúnmente aceptado que dadas las características del problema a modelar, es el formalismo multifractal el enfoque más conveniente.

Cuando tratamos con estas señales y cómo ya se ha mencionado no es posible calcular los exponentes de Lipschitz a través de líneas de módulo máximo, siendo el concepto clave a modelar el denominado espectro multifractal. Dado que la teoría matemática wavelet establece igualmente que la transformada wavelet de módulo 
8.3. Aplicación a la cuantificacion multifractal de imágenes de suelos en estudios hidrológicos

máximo se relaciona directamente con la caracterización multifractal de señales a través de conceptos tales como la función de partición $Z(q, s)$ o el exponente de escalado $\tau_{q}$, se inició la investigación en cómo aplicar estos principios al problema presentado. Al aplicar este procedimiento en (Piñuela et al., 2007b) sobre el mismo conjunto de imágenes objeto del estudio de (Tarquis y McInnes, 2005) se obtuvieron los resultados esperados concluyendo que la teoría wavelet puede utilizarse también para la caracterización multifractal de imágenes del mismo modo que las técnicas de box-counting utilizadas habitualmente.

En este sentido, durante estos últimos años y en paralelo con el periodo de investigación que ha ocupado esta tesis la aplicación de la transformada wavelet de módulo máximo se ha convertido en un estándar de facto para el cálculo de los distintos parámetros del análisis multifractal. De este modo, no sólo el trabajo realizado en nuestra investigación si no distintas contribuciones en distintos ámbitos han validado que este enfoque ha sido el adecuado.

Y como ya mencionábamos al inicio del capítulo este trabajo de investigación va más allá de demostrar la validez del enfoque wavelet aplicado a estructuras multifractales pues en contraposición con otras técnicas, la transformada wavelet permite realizar un análisis localizado tanto en el espacio como en distintas escalas, de las estructuras y singularidades presentes en la señal o imagen objeto de estudio. Así lo demuestran los resultados publicados en (Piñuela et al., 2010) y documentados en el capítulo final de este trabajo de tesis y que son sin duda la principal contribución realizada. 



\section{Capítulo 9}

\section{Futuras líneas de investigación}

Dos han sido las líneas de investigación iniciadas a lo largo de esta tesis que finalmente se han decidido incluir como referencia para futuros trabajos.

Por un lado se presenta como considerando cada horizonte de un suelo como una realización de un proceso estocástico, podemos analizar la varianza de este proceso estocástico a partir de una descomposición wavelet obteniendo información de las variaciones de cada señal o imagen en términos de las diferentes escalas de análisis. El parámetro a utilizar propuesto es la denominada varianza rotada acumulativa (rotated cumulative variance definida en (Percival y Walden, 2007)) y derivada de otra variante más de transformada wavelet como es la MODWT (Maximal Overlap Discrete Wavelet Transform). Unos primeros resultados fueron presentados en Abril de 2008, en (Torres et al., 2008). Los conceptos clave para continuar con esta línea de investigación se describen a continuación.

Y por último, teniendo en cuenta que el resultado del análisis de un suelo es un volumen de $256 \times 256 \times 256$ vowels surge de manera inmediata la idea de extender el trabajo realizado a técnicas de análisis en tres dimensiones siguiendo las ideas publicadas en (Piñuela et al., 2009). En este sentido se incluyen en este apartado distintas referencias recomendadas como punto de partida del análisis wavelet multidimensional a través del denominado esquema "Lifting" ((Sweldens, 1997)).

\subsection{Cuantificación basada en la MODWT y correlación wavelet}

Esta línea de investigación, como se ha mencionado, parte de la denominada MODWT. En contraposición a la transformada wavelet discreta (DWT), la MODWT de nivel $J_{0}$ es una transformada no ortogonal con un alto grado de redundancia. Para los coeficientes resultantes de aplicar un MODWT usaremos la notación $\widetilde{\mathbf{W}}_{1}, \widetilde{\mathbf{W}}_{2}$, $\ldots, \widetilde{\mathbf{W}}_{J_{0}}$ para los vectores que contienen los coeficientes wavelets y $\widetilde{\mathbf{V}}_{J_{0}}$ para los coeficientes asociados a la función de escala.

De esta manera $\widetilde{\mathbf{W}}_{j}$ contiene información de los cambios de $\mathbf{X}$ asociados a la escala $\tau_{j}=2^{j-1}$. Las propiedades claves que distinguen la MODWT de la DWT son (Percival y Walden, 2007):

1. Mientras que de partida la DWT de nivel $J_{0}$ nos restringe a señales cuya longitud sea múltiplo de $2^{J_{0}}$, la MODWT está bien definida para cualquier longitud 
de señal a cambio de un mayor coste computacional.

2. Al igual que la DWT, la MODWT está asociada a un análisis multirresolución de la señal, pero en esta ocasión los detalles $\widetilde{\mathcal{D}}_{j}$ y la aproximación $\widetilde{\mathcal{S}}_{J_{0}}$ presentan la ventaja de ser invariantes al desplazamiento de manera que un desplazamiento en el tiempo se refleja en un desplazamiento en los espacios de detalle y de aproximación en la misma medida.

3. Tanto los detalles como la aproximación en un MODWT siempre están asociados a filtros de fase cero.

4. En el caso de la MODWT la redundancia en los coeficientes dificulta realizar un análisis en términos de conservación de energía entre el dominio del tiempo y el dominio transformado, pero sigue siendo posible realizar ese análisis.

\subsubsection{Definición e implementación de la Maximal Overlap Discrete Wavelet Transform}

\section{Definición.}

Se definen los coeficientes wavelets y de escala del nivel $j$ mediante las siguientes ecuaciones:

$$
\begin{aligned}
\widetilde{W}_{j, t} & \equiv \sum_{l=0}^{L_{j}-1} \widetilde{h}_{j, l} X_{t-l \bmod N} \\
\widetilde{V}_{j, t} & \equiv \sum_{l=0}^{L_{j}-1} \widetilde{g}_{j, l} X_{t-l \bmod N}
\end{aligned}
$$

para $t=0, \ldots, N-1$ con $\widetilde{h}_{j, l} \equiv h_{j, l} / 2^{j / 2}$ y $\widetilde{g}_{j, l} \equiv g_{j, l} / 2^{j / 2}$ son filtros de longitud $L_{j}$.

Para establecer tanto los algoritmos de análisis / sintesís como la relación entre energía de la señal original y los coeficientes transformados el proceso pasa por definir los filtros $\left\{\widetilde{h}_{j, l}^{o}\right\}$ y $\left\{\widetilde{g}_{j, l}^{o}\right\}$ como los filtros obtenidos al periodizar los filtros habituales de la DWT hasta alcanzar una longitud $N$ y renormalizar su energía de manera que lo que realmente periodizamos es $\left\{\widetilde{h}_{l}\right\} \equiv\left\{h_{l} / \sqrt{2}\right\}$ y $\left\{\widetilde{g}_{l}\right\} \equiv\left\{g_{l} / \sqrt{2}\right\}$.

De este modo en notación matricial resulta:

$$
\begin{aligned}
\widetilde{\mathbf{W}}_{j} & =\widetilde{\mathcal{W}}_{j} \mathbf{X} \\
\widetilde{\mathbf{V}}_{j} & =\widetilde{\mathcal{V}}_{j} \mathbf{X}
\end{aligned}
$$

con:

$$
\widetilde{\mathcal{W}}_{j} \equiv\left[\begin{array}{cccccc}
\widetilde{h}_{j, 0}^{o} & \widetilde{h}_{j, N-1}^{o} & \widetilde{h}_{j, N-2}^{o} & \cdots & \widetilde{h}_{j, 2}^{o} & \widetilde{h}_{j, 1}^{o} \\
\widetilde{h}_{j, 1}^{o} & \widetilde{h}_{j, 0}^{o} & \widetilde{h}_{j, N-1}^{o} & \cdots & \widetilde{h}_{j, 3}^{o} & \widetilde{h}_{j, 2}^{o} \\
\widetilde{h}_{j, 2}^{o} & \widetilde{h}_{j, 1}^{o} & \widetilde{h}_{j, 0}^{o} & \cdots & \widetilde{h}_{j, 4}^{o} & \widetilde{h}_{j, 3}^{o} \\
\vdots & \vdots & \vdots & \cdots & \vdots & \vdots \\
\widetilde{h}_{j, N-2}^{o} & \widetilde{h}_{j, N-3}^{o} & \widetilde{h}_{j, N-4}^{o} & \cdots & \widetilde{h}_{j, 0}^{o} & \widetilde{h}_{j, n-1}^{o} \\
\widetilde{h}_{j, N-1}^{o} & \widetilde{h}_{j, N-2}^{o} & \widetilde{h}_{j, N-3}^{o} & \cdots & \widetilde{h}_{j, 1}^{o} & \widetilde{h}_{j, n-0}^{o}
\end{array}\right]
$$


Por su lado $\widetilde{\mathcal{V}}_{j}$ tendrá una expresión equivalente utilizando el filtro $\widetilde{g}_{j, l}^{o}$ de manera que:

$$
\widetilde{\mathcal{D}}_{j} \equiv \widetilde{\mathcal{W}}_{j}^{T} \widetilde{\mathbf{W}}_{j}
$$

Y:

$$
\widetilde{\mathcal{S}}_{j} \equiv \widetilde{\mathcal{V}}_{j}^{T} \widetilde{\mathbf{V}}_{j}
$$

\subsubsection{Análisis espacio-escala de suelos agrícolas mediante varianza wavelet}

Para llegar al concepto de varianza wavelet (Percival, 1995) se hace necesario usar términos estadísticos como el de proceso estocástico en el sentido de que en el análisis realizado sobre cada uno de los volúmenes nuestros experimentos, cada corte bidimensional será una realización de ese proceso estocástico.

A nivel teórico, sea $\left\{X_{t}: t=\ldots-1,0,1, \ldots\right\}$ un proceso estocástico de valores reales y sea:

$$
\bar{W}_{j, t}=\sum_{l=0}^{L_{j} s-1} \widetilde{h}_{j, l} X_{t-l},
$$

Denotamos por $\widetilde{h}_{j, l}$ al proceso estocástico resultante de filtrar $\left\{X_{t}\right\}$ con el filtro wavelet de la MODWT y definimos la varianza wavelet asociada a la escala $\tau_{j}$ como:

$$
v_{X, t}^{2}\left(\tau_{j}\right) \equiv \operatorname{var}\left\{\bar{W}_{j, t}\right\}
$$

donde en los casos de interés podemos eliminar la dependencia del tiempo de la varianza de manera que:

$$
v_{X}^{2}\left(\tau_{j}\right) \equiv \operatorname{var}\left\{\bar{W}_{j, t}\right\}
$$

Si la transformada de Fourier parte de la densidad espectral de potencia $S_{Y}(\cdot)$ descompone la varianza entre determinadas frecuencias según:

$$
\int_{-1 / 2}^{1 / 2} S_{Y}(f) d f=\sigma_{Y}^{2} \equiv \operatorname{var}\left\{Y_{t}\right\}
$$

La transformada wavelet descompone esa misma información a través de las escalas en función de la varianza wavelet según:

$$
\sum_{j=1}^{\infty} v_{Y}^{2}\left(\tau_{j}\right)=\sigma_{Y}^{2} \equiv \operatorname{var}\left\{\bar{W}_{j, t}\right\}
$$

En lugar de (9.12), en nuestra aplicación se estudia la dependencia respecto del tiempo de la varianza wavelet escala a escala mediante el cálculo de varianzas rotadas acumulativas (rotated cumulative variance) definido por (Percival y Walden, 2007) según:

$$
\left.C_{j, t}=\frac{1}{N} \sum_{u=0}^{t} \bar{W}_{j, u+(m}^{2} \text { mód } N\right)
$$

El resultado de calcular esta varianza sobre el volumen B de los diferentes horizontes de las figuras (7.15, (7.16, (7.17) y (7.18) se muestran en la figura 9.1): 


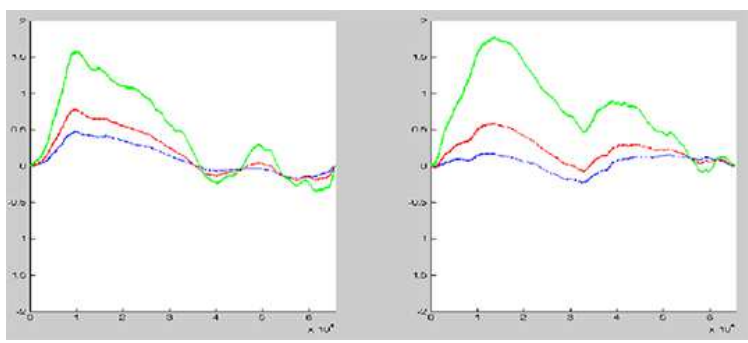

(a) A2

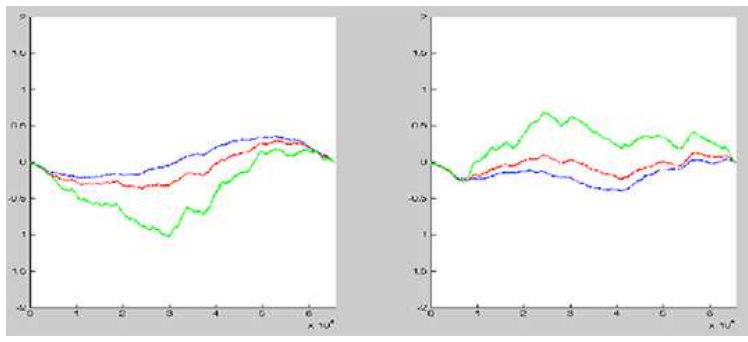

(b) $\mathrm{AB}$

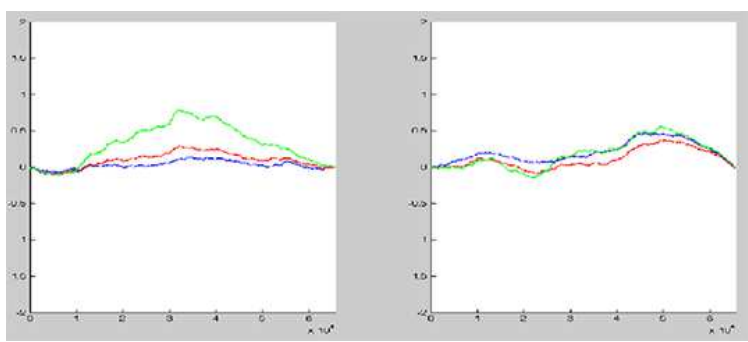

(c) Bt2

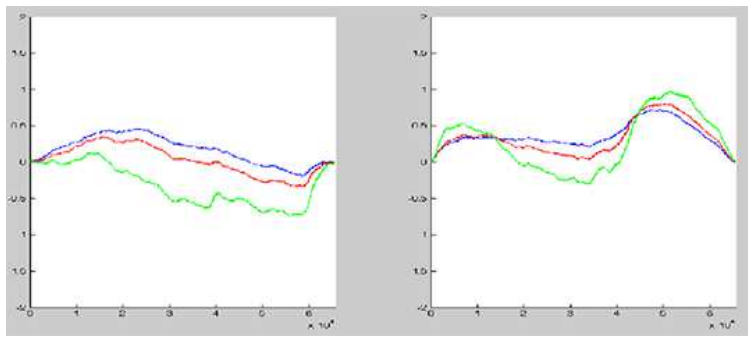

(d) $\mathrm{Bt} / \mathrm{Bw}$

Figura 9.1: Ejemplo de análisis espacio-escala a partir de la varianza wavelet

En estas figuras se muestra el análisis aplicado a tres escalas diferentes $(j=0$ en línea azul, $j=2$ en rojo y $j=4$ en verde) tanto para los coeficientes horizontales (parte izquierda de la figura de cada uno de los horizontes), como para los coeficientes verticales. La coherencia de los resultados obtenidos con las conclusiones de apartados anteriores llevan a considerar que la información obtenida puede ser de gran valor para completar la caracterización de imágenes presentadas a lo largo de este trabajo de tesis requiriendo un estudio de aparente gran interés y que sin duda tiene sentido como futura línea de trabajo. Destacar también su relación con el trabajo de (Lark, 2005) basado en el trabajo de (Wang y Johnson, 2002) en análisis de series simbólicas 
(donde el valor en cada muestra puede tomar un valor dentro de un conjunto finito y limitado de símbolos).

\subsection{Análisis 3D en el dominio escala-espacio}

Tal y como fue publicado en (Piñuela et al., 2009 ) se plantea como objetivo de esta línea de investigación el realizar un análisis global de los volúmenes tridimensionales obtenidos como resultado del proceso de tomografía computarizada en contraposición al análisis según cortes bidimensionales específicos en el que se ha centrado principalmente este trabajo de tesis. La diferencia entre el volumen y los cortes bidimensionales considerados hasta ahora se muestran en la figura 9.2.

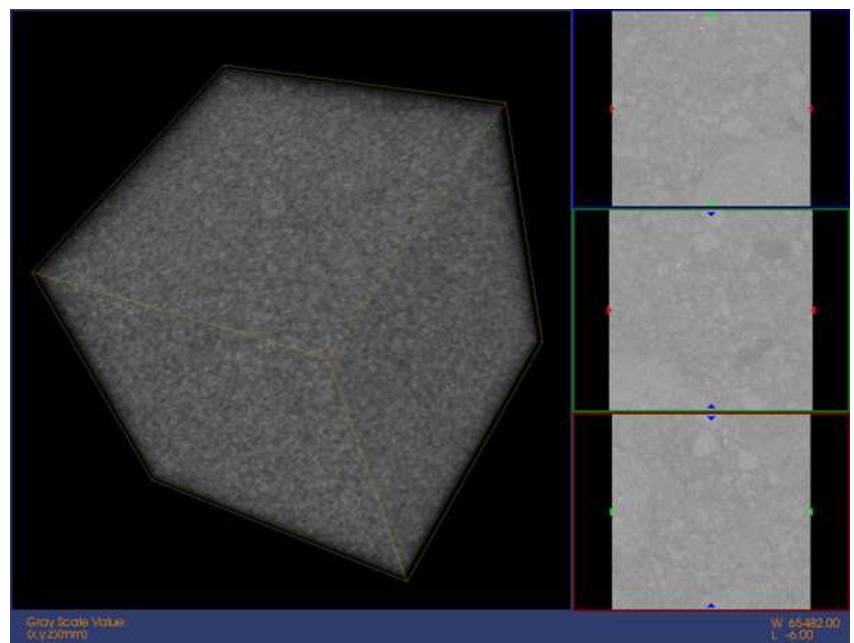

(a) A2 / Render 3D

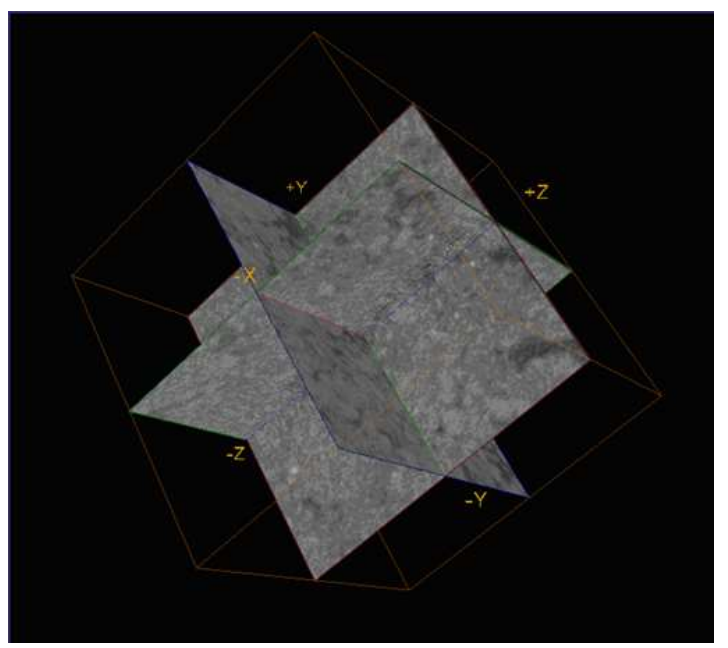

(b) A2 / Planos ortogonales

Figura 9.2: Volumen resultante de la tomografía axial

A través del análisis wavelet integrado en tres dimensiones del volumen asociado a un suelo concreto es de esperar nuevos resultados e interpretaciones físicas que 
han quedado fuera de este trabajo de tesis. No obstante, se describe a continuación las bases matemáticas del análisis wavelet en múltiples dimensiones y unos primeros resultados de análisis multifractal en tres dimensiones.

\subsubsection{Análisis Multifractal Multidimensional}

Para una primera aproximación de cómo llevar a un análisis multidimensional los conceptos del formalismo multifractal basta con aplicar la técnica "box-count" en direcciones concretas del volumen. Es decir, en dos dimensiones por ejemplo, podemos considerar aplicar el análisis "box-count" unidimensional a través de diferentes direcciones en lugar de considerar particiones cuadradas. Esto lleva a obtener una dimensión fractal generalizada $D_{q}$ en cada una de esas direcciones tal y cómo se muestra en la figura $(9.3)$ donde se ha realizado este análisis sobre el corte bidimensional $B$ del suelo $A 2$, donde se ve como la dimensión obtenida en la dirección noroeste es la que resulta en una dimensión más irregular en relación con el resto de orientaciones tal como era de esperar de la simple inspección visual de la imagen analizada.

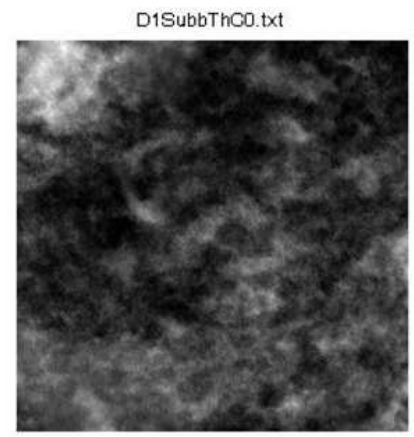

(a) Subvolumen $B$, Suelo $A 2$

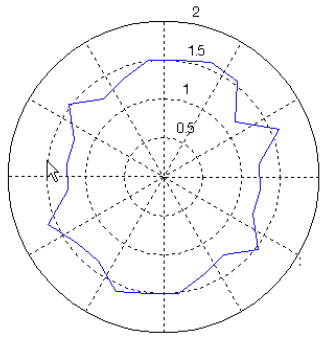

(b) A2 / Planos ortogonales

Figura 9.3: Dimensión fractal generalizada computada en 24 direcciones

Extendiendo este concepto a tres dimensiones resultan las imágenes mostradas en (9.4) en las que se aprecian importantes variaciones en función de la orientación elegida.

\subsubsection{Análisis Wavelets Multidimensional}

La forma más evidente de extender el análisis wavelet a múltiples dimensiones es a través de procesamiento separable. Del mismo modo que en dos dimensiones aplicábamos distintas variantes de transformada wavelet primero a las filas y luego a las columnas de una imagen, cuando se trata de analizar objetos o formas tridimensionales simplemente podemos extender este proceso a una tercera dimensión. Este método basado en la propiedad de separabilidad de la transformada wavelet se relaciona directamente con calcular productos tensoriales de las funciones de base (Dudgeon y Mersereau, 1984).

Procediendo de este modo se realizan divisiones rectangulares del espectro o escala que dan preferencia al análisis siguiendo los ejes cartesianos, y no se tiene en 


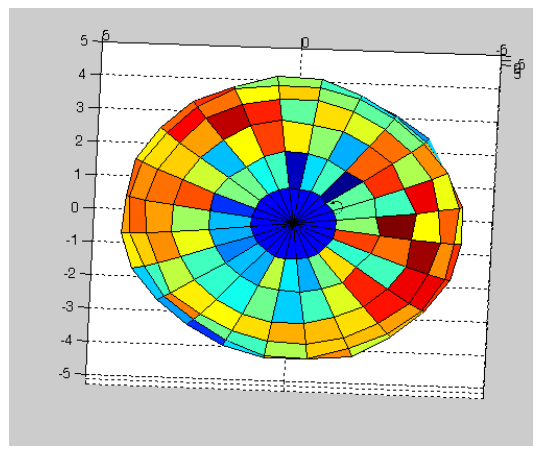

(a) Subvolumen $B$, Suelo $A 2$

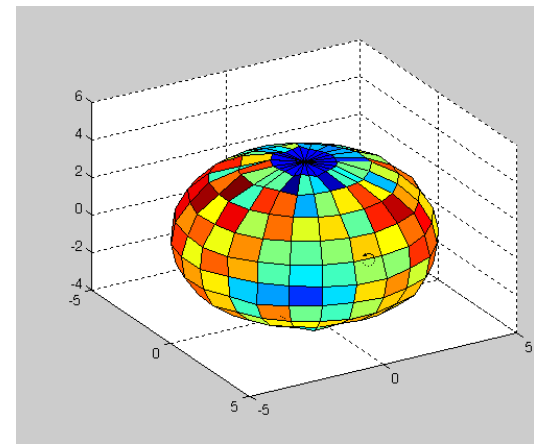

(b) A2 / Planos ortogonales

Figura 9.4: Dimensión fractal generalizada 3D

cuenta otras direcciones que pueden ser en ocasiones más relevantes para un análisis multiescala concreto. Estos esquemas no separables son sin duda en este caso de gran interés refiriendo al lector a (Kovačević y Vetterli, 1995$)$ para profundizar en sus implicaciones.

Para considerar otro tipo de particiones del espacio se recomienda recurrir esquema "Lifting" desarrollado inicialmente en (Sweldens, 1997) como método para construir de manera sencilla bases wavelets con distintas características incluyendo la geometría del soporte de la base wavelet diseñada.

De esta forma se construyen bases wavelets de cualquier dimensión y distintas geometrías que en consecuencia llevarán a divisiones no rectangulares del espacio frecuencia-escala (Kovacevíc y Sweldens, 2000). Esta línea de trabajo permitiría relacionar la metodología wavelet con el formalismo mulifractal aplicado en direcciones arbitrarias ofreciendo potencialmente una caracterización mucho más completa de los volúmenes tridimensionales obtenidos con las modernas técnicas de tomografía computarizada, para la caracterización hidrológica de los distintos tipos de suelos.

Algunos estudios que pueden consultarse como referencia de aplicación del formalismo multifractal en tres dimensiones pueden encontrarse en campos tan diversos como (Zhang et al., 2006) centrado en resonancias magnéticas del cerebro extendiendo las técnicas de cálculo de (Buchnicek et al., 2000) o el análisis de asteroides presentado en (Jalobeanu, 2003). Ya centrados en la relación entre multifractales y transformada wavelet en múltiples dimensiones destacan los trabajos de (Kestener y Arneodo, 2003) y (Kestener y Arneodo, 2004). 



\section{Bibliografía}

Abry, P., Goncalves, P. y VéHel, J. Scaling, fractals and wavelets. John Wiley \& Sons, 2013.

Anderson, S., Gantzer, C., Boone, J. y Tully, R. Rapid nondestructive bulk density and soil-water content determination by computed tomography. Soil Science Society of America Journal, vol. 52(1), páginas 35-40, 1988.

Arneodo, A., Bacry, E. y Muzy, J. F. Solving the inverse fractal problem from wavelet analysis. EPL (Europhysics Letters), vol. 25(7), página 479, 1994.

Arneodo, A., Grasseau, G. y Holschneider, M. Wavelet transform of multifractals. Phys. Rev. Lett., vol. 61, páginas 2281-2284, 1988.

Balakumaran, T., Vennila, I. y Shankar, C. Microcalcification detection using multiresolution analysis and neural network. International Journal of Recent Trends in Engineering, vol. 2(2), páginas 208-211, 2009.

Ballesteros, F., Oropesa, A., Martin, L. y Andina, D. Mammography classification using wavelets. En Automation Congress, 2002 Proceedings of the 5th Biannual World, vol. 13, páginas 293-300. 2002.

de la Barcena, A. M., Cedeno, A. M., Andina, D. y Pinuela, J. A. Modeling logic and neural approaches to bankruptcy prediction models. 2010.

BARni, M. y BARTOLINI, F. Watermarking systems engineering: enabling digital assets security and other applications. CRC Press, 2004.

Barni, M., Bartolini, F., Cappellini, V., Lippi, A. y Piva, A. Dwt-based technique for spatio-frequency masking of digital signatures. En Electronic Imaging'99, páginas 31-39. International Society for Optics and Photonics, 1999.

Bouchaud, J. y Potters, M. Theory of financial risk and derivative pricing: from statistical physics to risk management. Cambridge university press, 2003.

Buchnicek, M., Nezadal, M. y Zmeskal, O. Numeric calculation of fractal dimension. En Proceedings of the third conference on prediction, synergetic and more, páginas 10-5. 2000.

Buldyrev, S., Goldberger, A., Havlin, A., Mantegna, R., Matsa, M., Peng, C., Simons, M. y Stanley, H. Long-range correlation properties of coding and noncoding dna sequences: Genbank analysis. Physical Review E, vol. 51(5), página 5084, 1995. 
Bunde, A., Havlin, S., Kantelhardt, J., Penzel, T., Peter, J. y Voigt, K. Correlated and uncorrelated regions in heart-rate fluctuations during sleep. Physical Review Letters, vol. 85(17), página 3736, 2000.

Burt, P. y Adelson, E. The laplacian pyramid as a compact image code. IEEE Transactions on Communications, vol. 31(4), páginas 532-540, 1983.

CAnny, J. A computational approach to edge detection. IEEE Transactions on Pattern Analysis and Machine Intelligence, vol. 8(6), páginas 679-698, 1986.

Cedeno, A. M., de la Barcena, A. M., Jimenez-Trillo, J. A., Pinuela, J. A. y AndinA, D. Artificial metapasticity neural network applied to credit scoring. INT J NEURAL SYST, vol. 21(4), páginas 311-317, 2011.

Chui, C. An introduction to wavelets, vol. 1. Academic press, 2014.

Daubechies, I. Ten Lectures on Wavelets. Society for Industrial and Applied Mathematics, Philadelphia, PA, USA, 1992.

David L. Donoho, I. M. J. Ideal spatial adaptation by wavelet shrinkage. Biometrika, vol. 81(3), páginas 425-455, 1994.

Dudgeon, D. E. y Mersereau, R. M. Multidimensional digital signal processing. Prentice-Hall Signal Processing Series, Englewood Cliffs: Prentice-Hall, 1984, vol. $1,1984$.

Elliot, T. y Heck, R. A comparison of 2 d vs. 3d thresholding of x-ray ct imagery. Canadian Journal of Soil Science, vol. 87(4), páginas 405-412, 2007.

Falconer, K. Fractal Geometry: Mathematical Foundations and Applications. Wiley, 2004. ISBN 9780470871355.

FluRY, M. y Fluhler, H. Brilliant blue fcf as a dye tracer for solute transport studies. a toxicological overview. J.Environ. Qual., vol. 23, páginas 1108-1112, 1994 .

Flury, M. y Fluhler, H. Tracer characteristics of brilliant blue. Soil Sci. Soc. Am. J., vol. 59, páginas 22-27, 1995.

Folorunso, O., Puente, C., Rolston, D. y Pinzon, J. Statistical and fractal evaluation of the spatial characteristics of soil surface strength. Soil Science Society of America Journal, vol. 58(2), páginas 284-294, 1994.

Fombellida, J., Torres, S., Piñuela, J. y Andina, D. Artificial metaplasticity: Application to MIT-BIH arrhythmias database. En Bioinspired Computation in Artificial Systems - International Work-Conference on the Interplay Between Natural and Artificial Computation, IWINAC, páginas 399-408. 2015.

GABOR, D. Theory of communication. part 1: The analysis of information. Journal of the Institution of Electrical Engineers-Part III: Radio and Communication Engineering, vol. 93(26), páginas 429-441, 1946. 
Gibson, J., Lin, H. y Bruns, M. A comparison of fractal analytical methods on 2- and 3-dimensional computed tomographic scans of soil aggregates. Geoderma, vol. 134, páginas 335-348, 2006.

Gonzálvez, B. y Piñuela, J. A. Análisis de singularidades mediante transformadas wavelet. Universidad Europea de Madrid, 2008.

Grevers, M. y Jong, E. D. Evaluation of soil-pore continuity using geostatistical analysis on macroporosity in serial sections obtained by computed tomography scanning. Tomography of Soil-Water-Root Processes, páginas 73-86, 1994.

HAN. Fractal volatility of financial time series. 2011.

Heuvelman, W. y McInnes, K. Spatial variability of water fluxes in soil: a field study. Soil Sci. Soc. Am. J., vol. 61, páginas 1037-1041, 1997.

Hounsfield, G. Computerized transverse axial scanning (tomography): Part 1. description of system. The British journal of radiology, vol. 46(552), páginas 10161022, 1973.

Hsung, T. y Siu, W. Denoising by singularity detection. IEEE Trans. on Signal Processing, vol. 47(11), páginas 3139-3144, 1999.

Hu, K., Ivanov, P., Chen, Z., Carpena, P. y Stanley, H. Effect of trends on detrended fluctuation analysis. Physical Review E, vol. 64(1), página 011114, 2001.

Ivanov, P., Rosenblum, M., Peng, C., Mietus, J., Havlin, S., Stanley, H. y GoldBerger, A. Scaling behaviour of heartbeat intervals obtained by waveletbased time-series analysis. Nature, vol. 383(6598), páginas 323-327, 1996.

JaLobeanu, A. Fractal 3-d modeling of asteroids using wavelets on arbitrary meshes. En Proc. of IAFA'03. 2003.

Kantelhardt, J., Koscielny-Bunde, E., , Rego, H., Havlin, S. y Bunde, A. Detecting long-range correlations with detrended fluctuation analysis. Physica A: Statistical Mechanics and its Applications, vol. 295(3), páginas 441-454, 2001.

Kantelhardt, J. W., Zschiegner, S. A., Koscielny-Bunde, E., Havlin, S., Bunde, A. y Stanley, H. E. Multifractal detrended fluctuation analysis of nonstationary time series. Physica A: Statistical Mechanics and its Applications, vol. 316(1), páginas 87-114, 2002.

Kestener, P. y Arneodo, A. Three-dimensional wavelet-based multifractal method: The need for revisiting the multifractal description of turbulence dissipation data. Physical review letters, vol. 91(19), página 194501, 2003.

Kestener, P. y Arneodo, A. Generalizing the wavelet-based multifractal formalism to random vector fields: Application to three-dimensional turbulence velocity and vorticity data. Physical review letters, vol. 93(4), página 044501, 2004. 
Koscielny-Bunde, E., Bunde, A., Havlin, S., Roman, H., Goldreich, Y. y Schellnhuber, H. Indication of a universal persistence law governing atmospheric variability. Physical Review Letters, vol. 81(3), página 729, 1998.

Kovacevíc, J. y Sweldens, W. Wavelet families of increasing order in arbitrary dimension. IEEE Trans on Image Processing, vol. 9, páginas 480-496, 2000.

Kovačević, J. y Vetterli, M. Nonseparable two-and three-dimensional wavelets. IEEE Transactions on Signal Processing, vol. 43(5), páginas 1269-1273, 1995.

Kravchenko, A., Boast, C. y Bullock, D. Multifractal analysis of soil spatial variability. Agronomy Journal, vol. 91(6), páginas 1033-1041, 1999.

Laine, A., Schuler, S., Fan, J. y Huda, W. Mammographic feature enhancement by multiscale analysis. IEEE Transactions on Medical Imaging, vol. 13(4), páginas 725-740, 1994.

LARK, R. Spatial analysis of categorical soil variables with the wavelet transform. European journal of soil science, vol. 56(6), páginas 779-792, 2005.

Lewis, A. y Knowles, G. Image compression using the 2-d wavelet transform. IEEE Trans. on Image Processing, vol. 1, páginas 245-250, 1992.

Lin, H., McInnes, K., Wilding, L. y Hallmark, C. Effective porosity and flow rate with infiltration at low tensions into a well-structured subsoil. T.ASAE, vol. 39, páginas 131-133, 1996.

Mallat, S. A theory for multiresolution signal decomposition: The wavelet representation. IEEE Transactions Pattern Recognition and Machine Intelligence, vol. 11(7), páginas 674-693, 1989.

Mallat, S. A wavelet tour of signal processing. Academic Press, 1998.

Mallat, S. y Hwang, W. L. Singularity detection and processing with wavelets. IEEE Transactions. Information Theory, vol. 38, páginas 617-643, 1992.

Mallat, S. y Zhong, S. Characterization of signals from multiscale edges. IEEE Transactions on Pattern Anal. and Mach. Intell., vol. 14(7), páginas 710-732, 1992.

Mandelbrot, B. How long is the coast of britain. Science, vol. 156(3775), páginas 636-638, 1967.

Mandelbrot, B. The Fractal Geometry of Nature. W. H. Freeman and Company, 1977.

Matteo, T. D., Aste, T. y Dacorogna, M. Long-term memories of developed and emerging markets: Using the scaling analysis to characterize their stage of development. Journal of Banking and Finance, vol. 29(4), páginas 827-851, 2005.

Moisy, F. Computing a fractal dimension with matlab: $1 \mathrm{~d}, 2 \mathrm{~d}$ and $3 \mathrm{~d}$ box-counting. 2008 . 
Morales, R., Matteo, T. D., Gramatica, R. y Aste, T. Dynamical generalized hurst exponent as a tool to monitor unstable periods un financial time series. Physica A: Statistical Mechanics and its Applications, vol. 391(11), páginas 31803189, 2012.

Muller, J. Characterization of pore space in chalk by multifractal analysis. Journal of Hydrology, vol. 187(1), páginas 215-222, 1996.

Muzy, J., Bacry, E. y Arneodo, A. Wavelets and multifractal formalism for singular signals: application to turbulence data. Physical Review Letters, vol. 67(25), página 3515, 1991.

Muzy, J., BACRY, E. y ARneodo, A. Multifractal formalism for fractal signals: The structure-function approach versus the wavelet-transform modulus-maxima method. Physical review E, vol. 47(2), página 875, 1993.

Pachepsky, Y., Giménez, D., Crawford, J. y Rawls, W. Conventional and fractal geometry in soil science. Pachepsky, Crawford, Rawls (Eds), Fractals in Soil Science, 2000.

Percival, D. y Walden, A. Wavelet methods for time series analysis. Cambridge Univ. Press, 2007.

Percival, D. P. On estimation of the wavelet variance. Biometrika, vol. 82(3), páginas 619-631, 1995.

Perfect, E., Gentry, R., Sukop, M. y Lawson, J. Multifractal sierpinski carpets: Theory and application to upscaling effective saturated hydraulic conductivity. Geoderma, vol. 134, páginas 240-252, 2006.

Perret, J., Prasher, S., Kantzas, A. y Langford, C. 3-d visualization of soil macroporosity using x-ray cat scanning. Canadian Agricultural Engineering, vol. 39(4), páginas 249-262, 1997.

Peyton, R., Gantzer, C., Anderson, S., Haeffner, B. y Pfeifer, P. Fractal dimension to describe soil macropore structure using x ray computed tomography. Water resources research, vol. 30(3), páginas 691-700, 1994.

Pierret, A., Caapowiez, Y., Belzunces, L. y Moran, L. 3d reconstruction and quantification of macropores using x-ray computed tomography and image analysis. Geoderma, vol. 106, páginas 247-271, 2002.

Piñuela, J., Andina, D. y TARquis, A. Multifractal 3d spatial-scale analysis of soil variables using wavelets. En E.G.U. 2009 6th General Assembly. Viena, Austria, 2009.

Piñuela, J. A. Wavelet Packets: Procesamiento de imágenes en el dominio transformado. Universidad Politécnica de Madrid, 2000.

Piñuela, J. A., Alvarez, A., Heck, R. y Tarquis, A. Quantifying a soil pore distribution from 3d images: multifractal spectrum through wavelet approach. Geoderma, vol. 155, páginas 203-210, 2010. 
Piñuela, J. A., Andina, D. y Florez, I. Watermarking: Búsqueda y detección de copias ilegales de imágenes digitales. En Mundo Internet. 2007a.

Piñuela, J. A., Andina, D., McInnes, K. y Tarquis, A. Wavelet analysis in a structured clay soil using 2d images. Nonlinear Process in Geophysics, vol. 14, páginas 425-434, 2007b.

Posadas, A., Giménez, D., Quiroz, R. y Protz, R. Multifractal characterization of soil pore systems. Soil Science Society of America Journal, vol. 67(5), páginas 1361-1369, 2003.

Rioul, O. y VetTerli, M. Wavelets and signal processing. IEEE signal processing magazine, vol. 8(LCAV-ARTICLE-1991-005), páginas 14-38, 1991.

Said, A., Pearlman, W. ET Al. A new, fast, and efficient image codec based on set partitioning in hierarchical trees. IEEE Transactions on Circuits and Systems for Video Technology, vol. 6(3), páginas 243-250, 1996.

ShapiRo, J. Embedded image coding using zerotrees of wavelet coefficients. IEEE Transactions on Signal Processing, vol. 41(12), páginas 3445-3462, 1993.

Strang, G. y NGUyen, T. Wavelets and filter banks. SIAM, 1996.

STRUZIK, Z. Direct multifractal spectrum calculation from the wavelet transform. CWI. Information Systems, 1999.

Sweldens, W. The lifting scheme: A construction of second generation wavelets. SIAM J. Math. Anal, vol. 2, páginas 511-546, 1997.

Taina, I., Heck, R. y Elliot, T. Application of x-ray computed tomography to soil science: A literature review. Canadian Journal of Soil Science, vol. 88(1), páginas 1-19, 2008.

TARquis, A. M. y McInnes, K. Multiscaling analysis in a structured clay soil using 2d images. Journal of Hydrology, vol. 322, páginas 236-246, 2005.

Torres, J., Piñuela, J., Andina, D. y Tarquis, A. Spatial-scale analysis of soil variables from 3d images using wavelet correlation. En E.G.U. 2008 5th General Assembly. Viena, Austria, 2008.

Turiel, A. Singularity extraction in natural images. Available online at Citeseer (Scientific Literature Digital Library), vol. http://citeseer.ist.psu.edu/turiel01singularity.html, 2001.

VADAKKAN, T. Multifractal spectrum of a binary image. 2009.

Vetterli, M. y Herley, C. Wavelets and filter banks: Theory and design. IEEE Trans. on Signal Processing, vol. 40, páginas 2207-2232, 1992.

Vetterli, M. y KovaceVic, J. Wavelets and subband coding. LCAV-BOOK-1995001. Prentice-hall, 1995. 
Vetterli, M. y LeGall, D. Perfect reconstruction fir filter banks: Some properties and factorizations. IEEE Trans. on Acoust. Speech and Signal Processing, vol. 37, páginas 1057-1071, 1989.

Wang, T. y Karayiannis, N. Detection of microcalcifications in digital mammograms using wavelets. IEEE Transactions on Medical Imaging, vol. 17(4), páginas 498-509, 1998.

Wang, W. y Johnson, D. Computing linear transforms of symbolic signals. IEEE Transactions on Signal Processing, vol. 50(3), páginas 628-634, 2002.

Zhang, L., Liu, J., Dean, D., Sahgal, V. y Yue, G. A three-dimensional fractal analysis method for quantifying white matter structure in human brain. Journal of neuroscience methods, vol. 150(2), páginas 242-253, 2006.

Zhong, J. y Ning, R. Image denoising based on wavelets and multifractals for singularity detection. IEEE Trans. on Image Processing, vol. 14(10), páginas 1435$1447,2005$. 